UNIVERSIDADE DE SÃO PAULO

INSTITUTO DE FÍSICA DE SÃO CARLOS

DEPARTAMENTO DE FÍSICA E CIÊNCIAS DOS MATERIAIS

Waldir Avansi Junior

Síntese de nanopartículas de óxido de vanádio obtidas pela decomposição de peróxido

SÃo CARLOS - SÃO PAULO

2010 



\section{Síntese de nanopartículas de óxido de vanádio obtidas pela decomposição de peróxido}

Tese apresentada ao Programa de Pós-Graduação em Física do Instituto de Física de São Carlos, Universidade de São Paulo, para obtenção do título de Doutor em Ciência.

Área de concentração: Física Aplicada.

Orientador: Prof. Dr. Valmor Roberto Mastelaro

\section{SÃO CARLOS}




\section{AUTORIZO A REPRODUÇÃO E DIVULGAÇÃO TOTAL OU PARCIAL DESTE TRABALHO, POR QUALQUER MEIO CONVENCIONAL OU ELETRÔNICO, PARA FINS DE ESTUDO E PESQUISA, DESDE QUE CITADA A FONTE.}

Avansi Junior, Waldir

Síntese de nanopartículas de óxido de vanádio obtidas pela decomposição de peróxido./ Waldir Avansi Junior; orientador Valmor Roberto Mastelaro- São Carlos, 2010.

$153 p$.

Tese (Doutorado em Ciência - Área de concentração: Física Aplicada) - Instituto de Física de São Carlos da Universidade de São Paulo.

1. Pentóxido de vanádio. 2. Materiais nanoestruturados. 3. Síntese hidrotermal. 4. Caracterização estrutural 5. Crescimento de cristais. I. Título. 
Este exemplar foi revisado e alterado em relação a versão original, sob exclusiva responsabilidade do autor.

São Carlos, 29 de outubro de 2010.

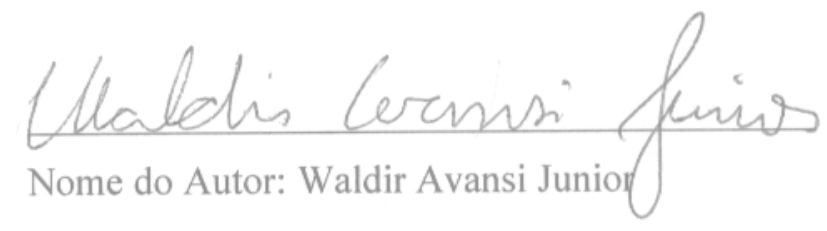





\section{DEDICATÓRIA}

Dedico este trabalho aos meus pais e irmãos pelo amor e apoio incondicional. 


\section{AGRADECIMENTOS}

Agradeço ao Prof. Dr. Valmor Roberto Mastelaro pela orientação, ajuda, discussão e oportunidade de desenvolver este trabalho.

Ao Dr. Caue Ribeiro, pesquisador da Embrapa Instrumentação Agropecuária, pelo inestimável auxílio na realização deste trabalho.

Ao Prof. Dr. Edson Roberto Leite e ao Prof. Dr. Elson Longo por disponibilizar a infraestrutura do Laboratório Interdisciplinar de Eletroquímica e Cerâmica (LIEC) da Universidade Federal de São Carlos (UFSCAR).

Ao Prof. Dr. Cristiano Luis Pinto de Oliveira, do Instituto de Física da Universidade de São Paulo (IF-USP) pelo auxilio no tratamento e discussão dos dados de espalhamento de raios $\mathrm{X}$ a baixo ângulo (SAXS).

Agradeço ao Rorivaldo Camargo, do LIEC-UFSCAR, pela amizade e pela obtenção das imagens de microscopia eletrônica de varredura (MEV).

Ao Laboratório Nacional de Luz Síncroton (LNLS) pela disponibilização das linhas de luz XAFS e SAXS, assim como seus funcionários, por sua competência e apoio.

Ao Dr. Jefferson Bettini e ao Paulo Cesar Silva, do Laboratório de Microscopia Eletrônica (LME) do LNLS pela orientação e valiosa ajuda na operação dos equipamentos.

Ao Prof. Dr. Conrado Ramos Moreira Afonso, pelo treinamento na utilização do microscópio de transmissão eletrônica (MET) JEOL-2100, alem da ajuda e orientação na obtenção de imagens de MET.

Ao Prof. Dr. Marcelo Orlandi do LIEC da Unesp, Campus de Araraquara, pela disponibilização do microscópio eletrônico de varredura (MEV).

Aos professores, as bibliotecárias e demais funcionários do IFSC.

Agradeço ao corpo técnico e a secretária, Erica Regina de Favari Signini, do GCCMC pela disponibilidade e amizade em todos os momentos.

Aos meus colegas do GCCMC com quem convivi durante esses anos pela troca de conhecimento, experiências e pela amizade.

À FAPESP pelo suporte financeiro para a realização deste trabalho. 
Aos amigos e companheiros: Rafael Silva, Geraldo Frigo, Luis Fernando Silva, Manoel Roncon, Vinicius Dantas de Araujo, Angelo Perinotto, Higor Favarim e Maria Inês Basso Bernardi.

Aos meus pais, Waldir Avansi e Lourdes Silva Avansi, e irmãos, Guilherme Daniel Avansi e Gisele Paulo Avansi, pelo apoio incondicional.

Agradeço à Mariana Devito Castro, por estar ao meu lado em todos os momentos.

Enfim, a todos aqueles que de forma direta ou indiretamente contribuíram para a realização deste trabalho. 


\section{RESUMO}

\section{AVANSI, Waldir. Síntese de Nanopartículas de Óxido de Vanádio obtidas pela} decomposição do Peróxido. 2010. 151 p. Tese (Doutorado em Física Aplicada) - Instituto de Física de São Carlos, Universidade de São Paulo, São Carlos, 2010.

A utilização de novas rotas de síntese de materiais nanoestruturados tem levado à obtenção de materiais apresentando novas propriedades e aplicações. Apesar da grande quantidade de trabalhos dedicados a síntese de compostos nanoestruturados, ainda não está totalmente compreendido o mecanismo de crescimento desta classe de materiais. Diante disso, o presente trabalho teve como principal objetivo realizar um estudo sistemático da síntese e do processo de crescimento das nanoestruturas de óxido de vanádio obtidas pelo método da decomposição de peróxido através do tratamento hidrotermal. Por meio do controle do tempo e da temperatura de síntese, foi possível obter nanoestruturas de pentóxido de vanádio com diferentes fases cristalinas e morfologias. Os resultados de espectroscopia Raman e difração de raios $\mathrm{X}(\mathrm{DRX})$ mostraram que o tratamento hidrotermal da solução em temperaturas de até $180^{\circ} \mathrm{C}$, durante 2 horas, leva à formação da fase $\mathrm{V}_{2} \mathrm{O}_{5} n \mathrm{H}_{2} \mathrm{O}$ monoclínica, apresentando uma orientação preferencial na direção $00 l$. A partir desta temperatura, o material obtido passou a ter fase ortorrômbica perdendo sua orientação preferencial. Através das medidas de termogravimetria (TG) foi observado que, dependendo da condição de síntese, as amostras apresentam diferentes quantidades de moléculas de água $\left(\mathrm{H}_{2} \mathrm{O}\right)$ intercaladas em sua estrutura. Imagens de microscopia eletrônica mostraram que as nanoestruturas obtidas podem possuir a forma de fitas, fios ou bastões. Utilizando a técnica de espectroscopia de absorção de raios $\mathrm{X}$ (XAS), foi possível verificar a presença de íons de $\mathrm{V}^{4+}$ nas amostras de fase monoclínica, o que não foi observado naquelas que possuem estrutura ortorrômbica. Pela técnica de XAS também observou-se que a ordem local ao redor do átomo de vanádio depende da fase cristalina e também da morfologia das nanoestruturas obtidas. O estudo do mecanismo de crescimento da nanoestrutura de $\mathrm{V}_{2} \mathrm{O}_{5} n \mathrm{H}_{2} \mathrm{O}$ mostrou que ocorre um crescimento lateral, o qual pode ser descrito pelo mecanismo denominado Coalescência Orientada ou "Oriented attachment" (OA). Finalmente, através da decomposição do peróxido de vanádio, foi possível obter compostos vanadatos contendo cátions de $\mathrm{Na}^{+}$em sua estrutura. 
Palavras chave: Pentóxido de vanádio. Materiais nanoestruturados. Síntese hidrotermal. Caracterização estrutural. Crescimento de cristais. 
AVANSI, Waldir. Synthesis of Vanadium Oxide Nanoparticles obtained by the decomposition of peroxide. 2010. 151 p. Tese (Doutorado em Física Aplicada) - Instituto de Física de São Carlos, Universidade de São Paulo, São Carlos, 2010.

The use of new routes for nanostructured materials synthesis has lead to materials with new properties and applications. Despite the large amount of works devoted to the synthesis of nanostructured materials, the crystal growth mechanism of this class of materials still unclear. Thus, this study aimed to perform a systematic study of the synthesis and the growth mechanism of the vanadium oxide hydrate obtained by the method of decomposition of peroxide using hydrothermal treatment. By controlling synthesis time and temperature it was possible to achieve vanadium pentoxide nanostructures with different crystalline phases and morphologies. The results of Raman spectroscopy and X-ray diffraction (XRD) showed that the hydrothermal treatment of the solution at temperatures up to $180^{\circ} \mathrm{C}$ for two hours leads to formation of the $\mathrm{V}_{2} \mathrm{O}_{5} \mathrm{nH}_{2} \mathrm{O}$ monoclinic phase with a preferential orientation on $00 \mathrm{l}$ direction. From this temperature on the material obtained began to present the orthorhombic phase misleading its preferential orientation. Through thermogravimetry (TG) measurements it was seen that depending on the synthesis condition the samples contains different amounts of water molecules $\left(\mathrm{H}_{2} \mathrm{O}\right)$ interleaved in their structure. Images of transmission electron microscopy (TEM) showed that the $\mathrm{V}_{2} \mathrm{O}_{5} \mathrm{nH}_{2} \mathrm{O}$ compound could have different morphologies such as ribbons, wires and rods. From X-Ray Absorption spectroscopy (XAS) measurements, it was observed the presence of $\mathrm{V}^{4+}$ ions in the monoclinic phase samples, which was not observed on orthorhombic structure samples. Through the XAS technique was also observed that the local order around the vanadium atom depends on the crystalline phase and the morphology of the as-obtained samples. The study of the crystal growth mechanism of $\mathrm{V}_{2} \mathrm{O}_{5} n \mathrm{H}_{2} \mathrm{O}$ nanostructures showed that the wide growth can be explained by the mechanism denominated Oriented Attachment (OA). Finally, through vanadium peroxide decomposition vanadates compounds containing $\mathrm{Na}^{+}$cation in its structure were carried out. 
Keywords: Vanadium pentoxide. Nanostructured materials. Hydrothermal synthesis. Structural characterization. Crystal growth. 


\section{LISTA DE FIGURAS}

Figura 1 - Estrutura cristalina ortorrômbica do composto $\mathrm{V}_{2} \mathrm{O}_{5}$. (1)......... 28

Figura 2 - Modelo estrutural "degrau" proposto por Legendre e colaboradores para o composto $\mathrm{V}_{2} \mathrm{O}_{5} n \mathrm{H}_{2} \mathrm{O}(33,34)$......

Figura 3 - Modelo estrutural do composto $\mathrm{V}_{2} \mathrm{O}_{5} \mathrm{nH}_{2} \mathrm{O}$ obtido através da técnica de PDF. (37).

Figura 4 - Estrutura local do composto $\mathrm{V}_{2} \mathrm{O}_{5} n \mathrm{H}_{2} \mathrm{O}$ de acordo com o trabalho de Stizza e colaboradores. (38) O circulo preenchido representa os átomos de vanádio enquanto que os círculos "vazios" representam os átomos de oxigênio.

Figura 5- Formação de nanofitas de $\mathrm{V}_{2} \mathrm{O}_{5} \mathrm{nH}_{2} \mathrm{O}$ pelo processo de condensação e polimerização. (25).

Figura 6 - Formação de nanofios e nanobastões de $\mathrm{V}_{2} \mathrm{O}_{5} n \mathrm{H}_{2} \mathrm{O}$ dependendo da presença de $\mathrm{H}_{3} \mathrm{O}^{+}$ou de $\mathrm{CH}_{3} \mathrm{COOH}$ intercalados e o processo de quebra proposto por Li e colaboradores. (15)

Figura 7 - Modelo de formação de nanofios de composição $\mathrm{V}_{2} \mathrm{O}_{4} 0,25 \mathrm{H}_{2} \mathrm{O}$ a partir de partículas de $\mathrm{V}_{2} \mathrm{O}_{4}$ em condições hidrotermais propostos por Wei e colaboradores. (58)

Figura 8 - Ilustração do efeito de moléculas orgânicas atuando como "templates". (26) .......38

Figura 9 - Ilustração do modelo de crescimento de partículas pelo modelo de Maturação de Ostwald.

Figura 10 - Ilustrações do crescimento de nanoestruturas através do mecanismo de Coalescencia Orientada (OA). (76).

Figura 11 - Imagem de microscopia eletrônica de transmissão (MET) de nanopartículas de $\mathrm{TiO}_{2}$ de fase anatase apresentando uma auto-organização espontânea quando submetida a um tratamento hidrotermal. (65)

Figura 12 - Ilustração de processo de crescimento em condições hidrotermais de acordo com o mecanismo de OA: (a) em um sistema disperso; (b) em um sistema aglomerado; (c) em um sistema aglomerado contendo anions orgânicos agindo como surfactantes. (66) 
Figura 13 - (a) Modelo do mecanismo de crescimento por OA, levando a coalescência de duas partículas; (b) Imagens de HR-TEM de duas nanopartículas coalescidas de $\mathrm{SnO}_{2}$. (75)

Figura 14 - Ilustração do processo de coalescência de duas superfícies ativas denominado de "polymerization OA model" proposto por Ribeiro e colaboradores. (73) ........ 45

Figura 15 - Esquema experimental utilizado na preparação das amostras. 50

Figura 16 - Montagem experimental utilizada no tratamento hidrotermal dinâmico: (a) imagem da célula hidrotermal, da placa de agitação e do controlador de tempo de tratamento e temperatura; (b) imagem da parte superior da célula hidrotermal, contendo uma válvula de alivio, um manômetro e um termopar e (c) imagem do jarro da célula hidrotermal e do recipiente de teflon onde é colocada a solução para tratamento.

Figura 17 - Coeficiente de absorção de raios $X$ na borda $\mathrm{K}$ do átomo de cobre para uma amostra de cobre metálico. (95)

Figura 18 - Difratograma de raios $\mathrm{X}$ do composto pentóxido de vanádio $\left(\mathrm{V}_{2} \mathrm{O}_{5}\right)$, utilizado como precursor.

Figura 19 - Espectro Raman composto pentóxido de vanádio $\left(\mathrm{V}_{2} \mathrm{O}_{5}\right)$, utilizado como precursor.

Figura 20 - Difratogramas de raios $\mathrm{X}$ das amostras : AM01 (tratada a $60^{\circ} \mathrm{C}$ durante 6horas), AM02 $\left(120^{\circ} \mathrm{C}\right.$ durante 6 horas), AM03 $\left(160^{\circ} \mathrm{C}\right.$ durante 24 horas), AM04 $\left(180^{\circ} \mathrm{C}\right.$ durante 6 horas), AM05 $\left(180^{\circ} \mathrm{C}\right.$ durante 24 horas) e AM06 $\left(200^{0} \mathrm{C}\right.$ durante 24 horas).

Figura 21 - Curvas de termogravimetria ( TG ) das amostras: AM01, AM02, AM03, AM05 e AM06.

Figura 22 - Espectro micro-Raman das amostras: AM01 $\left(60^{\circ} \mathrm{C}, 6 \mathrm{~h}\right)$, AM02 $\left(120^{\circ} \mathrm{C}, 6 \mathrm{~h}\right)$, AM05 $\left(180^{\circ} \mathrm{C}, 24 \mathrm{~h}\right)$ e AM06 $\left(200^{\circ} \mathrm{C}, 24 \mathrm{~h}\right)$.

Figura 23 -Imagens de FE-STEM das amostras: (a) AM01; (b) AM02, (c) AM03, (d) AM04, (e) AM05 e (f) AM06.

Figura 24 - (a) e (b) Imagens de HR-TEM da amostra obtida a $60^{\circ} \mathrm{C}$ durante 6 horas (AM01)

Figura 25 - (a) e (b) Imagens de HR-TEM da amostra obtida a $200^{\circ} \mathrm{C}$ durante 24 horas (AM06).....

Figura 26 - Espectro XANES na borda $\mathrm{K}$ do Vanádio do composto de referência, da folha do vanádio metálico e das amostras AM01, AM02, AM05 e AM06. 
Figura 27 - (a) região expandida da pré - borda das amostras: AM01, AM02, AM05, AM06 e do composto de referência $\left(\mathrm{V}_{2} \mathrm{O}_{5}\right.$ ortorrômbico); (b) região expandida da primeira derivada do espectro XANES da região da pré-borda de absorção das amostras AM01, AM02, AM05, AM06, do composto de referência $\left(\mathrm{V}_{2} \mathrm{O}_{5}\right.$ ortorrômbico) e do $\mathrm{V}$ metálico.

Figura 28 - Detalhes da primeira esfera de coordenação do composto $\mathrm{V}_{2} \mathrm{O}_{5}$ 73

Figura 29 - Espectro XANES na borda K do Vanádio para a amostra AM01 (a) e AM06 (b) em função do ângulo de incidência do feixe em relação a amostra.

Figura 30 - Modulo da transformada de Fourier (FT) do espectro EXAFS das amostras AM01 (a) e AM06 (b) coletados em diferentes orientações em relação ao feixe de raios $X$.

Figura 31 - (a) Espectro EXAFS das amostras AM05, AM06 e do composto utilizado como referência. (b): Modulo da transformada de Fourier não corrigida do espectro EXAFS coletados a $90^{\circ}$ em relação ao feixe incidente de raios X.

Figura 32 - (a) Módulo da transformada de Fourier (TF) não corrigida do espectro de EXAFS das simulações dos caminhos de espalhamento utilizando os parâmetros da Tabela 4; (b) Módulo da TF não corrigida do espectro de EXAFS da soma dos caminhos de espalhamento simulados em (a).

Figura 33 - Ajuste dos dados da amostra padrão $\left(\mathrm{V}_{2} \mathrm{O}_{5}\right.$ ortorrômbico): (a) magnitude da transformada de Fourier do espectro experimental e ajuste teórico; (b) espectro EXAFS experimental e ajuste teórico.

Figura 34 - Ajuste da amostra AM05: (a) magnitude da transformada de Fourier do espectro experimental e ajuste teórico; (b) espectro EXAFS experimental e ajuste teórico.

Figura 35 - Ajuste da amostra AM06: (a) magnitude da transformada de Fourier do espectro experimental e ajuste teórico; (b) espectro EXAFS experimental e ajuste teórico.

Figura 36 - Medidas de DRX da amostra utilizada como solução precursora e das amostras submetidas ao tratamento hidrotermal durante 0 e 7200 minutos.

Figura 37 - Imagens de FE - STEM das nanofitas obtidas a partir da solução precursora (a) e a partir da amostra diluida e submetida a um tratamento hidrotermal durante 7200 minutos. 
Figura 38 - Distribuição da largura das nanofitas $\mathrm{V}_{2} \mathrm{O}_{5} \mathrm{nH}_{2} \mathrm{O}$ submetidas a um tratamento hidrotermal a $80^{\circ} \mathrm{C}$ durante: (a) 0; (b) 240; (c) 480; (d) 720; (e) 1440; (f) 2160; (g) 2880; (h) 4320 e (i) 5760 e (j) 7200 minutos.

Figura 39 - Evolução temporal do tamanho médio da largura (d) em função do tempo de tratamento hidrotermal a $80^{\circ} \mathrm{C}$.

Figura 40 - Distribuição da largura das nanofitas $\mathrm{V}_{2} \mathrm{O}_{5} \mathrm{nH}_{2} \mathrm{O}$ submetidas a um tratamento hidrotermal a $120^{\circ} \mathrm{C}$ durante: (a) 0; (b) 240; (c) 360; (d) 480; (e) 720; (f) 1440; (g) 2880; (h) 4320 e (i) 7200 minutos.

Figura 41 - Evolução temporal do tamanho médio da largura $(d)$ em função do tempo de tratamento hidrotermal a $120^{\circ} \mathrm{C}$.

Figura 42 - (a) Imagens HR - TEM de dois nanobastões colados lateralmente e uma imagem de HR-TEM expandida da região A (b) e da região B (c).

Figura 43 - Distribuição da largura das amostras submetidas a um tratamento hidrotermal em diferentes temperaturas durante 24 horas: (a) AM02; (b) AM03; (c) AM05; (d) AM06.

Figura 44 - (a) e (b) Imagens de FE-MEV da seção transversal da amostra AM05. 101

Figura 45 - (a) e (b) Imagens de FE-MEV da seção transversal da amostra AM06.

Figura 46 - (a) Imagens de MET da seção transversal da amostra AM06; (b) análise composicional por EDS da região observada em (a); (c) Imagens de HRTEM da seção transversal da amostra AM06.

Figura 47 - Curvas de espalhamento de SAXS para as amostras AM02, AM03, AM05 e AM06.

Figura 48 - Modelo utilizado para o ajuste teórico dos dados para a AM05.

Figura 49 - Curva experimental do espalhamento de SAXS e ajuste teórico para a amostra AM05

Figura 50 - Curva experimental do espalhamento de SAXS e ajuste teórico para a amostra AM06.

Figura 51- Esquema do mecanismo de evolução da morfologia em condições hidrotermais a partir das nanofitas de $\mathrm{V}_{2} \mathrm{O}_{5} \mathrm{nH}_{2} \mathrm{O}$ até a formação de nanobastões.

Figura 52 - Padrão de difração de raios $\mathrm{X}$ das nanofitas de $\mathrm{V}_{2} \mathrm{O}_{5} n \mathrm{H}_{2} \mathrm{O}$ e das amostras NaV01, NaV02 e NaV03 obtidas através do tratamento hidrotermal

Figura 53 - Curva de TG das amostras NaV01, NaV02 e NaV03. 
Figura 54 - Imagens de campo claro de FE - STEM das amostras (a) NaV01, (b)NaV02

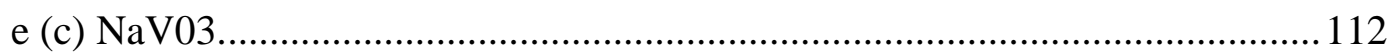

Figura 55 - Imagem de campo escuro de FE-STEM da amostra NaV02............................ 112

Figura 56 - Distribuição da largura das amostras obtidas através do tratamento hidrotermal: (a) NaV01; (b) NaV02; (c) NaV03............................................ 113

Figura 57 - (a) Imagens MET da amostra NaVO2; (b) Espectro EDS da região A............... 114

Figura 58 - (a) Imagens de HR-TEM da amostra NaV01; (b) imagem ampliada da

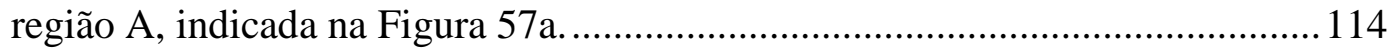

Figura 59 - Espectro XANES na borda K do Vanádio das amostras NaV01, NaV02, do composto $\mathrm{V}_{2} \mathrm{O}_{5} \mathrm{nH}_{2} \mathrm{O}$ e da fase $\mathrm{V}_{2} \mathrm{O}_{5}$ ortorrômbica.

Figura 60 - (a) região da pré - borda do espectro XANES das amostras NAV02 e $\mathrm{V}_{2} \mathrm{O}_{5} \mathrm{nH}_{2} \mathrm{O}$ e do composto $\mathrm{V}_{2} \mathrm{O}_{5}$ ortorrômbico; (b) primeira derivada dos espectros apresentados na Figura 59a. 


\section{LISTA DE TABELAS}

Tabela 1 - Condições experimentais para a obtenção das amostras submetidas a um tratamento hidrotermal:

Tabela 2 - Valores da distância basal d e quantidade de moléculas de $\mathrm{H}_{2} \mathrm{O}$ n, nas amostras AM01 e AM02

Tabela 3 - Posição e intensidade da pré-borda e da borda de absorção das amostras estudadas, do vanádio metálico e da amostra de referência $\left(\mathrm{V}_{2} \mathrm{O}_{5}\right.$ ortorrômbica).

Tabela 4 - Parâmetros estruturais para $\mathrm{o}$ composto $\mathrm{V}_{2} \mathrm{O}_{5}$ ortorrômbico obtido pelo programa Artemis

Tabela 5 - Resultados estruturais obtidos pelo ajuste do espectro experimental de EXAFS para o composto padrão $\left(\mathrm{V}_{2} \mathrm{O}_{5}\right.$ ortorrômbico):

Tabela 6 - Resultados estruturais obtidos do ajustes do espectro de EXAFS para as amostras AM5 e AM06 para a primeira esfera de coordenação.

Tabela 7 - Resultados estruturais obtidos do ajustes do espectro de EXAFS para as amostras AM5 e AM06 para a segunda esfera de coordenação.

Tabela 8 - Largura média das nanofitas (d) em função do tempo de tratamento hidrotermal a $80^{\circ} \mathrm{C}$

Tabela 9 - Largura média das nanofitas (d) em função do tempo de tratamento hidrotermal a $120^{\circ} \mathrm{C}$

Tabela 10 - Condições experimentais de síntese e características das amostras obtidas neste trabalho.

Tabela 11 - Largura média (d) das nanoestruturas para as amostras obtidas em diferentes temperaturas durante 24 horas: 


\section{Sumário}

1 INTRODUÇÃO ...............................................................................................................25

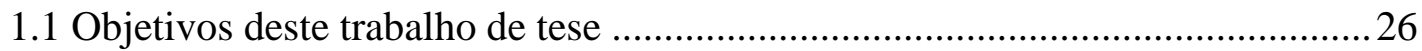

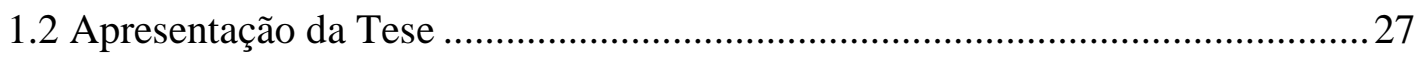

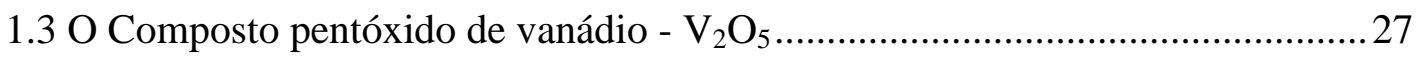

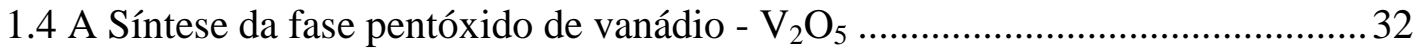

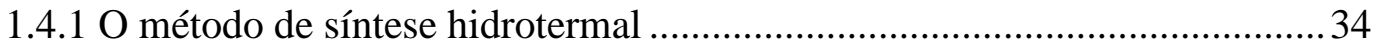

1.4.2 Evolução morfológica das nanoestruturas de óxidos de vanádio obtidas em

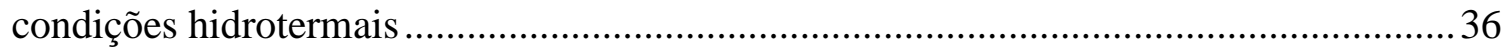

1.5 O Mecanismo de crescimento em condições hidrotermais.................................. 38

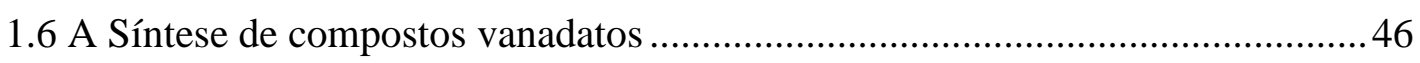

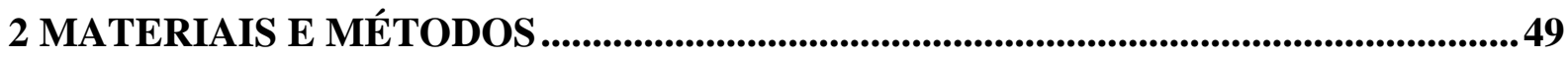

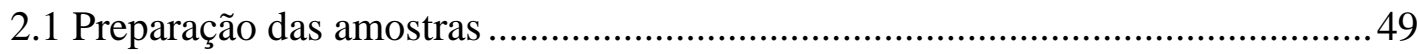

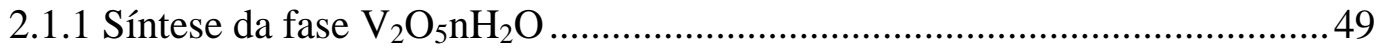

2.1.2 Estudo do mecanismo de crescimento ....................................................52

2.1.3 Síntese em presença de $\mathrm{NaOH}$.................................................................5

2.2 Técnicas de caracterização utilizadas ............................................................54

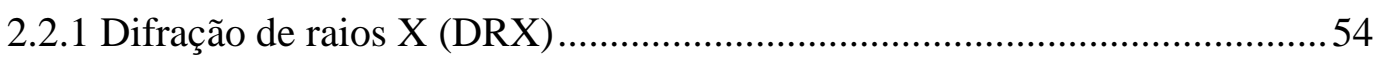

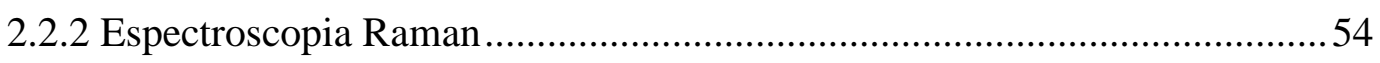

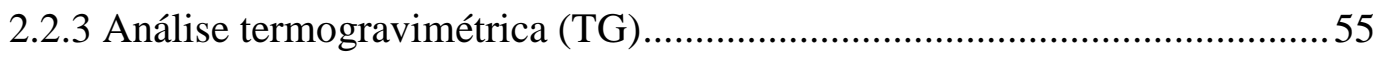

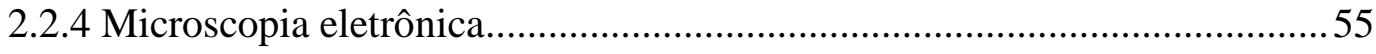

2.2.5 Espectroscopia de absorção de raios X (XAS) ……....................................57

2.2.6 Espalhamento de raios X a baixo ângulo (SAXS) ......................................59

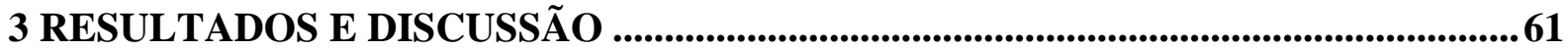

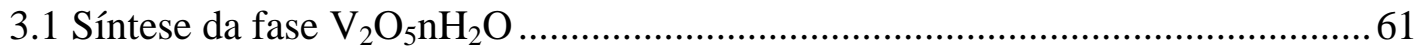

3.1.1 Estudo da ordem local das amostras nanoestruturadas através da técnica de

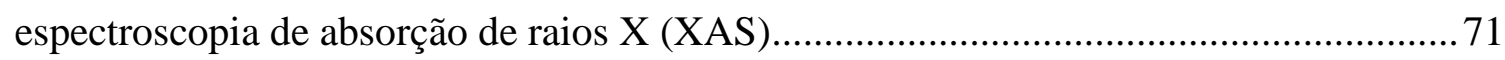

3.2 Estudo do mecanismo de crescimento do composto $\mathrm{V}_{2} \mathrm{O}_{5}$ nanoestruturado ...... 85 
3.3 Estudo da evolução morfológica das nanoestruturas de $\mathrm{V}_{2} \mathrm{O}_{5} \mathrm{nH}_{2} \mathrm{O}$ 97

3.3.1 Estudo da morfologia das nanoestruturas em solução através da técnica de SAXS 104

3.3.2 Modelo proposto para a mudança de morfologia. 107

3.4 Estudo da síntese em presença de $\mathrm{NaOH}$. 109

4 CONCLUSÕES 119

SUGESTÕES PARA TRABALHOS FUTUROS 121

REFERÊNCIAS 123

APÊNDICE 1. 133

A.1 ESPECTROSCOPIA DE ABSORÇÃO DE RAIOS X (XAS) 133

A.1.1 Absorção de fótons pela matéria 133

A.1.2 Espectroscopia de absorção de raios X (XAS). 135

A.1.2.1 A região de EXAFS......................................................................... 136

A.1.2.1.1 Origem do sinal EXAFS............................................................... 136

A.1.2.1.2 A Equação de EXAFS ................................................................ 138

A.1.2.1.3 Análise padrão das oscilações EXAFS ........................................... 141

A.1.2.1.4 Efeito do intervalo em $\mathrm{k}$ do sinal EXAFS ....................................... 144

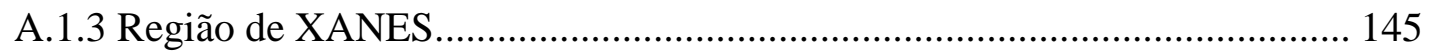

A.1.3.1 Análise dos espectros de XANES ..................................................... 145

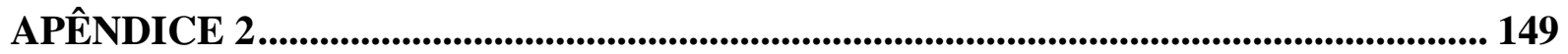

A.2 - MEDIDAS DE ESPALHAMENTO DE RAIOS X A BAIXO ÂNGULO (SAXS) 149 


\section{INTRODUÇÃO}

O tamanho atual dos micro-dispositivos tem estimulado nos últimos anos uma ampla pesquisa visando diminuir sua dimensão em pelo menos uma ordem de magnitude e o uso de materiais nanoestruturados, é considerada uma das opções para atingir esse objetivo. (1)

É bem estabelecido que a obtenção do mesmo material na forma nanoestruturada leva a uma mudança significativa em suas propriedades estruturais, físicas e químicas, principalmente devido ao aumento da razão da área superficial em relação ao volume da amostra. $(2,3)$

Entre os principais objetivos a serem alcançados no estudo de materiais nanoestruturados estão, a compreensão e o domínio dos diferentes métodos de síntese em sua forma isolada, os efeitos sobre as nanopartículas quando de sua agregação e o desenvolvimento de uma nova classe de materiais de alto desempenho quando comparados aos materiais convencionais.

Do ponto de vista da obtenção desses materiais, o grande desafio está no processo de síntese que possibilitam a obtenção de forma controlada de materiais nanoestruturados com composição química, formas e tamanhos homogêneos. Os métodos de obtenção de materiais nanoestruturados baseados em sínteses químicas apresentam-se como uma das opções para transpor tais desafios por possibilitarem não só o controle do tamanho das partículas bem como sua morfologia. $(1,4,5)$ Materiais nanoestruturados apresentando diferentes formas, como nanofios e nanotubos, apresentam um grande interesse uma vez que o efeito de confinamento quântico desses sistemas depende do seu tamanho, da morfologia além do aumento da área superficial do material. $(2,3,6)$

A obtenção de materiais apresentando diferentes morfologias está diretamente relacionada à cinética de crescimento envolvida no processo de síntese. Diferentes métodos 
vêm sendo utilizados na síntese de nanomateriais apresentando um determinado grau de anisotropia. (7-9) Por exemplo, nanomateriais de composição CdS, CdSe e $\mathrm{TiO}_{2}$ apresentando anisotropia em sua morfologia foram produzidos através do controle da cinética de crescimento dos cristais. Nestes casos, o processo de nucleação ocorreu segundo o processo conhecido como Maturação de Ostwald, ou “Ostwald Ripening”. (7-9)

Recentemente, materiais nanoestruturados preparados a partir de uma solução obtida através da decomposição de peróxidos e um posterior tratamento hidrotermal apresentaram um grau maior de anisotropia em sua morfologia. (10-13) Foi observado que as partículas obtidas a partir desse método de síntese apresentam um mecanismo de crescimento orientado, diferente dos mecanismos observados anteriormente, que foi denominado de Colescência Orientada, ou "Oriented Attachment". (10-13)

Embora o mecanismo de crescimento de materiais nanoestruturados terem sido recentemente extensivamente estudado devido ao grande interesse no controle do tamanho e da morfologia, ao nosso conhecimento, nenhum trabalho tem sido dedicado ao estudo do mecanismo de crescimento de nanoestruturas de $\mathrm{V}_{2} \mathrm{O}_{5}$ na sua forma hidratada ou mesmo ao estudo sistemático dos parâmetros de síntese quando obtida através do método hidrotermal.

\subsection{Objetivos deste trabalho de tese}

Esta tese de doutorado tem como principal objetivo a síntese de nanoestruturas de óxido de vanádio hidratado através do método de decomposição de peróxido utilizando o método hidrotermal abordando principalmente a dependência estrutural e morfológica do material em função das variáveis de síntese deste método.

Além disso, com o objetivo de melhor compreender a cinética de crescimento das nanoestruturas obtidas, um estudo do processo de crescimento destas nanoestruturas também será realizado e comparado ao observado em outros materiais que foram preparados utilizando a mesma metodologia de síntese.

Finalmente, serão apresentados os resultados a respeito da potencialidade desta rota de síntese na obtenção de compostos a base de vanádio contendo cátions em sua estrutura. 


\subsection{Apresentação da Tese}

A seguir, serão apresentados uma breve descrição do composto de pentóxido de vanádio $\left(\mathrm{V}_{2} \mathrm{O}_{5}\right)$ hidratado ou desidratado, um resumo de alguns trabalhos que tiveram como objetivo a síntese do composto $\mathrm{V}_{2} \mathrm{O}_{5}$ ou compostos a base de vanádio nanoestruturados e finalmente um resumo de alguns dos mecanismos de crescimento de materiais nanoestruturados presentes na literatura.

No Capítulo 2, apresentamos os métodos utilizados na preparação das amostras bem como as técnicas utilizadas em sua caracterização.

Os resultados obtidos e as discussões serão apresentados no Capítulo 3.

Finalmente, o Capítulo 4, traz as conclusões obtidas com a realização desse trabalho e as perspectivas de trabalhos futuros.

\subsection{Composto pentóxido de vanádio $-\mathrm{V}_{2} \mathrm{O}_{5}$}

Os compostos de óxidos de vanádio têm despertado por décadas o interesse de inúmeros pesquisadores principalmente no que diz respeito ao seu grande potencial de aplicação, como por exemplo, em catálise $(1,14,15)$, como sensores (16-19) e em eletroquímica. (1, 20-24) Chama a atenção, inicialmente, tanto a diversidade estequiométrica como a quantidade de diferentes estruturas cristalinas que estes compostos podem adotar. São apenas quatro os óxidos de vanádio onde todos os átomos de vanádio possuem um único estado de oxidação: $\mathrm{VO}, \mathrm{V}_{2} \mathrm{O}_{3}, \mathrm{VO}_{2} \mathrm{e}_{2} \mathrm{O}_{5}$, onde $\mathrm{V}$ assume respectivamente as valências +2 , $+3,+4$ e +5 . Os demais óxidos formam sólidos onde os átomos de vanádio apresentam valências mistas. (1)

Dentre os compostos de óxido de vanádio que podem ser obtidos, o pentóxido de vanádio $\left(\mathrm{V}_{2} \mathrm{O}_{5}\right)$, além de tratar-se da mais estável fase entre os óxidos de vanádio, apresenta um conjunto de propriedades diferenciadas fazendo desse composto um dos mais estudados. $(1,25,26)$ 
Devido a sua estrutura na forma de camadas, o $\mathrm{V}_{2} \mathrm{O}_{5}$ é um composto típico de intercalação, ou seja, possui uma propriedade de inserção de "íons hóspedes" nas cavidades de sua estrutura. $(1,25,26)$ Este processo refere-se como uma intercalação reversível de espécies móveis (átomos, moléculas ou íons) que atuam como hospedes em uma matriz cristalina hospedeira que contém um sistema interconectado de sítios da rede, mantendo sua integridade estrutural. A estrutura do composto $\mathrm{V}_{2} \mathrm{O}_{5}$ apresenta uma característica bidimensional de camadas com uma anisotropia estrutural ao longo comprimento das seis ligações V-O.

A Figura 1 apresenta a estrutura cristalina ortorrômbica do composto $\mathrm{V}_{2} \mathrm{O}_{5}$ que consiste de camadas de unidades $\mathrm{VO}_{5}$ na forma piramidal de base quadrada que se conectam pelos seus vértices. (1)

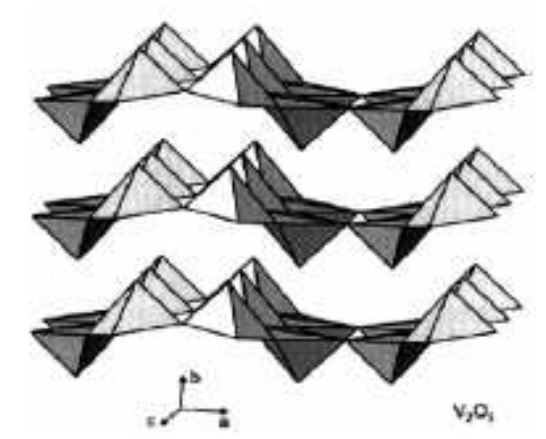

Figura 1 - Estrutura cristalina ortorrômbica do composto $\mathrm{V}_{2} \mathrm{O}_{5}$. (1)

Diferentes trabalhos encontrados na literatura apresentam resultados sobre a síntese do pentóxido de vanádio hidratado $\left(\mathrm{V}_{2} \mathrm{O}_{5} n \mathrm{H}_{2} \mathrm{O}\right)$. (1, 18, 19, 25, 27-32) Segundo estes trabalhos, a fase $\mathrm{V}_{2} \mathrm{O}_{5} n \mathrm{H}_{2} \mathrm{O}$ é composta por partículas na forma de fitas que possuem moléculas de água $\left(\mathrm{H}_{2} \mathrm{O}\right)$ intercaladas entre as camadas de $\mathrm{V}_{2} \mathrm{O}_{5}$. A presença de moléculas de água $(n)$ intercalada faz com que ocorra um aumento da distância entre as camadas $\mathrm{V}_{2} \mathrm{O}_{5}$, aumentando assim a capacidade de intercalação de outros elementos nesta estrutura. (1, 25, 27-31)

Segundo Wang e colaboradores, a potencialidade de aplicações da fase $\mathrm{V}_{2} \mathrm{O}_{5} n \mathrm{H}_{2} \mathrm{O}$ está diretamente relacionada à quantidade de moléculas de água $(n)$ intercalada. $(1,28)$ Estes autores mostraram que um filme formado pela fase $\mathrm{V}_{2} \mathrm{O}_{5} 0,3 \mathrm{H}_{2} \mathrm{O}$ intercalada com $\mathrm{Li}^{+}$exibe uma melhor desempenho eletroquímica quando comparado à fase com $n$ igual 0,6 ou igual a 1,6. (28) 
Liu e colaboradores estudaram a sensibilidade destes materiais à detecção de gás e mostraram que o composto $\mathrm{V}_{2} \mathrm{O}_{5} n \mathrm{H}_{2} \mathrm{O}$ é sensível ao etanol em baixas concentrações $(<10$ ppm) enquanto que sua forma desidratada, $\mathrm{V}_{2} \mathrm{O}_{5}$, apresentou uma melhor sensibilidade em detectar altas concentrações. (17) Em um segundo estudo, Liu e colaboradores apresentaram resultados promissores para essas nanofitas cobertas com nanopartículas de $\mathrm{Fe}_{2} \mathrm{O}_{3}, \mathrm{TiO}_{2} \mathrm{e}$ $\mathrm{SnO}_{2}$. Segundo os autores, essas amostras quando comparadas as amostras puras apresentam um aumento significativo na sensibilidade a diferentes gases como etanol, benzeno, ciclohexano, gasolina, $\mathrm{NH}_{3}$ e $\mathrm{H}_{2} \mathrm{~S}$ (16). Alguns trabalhos na literatura também reportam resultados promissores de sensibilidade ao álcool de fibras macroscópicas preparadas à base de $\mathrm{V}_{2} \mathrm{O}_{5} n \mathrm{H}_{2} \mathrm{O}$ nanoestruturado. $(18,19)$

Legendre e colaboradores apresentaram um estudo estrutural do composto $\mathrm{V}_{2} \mathrm{O}_{5} n \mathrm{H}_{2} \mathrm{O}$ através da técnica de difração de elétrons (DE) e difração de raios X (DRX). (33, 34) De acordo com estes trabalhos, a fase $\left(\mathrm{V}_{2} \mathrm{O}_{5} n \mathrm{H}_{2} \mathrm{O}\right)$ possui uma estrutura anisotrópica quando depositada na superfície de um substrato. Além disso, a fase $\mathrm{V}_{2} \mathrm{O}_{5} n \mathrm{H}_{2} \mathrm{O}$ é formada de fitas emaranhadas de aproximadamente $100 \mathrm{~nm}$ de comprimento e $10 \mathrm{~nm}$ de largura. Essas fitas apresentam uma estrutura em duas dimensões formadas por blocos contendo aproximadamente 10 átomos de vanádio conectados entre si através de moléculas de água que por sua vez possuem uma ligação muito forte com a estrutura ortorrômbica do $\mathrm{V}_{2} \mathrm{O}_{5}$. Segundo esses mesmos autores, a estrutura da fase $\mathrm{V}_{2} \mathrm{O}_{5} n \mathrm{H}_{2} \mathrm{O}$ pode ser descrita por um modelo de camada semelhante ao observado na estrutura da fase $\mathrm{V}_{2} \mathrm{O}_{5}$ ortorrômbica, apresentando, entretanto uma estrutura na forma de um "degrau” em torno de 2,9 Á. A Figura 2 apresenta esta estrutura proposta por Legendre e colaboradores. $(33,34)$

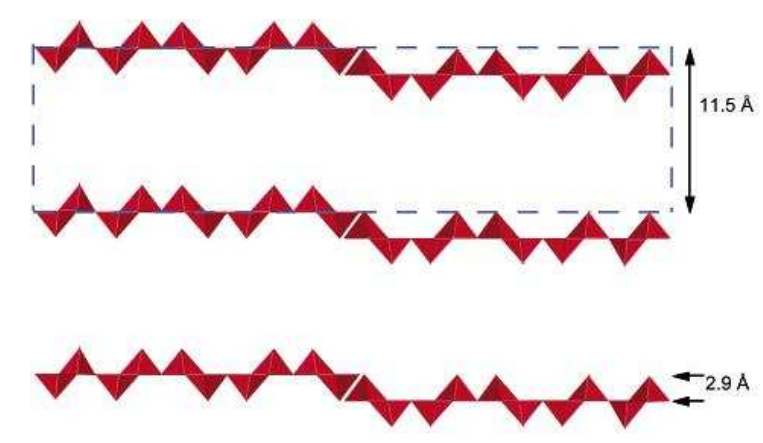

Figura 2 - Modelo estrutural "degrau" proposto por Legendre e colaboradores para o composto $\mathrm{V}_{2} \mathrm{O}_{5} n \mathrm{H}_{2} \mathrm{O}$ (33, 34). 
Adelbert e colaboradores também estudaram a estrutura da fase $\mathrm{V}_{2} \mathrm{O}_{5} n \mathrm{H}_{2} \mathrm{O}$ através da técnica de DRX e análise termogravimétrica (TG). (32) Através de medidas de (TG), foi observado que a desidratação da fase $\mathrm{V}_{2} \mathrm{O}_{5} n \mathrm{H}_{2} \mathrm{O}$ ocorre em três estágios; o primeiro a partir da temperatura ambiente até aproximadamente $120^{\circ} \mathrm{C}$ com a perda de moléculas de água fracamente ligadas; o segundo observou-se uma perda de moléculas de água entre 210 e $270^{\circ} \mathrm{C}$ e finalmente, no terceiro estágio, em torno de $300^{\circ} \mathrm{C}$, a molécula de água encontra-se ligada quimicamente à estrutura. Foi também observado que em $350^{\circ} \mathrm{C}$, onde praticamente toda a água foi eliminada da estrutura, ocorre o aparecimento da fase $\mathrm{V}_{2} \mathrm{O}_{5}$ ortorrômbica. (32)

Através da medida dos espectros Raman e infravermelho, Abello e colaboradores apresentaram um estudo estrutural da fase $\mathrm{V}_{2} \mathrm{O}_{5} n \mathrm{H}_{2} \mathrm{O}$ com $n=1,6,1,2,0,6,0,4$ e 0,3. (35) Segundo estes autores, quando $n \approx 0,3$, as camadas de $\mathrm{V}_{2} \mathrm{O}_{5}$ estão conectadas através de ligações $\mathrm{V}=\mathrm{O}-\mathrm{V}$ onde a molécula de água está presa à cavidade da estrutura ligada por dois átomos de hidrogênio com o oxigênio da rede. Quando $n \approx 0,6$, os á tomos de vanádio estão coordenados com a molécula de água pela banda $\mathrm{V}_{-}-\mathrm{OH}_{2}$. Para $0,6<n<1,4$, três tipos de moléculas de água estão presentes na estrutura, em bom acordo com as medidas de análise térmica. (35)

Diferentemente dos resultados obtidos por Legendre e colaboradores (33, 34), Oka e colaboradores através de um estudo por DRX propuseram que a estrutura da fase $\mathrm{V}_{2} \mathrm{O}_{5} n \mathrm{H}_{2} \mathrm{O}$, com $n \approx 2,0$ é formada por uma camada dupla de $\mathrm{V}_{2} \mathrm{O}_{5}$ separadas de 2,9 $\AA$. (36)

O modelo proposto por Oka e colaboradores foi recentemente confirmado por Petkov e colaboradores através do estudo da estrutura tridimensional da fase $\mathrm{V}_{2} \mathrm{O}_{5} n \mathrm{H}_{2} \mathrm{O}$ utilizando a técnica de PDF (“atomic pair distribution function”). (37) Estes autores observaram que em uma escala atômica, a estrutura do composto $\mathrm{V}_{2} \mathrm{O}_{5} n \mathrm{H}_{2} \mathrm{O}$ pode ser descrita como uma camada dupla de $\mathrm{V}_{2} \mathrm{O}_{5}$ empilhada ao longo do eixo $c$ de uma célula unitária monoclínica.

A Figura 3 apresenta a estrutura da fase $\mathrm{V}_{2} \mathrm{O}_{5} n \mathrm{H}_{2} \mathrm{O}$ proposta por Petkov e colaboradores. 


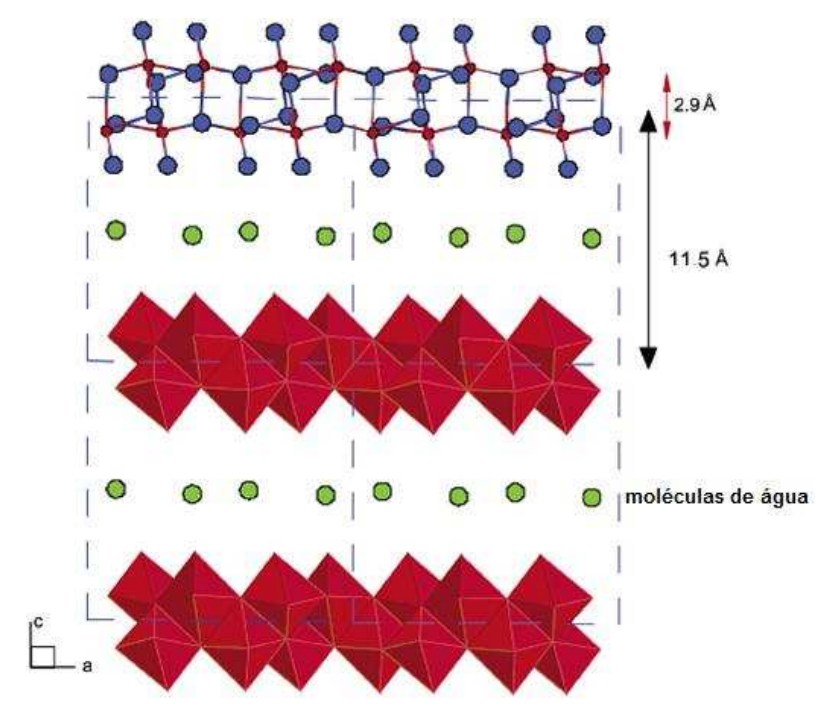

Figura 3 - Modelo estrutural do composto $\mathrm{V}_{2} \mathrm{O}_{5} \mathrm{nH}_{2} \mathrm{O}$ obtido através da técnica de PDF. (37)

A estrutura e as propriedades do composto $\mathrm{V}_{2} \mathrm{O}_{5} n \mathrm{H}_{2} \mathrm{O}$ podem também depender da razão entre os íons $\mathrm{V}^{4+} \mathrm{e}^{5+}$ presentes na estrutura. (25-27) Foi observado que a distância basal $d$ entre as nanofitas aumenta com o aumento da quantidade de $\mathrm{V}^{4+}$ e que esta variação é reversível até o estado de redução correspondente a razão $\left(\mathrm{V}^{4+}\right) /\left(\mathrm{V}^{4+}+\mathrm{V}^{5+}\right)$ igual a $20 \%$. (27) Acima deste valor, o xerogel $\mathrm{V}_{2} \mathrm{O}_{5} n \mathrm{H}_{2} \mathrm{O}$ não é mais estável ocorrendo segregação. Segundo Livage e colaboradores, o aumento da quantidade de íons $\mathrm{V}^{4+}$ faz com que o gel adquira uma coloração verde-escuro e a quantidade de água, $n$, aumente. (27)

Diferentes autores estudaram o estado de oxidação e a estrutura local dos íons vanádio através da técnica de absorção de raios X (XAS) $(22,23,30,31,38-40)$. Segundo Mansour e colaboradores, a fração de íons $\mathrm{V}^{4+}$ pode ser determinada analisando o deslocamento de picos presentes na pré-borda e da borda principal do espectro de absorção do átomo de vanádio. Estes autores também mostraram que a quantidade de água intercalada presente na estrutura do $\mathrm{V}_{2} \mathrm{O}_{5} n \mathrm{H}_{2} \mathrm{O}$ faz com que ocorra uma mudança na ordem local do átomo de V. (31)

Pelo fato dos raios $\mathrm{X}$ produzidos em um laboratório síncroton serem altamente polarizados, Stizza e colaboradores estudaram o efeito da anisotropia morfológica do composto $\mathrm{V}_{2} \mathrm{O}_{5} 1,6 \mathrm{H}_{2} \mathrm{O}$ através da técnica XAS. (38) Analisando os espectros nas regiões de XANES ("X-ray absorption near edge structure") e EXAFS ("Extended X-ray Absorption Fine Structure"), estes autores observaram que a estrutura do composto $\mathrm{V}_{2} \mathrm{O}_{5} n \mathrm{H}_{2} \mathrm{O}$ é formada por unidades tipo $\mathrm{VO}_{5}$ com a ligação do tipo $\mathrm{V}=\mathrm{O}$ na direção $z$ perpendicular ao plano basal da pirâmide de oxigênio. (38) Esta estrutura está ilustrada pela Figura 4. 


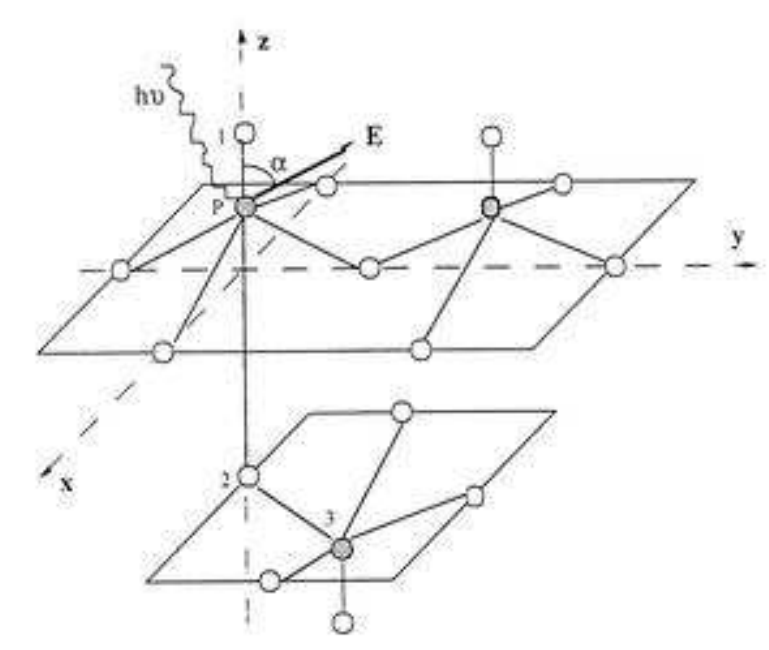

$\boldsymbol{P}=$ átomo absorvedor

$\boldsymbol{E}=$ campo elétrico

$\boldsymbol{\alpha}=\hat{a}$ ngulo entre $\boldsymbol{E}$ e a direção do eixo $z$

Figura 4 - Estrutura local do composto $\mathrm{V}_{2} \mathrm{O}_{5} n \mathrm{H}_{2} \mathrm{O}$ de acordo com o trabalho de Stizza e colaboradores. (38) O circulo preenchido representa os átomos de vanádio enquanto que os círculos "vazios" representam os átomos de oxigênio.

Confirmando o modelo estrutural proposto por Oka e colaboradores, o trabalho apresentado por Georgetti e colaboradores também evidenciou a presença de bicamadas de $\mathrm{V}_{2} \mathrm{O}_{5}$ dando origem à estrutura de $\mathrm{V}_{2} \mathrm{O}_{5} n \mathrm{H}_{2} \mathrm{O}$. (39)

\subsection{A Síntese da fase pentóxido de vanádio $-\mathrm{V}_{2} \mathrm{O}_{5}$}

Em relação ao processo de síntese, o composto $\mathrm{V}_{2} \mathrm{O}_{5}$ nanoestruturado vem sendo obtido através de diferentes métodos como evaporação térmica $(41,42)$, moagem mecânica (43) e micelas reversas $(20,44)$ ou então através do tratamento térmico do composto $\mathrm{V}_{2} \mathrm{O}_{5} n \mathrm{H}_{2} \mathrm{O}$ obtido através do método de síntese denominado de sol-gel $(1,17)$ e resfriamento em água. (37)

A síntese do composto $\mathrm{V}_{2} \mathrm{O}_{5} n \mathrm{H}_{2} \mathrm{O}$ através da rota sol-gel tem sido uma das mais utilizadas por ser considerada uma metodologia relativamente rápida de síntese e por não ser necessária a utilização de altas temperaturas. Este procedimento de síntese pode ser desenvolvido de três maneiras: (1) acidificação do composto $\mathrm{NaVO}_{3}$ usando o processo por troca de íons e polimerização de $\mathrm{HVO}_{3}$ resultante em água; (2) hidrólise e condensação do 
alcóxido de vanádio e (3) reação entre peróxido de hidrogênio $\left(\mathrm{H}_{2} \mathrm{O}_{2}\right)$ e pentóxido de vanádio $\left(\mathrm{V}_{2} \mathrm{O}_{5}\right)$ na forma de pó. (1)

Holland e colaboradores utilizando técnicas de análise como XANES, área superficial por BET (Brunauer, Emmett e Teller), FTIR (“Fourier transform infrared") e TG mostraram que o composto $\mathrm{V}_{2} \mathrm{O}_{5} n \mathrm{H}_{2} \mathrm{O}$, obtido a partir da acidificação do composto de $\mathrm{NaVO}_{3}$ ou pela hidrólise e condensação de alcóxido de vanádio possuem propriedades semelhantes. (23) Entretanto, a rota utilizando o composto $\mathrm{NaVO}_{3}$ pode levar a contaminação de íons de sódio e a concentração de vanádio esta sujeita a mudanças devido a água adicional introduzida na resina durante o processo de troca de íon. Na rota utilizando alcóxido, a alta reatividade do alcóxido e a dependência de fatores como o $\mathrm{pH}$, temperatura e concentração de reagentes fazem com que na síntese do composto $\mathrm{V}_{2} \mathrm{O}_{5} n \mathrm{H}_{2} \mathrm{O}$, sejá necessário adicionar agentes para o controle da reação. (1)

Desta forma, a rota baseada na reação entre o composto $\mathrm{H}_{2} \mathrm{O}_{2}$ e o composto $\mathrm{V}_{2} \mathrm{O}_{5}$ tem se mostrado relativamente mais "fácil" e "limpa", despertando assim a atenção de muitos pesquisadores $(1,29)$. Alonso e colaboradores apresentaram um estudo de NMR da síntese do gel $\mathrm{V}_{2} \mathrm{O}_{5} n \mathrm{H}_{2} \mathrm{O}$ através da reação de $\mathrm{V}_{2} \mathrm{O}_{5}$ com peróxido de hidrogênio $\left(\mathrm{H}_{2} \mathrm{O}_{2}\right)$. (29) Segundo esses autores, a dissolução do $\mathrm{V}_{2} \mathrm{O}_{5}$ pelo $\mathrm{H}_{2} \mathrm{O}_{2}$ leva a formação da espécie diperoxo $\left[\mathrm{VO}\left(\mathrm{O}_{2}\right)_{2}\right]^{-}$não estável em solução, esta espécie é decomposta progressivamente formando $\left[\mathrm{VO}\left(\mathrm{O}_{2}\right)\right]^{+}$e então a espécie vanadato, liberando oxigênio. Assim, a solução de ácido decavanádico $\left[\mathrm{H}_{\mathrm{n}} \mathrm{V}_{10} \mathrm{O}_{28}\right]^{(6-\mathrm{n})}$ que é formada após algumas horas é dissociado dando origem a polimerização do gel $\mathrm{V}_{2} \mathrm{O}_{5} n \mathrm{H}_{2} \mathrm{O}$ (29). Ainda segundo Alonso e colaboradores, o processo de formação de $\mathrm{V}_{2} \mathrm{O}_{5} n \mathrm{H}_{2} \mathrm{O}$ através da decomposição do peróxido de hidrogênio é similar ao processo de formação utilizando uma coluna de troca iônica. (29) Esse processo de acidificação é evidenciado pela coloração amarela da solução alguns minutos após a síntese que, segundo alguns trabalhos encontrados na literatura, ocorre devido ao aumento de coordenação do $\mathrm{V}^{5+}$ através da adição de duas moléculas de água. $(25,26)$ Uma molécula de água liga-se em oposição ao $\mathrm{V}=\mathrm{O}$ enquanto a outra se posiciona no plano equatorial. $\mathrm{O}$ processo de condensação não pode ocorrer ao longo da direção $z$, uma vez que não existe grupo $\mathrm{V}-\mathrm{OH}$, ocorrendo apenas no plano $x y$ dando origem a morfologia 2-D desse material. Ao longo da direção de $\mathrm{H}_{2} \mathrm{O}-\mathrm{V}-\mathrm{OH}$, ocorre o processo de olação, enquanto que ao longo da direção de $\mathrm{HO}-\mathrm{V}-\mathrm{OH}$, ocorre o processo de oxolação. Como a reação de olação ocorre mais rapidamente, essa reação também contribui com a origem da forma de fitas dessas nanoestruturas. $(25,26)$ 
A Figura 5 ilustra o processo de formação dessas nanofitas, processo este que ocorre de forma espontânea, ou seja, pode ocorrer em temperaturas ambiente, entretanto, podendo levar vários dias para ocorrer. (25)

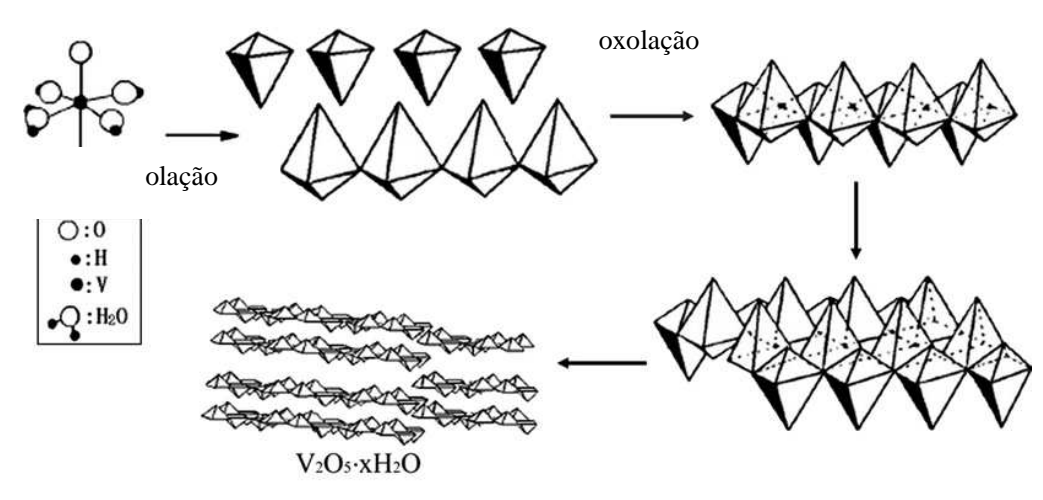

Figura 5 - Formação de nanofitas de $\mathrm{V}_{2} \mathrm{O}_{5} \mathrm{nH}_{2} \mathrm{O}$ pelo processo de condensação e polimerização. (25)

É bem estabelecido que as propriedades físicas e químicas dos materiais nanoestruturados são fortemente correlacionadas ao tamanho e morfologia das nanoestruturas obtidas. (3, 5, 6, 45) Além dos estudos anteriormente citados, é possível encontrar na literatura estudos recentes sobre a síntese de óxido de vanádio com diferentes morfologias como, por exemplo, nanotubos. $(21,46-50)$ Estas diferenças de morfologia e também tamanho estão relacionadas diretamente as condições e/ou processo de sínteses empregadas.

\subsubsection{O método de síntese hidrotermal}

Dentre os métodos de síntese que vem sendo utilizado na busca de materiais apresentando novas morfologias e dimensões, o método de síntese baseado no tratamento hidrotermal tem sido muito explorado. $(1,51,52) \mathrm{O}$ termo hidrotermal, usado pela primeira vez pelo geologista britânico Roderick Murchison, refere-se a uma reação heterogênea em presença de um mineralizador ou de um solvente aquoso de modo a dissolver e recristalizar materiais que são insolúveis em condições normais de síntese. (51) Embora a técnica 
hidrotermal tenha atingido um grande avanço, não há unanimidade em sua definição. Diante das diversas definições do termo hidrotermal, Byrappa e colaboradores propuseram utilizar o termo hidrotermal como "qualquer reação química heterogênea em um sistema fechado na presença de um solvente e uma pressão maior que 1 atm”. $(51,52)$ Recentemente, Yoshimura e colaboradores utilizaram uma definição ainda mais geral, denotando o termo hidrotermal a "qualquer reação química, que ocorra em um sistema fechado, aquoso ou não aquoso, em condições supercríticas ou subcríticas". (52)

Neste contexto a água torna-se um constituinte muito importante para o sistema hidrotermal principalmente por possuir propriedades únicas sob diferentes condições de temperatura e pressão como importantes mudanças em sua viscosidade, na densidade e na constante dielétrica. $(1,51,52)$ Foi observado que essas mudanças podem influenciar de forma significativa a mobilidade de moléculas ou íons contidos na solução. A grande vantagem da síntese através do tratamento hidrotermal é a possibilidade de variar os parâmetros de síntese como a temperatura de tratamento, a concentração de solventes, a introdução ou remoção de aditivos entre outros. Outro fator importante é o fato de ser possível obter quase $100 \%$ de eficiência na conversão do material precursor. $(1,51,52)$

Recentemente, diversos trabalhos de síntese baseados no tratamento hidrotermal mostraram ser possível obter o composto $\mathrm{V}_{2} \mathrm{O}_{5}$ hidratado ou não apresentando diferentes morfologias e/ou estruturas dependendo apenas da rota de síntese empregada $(15-17,24,44$, 46, 47, 49, 53-55) ou dos parâmetros de síntese utilizados. $(15,56)$

Através do tratamento hidrotermal a uma temperatura de $180^{\circ} \mathrm{C}$, Pan e colaboradores obtiveram nanoestruturas ordenadas de $\mathrm{V}_{2} \mathrm{O}_{5} 0,3 \mathrm{H}_{2} \mathrm{O}$ na forma de bastões utilizando como precursores o composto $\mathrm{NH}_{4} \mathrm{VO}_{3}$ e o acido nítrico $\left(\mathrm{HNO}_{3}\right)$ para o controle de $\mathrm{pH}$. (55) No entanto, Pan e colaboradores não conseguiram obter apenas as nanoestruturas de composição $\mathrm{V}_{2} \mathrm{O}_{5} 0,3 \mathrm{H}_{2} \mathrm{O}$ ocorrendo também a formação de diferentes estados de hidratação $(0,3<n<$ 1,7) e a fase desidratada $\mathrm{V}_{2} \mathrm{O}_{5}$ ortorrômbica. (55) Através de uma rota de síntese similar, Liu e colaboradores mostraram ser possível obter a fase $\mathrm{V}_{2} \mathrm{O}_{5}$ ortorrômbica na forma de nanobastões submetendo a amostra $\mathrm{V}_{2} \mathrm{O}_{5} n \mathrm{H}_{2} \mathrm{O}$ a um tratamento hidrotermal a $180^{\circ} \mathrm{C}$ seguido de um tratamento térmico a $400^{\circ} \mathrm{C}$. (17) Recentemente, Gao e colaboradores mostrou ser possível obter nanobastões da ordem de $20 \mathrm{~nm}$ de largura através do tratamento hidrotermal da fase $\mathrm{V}_{6} \mathrm{O}_{13}$ durante um período de 4 dias somente utilizando água e uma temperatura de $200^{0}$ C. (57) 


\subsubsection{Evolução morfológica das nanoestruturas de óxidos de vanádio obtidas em condições hidrotermais}

É possível também encontrar na literatura trabalhos que descrevem a evolução morfológica das nanoestruturas de óxidos de vanádio em função das condições de síntese hidrotermal. $(15,56,58) \mathrm{Li}$ e colaboradores mostraram que, através do ajuste de $\mathrm{pH}$ da solução para um valor igual a 4, é possível obter nanofitas ou nanobastões diluindo o composto $\mathrm{NH}_{4} \mathrm{VO}_{3}$ com ácido sulfúrico ou ácido acético. (15) Segundo esses autores, após a formação de nanofitas de composição $\mathrm{V}_{2} \mathrm{O}_{5} n \mathrm{H}_{2} \mathrm{O}$ na presença de ácido sulfúrico, devido ao processo de desidratação, ocorre a quebra dessas nanofitas dando origem a nanofitas menores. Por outro lado, com a utilização do ácido acético, o tamanho maior das moléculas de $\mathrm{CH}_{3} \mathrm{COOH}$ intercaladas na estrutura do $\mathrm{V}_{2} \mathrm{O}_{5} n \mathrm{H}_{2} \mathrm{O}$ causa uma maior tensão interna fazendo com que as fitas possam gradualmente enrolar resultando na formação de nanobastões. (15)

Figura 6 ilustra o modelo proposto por Li e colaboradores para a mudança de morfologia das amostras. (15)

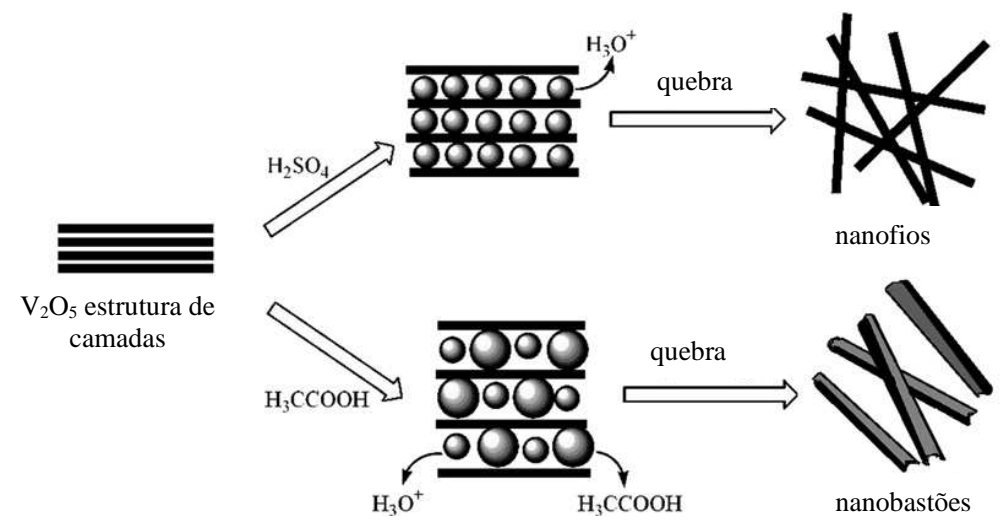

Figura 6 - Formação de nanofios e nanobastões de $\mathrm{V}_{2} \mathrm{O}_{5} n \mathrm{H}_{2} \mathrm{O}$ dependendo da presença de $\mathrm{H}_{3} \mathrm{O}^{+}$ou de $\mathrm{CH}_{3} \mathrm{COOH}$ intercalados e o processo de quebra proposto por Li e colaboradores. (15)

Zhou e colaboradores também obtiveram nanobastões da fase $\mathrm{V}_{2} \mathrm{O}_{5}$ ortorrômbica através do método hidrotermal usando como precursor o composto $\mathrm{VOSO}_{4} n \mathrm{H}_{2} \mathrm{O}$ e o como oxidante, o composto $\mathrm{KBrO}_{3}$. (56) Neste trabalho, os autores realizaram um estudo da formação de nanofios do composto $\mathrm{V}_{2} \mathrm{O}_{5}$ na fase ortorrômbica, onde observaram que o 
mecanismo de formação ocorre em dois estágios: o primeiro estágio está relacionado a formação da forma hidratada de $\mathrm{V}_{2} \mathrm{O}_{5} n \mathrm{H}_{2} \mathrm{O}$ atribuído pelos autores ao mecanismo de OR e o segundo, pela desidratação da fase $\mathrm{V}_{2} \mathrm{O}_{5} n \mathrm{H}_{2} \mathrm{O}$ na presença de $\mathrm{KBrO}_{3}$. Ainda, segundo esses autores, somente com a realização da síntese entre 160 e $180^{\circ} \mathrm{C}$ e na presença de um forte oxidante, como $\mathrm{KBrO}_{3}$, foi possível gerar a força motriz necessária para remover as moléculas de $\mathrm{H}_{2} \mathrm{O}$ presentes entre as camadas da estrutura de $\mathrm{V}_{2} \mathrm{O}_{5} n \mathrm{H}_{2} \mathrm{O}$ e assim formar a fase $\mathrm{V}_{2} \mathrm{O}_{5}$ ortorrômbica. (56)

Wei e colaboradores estudaram a síntese do composto nanoestruturado unidimensional (1D) $\mathrm{V}_{2} \mathrm{O}_{4} 0,25 \mathrm{H}_{2} \mathrm{O}$ partindo de partículas de $\mathrm{V}_{2} \mathrm{O}_{4}$ e utilizando água como solvente.(58) De acordo com esses autores, quando esta amostra foi tratada em condições hidrotermais a uma temperatura de $90^{\circ} \mathrm{C}$ durante 24 horas, foi possível observar a presença de nanopartículas de $\mathrm{V}_{2} \mathrm{O}_{4} n \mathrm{H}_{2} \mathrm{O}$ com uma estrutura de camadas, ou seja, possuindo morfologia de nanofitas. Com o tratamento da amostra a $200^{\circ} \mathrm{C}$ durante 14 dias, observaram a presença de nanopartículas com morfologias de nanofios. De acordo com a literatura, o composto $\mathrm{V}_{2} \mathrm{O}_{4}$ possui uma fase metaestável que, em condições hidrotermais, dá origem ao composto hidratado $\mathrm{V}_{2} \mathrm{O}_{4} 0,25 \mathrm{H}_{2} \mathrm{O}$ com estrutura de camadas. As interações entre essas camadas hidratadas são relativamente fracas sendo gradualmente esfoliadas dando origem a nanofolhas. Essas nanofolhas possuem uma tensão intrínseca que deve gradualmente fazer com que as suas bordas enrolem. De forma a diminuir essa grande tensão a fim de diminuir a energia de superfície, essas nanofolhas quebram, dando origem então aos nanofios. (58) Baseados em seus resultados experimentais esses autores propuseram o modelo de formação das nanoestruturas apresentado na Figura 7. (58)

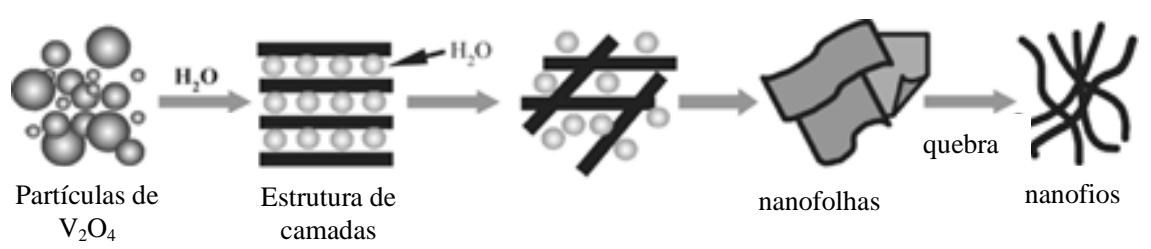

Figura 7 - Modelo de formação de nanofios de composição $\mathrm{V}_{2} \mathrm{O}_{4} 0,25 \mathrm{H}_{2} \mathrm{O}$ a partir de partículas de $\mathrm{V}_{2} \mathrm{O}_{4}$ em condições hidrotermais propostos por Wei e colaboradores. (58)

Alguns trabalhos mostram também que através do uso apropriado de algumas moléculas orgânicas que atuam como "templates", é possível controlar a morfologia das 
nanopartículas obtidas. $(21,26,47-49,59)$ Por exemplo, a adição de produtos orgânicos como hexadecilamina ao $\mathrm{V}_{2} \mathrm{O}_{5} n \mathrm{H}_{2} \mathrm{O}$ pode levar a formação de nanotubos de vanádio $(26,47,59)$.

A Figura 8 ilustra o efeito dessas moléculas orgânicas atuando como "templates" (26). De acordo com esses trabalhos, a adição destas moléculas a solução contendo $\mathrm{V}_{2} \mathrm{O}_{5} n \mathrm{H}_{2} \mathrm{O}$, quando submetidos ao tratamento hidrotermal, faz com que sejam intercalados à estrutura lamelar, provocando assim um enrolamento dessa estrutura. A variação de tamanho das nanoestruturas depende das condições de síntese empregadas, como tempo e temperatura de tratamento. $(26,47,59)$

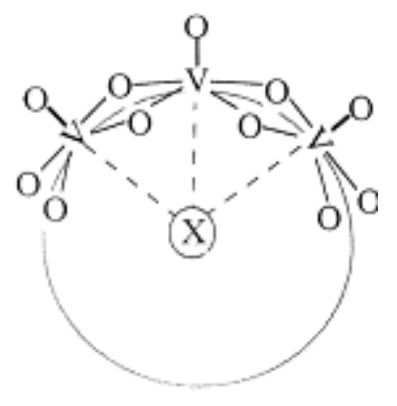

Figura 8 - Ilustração do efeito de moléculas orgânicas atuando como "templates". (26)

Em relação à obtenção de compostos $\mathrm{V}_{2} \mathrm{O}_{5} n \mathrm{H}_{2} \mathrm{O}$ nanoestruturados através da decomposição do peróxido assistido por tratamento hidrotermal, encontramos na literatura trabalhos utilizando diferentes precursores. $(53,54)$ Segundo Li e colaboradores, a obtenção da fase $\mathrm{V}_{2} \mathrm{O}_{5} n \mathrm{H}_{2} \mathrm{O}$ na forma denominada de "bundle-like" em temperaturas relativamente baixas somente foi possível na presença de íons $\mathrm{Co}^{2+}$ os quais induzem uma nucleação homogênea da fase $\mathrm{V}_{2} \mathrm{O}_{5} n \mathrm{H}_{2} \mathrm{O}$ promovendo assim seu crescimento. (53) Hu e colaboradores também obtiveram a fase $\mathrm{V}_{2} \mathrm{O}_{5} n \mathrm{H}_{2} \mathrm{O}$ com pequenas quantidades de íons de $\mathrm{V}^{4+}$ adicionando o $\mathrm{H}_{2} \mathrm{O}_{2}$ ao $\mathrm{VOSO}_{4}$ e submetendo a solução a um tratamento durante 24 horas a $180^{\circ} \mathrm{C}$. (54)

\subsection{O Mecanismo de crescimento em condições hidrotermais}

O fato das propriedades dos materiais nanoestruturados estarem diretamente relacionadas às suas dimensões e sua morfologia, o controle dos tamanhos e das formas das 
nanoestruturas aparece como um dos principais desafios do ponto de vista das aplicações em nanotecnologia. Diante disso o conhecimento do mecanismo de crescimento envolvido durante a evolução morfológica é de fundamental importância quando se busca a obtenção de amostras através de processos de síntese de forma eficiente e com boa qualidade de controle, possibilitando assim, a obtenção de materiais nanoestruturados com morfologias e tamanhos bem definidos e de forma controlada.

O mecanismo de crescimento que tem sido observado em diferentes materiais nanoestrturados é o mecanismo conhecido como Maturação de Ostwald, ou "Ostwald Ripening” (OR). (60) Esse mecanismo é baseado na dissolução das partículas e na reprecipitação dos íons devido à dependência do tamanho em relação a solubilidade do cristal. (60) O gradiente na concentração iônica da solução promove o transporte de soluto das partículas menores para as maiores. (60)

A Figura 9 ilustra o modelo de crescimento de partículas pelo mecanismo de Maturação de Ostwald.
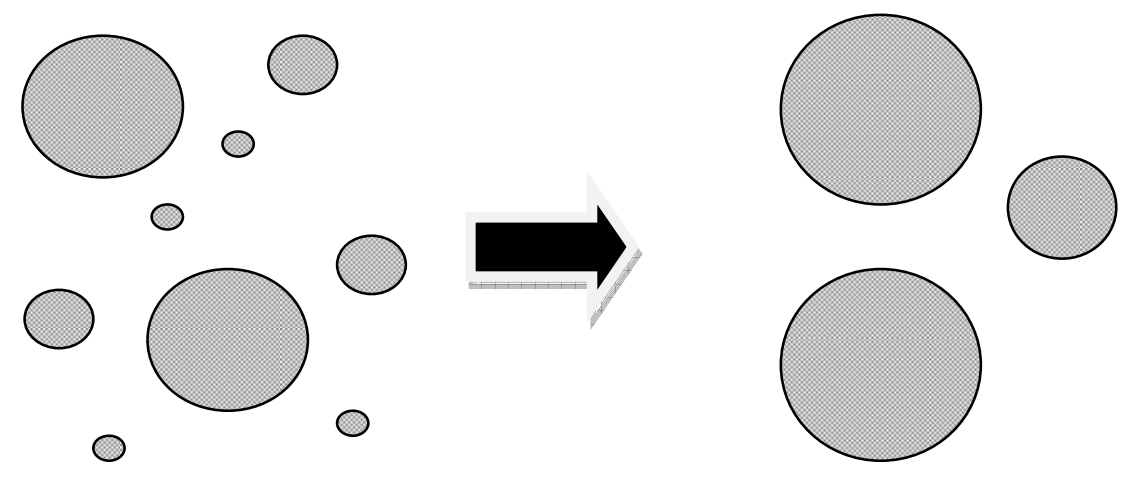

Figura 9 - Ilustração do modelo de crescimento de partículas pelo modelo de Maturação de Ostwald.

A equação cinética que descreve o mecanismo de OR é conhecida como equação de Lifshitz, Slyozov e Wagner (LSW) e pode ser escrita como (60-63):

$$
\vec{r}^{n}-\vec{r}_{0}^{n} \alpha t
$$

onde $\vec{r}^{n}$ corresponde ao raio da partícula e $n$ depende do tipo do processo envolvido no crescimento (por exemplo, para $n=3$ o crescimento é controlado pela difusão volumétrica de íons na vizinhança). (60-62) 
Apesar do fato de que muitos dos resultados experimentais terem sido adequadamente descritos através do modelo de OR, diversos trabalhos mostraram que somente este mecanismo não é suficiente para descrever de forma precisa o mecanismo de crescimento observado em alguns sistemas nanocristalinos. (7, 61, 62, 64-67)

Outro mecanismo de crescimento associado aos materiais nanoestruturados, e que tem sido muito aplicado recentemente é o mecanismo denominado como Coalescência Orientada, ou "Oriented Attachment" (OA). (66, 68-75) Ainda que esse mecanismo não seja totalmente compreendido, diferentes artigos têm discutido seu papel no processo de crescimento de nanopartículas apresentando diferentes formas. $(4,11,12,64,68-73,75)$.

Esse mecanismo tem sido proposto como outro processo significativo no crescimento de nanoestruturas, onde o crescimento é descrito pelo alinhamento cristalográfico e pela coalescência de partículas vizinhas levando a eliminação da interface comum das partículas. $(4,11,12,64,68-73,75)$ A força motriz para esse mecanismo é atribuída a redução da energia superficial e de contorno de grão. Pela natureza localizada do mecanismo de Coalescência Orientada, o processo leva freqüentemente à formação de nanopartículas ou nanoestruturas com morfologias irregulares, não observadas nos mecanismos clássicos. Estudos têm mostrado que o mecanismo é significativo nos primeiros estágios de crescimento, e pode estar envolvido na formação de partículas anisotrópicas em suspensão, como nanobastões e nanofios através do consumo das partículas como "blocos de construção". (4, $11,12,64,68-73,75)$

A Figura 10 ilustra alguns exemplos de formação de nanoestruturas atribuídas ao mecanismo de OA. (76) 


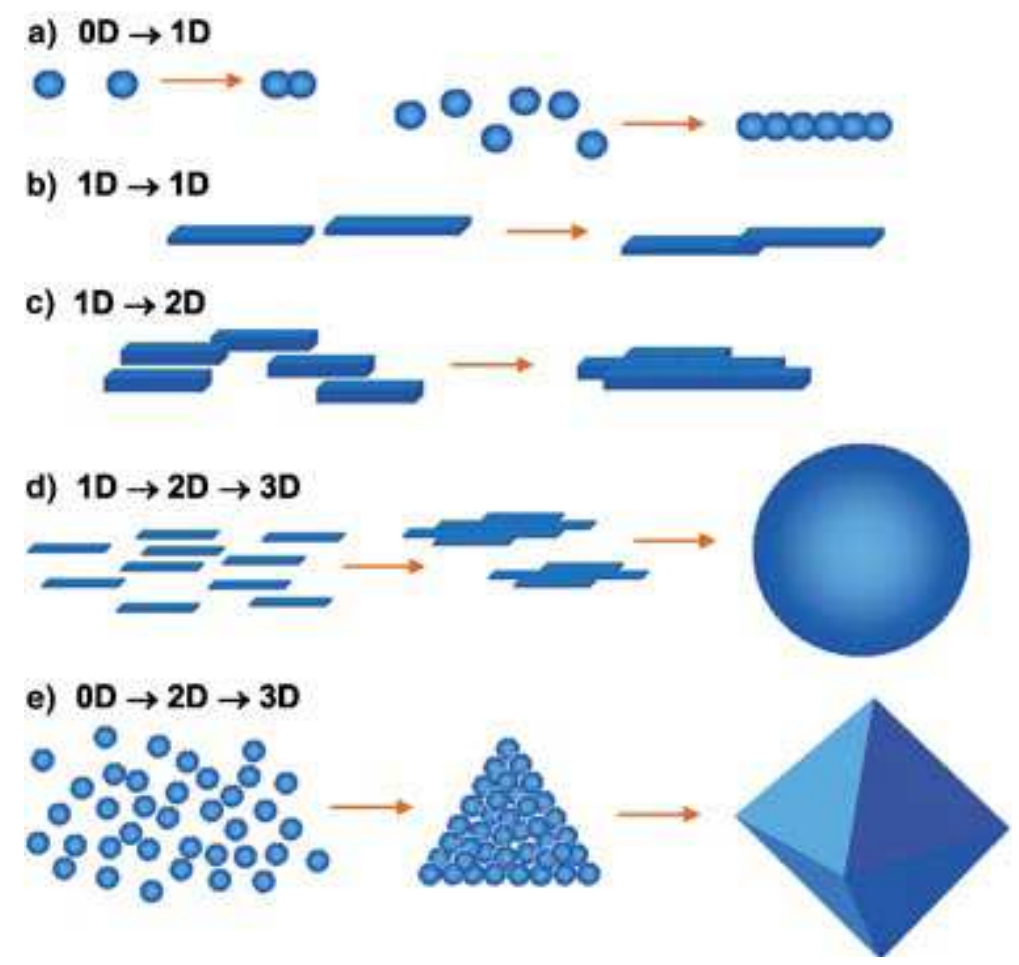

Figura 10 - Ilustrações do crescimento de diversas nanoestruturas através do mecanismo de Coalescência Orientada (OA). (76)

Na Figura 10a é possível observar uma ilustração para o caso de formação de nanoestruturas unidimensionais (1D) na forma de nanofios ou nanobastões através da autoorganização de nanocristais, como por exemplo de $\mathrm{TiO}_{2}$ (71) ou $\mathrm{ZnO}$. (77) Como foi observado por Lou e colaboradores para nanoestruturas de $\alpha-\mathrm{MoO}_{3}$, nanoestruturas 1D como nanobastões ou nanofitas também podem crescer através do empilhamento planar, Figura 10b. (78) Liu e colaboradores observaram que o mecanismo de OA de nanobastões de $\mathrm{ZnO}$ pode levar a formação nanoestruturas com maiores dimensões, como ilustra a Figura 10c, ou até mesmo nanoestruturas bidimensionais (2D) como folhas. (79) Em um segundo estudo, Liu e colaboradores também mostraram que o mecanismo ilustrado na Figura 10c pode ser utilizado para explicar a formação de estruturas tridimensionais (3D) como microesferas ocas através da auto-organização de nanofolhas, formadas a partir de nanofitas, Figura10d. (80) É possível ainda encontrar na literatura a formação de nanoestruturas complexas como octaedros formados através do mecanismo de OA, Figura10e, como observado por Yang e colaboradores para o $\mathrm{SnO}_{2}$. (76)

O mecanismo de OA torna-se muito pertinente em casos onde as partículas estão livres para se mover, como nos casos de partículas em solução, ou mesmo quando as partículas encontram-se lado a lado sobre um substrato podendo coalescer durante o crescimento. (64) 
Alguns trabalhos mostram que o crescimento de nanoestruturas pelo mecanismo de OA é caracterizado por defeitos estruturais na interface, atribuído a um processo imperfeito de coalescência, gerando deslocamentos de planos. (71) De acordo com os trabalhos relacionados a esse mecanismo, esse processo torna-se importante no caso de materiais nanocristalinos onde a coalescência entre as partículas reduz a energia total do sistema pela remoção da energia superficial relacionada às ligações não satisfeitas da superfície.

A Figura 11 apresenta, a título de exemplo, imagens de microscopia eletrônica de transmissão (MET) de nanopartículas do composto $\mathrm{TiO}_{2}$ em sua fase anatase. Pode ser observado que as nanopartículas se agruparam na mesma orientação cristalográfica gerando em seguida estruturas monocristalinas compostas de inúmeras partículas primárias. (65) A orientação cristalográfica de uma partícula com a outra é determinada pela minimização da energia superficial mais elevada. Quando duas nanopartículas se aproximam, elas são atraídas por forças de Van der Waals e devido à energia térmica, essas partículas podem se rearranjar e encontrar uma configuração de menor energia. $(65,70,71)$

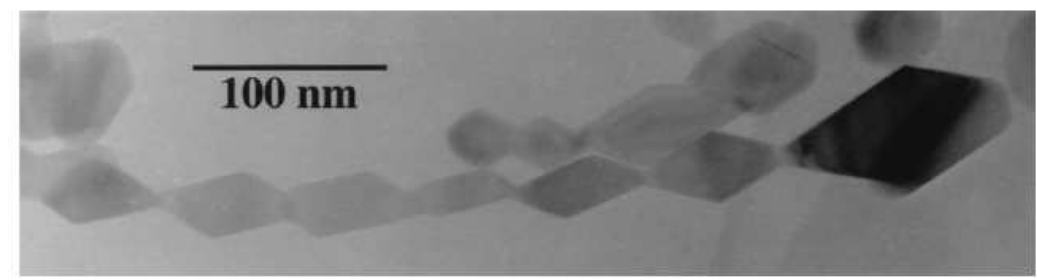

Figura 11 - Imagem de microscopia eletrônica de transmissão (MET) de nanopartículas de $\mathrm{TiO}_{2}$ de fase anatase apresentando uma auto-organização espontânea quando submetida a um tratamento hidrotermal. (65)

Por se tratar de um mecanismo de crescimento baseado em colisões das nanopartículas, mudanças do meio reacional como, por exemplo, a temperatura, a concentração, o uso de surfactantes e conseqüentemente o $\mathrm{pH}$ do meio, podem afetá-lo de maneira significativa. $(66,67,74)$

A Figura 12 apresenta uma ilustração do processo de crescimento de amostras nanoestruturadas em diferentes condições hidrotermais via o mecanismo de OA. (66) 
(a)

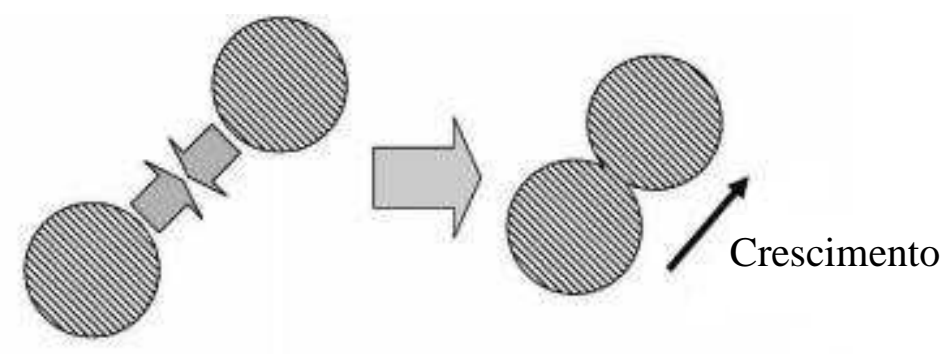

(b)
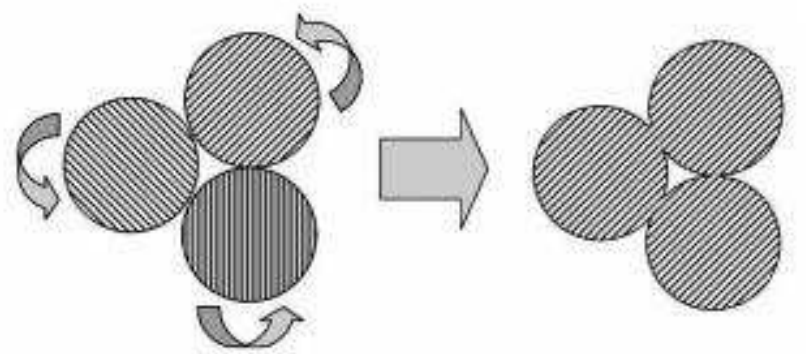

(c)
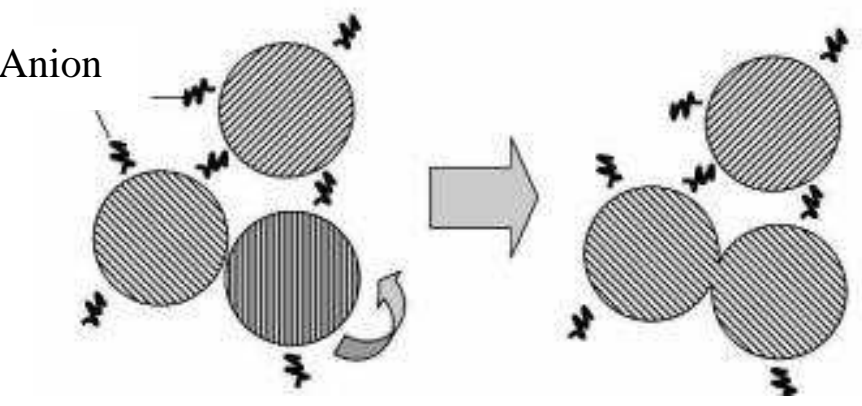

Figura 12 - Ilustração de processo de crescimento em condições hidrotermais de acordo com o mecanismo de OA: (a) em um sistema disperso; (b) em um sistema aglomerado; (c) em um sistema aglomerado contendo anions orgânicos agindo como surfactantes. (66)

Considerando que as nanoestruturas estão dispersas, Figura 12a, colisões sucessivas sem que ocorra a rotação das partículas podem levar a formação de nanopartículas anisotrópicas de tamanhos variados, sendo este crescimento anisotrópico e aleatório. Em condições de maior concentração de partículas, isto é, em um sistema aglomerado ( Figura 12b), após a colisão das partículas, pode ocorrer o alinhamento cristalográfico através da rotação da partícula podendo dar origem a nanocristais de tamanhos e forma variadas.

Lee e colaboradores em seu trabalho mostraram que através da alteração do meio, como por exemplo, o uso de um meio ácido, pode causar efeitos significativos no processo de crescimento, principalmente pela redução das colisões e/ou afetando o contato entre as partículas e conseqüentemente, seu mecanismo de crescimento. (66) A Figura 12c ilustra a ação desses agentes, onde, através do uso apropriado de surfactantes ou qualquer composto com uma afinidade específica a um plano cristalográfico da partícula, pode levar a um processo de crescimento de forma controlada, ou seja, levar a formação de uma nanopartícula 
de morfologia e/ou dimensão controlada. (66) Outro exemplo da ação de aditivos no mecanismo de crescimento por OA foi mostrado por Wang e colaboradores. (67) Esse autores estudaram a cinética do mecanismo de crescimento de nanopartículas de $\mathrm{ZnS}$ e observaram que é possível elevar a taxa de crescimento por OA através do aumento da concentração de $\mathrm{NaOH}$. (67)

Ribeiro e colaboradores apresentaram recentemente um modelo "cinético" de modo a descrever o crescimento de nanopartículas pelo mecanismo de OA. (75) De acordo com os resultados obtidos por esses autores, o modelo cinético descreve o mecanismo de crescimento por OA, de forma consistente ao modelo proposto por Zhang e Banfield. (64) Lee e colaboradores utilizaram o modelo cinético proposto por Ribeiro e colaboradores no estudo da evolução morfológica de nanopartículas de $\mathrm{SnO}_{2}$. (74) Neste trabalho, os autores mostraram que o mecanismo de crescimento denominado como OA pode realmente ser considerado um mecanismo efetivo na formação de nanocristais anisotrópicos da fase $\mathrm{SnO}_{2}$. (74)

A Figura 13a ilustra o processo de coalescência de duas partículas dando origem a uma partícula maior, segundo o modelo cinético usado para descrever o mecanismo de crescimento por OA, proposto por Ribeiro e colaboradores. (75) Na Figura 13b é possível observar que este mecanismo de crescimento através da coalescência de duas partículas observadas através de imagens de microscopia eletrônica de transmissão de alta resolução (HR-TEM). (75)

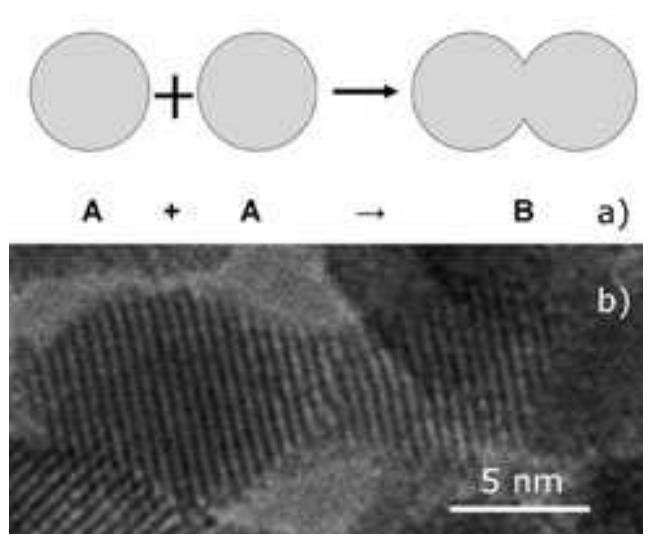

Figura 13 - (a) Modelo do mecanismo de crescimento por OA, levando a coalescência de duas partículas; (b) Imagens de HR-TEM de duas nanopartículas coalescidas de $\mathrm{SnO}_{2}$. (75)

Mais recentemente, Ribeiro e colaboradores propuseram uma adaptação para o mecanismo de crescimento via OA. (73) Nesta proposta, para descrever a formação de 
nanopartículas anisotrópicas em soluções coloidais, os autores aplicaram o conceito de polimerização onde a coalescência de duas partículas é interpretada de forma análoga a uma reação de policondensação. (73) Neste modelo adaptado, denominado de "polymerization OA model", a formação da nanoestrutura pode ser visualizada como a junção de duas superfícies ativas, como ilustra a Figura 14.

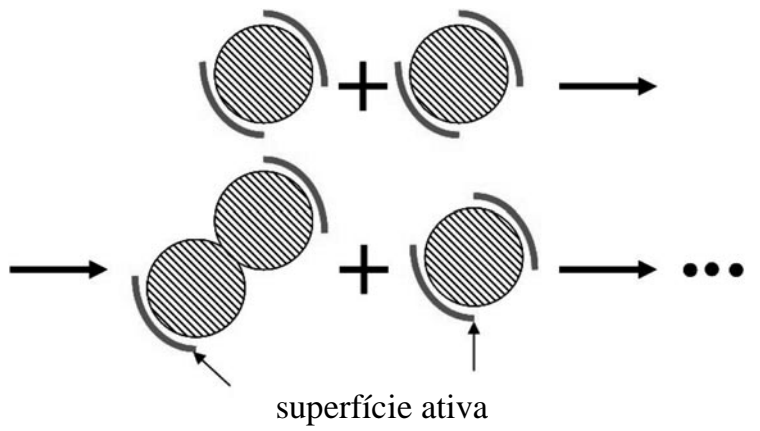

Figura 14 - Ilustração do processo de coalescência de duas superfícies ativas denominado de "polymerization OA model" proposto por Ribeiro e colaboradores. (73)

A equação que descreve a cinética de crescimento no modelo adaptado de OA através da polimerização por condensação pode ser escrita como (73):

$$
x_{\max }=-\frac{1}{\alpha \cdot \ln \left(\frac{8 \sqrt{2 k_{0} S_{0}} t}{1+8 \sqrt{2 k_{0} S_{0} t}}\right)}
$$

onde $S_{0}$ é a concentração inicial de superfícies ativas, $t$ é o tempo de tratamento e $\alpha$ é uma constante relacionada as partículas envolvidas no processo de coalescência, consideradas como monômeros, podendo possuir valores entre $0<\alpha<1$. Por exemplo, para uma partícula $m$ que colidirá com uma partícula $n$, sendo suas dimensões iguais, ou seja $m=n, \alpha$ será igual a 0,5. Uma discussão mais detalhada deste modelo e desta equação pode ser encontrada no trabalho publicado por Ribeiro e colaboradores. (73)

Um ponto importante nesta proposta é a sua aplicabilidade na direção de crescimento unidimensional do cristal, ou seja, análises independentes podem ser feitas em cada uma das direções da partícula final, desde que o modelo seja aplicado de forma a ser dependente somente do número de partículas conectadas. (73) Desta forma, este modelo cinético pode ser 
utilizado para explicar o crescimento de nanoestruturas anisotrópicas dando origem a nanocristais maiores (79) ou para obter materiais nanoestruturados com uma morfologia bem determinada. (81).

\subsection{A Síntese de compostos vanadatos}

Além dos óxidos de vanádio, os compostos a base de vanádio contendo cátions em sua estrutura vem também despertando um grande interesse da comunidade científica devido as suas diversas propriedades. (82-89)

Dentre estes compostos, os compostos vanadatos contendo metais alcalinos em sua estrutura têm sido muito estudados, sendo possível encontrar na literatura diversos trabalhos a respeito da síntese dessa classe de materiais. $(36,82-88,90,91)$

Durupthy e colaboradores estudaram o efeito do $\mathrm{pH}$ na formação de óxidos de vanádio através da adição de $\mathrm{Na}^{+}$e $\mathrm{TMA}^{+}$ao xerogel $\mathrm{V}_{2} \mathrm{O}_{5} 1,8 \mathrm{H}_{2} \mathrm{O}$. (91) Neste trabalho, observaram que, dependendo do $\mathrm{pH}$ da solução acidificada de metavanadato, a fase $\mathrm{Na}_{0.3} \mathrm{~V}_{2} \mathrm{O}_{5} 1,5 \mathrm{H}_{2} \mathrm{O}$ pode ser termodinamicamente estabilizada. Segundo esses autores, os cátions de $\mathrm{Na}^{+}$e $\mathrm{TMA}^{+}$ permanecem intercalados entre as camadas do xerogel $\mathrm{V}_{2} \mathrm{O}_{5} 1,8 \mathrm{H}_{2} \mathrm{O}$ fazendo com que perca a sua estrutura de camadas, ou seja, sua orientação preferencial. (91)

É possível também encontrar na literatura trabalhos recentes a respeito da obtenção de compostos vanadatos contendo metais alcalinos utilizando o método hidrotermal $(85,88,90$, 92). Dentre esses trabalhos, alguns mostraram que a presença de aditivos inorgânicos é crucial na obtenção dessa classe de materiais. $(90,93) \mathrm{Yu}$ e colaboradores obtiveram a fase $\mathrm{Na}_{2} \mathrm{~V}_{6} \mathrm{O}_{16} 3 \mathrm{H}_{2} \mathrm{O}$ adicionando a uma solução de $\mathrm{V}_{2} \mathrm{O}_{5}$ uma solução de $\mathrm{NaF}$. (93) Após um tratamento hidrotermal a $180^{\circ} \mathrm{C}$ durante 24 horas obtiveram a fase $\mathrm{Na}_{2} \mathrm{~V}_{6} \mathrm{O}_{16} 3 \mathrm{H}_{2} \mathrm{O}$ na forma de nanofitas apenas quando a síntese foi realizada na presença dos íons de $\mathrm{F}^{-}$. (93) Zhou e colaboradores mostraram que adicionando o $\mathrm{V}_{2} \mathrm{O}_{5}$ a uma solução de $\mathrm{NaHSO}_{4} \cdot \mathrm{H}_{2} \mathrm{O}$ ou $\mathrm{Na}_{2} \mathrm{SO}_{4}$, após submeter a solução ao tratamento hidrotermal nas mesmas condições, é possível obter de forma seletiva a fase $\mathrm{Na}_{2} \mathrm{~V}_{6} \mathrm{O}_{16} 3 \mathrm{H}_{2} \mathrm{O}$ ou a sua fase desidratada, $\mathrm{Na}_{2} \mathrm{~V}_{6} \mathrm{O}_{16}$ dependendo apenas dos precursores utilizados. Entretanto, a morfologia do material obtido por esses autores para as duas fases foi a de nanofios. (90) 
Utilizando como precursor o composto $\mathrm{V}_{2} \mathrm{O}_{5}$, dissolvido em acido hidroclórico, e adicionando o hidróxido de bário hidratado $\left(\mathrm{Ba}(\mathrm{OH})_{2} 8 \mathrm{H}_{2} \mathrm{O}\right)$, Pang e colaboradores, obtiveram nanofitas de $\mathrm{Ba}_{1+\mathrm{x}} \mathrm{V}_{6} \mathrm{O}_{16} \mathrm{nH}_{2} \mathrm{O}$ após um tratamento hidrotermal a $180^{\circ} \mathrm{C}$ durante $24 \mathrm{~h}$. Entretanto, segundo esses autores, somente após 10 dias foi possível observar a dissolução do $\mathrm{V}_{2} \mathrm{O}_{5}$ possibilitando a adição do $\mathrm{Ba}(\mathrm{OH})_{2} 8 \mathrm{H}_{2} \mathrm{O}$. Após a adição do $\mathrm{Ba}(\mathrm{OH})_{2} 8 \mathrm{H}_{2} \mathrm{O}$ Pang e colaboradores observaram o aumento do $\mathrm{pH}$, surgindo íons de polivanadatos que em seguida reagem com os íons de $\mathrm{Ba}^{2+}$, dando origem, quando tratadas em condições hidrotermais, a nanofitas de $\mathrm{Ba}_{1+\mathrm{x}} \mathrm{V}_{6} \mathrm{O}_{16} \mathrm{nH}_{2} \mathrm{O}$. (88)

Alguns trabalhos também demonstraram ser possível obter, através da síntese hidrotermal, e partindo da rota $\mathrm{V}_{2} \mathrm{O}_{5}-\mathrm{H}_{2} \mathrm{O}$, os compostos a base de vanádio contendo cátions em sua estrutura. $(85,92)$

Liu e colaboradores, utilizando como precursores $\mathrm{V}_{2} \mathrm{O}_{5}, \mathrm{H}_{2} \mathrm{O}_{2}$ e $\mathrm{NaCl}$, após o tratamento hidrotermal a $205^{\circ} \mathrm{C}$ durante 4 dias obtiveram nanobastões de $\mathrm{NaV}_{6} \mathrm{O}_{15}\left(\mathrm{Na}_{0.33} \mathrm{~V}_{2} \mathrm{O}_{5}\right)$. Segundo esses autores, devido a característica de sua estrutura cristalográfica, os nanobastões da fase $\mathrm{NaV}_{6} \mathrm{O}_{15}$ obtidos apresentaram grande potencialidade para serem aplicados como catodo em baterias recarregáveis de lítio. (85)

Lei e colaboradores mostraram ser possível obter nanobastões da fase $\mathrm{MnV}_{6} \mathrm{O}_{6}$ somente através da síntese hidrotermal usando como precursores as nanofitas de $\mathrm{V}_{2} \mathrm{O}_{5} n \mathrm{H}_{2} \mathrm{O}$, obtido utilizando-se a rota $\mathrm{V}_{2} \mathrm{O}_{5}-\mathrm{H}_{2} \mathrm{O}_{2}$, e o acetato de manganês hidratado $\mathrm{Mn}\left(\mathrm{CH}_{3} \mathrm{COO}\right)_{2} \cdot 4 \mathrm{H}_{2} \mathrm{O}$. Os resultados apresentados por estes autores, mostraram que, quando se adiciona o composto $\mathrm{Mn}\left(\mathrm{CH}_{3} \mathrm{COO}\right)_{2} 4 \mathrm{H}_{2} \mathrm{O}$ de forma direta a solução de peróxido de vanádio, amostras na forma de nanopartículas e nanofitas podem ser obtidas. (92) 


\section{MATERIAIS E MÉTODOS}

Neste capítulo, apresentaremos a metodologia utilizada na preparação das amostras bem como um resumo das técnicas de caracterização utilizadas durante a realização deste trabalho.

\subsection{Preparação das amostras}

\subsubsection{Síntese da fase $\mathrm{V}_{2} \mathrm{O}_{5} \mathrm{nH}_{2} \mathrm{O}$}

As amostras na forma de solução preparadas durante a realização deste trabalho foram obtidas através da decomposição do peróxido de hidrogênio adicionando-se o peróxido de hidrogênio $\left(\mathrm{H}_{2} \mathrm{O}_{2}\right)$ ao pentóxido de vanádio $\left(\mathrm{V}_{2} \mathrm{O}_{5}\right)$, mantendo-se fixa a razão molar de 1:10 $\left(\mathrm{V}_{2}: \mathrm{H}_{2} \mathrm{O}_{2}\right)$. Para a síntese das amostras foi utilizado como precursor o $\mathrm{V}_{2} \mathrm{O}_{5}$ da marca Puratronic, fornecido pela Alfa Aesar, com alto grau de pureza 99,995\% e o peróxido de hidrogênio de concentração molar de 30\% fornecido pela Synth.

Como o objetivo deste trabalho é o estudo sistemático do processo de síntese, optou-se por manter fixa a concentração de $\mathrm{V}_{2} \mathrm{O}_{5}$ em todo o processo de síntese. Através da dissolução do $\mathrm{V}_{2} \mathrm{O}_{5}$ em água destilada contendo $30 \% \mathrm{H}_{2} \mathrm{O}_{2}$, as soluções foram então preparadas de modo a obter uma concentração de $0,06 \mathrm{M}$ de peroxovanadato. Após aproximadamente 10 minutos, 
observou-se a formação de uma solução amarela clara, indicando a formação do peróxido de vanádio. (29) Uma vez preparada a solução, esta foi acondicionada em uma célula hidrotermal.

A Figura 15 apresenta o esquema utilizado na preparação das amostras.

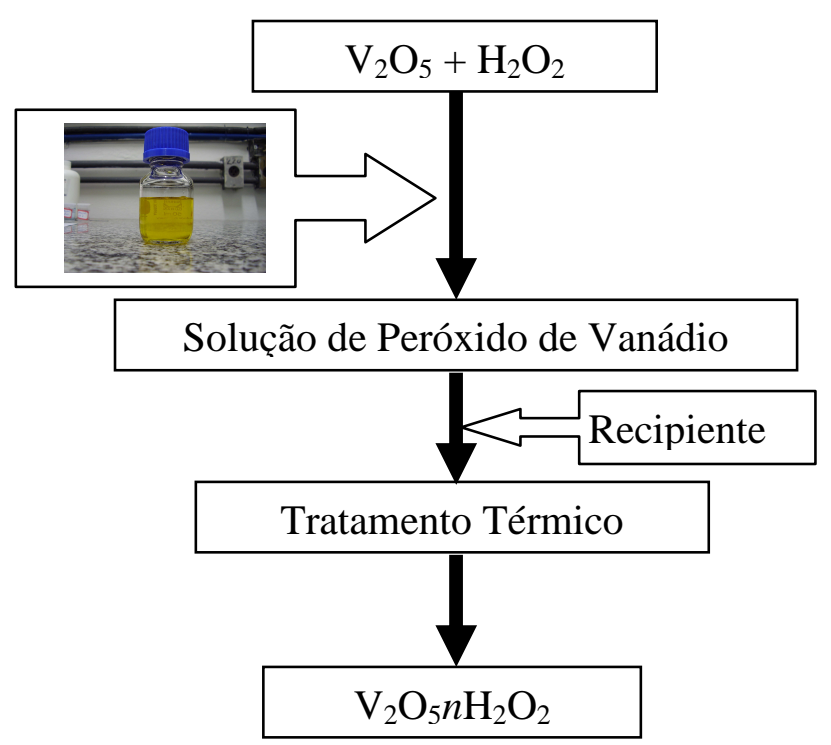

Figura 15 - Esquema experimental utilizado na preparação das amostras.

Nesta célula hidrotermal é possível realizar um controle fino da temperatura de tratamento, submeter à solução a uma agitação constante e monitorar a pressão gerada no sistema. Esta célula consiste de um micro-controlador de temperatura e tempo de tratamento, uma placa de agitação e de uma célula hidrotermal, Figura 16a. A célula hidrotermal também possui uma válvula para alivio de pressão e um termopar que fica em contato com a solução possibilitando a medida da temperatura de tratamento, além de um manômetro que permite monitorar a pressão durante o processo, Figura 16b. A solução é colocada em um recipiente e em seguida armazenada para então ser tratada, Figura 16c. Quando atingido o tempo de tratamento desejado, as amostras foram imediatamente resfriadas em um banho de gelo. É importante ressaltar que neste sistema a temperatura medida é aquela que a solução está sendo submetida uma vez que o termopar encontra-se em contato direto com a solução. A agitação magnética a qual a solução é submetida durante o tratamento também garante a ocorrência mínima de gradientes de temperatura na solução. 


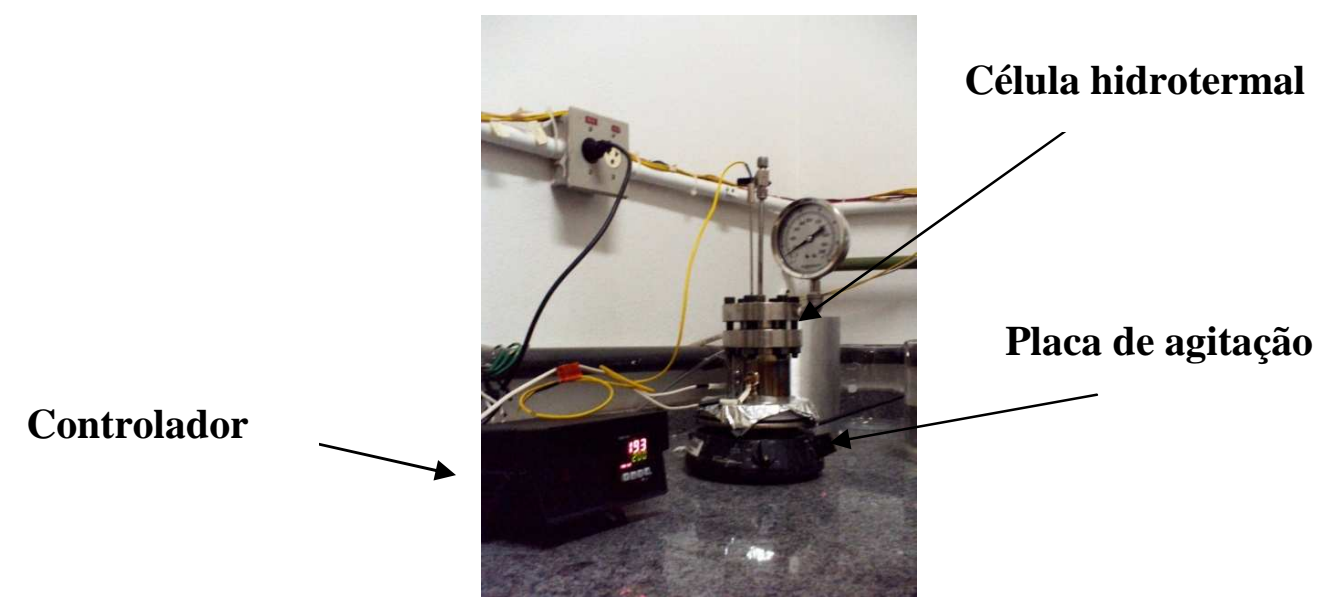

(a)

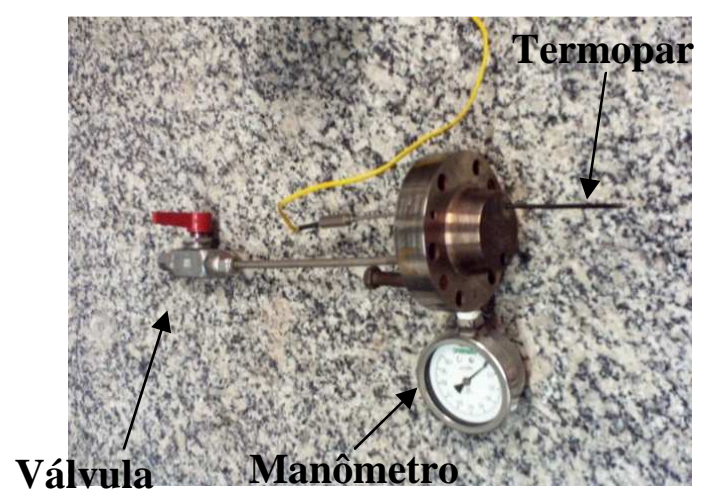

(b)

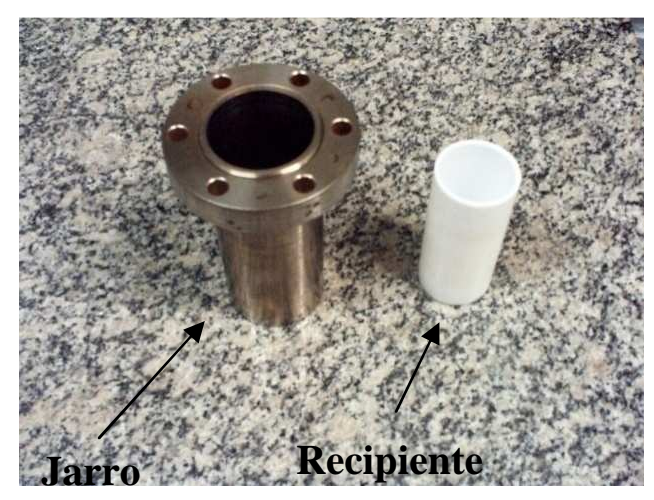

(c)

Figura 16 - Montagem experimental utilizada no tratamento hidrotermal dinâmico: (a) imagem da célula hidrotermal, da placa de agitação e do controlador de tempo de tratamento e temperatura; (b) imagem da parte superior da célula hidrotermal, contendo uma válvula de alivio, um manômetro e um termopar e (c) imagem do jarro da célula hidrotermal e do recipiente de teflon onde é colocada a solução para tratamento.

O intervalo de temperatura da síntese foi variado de 60 a $200^{\circ} \mathrm{C}$ com o tempo de tratamento variado entre 2 e 24 horas. Somente serão apresentados os resultados onde foram observadas mudanças estruturais e/ou morfológicas mais significativas.

A Tabela 1 apresenta a denominação adotada para as amostras e as respectivas condições experimentais utilizadas (temperatura, tempo de tratamento e pressão atingida). 
Tabela 1 - Condições experimentais para a obtenção das amostras submetidas a um tratamento hidrotermal:

\begin{tabular}{cccc}
\hline Amostra & $\begin{array}{c}\text { Temperatura } \\
\left({ }^{\mathbf{0}} \mathbf{C}\right)\end{array}$ & $\begin{array}{c}\text { Tempo } \\
(\mathbf{h})\end{array}$ & $\begin{array}{c}\text { Pressão } \\
\left(\mathbf{K g f} / \mathbf{c m}^{\mathbf{2}}\right)\end{array}$ \\
\hline AM01 & 60 & 6 & 3 \\
AM02 & 120 & 24 & 7 \\
AM03 & 160 & 24 & 10 \\
AM04 & 180 & 6 & 13 \\
AM05 & 180 & 24 & 13 \\
AM06 & 200 & 24 & 17 \\
\hline
\end{tabular}

\subsubsection{Estudo do mecanismo de crescimento}

No estudo do mecanismo de crescimento das nanoestruturas de $\mathrm{V}_{2} \mathrm{O}_{5} n \mathrm{H}_{2} \mathrm{O}$, inicialmente, foi realizada a síntese das nanoestruturas através do procedimento descrito anteriormente. Embora tenha sido possível detectar indícios da formação da fase $\mathrm{V}_{2} \mathrm{O}_{5} n \mathrm{H}_{2} \mathrm{O}$ a $60^{\circ} \mathrm{C}$, optou-se por utilizar o tratamento a $80^{\circ} \mathrm{C}$ de modo a ter maior segurança da total decomposição do peróxido de vanádio e formação das nanoestruturas de $\mathrm{V}_{2} \mathrm{O}_{5} n \mathrm{H}_{2} \mathrm{O}$.

A solução contendo a fase $\mathrm{V}_{2} \mathrm{O}_{5} n \mathrm{H}_{2} \mathrm{O}$ monoclínica foi obtida através do tratamento do peróxido de vanádio, com concentração de $0,06 \mathrm{M}$, tratada a $80^{\circ} \mathrm{C}$ durante 4 horas e a $120^{\circ} \mathrm{C}$ durante um período de 6 horas. Estas soluções foram denominadas de soluções precursoras. As amostras obtidas nestas duas condições experimentais consistiram de uma suspensão coloidal estável contendo nanofitas de $\mathrm{V}_{2} \mathrm{O}_{5} n \mathrm{H}_{2} \mathrm{O}$ em água. De modo a garantir a decomposição total do peróxido após o processo de síntese, a solução obtida foi submetida a um tratamento de ultra-som durante 30 minutos.

Para o estudo da cinética de crescimento destas duas amostras, foram preparadas a partir destas duas amostras novas soluções diluindo a solução precursora em água destilada em uma razão 1/10 obtendo assim uma solução de concentração 0,006 mol de peroxovanadato. O uso de uma solução menos concentrada deve-se ao fato do mecanismo de crescimento ocorrer através de colisões das partículas presentes na solução. (74) Assim, uma solução menos concentrada possibilita monitorar possíveis eventos de colisão de forma mais 
clara. A solução menos concentrada foi então submetida novamente a um tratamento hidrotermal a $80^{\circ} \mathrm{C}$ por diversos períodos de tempo de $0,240,720,1440,2160,2880,4320$, 5760 e 7200 minutos. Para a solução precursora obtida a $120^{\circ} \mathrm{C}$ durante 6 horas, a solução foi também submetida novamente a um tratamento hidrotermal a $120^{\circ} \mathrm{C}$ durante períodos de tempo de 0, 240, 360, 480, 720, 1440, 2880, 4320 e 7200 minutos. A solução obtida em tempo "0", considerada como sendo aquela onde se obteve a partícula primária, foi obtida interrompendo o tratamento imediatamente ao atingir a temperatura de $80^{\circ} \mathrm{C}$ ou a $120^{\circ} \mathrm{C}$.

Nenhum ligante, surfactante ou monômero foi adicionado ao meio. Como descrito na seção anterior, após a interrupção do tratamento, as amostras foram resfriadas em um banho de gelo.

\subsubsection{Síntese em presença de $\mathrm{NaOH}$}

Para a síntese das nanoestruturas em presença do hidróxido de sódio $(\mathrm{NaOH})$ foram utilizadas duas rotas distintas. Na primeira rota, uma solução contendo nanofitas de $\mathrm{V}_{2} \mathrm{O}_{5} n \mathrm{H}_{2} \mathrm{O}$ foi preparada e a esta solução, foi adicionado $12 \mathrm{ml}$ de uma solução contendo 0,1 mol de $\mathrm{NaOH}$. Após ser adicionando o $\mathrm{NaOH}$, a solução apresentou um pH em torno de 7. As nanofitas de $\mathrm{V}_{2} \mathrm{O}_{5} n \mathrm{H}_{2} \mathrm{O}$ foram preparadas como descrito na seção 2.1.1. A amostra obtida através deste procedimento foi denominada como amostra NaV01.

Em um segundo procedimento, a solução contendo a mesma quantidade de $\mathrm{NaOH}$ foi adicionada diretamente a solução de peróxido de vanádio preparada como descrito na seção 2.1.1. Para esta amostra, que foi denominada como NaV02, o valor do $\mathrm{pH}$ apresentou um valor em torno de 2.

Para os dois procedimentos adotados, a soluções foram colocadas na célula hidrotermal. Com o objetivo de avaliar os possíveis efeitos da temperatura de tratamento na obtenção das nanoestruturas, a faixa de temperatura do tratamento hidrotermal foi variada de 120 a $200^{\circ} \mathrm{C}$ durante um período de 24 horas.

Após o término do tratamento nas condições desejadas, a célula hidrotermal foi submetida ao resfriamento em banho de gelo até a temperatura ambiente. O precipitado, apresentando uma cor vermelha foi seco a uma temperatura de $50{ }^{\circ} \mathrm{C}$ durante um período de 24 horas. 


\subsection{Técnicas de caracterização utilizadas}

A seguir serão apresentadas as técnicas utilizadas nas caracterizações das amostras obtidas.

\subsubsection{Difração de raios $X(D R X)$}

Com a finalidade de identificar as fases cristalinas presentes nas amostras assim como a existência de uma possível orientação preferencial, foi utilizada a técnica de difração de raios $\mathrm{X}(\mathrm{DRX})$.

O equipamento utilizado foi um difratômetro Rigaku Dmax 2500PC, configuração $\theta-2 \theta$, monocromador de grafite, ânodo rotatório e tubo de cobre, linha $k_{\alpha}(\lambda=1,5406 \AA \hat{)})$. O intervalo de varredura $2 \theta$ foi de 5 a 60 graus, passo de $0,02^{\circ}$ e tempo de varredura de 2 graus por minuto.

\subsubsection{Espectroscopia Raman}

A espectroscopia Raman é baseada na medida do deslocamento de energia do feixe de fótons incidente que é espalhado de um dado material. Nesta técnica, a mostra é iluminada com uma luz monocromática gerada por um laser. Os fótons incidentes induzem transições no material, e conseqüientemente, eles ganham ou perdem energia. O fenômeno envolvido nesse processo é a absorção de um fóton tal que a molécula é excitada a um estado "virtual" de energia, que possui um tempo de vida muito curto, promovendo a re-emissão quase imediata do fóton. A conservação da energia requer uma variação da energia vibracional da molécula. O espectro resultante é chamado espectro Raman. Esse espectro contém linhas com freqüências diferentes daquelas da radiação incidente. As linhas possuindo menores freqüências que a da radiação incidente são denominadas de linhas Stokes e àquelas com 
freqüências maiores são denominadas de Anti-Stokes. O processo de espalhamento Raman é proveniente da polarização da nuvem eletrônica da molécula pela oscilação do vetor campo elétrico do quantum incidente. A propriedade molecular importante, ligada ao espectro Raman é, portanto, a polarizabilidade da molécula, que contém informações sobre os modos vibracionais do material. As principais aplicações da espectroscopia Raman incluem, por exemplo, o estado físico (amorfo ou cristalino) e a identificação da fase cristalina.

Neste trabalho, a técnica de espectroscopia micro-Raman também foi utilizada na caracterização da estrutura local das amostras. As medidas foram realizadas a temperatura ambiente em um espectrômetro confocal Raman Alpha 300S-CRM200 da WITec, operando com um laser de Argônio $(\lambda=514,5 \mathrm{~nm})$. O espectro Raman foi coletado entre $100 \mathrm{~cm}^{-1} \mathrm{e}$ $1200 \mathrm{~cm}^{-1}$ apresentando uma resolução espectral em torno de $1 \mathrm{~cm}^{-1}$. As amostras foram excitadas pelo laser com uma potencia de $0.6 \mathrm{~mW}$. A baixa potência fui utilizada de modo a garantir que o feixe laser não modificasse as características das amostras. (94)

\subsubsection{Análise termogravimétrica (TG)}

A estabilidade térmica e a quantidade de água presente na estrutura do material foram analisadas através das curvas de Termogravimetria (TG) utilizando o equipamento da NETZSCH, TG 209.

As medidas foram realizadas em atmosfera de nitrogênio $\left(\mathrm{N}_{2}\right)$ da temperatura ambiente até $500^{\circ} \mathrm{C}$, a uma taxa de $10^{\circ} \mathrm{C}$ por minuto. Em todas as caracterizações, as amostras foram secas a $50^{\circ} \mathrm{C}$.

\subsubsection{Microscopia eletrônica}

Medidas de microscopia eletrônica de transmissão (MET) foram realizadas com o intuito de observar a morfologia dos materiais obtidos e determinar a dimensão das amostras nanoestruturadas. Para a investigação longitudinal das nanoestruturas, o material obtido foi 
disperso em água destilada e depositado em grades de cobre $(\mathrm{Cu})$. As grades de $\mathrm{Cu}$ possuem um filme de formvar em uma superfície e um filme de carbono (C) na superfície oposta.

De modo a observarmos a região da seção transversal das amostras obtidas, foi utilizada a técnica de preparação semelhante à descrita por Krumeich e colaboradores. (48) Para a preparação dessas amostras foram utilizadas as instalações do Laboratório de Microscopia Eletrônica (LME) do Laboratório Nacional de Luz Síncroton (LNLS) em Campinas-SP.

Com o objetivo de obter amostras orientadas em uma determinada direção, as amostras foram depositadas na superfície de um substrato de silício ( $\mathrm{Si}$ ) e recobertas com uma resina "epoxy" formando um "sanduiche com um segundo substrato de Si. Este sanduiche foi colocado em um cilindro de cobre e então preenchido com resina "epoxy". Após a resina estar curada, o cilindro foi fatiado em pedaços de modo a obter discos com espessura de aproximadamente $300 \mu \mathrm{m}$. Estes discos foram mecanicamente desgastados até uma espessura de aproximadamente $150 \mu \mathrm{m}$. Após esta etapa, foi realizado um polimento com alumina $\left(\mathrm{Al}_{2} \mathrm{O}_{3}\right)$ de $1 \mu \mathrm{m}$. Em seguida o disco é trocado de lado e desgastado de modo a obter uma espessura em torno de $80 \mu \mathrm{m}$. O desgaste da região central é feito através do equipamento Dimple Grinder Gatan, modelo 656, até obter uma espessura na região central de aproximadamente $15 \mu \mathrm{m}$, esta superfície é submetida então a um polimento com $\mathrm{Al}_{2} \mathrm{O}_{3}$. A última etapa a fim de obter uma área fina na amostra é o polimento iônico através do PIPS (“Precision Ion Polishing System”). O equipamento utilizado foi um PIMS, Gatan, com íons de argônio (Ar), operando em $4,5 \mathrm{KeV}$ com $+8^{0}$ de ângulo de incidência de um feixe e $-8^{0}$ de ângulo de incidência do segundo feixe. Após aproximadamente 15 minutos, quando apareceu um furo na região central da amostras, a energia dos canhões foi diminuída para $3 \mathrm{KeV}$ e os ângulos diminuídos para $+4^{0}$ e $-4^{0}$.

Para a obtenção de imagens de transmissão de modo a verificarmos a morfologia obtida bem como analisar as dimensões das amostras, foi utilizado um microscópio Zeiss VP Supra 35 contendo um canhão de emissão de campo (FEG) operando em modo de varredura (FE-STEM). As amostras foram também caracterizadas através da técnica de microscopia eletrônica de transmissão de alta resolução (HR-TEM) utilizando os microscópios JEOL JEM 3010 URP operando em $300 \mathrm{KeV}$ e um JEOL JEM 2010 URP operando em 200KeV.

A seção transversal das amostras foi analisada através da técnica de MET utilizando um microscópio JEOL JEM 2010 URP e através da técnica de MEV utilizando um microscópio JEOL JSM-7500f contendo um canhão por emissão de campo (FE-MEV). 


\subsubsection{Espectroscopia de absorção de raios X (XAS)}

Através da técnica de espectroscopia de absorção de raios X (XAS) é possível obter informações sobre a estrutura atômica e eletrônica da amostra sem que haja a necessidade da existência de ordem a longa distância. $(22,31)$

Na Figura 17 podemos observar o comportamento típico do espectro de absorção de raios $\mathrm{X}$. O espectro de absorção é dividido em três regiões: a região de pré-borda, a região XANES (X-Ray Absorption Near Edge Structure) e a região EXAFS (Extended X-ray Absorption Fine Structure). (95)

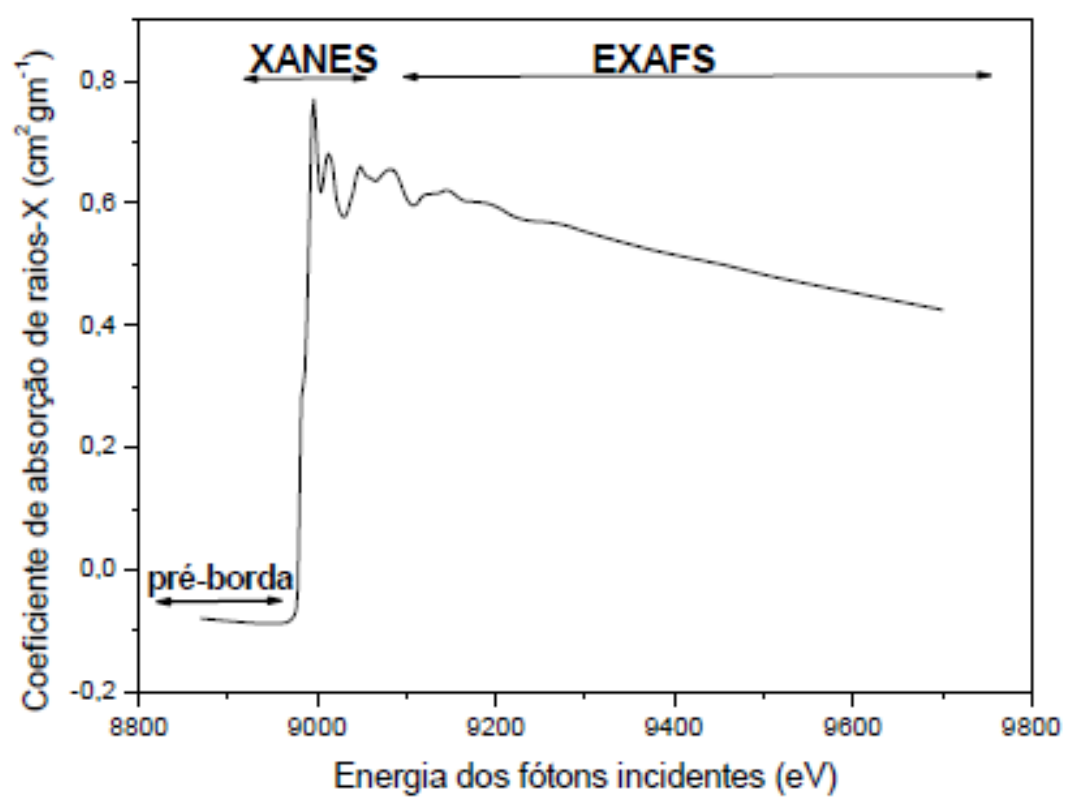

Figura 17 - Coeficiente de absorção de raios X na borda $\mathrm{K}$ do átomo de cobre para uma amostra de cobre metálico. (95)

A pré-borda que está localizada entre 2 e $10 \mathrm{eV}$ abaixo da borda de absorção pode apresentar estruturas de absorção de raios $\mathrm{X}$ devido a transições eletrônicas de níveis internos (1s, 2s, etc) para níveis externos parcialmente preenchidos ou não preenchidos. A probabilidade de transição e a intensidade da absorção observadas na região de pré-borda são determinadas em parte pela simetria do sítio do átomo absorvedor. A análise da posição e da intensidade da transição presente na região da pré-borda pode fornecer informações sobre o estado de oxidação e sobre a simetria do sítio do átomo absorvedor. (95) 
A região XANES compreende a região próxima da borda de absorção e se estende para cerca de 60 a $80 \mathrm{eV}$ após a borda. Para valores de energia logo acima da borda de absorção, o elétron é excitado para os primeiros estados desocupados acima do nível de Fermi. Por esse motivo, a análise do espectro XANES fornece informações a respeito da estrutura eletrônica do material. Nessa região, os fotoelétrons possuem energias cinéticas abaixo de $50 \mathrm{eV}$. Com esses valores de energia, a probabilidade de ocorrerem espalhamentos múltiplos do fotoelétron com os átomos vizinhos ao absorvedor é alta. Por isso, a estrutura do espectro de XANES é muito sensível a geometria local do sítio ocupado pelo átomo absorvedor e sua análise é mais complexa. (95)

A análise dos dados de EXAFS segue um procedimento padrão e existem alguns programas para este fim. A região de EXAFS fornece informações relacionadas a simetria local do átomo absorvedor como o número de coordenação, a distância de ligações e a desordem local. $(31,38,39)$

No caso da análise dos espectros XANES, excluindo os casos de análise qualitativa ou semi-quantitativa por comparação com padrões, sua análise requer o uso de cálculos mais avançados.

$\mathrm{O}$ espectro XANES foi medido na borda $\mathrm{K}$ do átomo de vanádio na linha de luz D08B-XAFS2 do LNLS. O espectro XANES foi coletado no modo de transmissão a temperatura ambiente utilizando um monocromador tipo "channel-cut" de Si (111). O espectro XANES foi medido de $40 \mathrm{eV}$ e $80 \mathrm{eV}$ antes e após a borda de absorção com passo de $0,3 \mathrm{eV}$ na região próxima a borda.

A análise do espectro na região de EXAFS foi realizada com a finalidade de confirmar os resultados qualitativos obtidos pelo espectro de XANES em relação a mudança no grau de simetria na primeira esfera de coordenação, bem como o número de coordenação das amostras obtidas com a mesma fase do composto de referência $\left(\mathrm{V}_{2} \mathrm{O}_{5}\right.$ ortorrômbico). $\mathrm{O}$ espectro EXAFS na borda $\mathrm{K}$ do átomo de vanádio (V) foi obtido na linha de luz D08BXAFS2 do Laboratório Nacional de Luz Síncroton (LNLS-Campinas) nas mesmas condições das medidas do espectro XANES. Foram coletados três espectros de EXAFS para cada amostra utilizando-se a média desses espectros para realizar a análise dos dados. Os espectros foram medidos na região entre $5380 \mathrm{eV}$ e $6300 \mathrm{eV}$. O passo utilizado para aquisição dos dados foi de $2 \mathrm{eV}$ com tempo de integração de $3 \mathrm{~s}$.

Para aquisição do espectro de XAS, as amostras foram depositadas em uma membrana polimérica. A propriedade natural de polarização de um feixe de radiação síncroton pode ser utilizada na caracterização estrutural de amostras que apresentam textura ou orientação 
preferencial. Com esse objetivo, os espectros XAS foram coletados com as amostras posicionadas a 25 e $90^{\circ}$ em relação ao feixe de raios $X$. De forma a obter uma boa reprodutibilidade durante a aquisição dos dados, a energia de calibração do monocromador foi verificada durante a coleta utilizando uma folha metálica de vanádio (V).

As análises dos espectros EXAFS foram realizadas utilizando o programa de análise IFEFFIT. (96-99)

Uma descrição mais detalhada a respeito da espectroscopia de XAS são apresentadas no Apêndice 1.

\subsubsection{Espalhamento de raios $\mathrm{X}$ a baixo ângulo (SAXS)}

A técnica de espalhamento de raios $\mathrm{X}$ a baixo ângulo (SAXS) é muito utilizada no estudo de sistemas coloidais uma vez que pode fornecer informações sobre o tamanho, a forma e as possíveis interações entre as partículas espalhadoras contidas nestes sistemas. As medidas de SAXS apresentadas neste trabalho foram realizadas no Laboratório Nacional de Luz Síncroton (LNLS) na linha D02A-SAXS2. A distância entre amostra e detector foi de $2019 \mathrm{~mm}$ e o comprimento de onda de $\lambda=1.488 \AA$. O tratamento dos dados experimentais foi realizada normalizando-se o sinal obtido pela intensidade do feixe incidente e multiplicando pela absorção da amostra. O espalhamento do solvente, neste caso água, foi subtraído dos dados de espalhamento para a solução contendo as nanoestruturas. Para o tratamento de dados foi utilizado o programa FIT2D. Os dados experimentais são apresentados como intensidade em função do vetor de espalhamento $q$, onde $q=(4 \pi / \lambda) \operatorname{sen} \theta$, sendo $\lambda$ o comprimento da radiação incidente e $2 \theta$ o ângulo de espalhamento. Modelos teóricos foram comparados com os dados experimentais utilizando o método de quadrados mínimos.

Uma descrição mais detalhada a respeito da técnica de SAXS e modelo teórico utilizado nas análises são apresentados no Apêndice 2. 


\section{RESULTADOS E DISCUSSÃO}

A seguir serão apresentados os resultados e as discussões em relação ao processo de síntese bem como sobre o mecanismo de crescimento e da evolução morfológica das nanoestruturas em função das condições de síntese. Também serão apresentados resultados e discussões a respeito da obtenção compostos vanadatos através da adição de hidróxido de sódio $(\mathrm{NaOH})$ ao processo de síntese.

\subsection{Síntese da fase $\mathrm{V}_{2} \mathrm{O}_{5} n \mathrm{H}_{2} \mathrm{O}$}

A Figura 18 e a Figura 19 apresentam, respectivamente, as medidas de difração de raios $\mathrm{X}(\mathrm{DRX})$ e micro-Raman do composto $\mathrm{V}_{2} \mathrm{O}_{5}$, utilizado como precursor. 


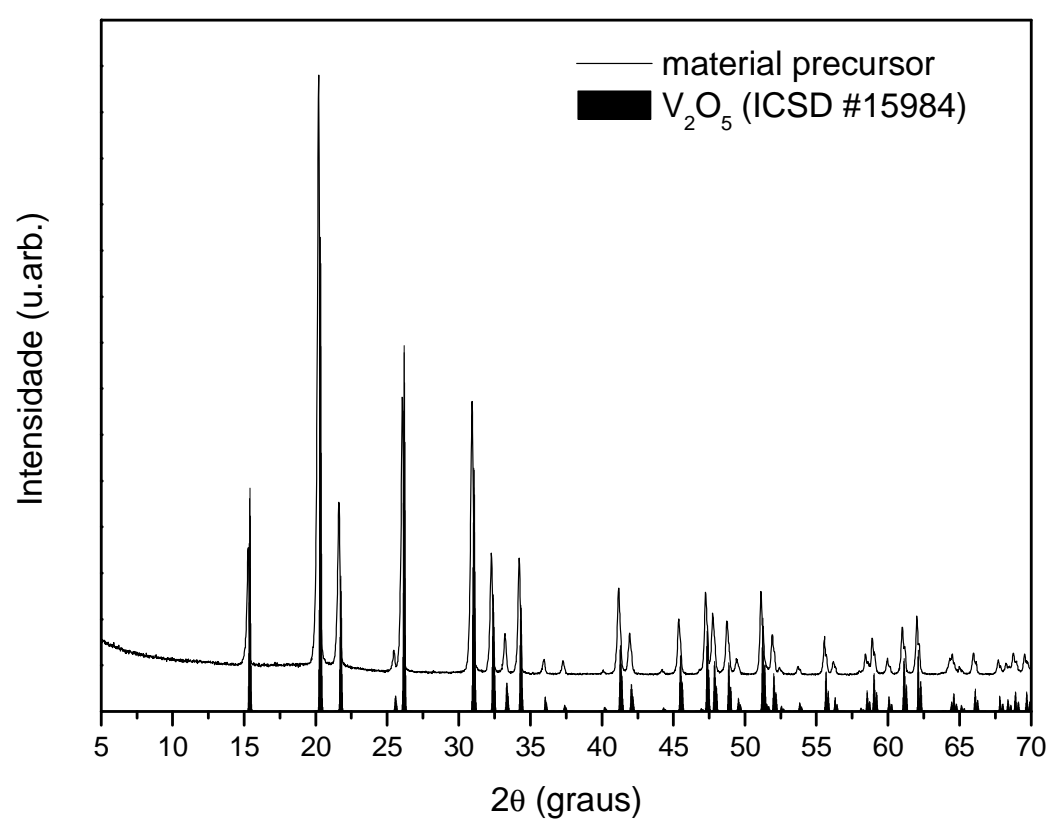

Figura 18 - Difratograma de raios $\mathrm{X}$ do composto pentóxido de vanádio $\left(\mathrm{V}_{2} \mathrm{O}_{5}\right)$, utilizado como precursor.

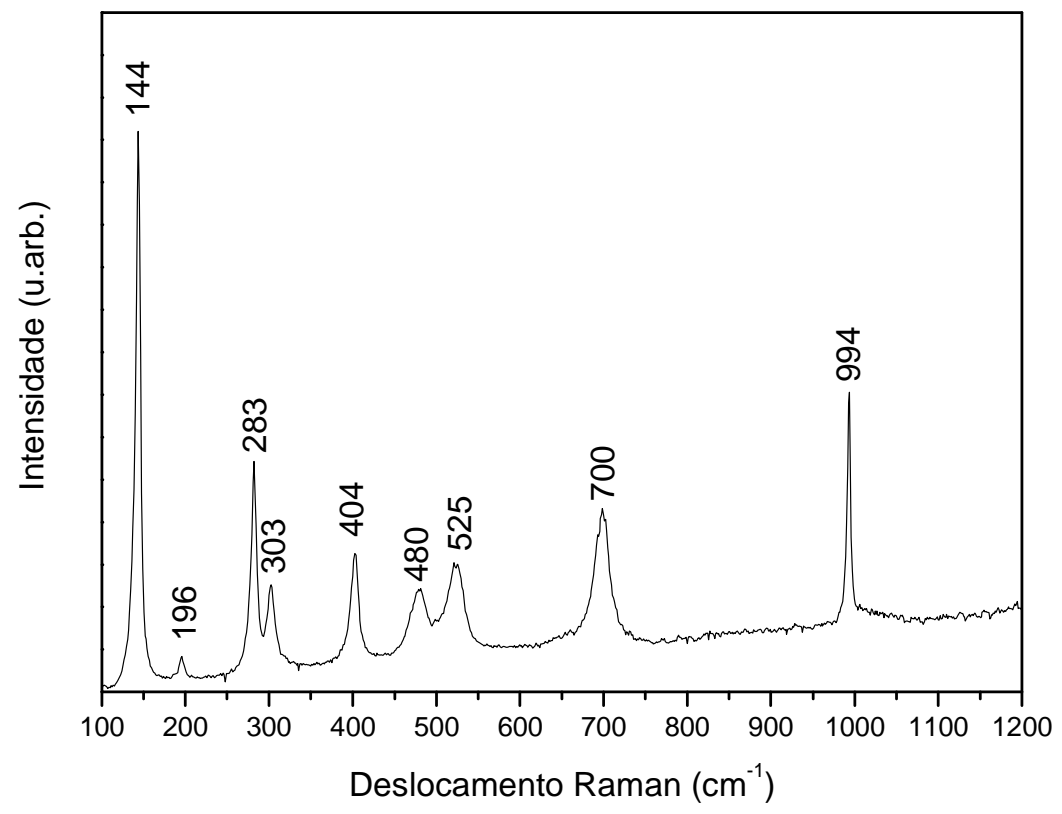

Figura 19 - Espectro Raman composto pentóxido de vanádio $\left(\mathrm{V}_{2} \mathrm{O}_{5}\right)$, utilizado como precursor.

A análise do padrão de difração de raios $\mathrm{X}$ apresentado na Figura 18 mostra que o composto utilizado como material precursor corresponde à fase cristalina ortorrômbica de 
$\mathrm{V}_{2} \mathrm{O}_{5}$ (ICSD \#15984). Na análise do espectro Raman, Figura 19, é possível observar bandas em 144, 196, 283, 303, 404, 480, 525, 700 e $994 \mathrm{~cm}^{-1}$ que de acordo com trabalhos encontrados na literatura, referem-se à fase cristalina ortorrômbica de $\mathrm{V}_{2} \mathrm{O}_{5}$ (35), confirmando assim os resultados de DRX.

Como mencionado na seção 2.1.1, a temperatura e o tempo de tratamento hidrotermal foi variado a fim de verificar o efeito destes parâmetros nas características do material obtido. Uma primeira observação importante foi de que a formação das nanoestruturas da fase $\mathrm{V}_{2} \mathrm{O}_{5} n \mathrm{H}_{2} \mathrm{O}$ ocorreu somente a partir de um tratamento hidrotermal a $60^{\circ} \mathrm{C}$ durante 6 horas (amostra AM01). Apesar de ter sido preparada uma grande quantidade de amostras, somente será apresentada nesta seção os resultados onde foram detectadas mudanças estruturais e/ou morfológicas que foram consideradas mais significativas.

A Figura 20 apresenta as medidas de DRX das amostras obtidas nas condições de síntese descritas na Tabela 1.

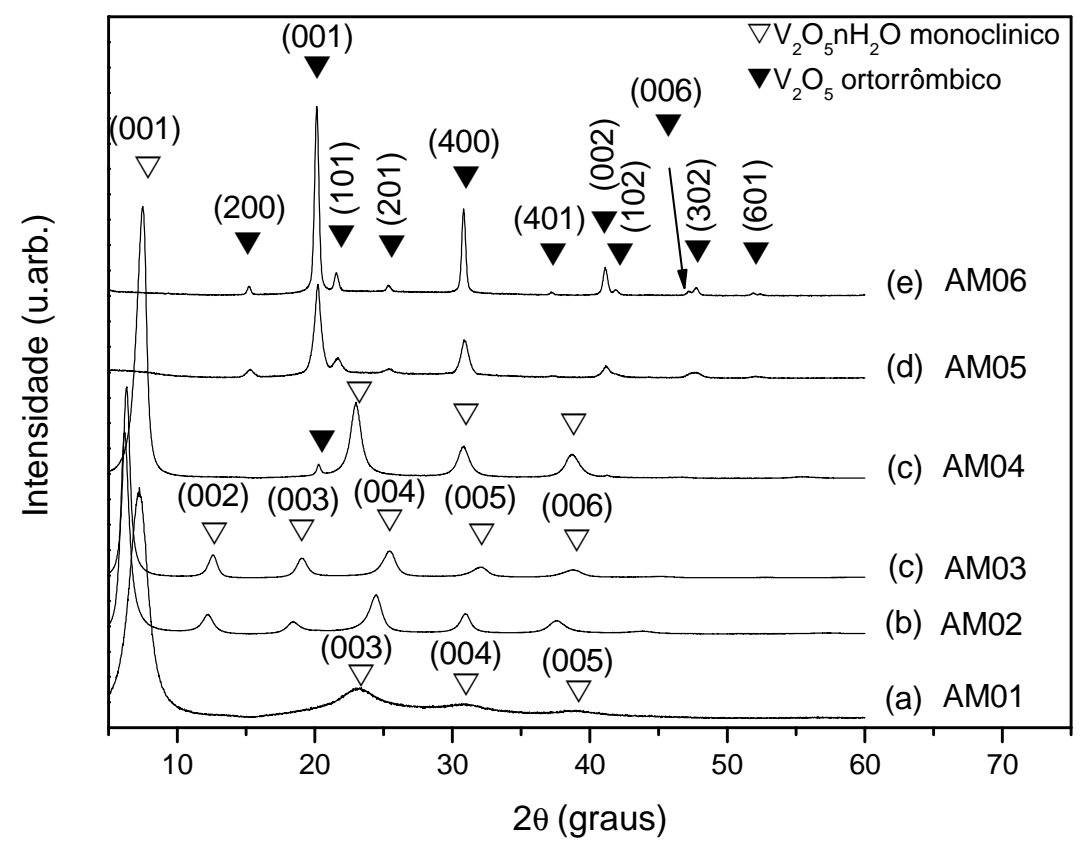

Figura 20 - Difratogramas de raios X das amostras: AM01 (tratada a $60^{\circ} \mathrm{C}$ durante 6horas), AM02 $\left(120^{\circ} \mathrm{C}\right.$ durante 6 horas), AM03 $\left(160^{\circ} \mathrm{C}\right.$ durante 24 horas $)$, AM04 $\left(180^{\circ} \mathrm{C}\right.$ durante 6 horas $)$, AM05 $\left(180^{\circ} \mathrm{C}\right.$ durante 24 horas $)$ e AM06 $\left(200^{\circ} \mathrm{C}\right.$ durante 24 horas $)$.

Os padrões de difração de raios $\mathrm{X}$ das amostras AM01, AM02, AM03 e AM04 apresentam uma série de planos de reflexão $00 l$ indicando a existência de uma orientação 
preferencial na direção $c$. Este padrões de DRX foram indexados à fase $\mathrm{V}_{2} \mathrm{O}_{5} n \mathrm{H}_{2} \mathrm{O}$ monoclínica apresentando parâmetros de rede $a=11,722 \AA, \quad b=3,570 \AA$ e $c=11,520$. (37) Utilizando a equação de Bragg, através do plano de difração (001), foi possível calcular o espaçamento basal, $d$, da estrutura $\mathrm{V}_{2} \mathrm{O}_{5} n \mathrm{H}_{2} \mathrm{O}$. (28) Os valores encontrados foram respectivamente iguais a 12,2, 14,3, 14,0 e 12,2 $\AA$ para as amostras AM01, AM02, AM03 e AM04. Através destes resultados é possível observar que com o aumento da temperatura, ocorre um aumento da distância basal, $d$, até as condições de síntese utilizadas para a amostra AM02.

A partir desta condição, mesmo aumentando a temperatura de síntese não foi possível observar mudanças estruturais até as condições empregadas na obtenção da amostra AM03. Estes resultados mostraram ser possível obter a fase $\mathrm{V}_{2} \mathrm{O}_{5} n \mathrm{H}_{2} \mathrm{O}$ monoclínica em uma temperatura relativamente inferior aos valores encontrados na literatura $(53,54)$ bem como a possibilidade de controlar a distância basal $(d)$ através da mudança de temperatura e do tempo de tratamento hidrotermal. Segundo diferentes trabalhos encontrados na literatura, a distância basal possui uma grande importância em relação à potencialidade de aplicação tecnológica deste material por afetar diretamente o processo de intercalação no material. $(1,25,28)$

No caso da amostra tratada a $180^{\circ} \mathrm{C}$ durante 6 horas (AM04), é possível observar a presença de um plano de difração adicional, em torno de $2 \theta$ igual a $20^{\circ}$, que foi indexado como pertencente a fase $\mathrm{V}_{2} \mathrm{O}_{5}$ ortorrômbica, indicando um inicio de transição de fase estrutural. Para esta amostra, a estrutura indexada como a fase $\mathrm{V}_{2} \mathrm{O}_{5} n \mathrm{H}_{2} \mathrm{O}$ monoclínica tem uma distância basal $d$ igual a 12,2Á, semelhante à amostra AM01. Quando a amostra foi tratada a $180^{\circ} \mathrm{C}$ durante 24 horas (amostra AM05) e posteriormente a $200{ }^{\circ} \mathrm{C}$ (amostra AM06), o padrão de DRX apresentou todos os picos de difração pertencentes a fase $\mathrm{V}_{2} \mathrm{O}_{5}$ ortorrômbica com parâmetros de rede $a=11.519 \AA$, $b=3.564 \AA$ e $c=4.373 \AA$, (ICSD \#15984), de maneira similar a observada para o DRX do composto utilizado como precursor, Figura 18. Para as amostras AM05 e AM06, foi possível também observar que ocorre a perda da orientação preferencial observada nas amostras indexadas como a fase $\mathrm{V}_{2} \mathrm{O}_{5} n \mathrm{H}_{2} \mathrm{O}$ monoclínica.

A estabilidade térmica das amostras foi analisada através das curvas de termogravimetria (TG). Em bom acordo com a literatura, as curvas de TG apresentadas na Figura 21 revelam a existência de três processos de desidratação bem definidos para as amostras AM01, AM02 e AM03. $(32,35)$ Embora as amostras AM05 e AM06 tenham sido indexadas como sendo a fase $\mathrm{V}_{2} \mathrm{O}_{5}$ ortorrômbica desidratada, é possível também observar a existência de uma pequena quantidade de moléculas de $\mathrm{H}_{2} \mathrm{O}$ intercaladas nestas amostras. 


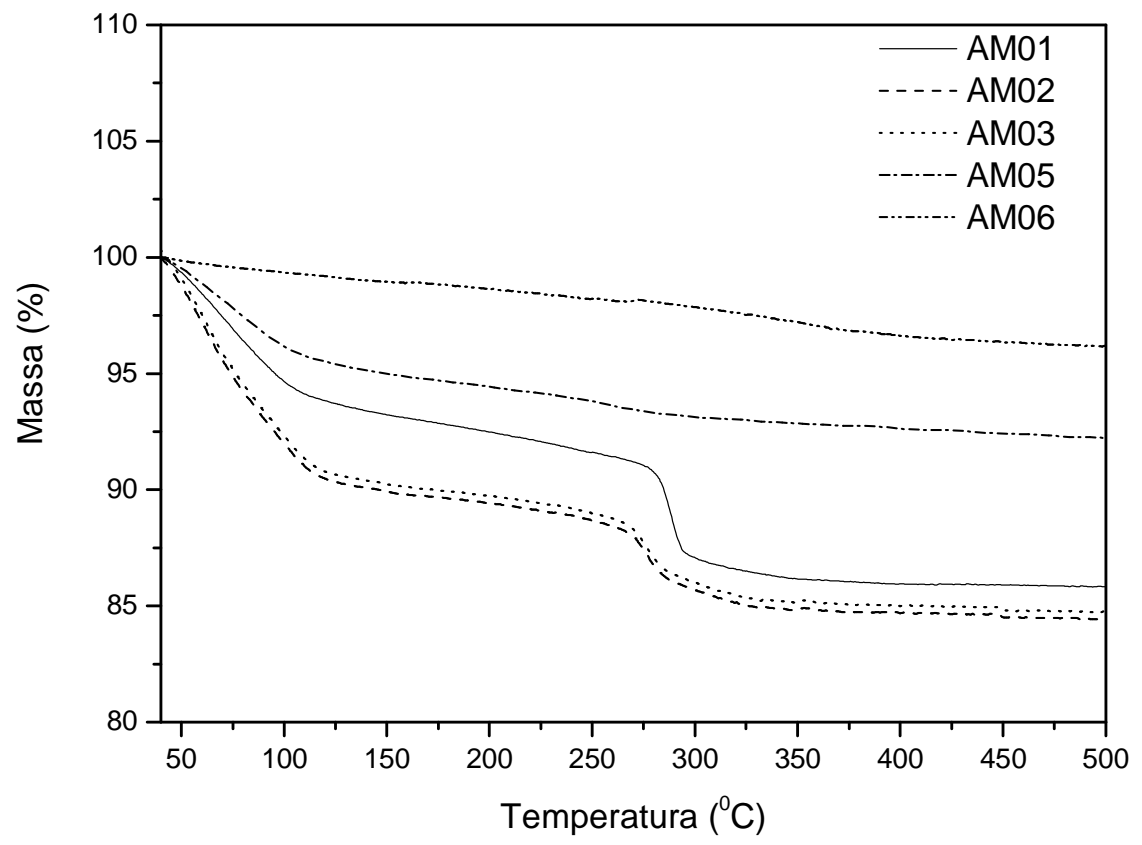

Figura 21 - Curvas de termogravimetria (TG) das amostras: AM01, AM02, AM03, AM05 e AM06.

A temperatura ambiente, as curvas de TG indicam que as amostras AM01, AM02, AM03, AM05 e AM06 contem respectivamente 1,8, 2,1, 2,0, 1,0 e 0,5 mols de moléculas de $\mathrm{H}_{2} \mathrm{O}$. A análise da curva de TG da amostra AM01 mostra que a perda de $\mathrm{H}_{2} \mathrm{O}$ adsorvida e fracamente ligada ocorre até $110^{\circ} \mathrm{C}$ e que o tratamento desta amostra nesta temperatura leva a formação de uma amostra de composição $\mathrm{V}_{2} \mathrm{O}_{5} 1,0 \mathrm{H}_{2} \mathrm{O}$. Aquecendo esta amostra até aproximadamente $280^{\circ} \mathrm{C}$ é possível, através da remoção de $\mathrm{H}_{2} \mathrm{O}$, obter a composição $\mathrm{V}_{2} \mathrm{O}_{5} 0,5 \mathrm{H}_{2} \mathrm{O}$. Acima desta temperatura é possível retirar as moléculas de $\mathrm{H}_{2} \mathrm{O}$ quimicamente ligadas à estrutura e conseqüentemente induzir a cristalização do material na fase ortorrômbica. $(32,35)$ Em relação a amostra AM02, um diferente valor de $n$ foi observado principalmente na região relativa a presença de água adsorvida e/ou fracamente ligada. Em bom acordo com os resultados de DRX, os resultados de TG das amostras AM02 e AM03 confirmam que as condições de síntese utilizadas para estas amostra não causam mudanças significativas no processo de intercalação da água.

A Tabela 2 apresenta os valores da distância basal $d$ e da quantidade de moléculas de $\mathrm{H}_{2} \mathrm{O}, n$, nas amostras AM01 e AM02. 
Tabela 2 - Valores da distância basal, $d$, e quantidade de moléculas de $\mathrm{H}_{2} \mathrm{O}, n$, nas amostras AM01 e AM02.

\begin{tabular}{ccc}
\hline Amostra & $\mathbf{d}(\breve{\mathbf{A}})$ & $\mathbf{n}$ \\
\hline AM01 & 12,2 & 1,8 \\
AM02 & 14,3 & 2,1 \\
\hline
\end{tabular}

Em bom acordo com a literatura, observou-se que o aumento da quantidade de moléculas de $\mathrm{H}_{2} \mathrm{O}$, $n$, está relacionado ao aumento da distância basal $d$. $(27,28)$ Para as amostras tratadas entre $120^{\circ} \mathrm{C}$ e $160^{\circ} \mathrm{C}$ durante 24 horas, não foram observadas mudanças significativas no valor de $n$ e $d$, indicando que a quantidade de moléculas de $\mathrm{H}_{2} \mathrm{O}$ na estrutura permanece estável mesmo com o aumento da temperatura de tratamento.

A medida de TG não foi realizada para a AM04 devido à coexistência das duas fases cristalinas. Em relação as amostras indexadas com a fase $\mathrm{V}_{2} \mathrm{O}_{5}$ ortorrômbica, amostras AM05 e AM06, as curvas de TG mostram respectivamente uma quantidade de 1,0 e 0,5 mol de moléculas de $\mathrm{H}_{2} \mathrm{O}$ na estrutura. Diferentemente das amostras anteriormente citadas, a curva de TG da amostra AM06 apresenta uma perda continua de água até aproximadamente $350^{\circ} \mathrm{C}$.

Quando a amostra foi obtida a $180^{\circ} \mathrm{C}$ durante 24 horas (amostra AM05), as curvas de TG mostraram uma menor quantidade de moléculas de $\mathrm{H}_{2} \mathrm{O}$ na estrutura $(n=1,0)$. Este fato sugere que a formação da fase ortorrômbica observada por DRX ocorre pela desidratação continua da fase monoclínica. Quando a amostra foi tratada por 24 horas a $200^{\circ} \mathrm{C}$ (AM06) ocorreu a formação de uma estrutura com menor quantidade de moléculas de $\mathrm{H}_{2} \mathrm{O}$, ou seja, $n=0,5$, confirmando que a formação da fase ortorrômbica ocorre através do processo de desidratação. Processo semelhante de desidratação da fase $\mathrm{V}_{2} \mathrm{O}_{5} n \mathrm{H}_{2} \mathrm{O}$ monoclínica dando origem a fase $\mathrm{V}_{2} \mathrm{O}_{5}$ ortorrômbica foi também observado por Zhou e colaboradores através da adição de um forte oxidante à síntese. (56)

Diferentes trabalhos descrevem a importância da quantidade de moléculas de $\mathrm{H}_{2} \mathrm{O}$ na estrutura do material $\mathrm{V}_{2} \mathrm{O}_{5} n \mathrm{H}_{2} \mathrm{O}$. (1, 25-28, 33, 34) Nossos resultados mostram que a quantidade dessas moléculas pode ser controlada de uma forma relativamente simples através das mudanças nas condições de síntese. Além disso, através dos resultados já apresentados, é possível observar que a forma mais desidratada da fase $\mathrm{V}_{2} \mathrm{O}_{5}$ é mais estável nestas condições.

A Figura 22 apresenta o espectro micro-Raman do óxido precursor $\mathrm{V}_{2} \mathrm{O}_{5}$ e das amostras AM01, AM02, AM05 e AM06. O espectro Raman da amostra AM03 não será apresentado uma vez que não apresenta mudanças significativas em relação a amostra AM02. 


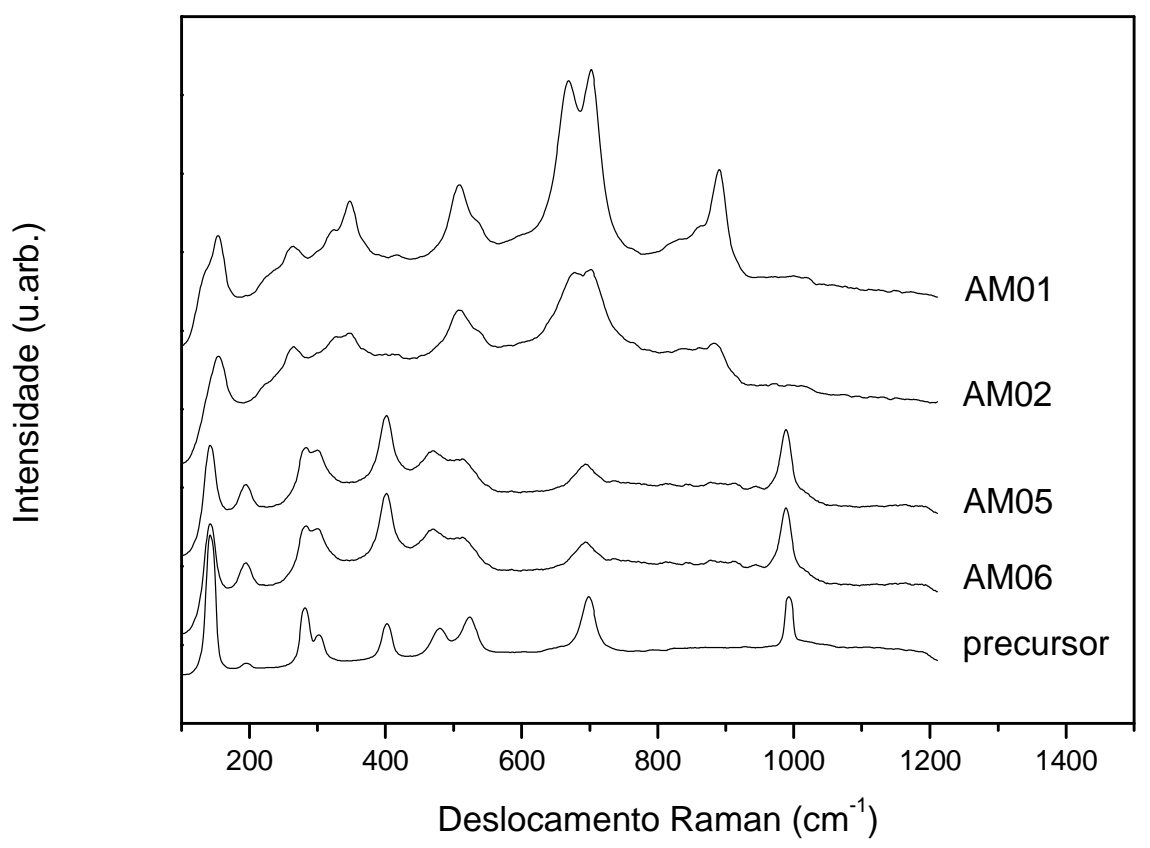

Figura 22 - Espectro micro-Raman das amostras: AM01 $\left(60^{\circ} \mathrm{C}, 6 \mathrm{~h}\right), \operatorname{AM} 02\left(120^{\circ} \mathrm{C}, 6 \mathrm{~h}\right), \operatorname{AM} 05\left(180^{\circ} \mathrm{C}, 24 \mathrm{~h}\right)$ e AM06 $\left(200^{\circ} \mathrm{C}, 24 \mathrm{~h}\right)$.

Como mostra a Figura 22, o espectro do óxido precursor apresenta bandas em 144, 196, 283, 303, 404, 480, 525, 700 e $994 \mathrm{~cm}^{-1}$ que foram indexadas a fase cristalina $\mathrm{V}_{2} \mathrm{O}_{5}$ ortorrômbica. (35) O espectro Raman das amostras AM01 e AM02 são similares apresentando bandas em 158, 262, 322, 348, 507, 665, 704 e $890 \mathrm{~cm}^{-1}$. De acordo com Abello e colaboradores e em bom acordo com os resultados de DRX e TG, o deslocamento dessas bandas em relação às bandas da a fase cristalina $\mathrm{V}_{2} \mathrm{O}_{5}$ ortorrômbica ocorre devido a presença de moléculas de $\mathrm{H}_{2} \mathrm{O}$ entre as camadas da estrutura. (35) Em relação às amostras AM05 e AM06, também em bom acordo com os resultados obtidos pela técnica de DRX, o espectro Raman é muito similar ao espectro do precursor indicando a similaridade estrutural destas amostras à fase $\mathrm{V}_{2} \mathrm{O}_{5}$ ortorrômbica. Embora tenha sido identificada a presença de moléculas de $\mathrm{H}_{2} \mathrm{O}$ nestas duas amostras, a não observação de mudanças significativas entre seus espectros Raman pode estar relacionado à pequena quantidade de moléculas de $\mathrm{H}_{2} \mathrm{O}$ presentes na estrutura. Segundo Abello e colaboradores, nas amostras contendo pequenas quantidades de moléculas de $\mathrm{H}_{2} \mathrm{O}$, o espectro Raman observado é muito similar ao material cristalino $\mathrm{V}_{2} \mathrm{O}_{5}$ de fase ortorrômbica. (35)

Imagens de microscopia eletrônica de transmissão, operando no modo de varredura (FE-STEM), foram utilizadas para investigar o efeito das variáveis de síntese sobre a 
morfologia das amostras. A Figura 23a, que apresenta a imagem da amostra obtida após tratamento hidrotermal em $60^{\circ} \mathrm{C}$ durante 6 horas (AM01), mostra claramente que as nanoestruturas possuem a forma de fitas com uma largura entre 20 e $30 \mathrm{~nm}$. Para as amostras AM02 e AM03, Figura 23b e Figura 23c, respectivamente, podemos observar uma morfologia similar a observada para a amostra AM01, ou seja, nanoestruturas na forma de fitas. Quando a amostra foi tratada a $180^{\circ} \mathrm{C}$ durante 6 horas (amostra AM04), Figura 23d, em bom acordo com os resultados obtidos através da técnica de DRX, as imagens de FE-STEM revelaram a presença de duas morfologias, nanofitas e nanofios. Aumentando o tempo de tratamento, amostra AM05, foi observado que as nanoestruturas apresentam apenas a morfologia na forma de nanofios com largura entre 10 e $20 \mathrm{~nm}$ (Figura 23e). Em relação a amostra obtida a $200^{\circ} \mathrm{C}$ durante 24 horas, amostra AM06, é possível observar uma mudança na morfologia de nanofitas para nanobastões, Figura 23f, apresentado uma largura entre 50 e $60 \mathrm{~nm}$. Zhou e colaboradores no estudo do mesmo tipo de amostra observaram também a formação de nanofios com diâmetro em torno de 40-50 nm. (56) É possível também observar através das imagens de FE-STEM que as nanoestruturas obtidas a $180^{\circ} \mathrm{C}$ (AM05) apresentam uma maior flexibilidade quando comparadas as nanopartículas da amostra obtida a $200^{\circ} \mathrm{C}$ (AM06). Este fato deve estar relacionado à maior quantidade de moléculas de $\mathrm{H}_{2} \mathrm{O}$ presentes na estrutura e as diferenças na morfologia dos materiais obtidos. (17)

Através destes resultados, além da mudança de fase relacionada ao processo de desidratação (35), nossos resultados mostram que a quantidade de moléculas de $\mathrm{H}_{2} \mathrm{O}$ também está relacionada à morfologia das amostras.

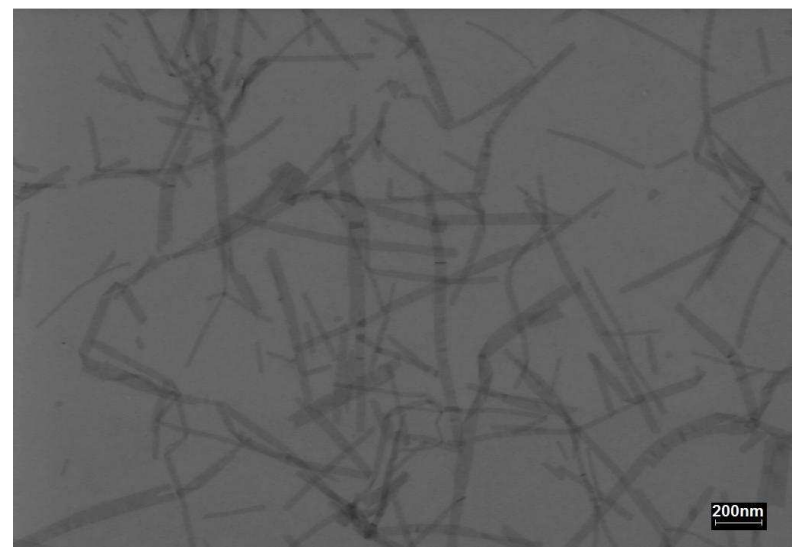

(a)

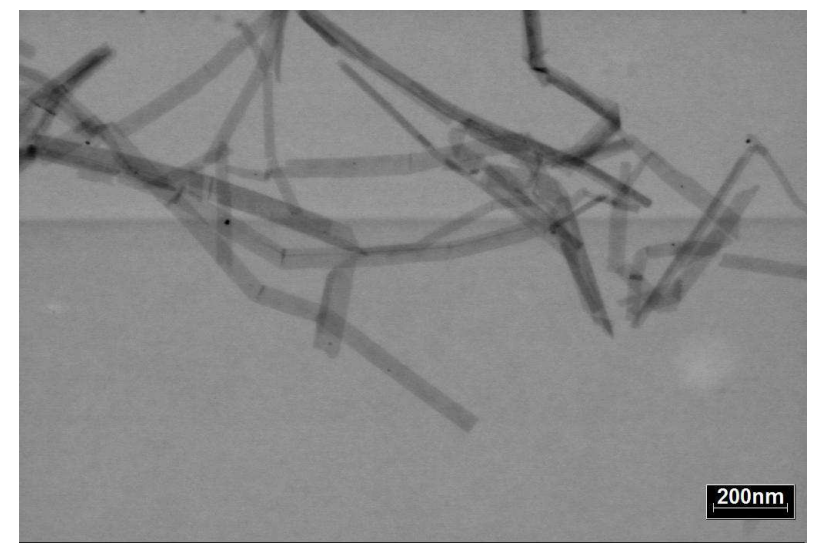

(b)

Continua... 
Continuação...

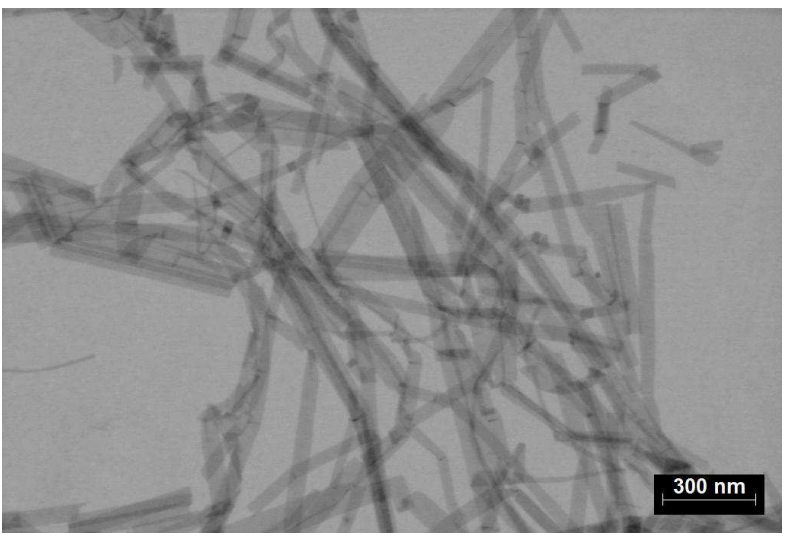

(c)

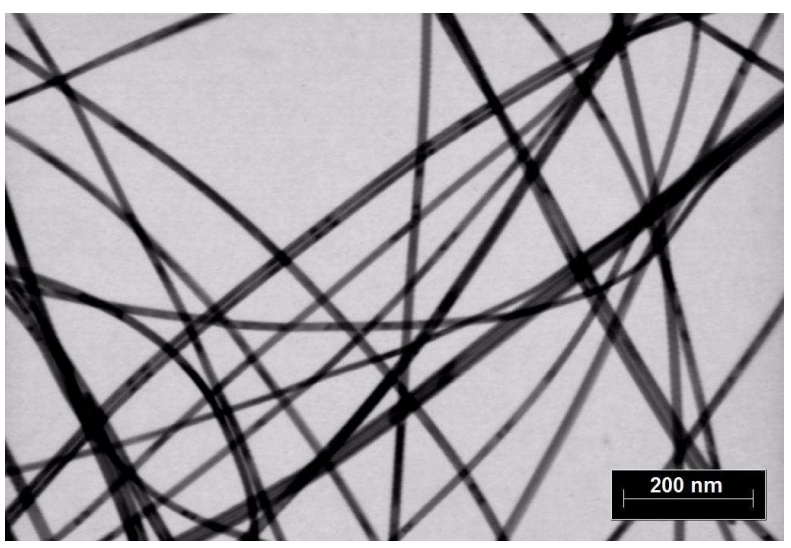

(e)

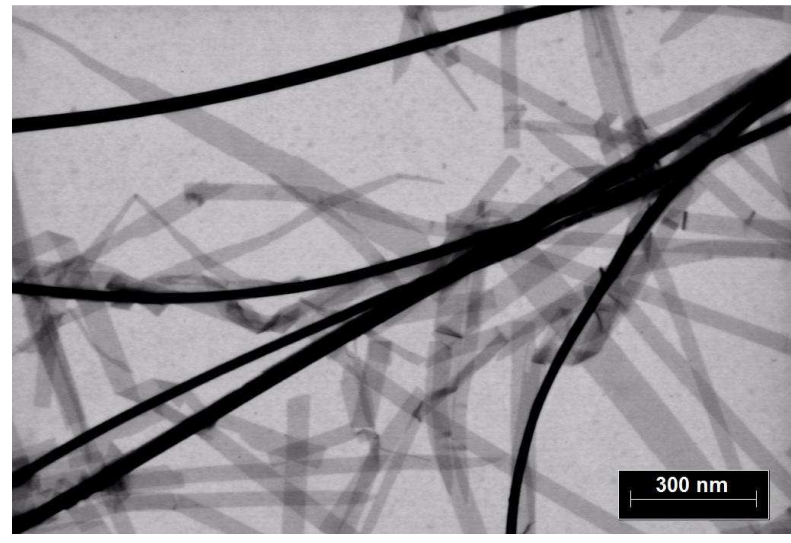

(d)

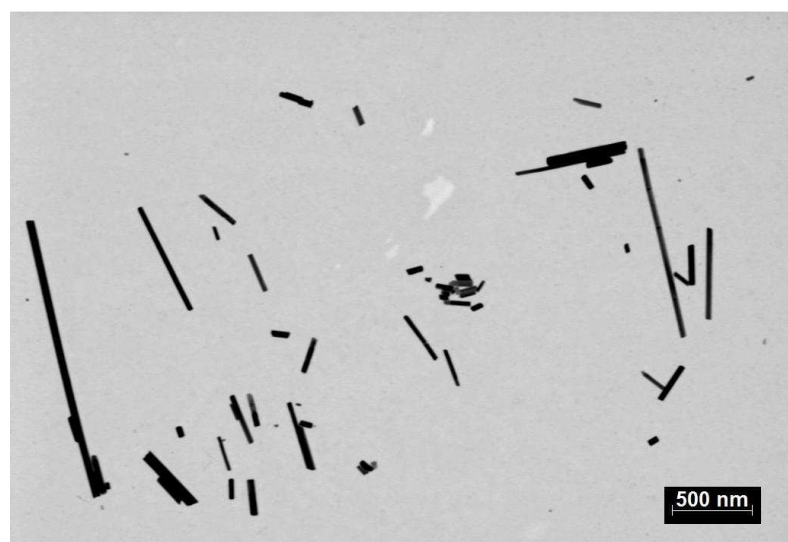

(f)

Figura 23 - Imagens de FE-STEM das amostras: (a) AM01; (b) AM02, (c) AM03, (d) AM04, (e) AM05 e (f) AM06.

A Figura 24a apresenta imagens de microscopia eletrônica de transmissão de alta resolução (HR-TEM) da amostra AM01. A Figura 24b, com uma maior ampliação, correspondente a região apresentada na Figura 24a, revela que a distância entre os planos vizinhos é igual a 0,36 nm. De acordo com os dados de DRX, esta distância está relacionada ao plano (010) da fase ortorrômbica, indicando que as nanofitas crescem ao longo da direção [010]. O mecanismo de formação dessas nanoestruturas pode ser explicado de acordo com o modelo proposto por Legendre e colaboradores, ilustrado na Figura 5. 


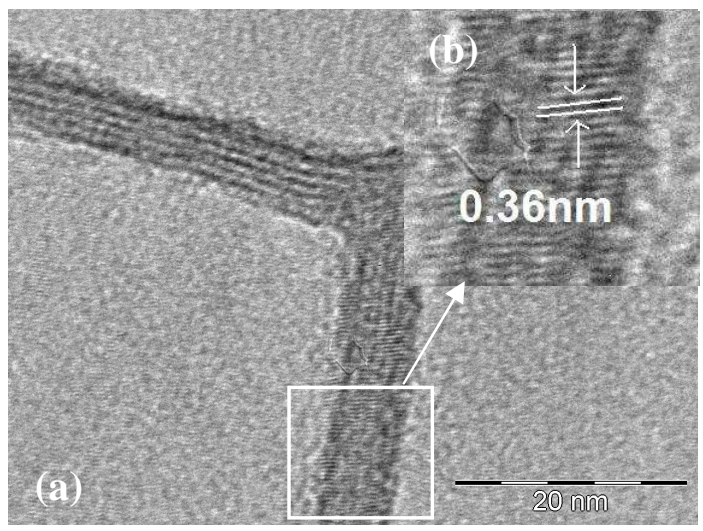

Figura 24 - (a) e (b) Imagens de HR-TEM da amostra obtida a $60^{\circ} \mathrm{C}$ durante 6 horas (AM01).

A Figura 25a e b apresenta uma imagem de HR-TEM da amostra AM06. Em bom acordo com os dados de DRX a Figura 25 mostra que esta amostra apresenta uma estrutura mais ordenada quando comparada a amostra AM01.

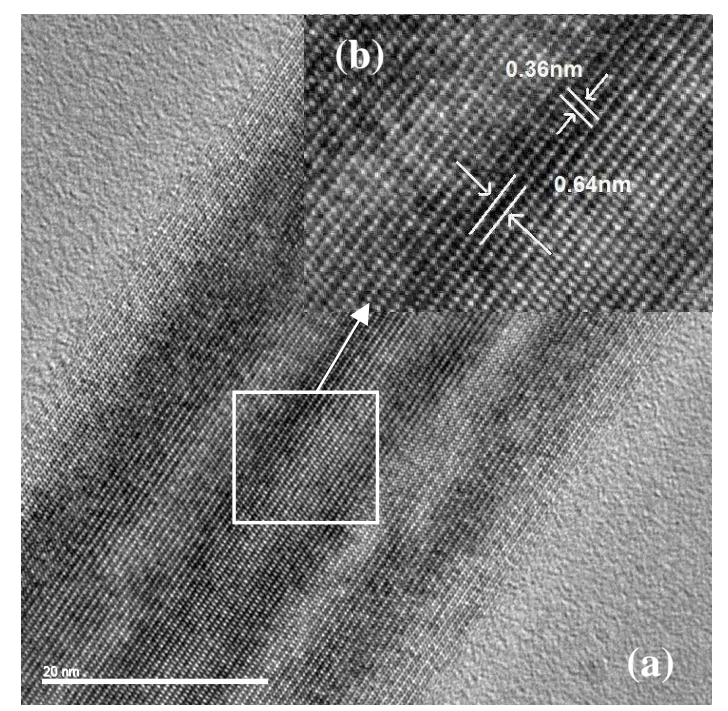

Figura 25 - (a) e (b) Imagens de HR-TEM da amostra obtida a $200^{\circ} \mathrm{C}$ durante 24 horas (AM06).

Uma ampliação da região indicada na Figura 25a, mostra que a distância entre os planos vizinhos ao longo do comprimento dos bastões é $0,36 \mathrm{~nm}$ e ao longo do diâmetro é 0,64nm, Figura 25b. Analisando os dados de DRX obtidos para estas amostras, também observamos que estas distâncias estão relacionadas, respectivamente, aos planos (010) e (200) da fase ortorrômbica do $\mathrm{V}_{2} \mathrm{O}_{5}$. O valor da distância relativa ao plano (010) é similar à distância na amostra AM01 na forma de nanofita que possui uma quantidade maior de 
moléculas de $\mathrm{H}_{2} \mathrm{O}$. Este fato é esperado uma vez que a presença de moléculas de $\mathrm{H}_{2} \mathrm{O}$ causa mudanças estruturais significativas ao longo da direção $c$, ou seja na direção $00 l$. $(32,35,37)$ Analisando em detalhe as imagens, é possível observar claramente que as nanoestruturas obtidas correspondem a materiais monocristalinos.

Em resumo, diante dos resultados apresentados nesta seção, observamos ser possível em condições experimentais bem definidas obter amostras com diferentes estruturas, morfologias e consequientemente, obter materiais com diferentes propriedades e potencialidades de aplicação. Os resultados apresentados mostraram também ser possível obter duas fases distintas, monoclínica e ortorrômbica, sem adicionar nenhum outro elemento à síntese, controlando apenas a temperatura e tempo de tratamento.

\subsubsection{Estudo da ordem local das amostras nanoestruturadas através da técnica de espectroscopia de absorção de raios X (XAS)}

Com o objetivo de caracterizar a ordem local e a estrutura eletrônica do átomo de vanádio em função das condições de síntese, a técnica de espectroscopia de absorção de raios $\mathrm{X}$ (XAS) foi utilizada. A seguir serão apresentados os resultados obtidos através do estudo dos espectros de XAS nas regiões de XANES e EXAFS.

\subsubsection{Estudo da ordem local das amostras nanoestruturadas na região de XANES.}

A Figura 26 apresenta o espectro XANES normalizado do composto de referência (fase ortorrômbica do composto $\mathrm{V}_{2} \mathrm{O}_{5}$ ), da folha metálica do vanádio (V) e das amostras AM01, AM02, AM05 e AM06. O espectro da amostra AM03 não será apresentado por não ter sido observado nenhuma mudança significativa. As medidas do espectro XANES apresentadas na Figura 26 foram realizadas mantendo as amostras a $90^{\circ}$ com relação ao feixe incidente. 


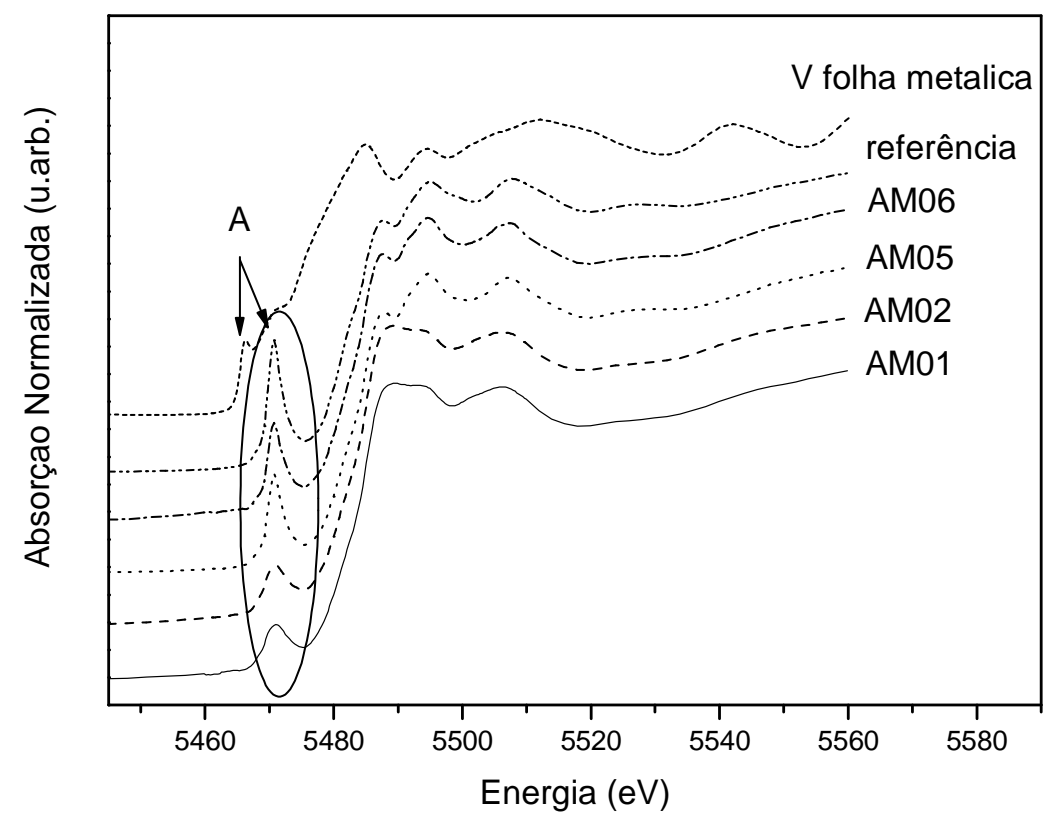

Figura 26 - Espectro XANES na borda K do Vanádio do composto de referência, da folha do vanádio metálico e das amostras AM01, AM02, AM05 e AM06.

Como pode ser observado na Figura 26, o espectro XANES das amostras AM01 e AM02 apresentam diferenças em relação ao espectro do composto de referência. Para as amostras indexadas como a fase $\mathrm{V}_{2} \mathrm{O}_{5} n \mathrm{H}_{2} \mathrm{O}$ monoclínica, o aumento da temperatura de tratamento de $60^{\circ} \mathrm{C}$ (AM01) para $120^{\circ} \mathrm{C}$ (AM02) não induz mudanças significativas no espectro XANES. No entanto, nas amostras obtidas em tratamento hidrotermal a 180 e $200^{\circ} \mathrm{C}$ (AM05 e AM06, respectivamente), o espectro XANES apresenta diferenças na região de préborda e pós-borda de absorção, quando comparado as amostras obtidas em temperaturas inferiores. No caso das amostras AM05 e AM06 é possível observar que os espectros XANES são similares à amostra de referência, apresentando, entretanto uma menor intensidade no pico presente na pré-borda (indicado como A), na Figura 26.

A transição observada na região da pré-borda, região $\mathrm{A}$, tem como origem uma transição do estado $1 s$ para o estado $3 d$ do átomo de vanádio. $(31,40)$ Esta transição, proibida pela regras de seleção em sistemas centro-simétricos, é permitida no caso de centros nãosimétricos através da hibridização entre os estados V $3 d$ e O $2 p$. $(31,40)$ A intensidade da transição da pré-borda está diretamente ligada a estrutura local em torno do átomo do vanádio. $(31,40)$ 
A Figura 27a apresenta a região da pré-borda das amostras estudadas em comparação com o composto de referência, enquanto que a Figura $27 \mathrm{~b}$ apresenta a primeira derivada das curvas apresentadas na Figura 27a.

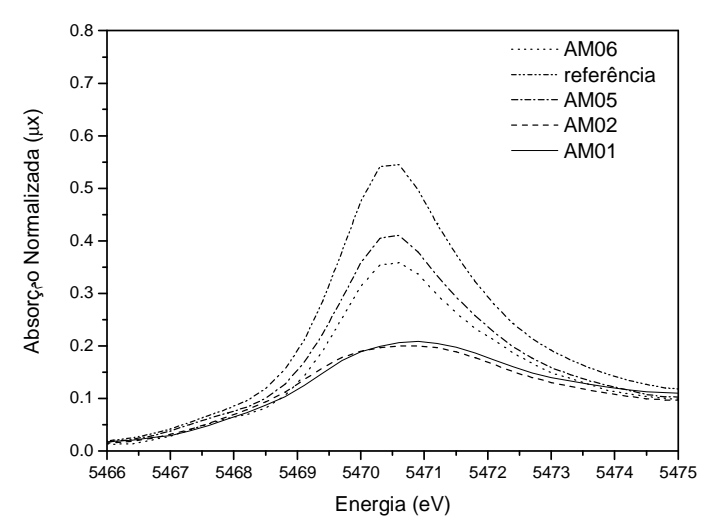

(a)

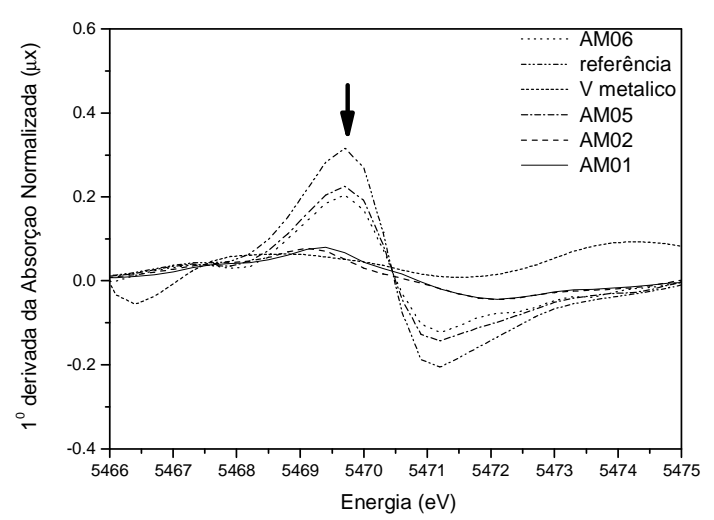

(b)

Figura 27 - (a) região expandida da pré-borda das amostras: AM01, AM02, AM05, AM06 e do composto de referência $\left(\mathrm{V}_{2} \mathrm{O}_{5}\right.$ ortorrômbico); (b) região expandida da primeira derivada do espectro XANES da região da pré-borda de absorção das amostras AM01, AM02, AM05, AM06, do composto de referência $\left(\mathrm{V}_{2} \mathrm{O}_{5}\right.$ ortorrômbico) e do $\mathrm{V}$ metálico.

É possível observar claramente que a intensidade da pré-borda de absorção das amostras estudadas, aumenta com o aumento da temperatura de síntese, sendo, entretanto inferior a do composto de referência, Figura 26a. De acordo com trabalhos encontrados na literatura $(31,40)$, o aumento da intensidade da pré-borda indica uma diminuição da distância $\mathrm{V}=0$ fazendo com que aumente o grau de distorção local.

A Figura 28 mostra maiores detalhes da primeira esfera de coordenação do composto $\mathrm{V}_{2} \mathrm{O}_{5}$.
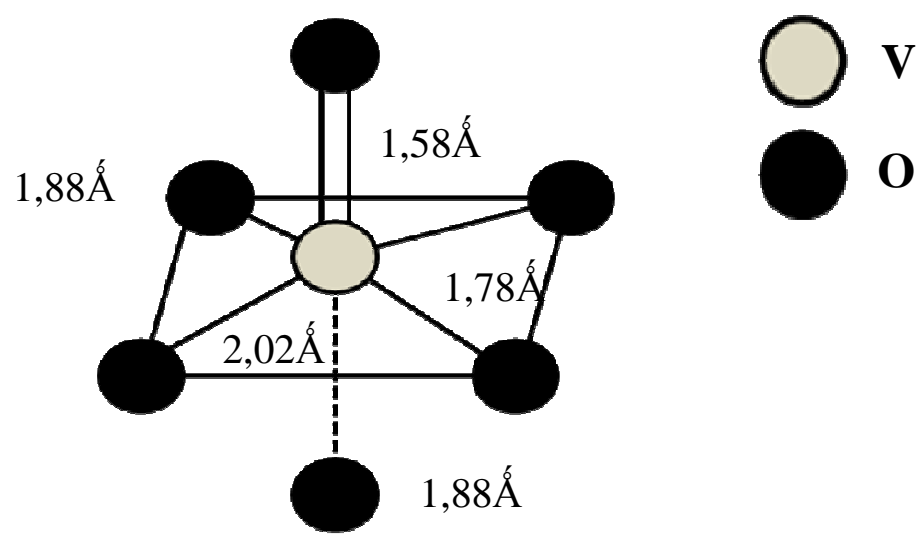

Figura 28 - Detalhes da primeira esfera de coordenação do composto $\mathrm{V}_{2} \mathrm{O}_{5}$. 
Pelo fato dos raios $\mathrm{X}$ produzidos em um anel síncroton serem altamente polarizados, Stizza e colaboradores mostraram a existência do efeito da anisotropia estrutural do composto xerogel $\mathrm{V}_{2} \mathrm{O}_{5} 1,6 \mathrm{H}_{2} \mathrm{O}$. (38) Este fato também foi observado através dos difratogramas de raios $\mathrm{X}$ obtidos para as amostras AM01 e AM02, Figura 20, apresentando de forma clara uma orientação preferencial na direção $00 l$, quando depositada em uma superfície. A existência deste tipo de orientação é típica deste material possuindo uma estrutura de camadas. (25-28, $33,34)$

De forma ilustrativa, podemos observar através do espectro XANES da amostra AM01 e AM06, Figura 29a e b, respectivamente, a diferença no espectro na região de pré e pósborda de absorção em função do ângulo de incidência entre a amostra e o feixe polarizado.

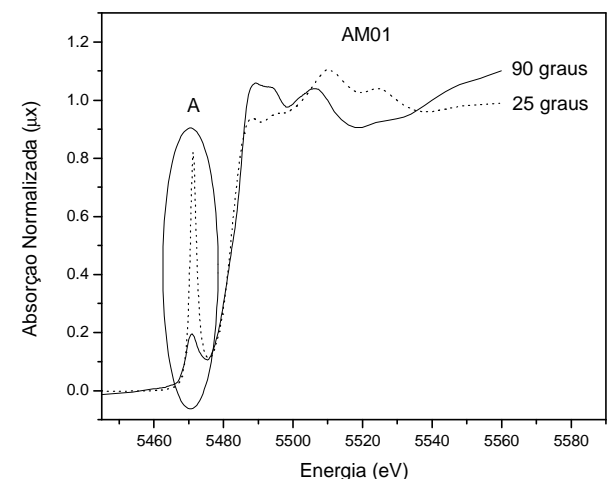

(a)

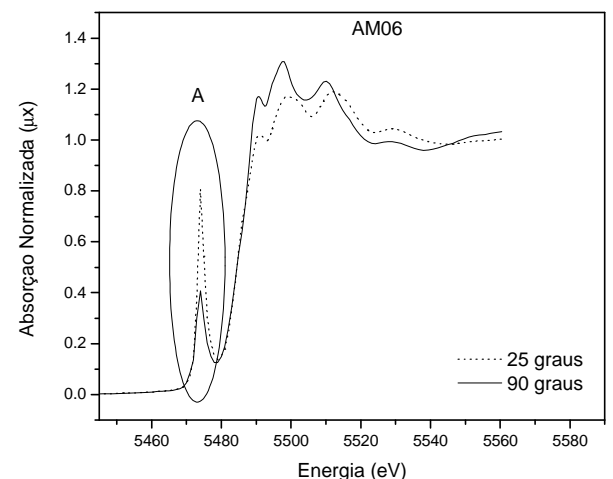

(b)

Figura 29 - Espectro XANES na borda K do Vanádio para a amostra AM01 (a) e AM06 (b) em função do ângulo de incidência do feixe em relação a amostra.

Para a amostra AM01 quando posicionada a 90 graus em relação ao feixe de raios X, observamos que a intensidade da transição A é muito inferior a do espectro medido quando a amostra foi posicionada a 25 graus. Esta diferença ocorre devido ao fato de que, quando a posicionada a $90^{\circ}$ em relação ao feixe, a absorção se dá principalmente pelos 4 átomos de oxigênios posicionados no plano basal da pirâmide formada na primeira esfera de coordenação, Figura 28. No caso dessa mesma amostra posicionada a 25 graus em relação ao feixe incidente, a absorção ocorre principalmente pelo átomo de oxigênio perpendicular ao plano basal, ou seja, ao átomo de $\mathrm{O}$ possuindo a ligação do tipo V=O, Figura 28. 
Na região de pós-borda de absorção é possível observar mudanças significativas nas oscilações EXAFS em função do ângulo entre a amostra e o feixe de raios X.

No caso da amostra AM06, também é possível observar mudanças tanto na região da pré-borda como na região da pós-borda de absorção. Entretanto, a diferença na intensidade da pré-borda é menor quando comparada ao observado para a amostra AM01. Na região da pósborda, é possível observar pequenas mudanças na intensidade das oscilações de EXAFS. Estes resultados estão em bom acordo com os resultados de DRX onde foi observada uma orientação preferencial na direção $00 l$ somente para a amostra AM01, ou seja, para as amostras $\mathrm{V}_{2} \mathrm{O}_{5} n \mathrm{H}_{2} \mathrm{O}$ de fase monoclínica.

Portanto, os resultados apresentados na Figura 29a e b, mostram que não é possível realizar um estudo comparativo dos espectros XANES em relação à estrutura local do V nas amostras $\mathrm{V}_{2} \mathrm{O}_{5} n \mathrm{H}_{2} \mathrm{O}$ apresentando a fase ortorrômbica e monoclínica.

A Tabela 3 apresenta a posição do pico referente à pré-borda $\left(E_{A}{ }^{*}\right)$, sua intensidade normalizada $\left(I_{A}\right)$ e a posição em energia da borda de absorção $\left(E_{b o r d a}\right)$ obtidas a partir da Figura $27 \mathrm{a}$ e b. Para determinar a energia da borda de absorção, $E_{b o r d a}$, considerou-se a medida a meia altura do espectro XANES normalizado. A calibração foi feita utilizando como referência o espectro do vanádio metálico $(\mathrm{E}=5465,4 \mathrm{eV})$.

Tabela 3 - Posição e intensidade da pré-borda e da borda de absorção das amostras estudadas, do vanádio metálico e da amostra de referência $\left(\mathrm{V}_{2} \mathrm{O}_{5}\right.$ ortorrômbica).

\begin{tabular}{cccc}
\hline Amostra & $\mathbf{E}_{\text {borda }}(\mathbf{e V})$ & $\mathbf{I}_{\mathbf{A}}($ intensidade $)$ & $\mathbf{E}_{\mathbf{A}} *(\mathbf{e V})$ \\
\hline AM01 & 5481,9 & 0,20 & 5469,4 \\
AM02 & 5481,9 & 0,21 & 5469,1 \\
AM05 & 5481,7 & 0,40 & 5469,7 \\
AM06 & 5481,9 & 0,36 & 5469,7 \\
$\mathbf{V}_{\mathbf{2}} \mathbf{O}_{\mathbf{5}}$ (referência) & 5481,4 & 0,54 & 5469,7 \\
V metálico & 5473,2 & 0,30 & 5467,9 \\
\hline
\end{tabular}

$E_{\text {borda }}:$ energia medida a meia altura do espectro XANES normalizado.

$E_{A}{ }^{*}$ : energia do ponto de inflexão da pré-borda determinada através da primeira derivada do espectro XANES normalizado

$I_{A}$ : intensidade do pico da pré-borda.

Através da análise da intensidade $I_{A}$ das amostras possuindo a fase ortorrômbica em relação ao estado de hidratação, Tabela 3, é possível observar que as amostras AM05 e AM06 
possuem intensidades similares, inferior a do composto utilizado como referência. Este fato indica que estas amostras possuem um grau maior de simetria quando comparada ao composto padrão, ou seja, ao $\mathrm{V}_{2} \mathrm{O}_{5}$ ortorrômbico na sua forma "bulk". Além disso, observouse que na amostra AM06, que possui menor estado de hidratação, a intensidade $I_{A}$ diminui levemente, sugerindo que o menor estado de hidratação leva a obtenção de uma amostra com maior grau de simetria local. (31)

Mansour e colaboradores estudaram a presença de íons $\mathrm{V}^{4+}$ em amostras de $\mathrm{V}_{2} \mathrm{O}_{5} n \mathrm{H}_{2} \mathrm{O}$ aerogel e ambigel através da técnica XAS. (31) Analisando os resultados apresentados na Tabela 3, é possível observar que não houve mudanças significativas na posição da borda de absorção das amostras quando comparadas ao composto de referência que possui estado de oxidação $\mathrm{V}^{5+}$.

Segundo Mansur e colaboradores, a energia do pico da pré-borda também é sensível a variação no estado de oxidação do vanádio. (31) De acordo com este trabalho, nas amostras com $\mathrm{n} \approx 0,5$ foi possível detectar a presença de íons $\mathrm{V}^{4+}$ com uma concentração estimada em 0,29 e 0,26 para as amostras aerogel e ambigel, respectivamente. (31) Na Figura 27b, para o V metálico observamos claramente um deslocamento para menores energias assim como a diminuição da intensidade do pico indicado pela seta, quando comparado ao espectro de $\mathrm{V}_{2} \mathrm{O}_{5}$. Este fato está relacionado a diferenças no estado de oxidação do vanádio, onde o $\mathrm{V}$ metálico possui o estado 0 enquanto que $\mathrm{o} \mathrm{V}_{2} \mathrm{O}_{5}$ possui o estado 5+.(31) A analise dos dados da Tabela 3 mostra um deslocamento para valores de menor energia e uma diminuição da intensidade desta transição no caso das amostras AM01 e AM02, indicando a presença de uma pequena quantidade de íons $\mathrm{V}^{4+}$ nestas amostras. Um deslocamento maior para a amostra AM02 indica uma maior quantidade de $\mathrm{V}^{4+}$ em relação a amostra AM01. (31) Para as amostras AM05 e AM06, indexadas como possuindo a fase ortorrômbica, não foi possível observar nenhum mudança no valor de $E_{A}{ }^{*}$ em relação ao composto de referência, que também possui a fase cristalina ortorrômbica.

Livage e colaboradores, em um estudo da síntese do composto $\mathrm{V}_{2} \mathrm{O}_{5} n \mathrm{H}_{2} \mathrm{O}$ a partir de alcóxidos ou de soluções aquosas, mostrou que sempre ocorre no processo de síntese a formação de espécies de $\mathrm{V}^{4+}$, que seriam em parte responsáveis por diversas propriedades deste composto. $(25,26)$ Os íons de $\mathrm{V}^{4+}$ estão localizados principalmente na superfície das partículas sendo responsáveis pelo processo de hidratação além de favorecer o processo de polimerização devido a fraca acidez da ligação $\mathrm{V}^{4+}{ }_{-} \mathrm{OH}$ quando comparado a ligação $\mathrm{V}^{5+}{ }_{-} \mathrm{OH}$. Através de medidas de EPR, Livage e colaboradores observaram a presença de íons $\mathrm{V}^{4+}$ somente em amostras de pentóxido de vanádio mais hidratada $\mathrm{V}_{2} \mathrm{O}_{5} 1,8 \mathrm{H}_{2} \mathrm{O}$, associando a 
presença de íons $\mathrm{V}^{4+}$ à presença de moléculas de água intercalada. (25-27) Ou seja, através de medidas de EPR, Livage e colaboradores observaram que o pentóxido de vanádio hidratado $\left(\mathrm{V}_{2} \mathrm{O}_{5} n \mathrm{H}_{2} \mathrm{O}\right)$ quando aquecido, de forma a desidratar-se $(n \approx 0,5)$, não apresenta variação no espectro de EPR, quando comparado com a amostra cristalina de $\mathrm{V}_{2} \mathrm{O}_{5}$, o que não ocorre para a amostra mais hidratada $\mathrm{V}_{2} \mathrm{O}_{5} 1,8 \mathrm{H}_{2} \mathrm{O}$. (27) Esse fato pode ser explicado pelo estudo estrutural da fase $\mathrm{V}_{2} \mathrm{O}_{5} n \mathrm{H}_{2} \mathrm{O}$, apresentado por Abello e colaboradores. (35) Neste trabalho, analisando espectros vibracionais para as amostras com $n=1,6,1,2,0,6,0,4$ e 0,3 , observaram que para $n \approx 0,3$, as camadas de $\mathrm{V}_{2} \mathrm{O}_{5}$ estão conectadas de forma semelhante ao observado para o composto cristalino $\mathrm{V}_{2} \mathrm{O}_{5}$ de fase ortorrômbica cristal, ou seja, através de ligações $\mathrm{V}=\mathrm{O}-\mathrm{V}$, onde a molécula de água está presa à cavidade da estrutura ligada por dois átomos de hidrogênio com o oxigênio da rede, o que deve estar acontecendo para o composto $\mathrm{V}_{2} \mathrm{O}_{5} 0,5 \mathrm{H}_{2} \mathrm{O}$ analisado por Livage e colaboradores (25-27). Recentemente, Kweon e colaboradores também observaram um aumento da quantidade de íons de $\mathrm{V}^{4+}$ na presença de moléculas de água intercaladas na estrutura dos nanotubos de vanádio. (50)

Assim, os resultados obtidos em relação às amostras AM01 e AM02, ou seja, a maior presença de íons de $\mathrm{V}^{4+}$ para a amostra AM02, está de bom acordo com a literatura, uma vez que, as medidas de TG e DRX mostram uma quantidade maior de moléculas de $\mathrm{H}_{2} \mathrm{O}$ e um maior valor de $\mathrm{d}, n \approx 2,1$ e $d \approx 14,3$ (Tabela 2), para a amostra AM02. Embora não tenha sido possível observar deslocamentos nos espectros de XANES para as amostras AM05 e AM06, não é possível excluir totalmente a presença de pequenas quantidades de íons de $\mathrm{V}^{4+}$ nestas amostras. (27, 31). Podemos afirmar que o estado de oxidação do átomo de vanádio nas amostras AM05 e AM06 é preferencialmente 5+, sendo a quantidade de íons $\mathrm{V}^{4+}$ certamente menor do que para as amostras AM01 e AM02. Diferente ao observado por Mansour e colaboradores, a não observação de uma quantidade significativa de íons $\mathrm{V}^{4+}$ na amostra AM06 contendo $n \approx 0,5$, pode estar relacionada ao processo de obtenção de tal estrutura, uma vez que, esses autores obtiveram a estrutura $\mathrm{V}_{2} \mathrm{O}_{5} 0,5 \mathrm{H}_{2} \mathrm{O}$ através de tratamento térmico da amostra $\mathrm{V}_{2} \mathrm{O}_{5} 2, \mathrm{OH}_{2} \mathrm{O}$. (31)

Finalmente, a análise do espectro XANES nas amostras obtidas a diferentes temperaturas no sistema hidrotermal mostrou que a estrutura local formada pela unidade piramidal $\mathrm{VO}_{5}$ torna-se menos distorcida a medida que a amostra torna-se mais desidratada, ou seja, passa da morfologia na forma de nanofitas para nanobastões. 


\subsubsection{Estudo da ordem local das amostras nanoestruturadas na região de EXAFS.}

Com a finalidade de confirmar os resultados qualitativos obtidos através da análise do espectro XANES, será apresentada a seguir a análise na região de EXAFS para as amostras AM05 e AM06.

É possível encontrar na literatura diferentes estudos do espectro de EXAFS em amostras de $\mathrm{V}_{2} \mathrm{O}_{5} 1,8 \mathrm{H}_{2} \mathrm{O}$ na forma de nanofitas $(31,38,39)$, no entanto, ao nosso conhecimento, não encontramos nenhum trabalho da análise da ordem local em amostras na forma de nanofios e nanobastões.

Com o objetivo de analisar e comparar os efeitos de orientação estrutural das amostras na região de EXAFS com o espectro obtido para a região de XANES, a Figura 30a e b, apresenta respectivamente, o módulo da transformada de Fourier (FT) do espectro EXAFS para as amostras AM01 e AM06. Como mencionado anteriormente, estes espectros foram obtidos posicionando as amostras a $25^{\circ}$ e $90^{\circ}$ em relação ao feixe de raios $\mathrm{X}$.

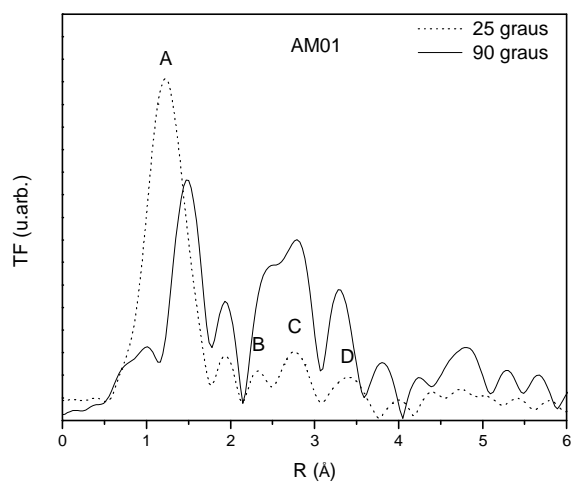

(a)

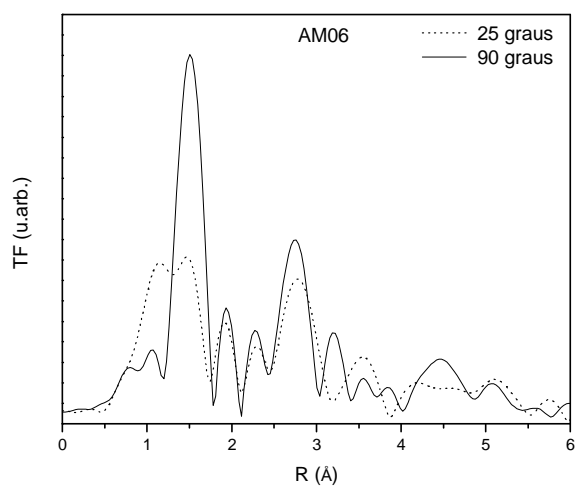

(b)

Figura 30 - Modulo da transformada de Fourier (FT) do espectro EXAFS das amostras AM01 (a) e AM06 (b) coletados em diferentes orientações em relação ao feixe de raios $\mathrm{X}$.

$\mathrm{Na}$ Figura 30a, podemos observar claramente diferenças entre os espectros obtidos para a amostra AM01 quando posicionada a 25 e $90^{\circ}$ em relação ao feixe. Como foi observado através da análise do espectro XANES, as medidas do espectro EXAFS mostram de forma clara uma orientação preferencial da unidade piramidal de $\mathrm{VO}_{5}$ na amostra $\mathrm{AM} 01$, 
ou seja, nas nanoestruturas de $\mathrm{V}_{2} \mathrm{O}_{5} n \mathrm{H}_{2} \mathrm{O}$ de fase monoclínica. $\mathrm{O}$ espectro obtido para a amostra posicionada a $25^{\circ}$ em relação ao feixe incidente, apresenta uma transformada de Fourier do espectro de EXAFS dominado principalmente por um primeiro pico, denominado $A$. Este pico é atribuído ao átomo de oxigênio perpendicular ao plano basal, ou seja, que possui a ligação do tipo $\mathrm{V}=\mathrm{O}$, Figura 28. (38) É evidente que este espectro não apresenta somente a contribuição deste átomo pelo fato de ser possível observar a presença de outros picos situados a maiores distâncias. As esferas de coordenação B, C e D estão relacionadas aos átomos de oxigênio situados no plano basal da pirâmide e de outros átomos situados além da primeira esfera de coordenação, uma vez que, embora orientada, as amostras não foram posicionadas em um ângulo de 0 graus em relação ao feixe, posição esta que diminuiria a contribuição desses outros átomos. Além disso, as esferas de coordenação B, C e D possuem também contribuições do átomo de oxigênio posicionado no sentido oposto a ligação $\mathrm{V}=\mathrm{O}$, Figura 28. (38)

Em relação à amostra AM06, Figura 30b, é possível também observar mudanças na transformada de Fourier principalmente no que diz respeito a primeira esfera de coordenação, relacionado as ligações V-O. Entretanto, é possível observar que para esta amostra, as contribuições estruturais adicionais de átomos situados a maiores distâncias é mais evidente do que observado para a amostra AM01. Os resultados apresentados para a amostra AM06 sugerem que o espectro de EXAFS deve ser analisado de forma mais detalhada, podendo somente afirmar que sua estrutura não possui o grau de orientação observado para a amostra AM01.

A Figura 31a e b apresentam respectivamente o espectro de EXAFS e as respectivas transformadas de Fourier (TF) das amostras AM05, AM06 e do composto de referência $\left(\mathrm{V}_{2} \mathrm{O}_{5}\right.$ ortorrômbico) coletados a $90^{\circ}$ em relação ao feixe incidente de raios X. A TF foi obtida utilizando uma janela na região de $3,5<\mathrm{k}<14 \AA^{-1}$ do espectro EXAFS. 


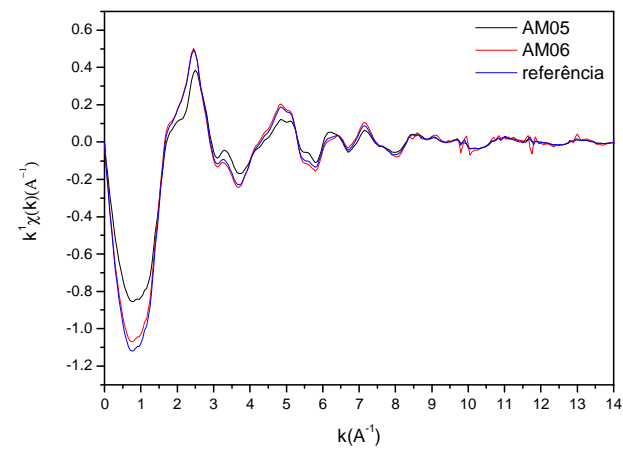

(a)

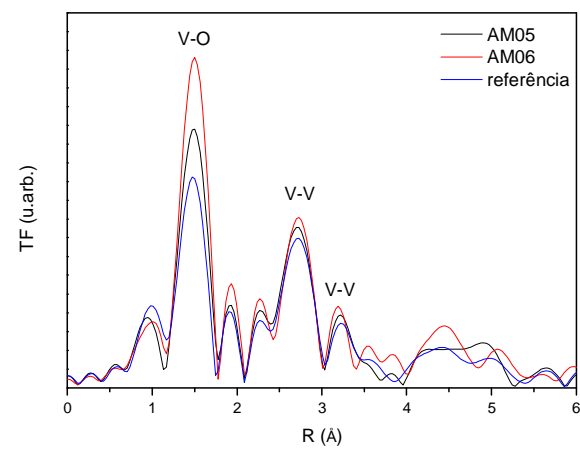

(b)

Figura 31 - (a) Espectro EXAFS das amostras AM05, AM06 e do composto utilizado como referência. (b): Modulo da transformada de Fourier não corrigido do espectro EXAFS coletados a $90^{\circ}$ em relação ao feixe incidente de raios $\mathrm{X}$.

Analisando a Figura 31b, é possível observar que o módulo da TF não corrigida do espectro de EXAFS apresenta três esferas de coordenação bem definidas para as três amostras. Esses picos são dominados por contribuições de espalhamento simples sendo que o primeiro pico, situado em torno de $1,56 \AA \hat{~}$ está relacionado às ligações do vanádio com os átomos de oxigênio mais próximos, Figura 28, enquanto que a segunda esfera, localizada em torno de 2,75Á, está relacionada aos átomos de vanádio situados na pirâmide adjacente. (38) A terceira esfera de coordenação também é dominada pela contribuição do espalhamento simples das ligações vanádio-vanádio. No entanto, nessa terceira esfera, contribuições de espalhamento múltiplo começam a ficar significativas. $(31,38,39)$ Desta forma, serão analisados apenas a primeira e a segunda esfera de coordenação.

$\mathrm{Na}$ Figura 31b é possível observar claramente que o primeiro pico apresenta um aumento de amplitude com o aumento da temperatura de síntese, enquanto que para as outras três esferas de coordenação, é possível observar mudanças mais discretas em suas amplitudes. Essas mudanças de amplitude podem ser associadas a mudanças no grau de desordem $\left(\sigma^{2}\right)$, que pode ser térmica ou estrutural, e/ou mudança no número de coordenação $(\mathrm{CN})$ ao redor do átomo de vanádio. $(31,38,39)$. O grau de desordem $\left(\sigma^{2}\right)$ é conhecido como fator de Debye. (95)

Através do ajuste do espectro EXAFS de um composto com estrutura conhecida, é possível obter o valor de $\mathrm{E}_{0}$ (diferença entre a energia da borda de absorção teórica e experimental) e de $\mathrm{S}_{0}{ }^{2}$ (fator de redução do elétron) de modo que possam ser utilizados na simulação do espectro EXAFS para as amostras AM05 e AM06. O termo $\Delta \mathrm{R}$ refere-se à 
diferença teórica e experimental da distância do átomo absorvedor para o átomo de coordenação em um único evento de espalhamento. Diante da necessidade da utilização de um composto com estrutura conhecida, utilizamos como composto de referência o $\mathrm{V}_{2} \mathrm{O}_{5}$ de fase cristalina ortorrômbica.

Para realizar o ajuste do sinal de EXAFS da amostra de referência, foi considerado na primeira esfera de coordenação apenas os 4 primeiros átomos de oxigênio $\left(\mathrm{O}_{1}, \mathrm{O}_{2}, \mathrm{O}_{3}\right.$ e $\left.\mathrm{O}_{4}\right)$, Figura 28, enquanto que na segunda esfera consideramos um átomo de vanádio $\left(\mathrm{V}_{1}\right)$ e um átomo de oxigênio $\left(\mathrm{O}_{1}\right)$.

A Tabela 4 apresenta os parâmetros estruturais utilizados no ajuste dos dados experimentais do composto de referência de acordo com a estrutura da primeira esfera de coordenação apresentada na Figura 28. Através dos resultados da simulação da primeira e segunda esferas de coordenação do composto utilizado como padrão $\left(\mathrm{V}_{2} \mathrm{O}_{5}\right.$ de fase cristalina ortorrômbica) ,apresentados na tabela 4, podemos observar que de fato a primeira e segunda esfera de coordenação apresentam apenas as contribuições dos átomos considerados no ajuste dos dados experimentais, Figura 32a, ou seja, 4 átomos de oxigênio $\left(\mathrm{O}_{1}, \mathrm{O}_{2}, \mathrm{O}_{3}\right.$ e $\left.\mathrm{O}_{4}\right)$ na primeira esfera e 1 átomo de vanádio $\left(\mathrm{V}_{1}\right)$ e 1 átomo de oxigênio $\left(\mathrm{O}_{1}\right)$ na segunda esfera de coordenação. Estas contribuições ficam ainda mais clara através da soma dessas simulações apresentadas na Figura 32b, que possui espectro similar ao observado para as amostras estudadas. Os parâmetros estruturais apresentados na Tabela 4, bem como as simulações, foram obtidas através do programa Artemis e estão de bom acordo com os resultados encontrados na literatura através de medidas como difração de raios X. (96-99)

Tabela 4 - Parâmetros estruturais para o composto $\mathrm{V}_{2} \mathrm{O}_{5}$ ortorrômbico obtido pelo programa Artemis.

\begin{tabular}{ccc}
\hline Átomo & $\mathbf{R}(\mathbf{\AA})$ & Degenerescência \\
\hline $\mathbf{O}_{\mathbf{1}}$ & 1,586 & 1 \\
$\mathbf{O}_{\mathbf{2}}$ & 1,781 & 1 \\
$\mathbf{O}_{\mathbf{3}}$ & 1,878 & 2 \\
$\mathbf{O}_{\mathbf{4}}$ & 2,022 & 1 \\
$\mathbf{O}_{\mathbf{5}}$ & 2,787 & 1 \\
$\mathbf{V}_{\mathbf{1}}$ & 3,019 & 2 \\
\hline
\end{tabular}




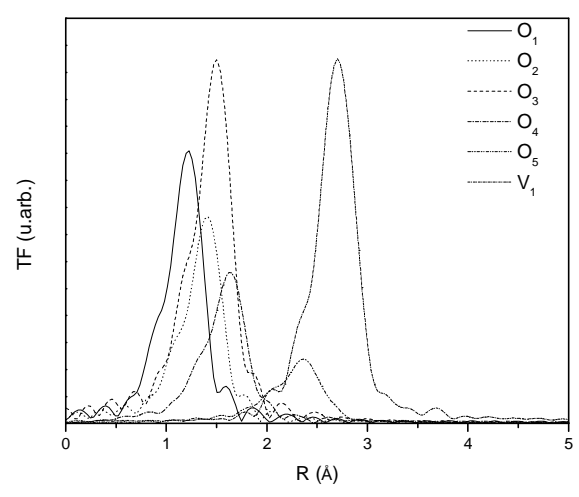

(a)

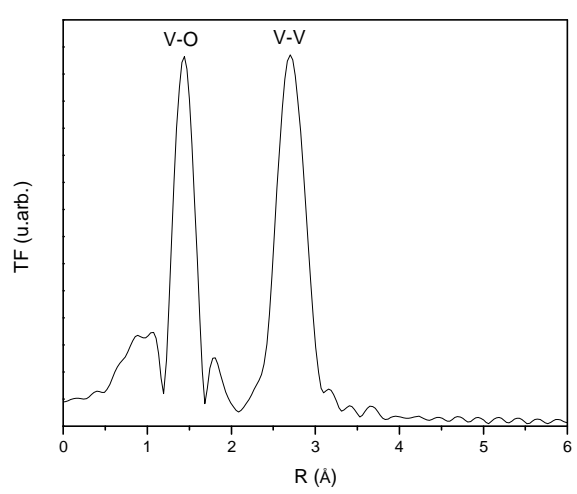

(b)

Figura 32 - (a) Módulo da transformada de Fourier (TF) não corrigida do espectro de EXAFS das simulações dos caminhos de espalhamento utilizando os parâmetros da Tabela 4; (b) Modulo da TF não corrigida do espectro EXAFS da soma dos caminhos de espalhamento simulados em (a).

A Figura 33a e b mostra uma boa qualidade do ajuste teórico ao experimental obtido através da comparação do espectro EXAFS e sua respectiva transformada de Fourier (TF). Para este ajuste foi obtido um fator-R de 0,02.

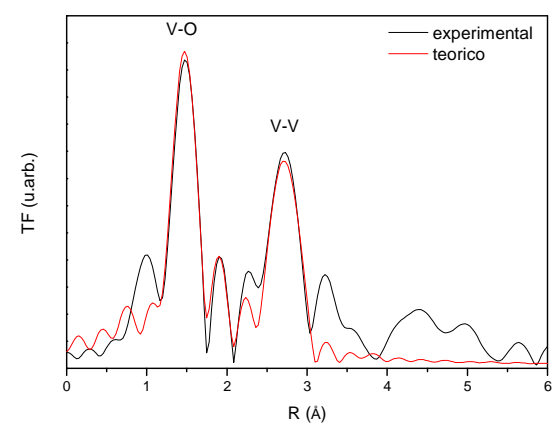

(a)

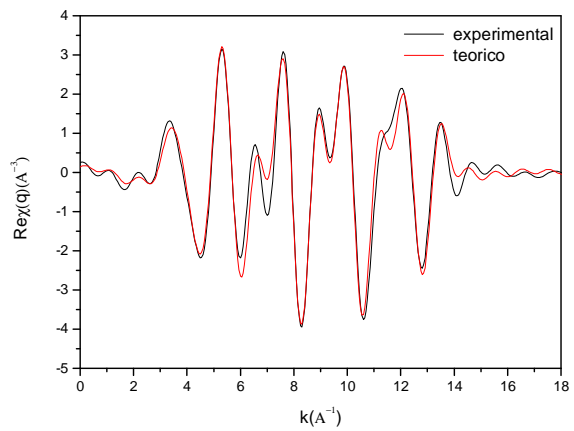

(b)

Figura 33 - Ajuste dos dados da amostra padrão $\left(\mathrm{V}_{2} \mathrm{O}_{5}\right.$ ortorrômbico): (a) magnitude da transformada de Fourier do espectro experimental e ajuste teórico; (b) espectro EXAFS experimental e ajuste teórico.

Os valores obtidos através do ajuste teórico, a partir da Figura 33 estão apresentados na Tabela 5. 
Tabela 5 - Resultados estruturais obtidos pelo ajuste do espectro experimental de EXAFS para o composto padrão $\left(\mathrm{V}_{2} \mathrm{O}_{5}\right.$ ortorrômbico):

\begin{tabular}{cccc|ccc}
\hline \multicolumn{4}{c|}{ 1 esfera $(\mathbf{V}-\mathbf{O})$} & \multicolumn{3}{c}{ 2 esfera $(\mathbf{V}-\mathbf{V})$} \\
\hline $\mathbf{S}_{\mathbf{0}}{ }^{2}$ & $\mathbf{E}_{\mathbf{0}}(\mathbf{e V})$ & $\Delta \mathbf{R}(\AA)$ & $\boldsymbol{\sigma}^{2}(\AA)$ & $\left.\mathbf{S}_{\mathbf{0}}{ }^{(}\right)$ & $\Delta \mathbf{R}(\AA)$ & $\boldsymbol{\sigma}^{2}(\AA)$ \\
$1,1 \pm 0,1$ & $0,5 \pm 2,1$ & $0,018 \pm 0,011$ & $0,004 \pm 0,001$ & $0,8 \pm 0,2$ & $0,024 \pm 0,017$ & $0,005 \pm 0,002$ \\
\hline
\end{tabular}

Para obter o número de coordenação $(\mathrm{CN})$, o fator de Debye $(\sigma)$ e o valor de $\Delta \mathrm{R}$ da primeira e segunda esfera de coordenação das amostras AM05 e AM06, foram considerados como ponto de partida os dados cristalográficos utilizados no ajuste da amostra de referência apresentados na Tabela 5.

Fixando os parâmetros $\mathrm{S}_{0}^{2}$ e $\Delta \mathrm{E}$ obtidos através do ajuste da amostra de referência, foi possível obter as informações estruturais das amostras AM05 e AM06 que são apresentados na Tabela 6. Embora a análise dos espectros EXAFS apresente considerável complexidade da estrutura local ao redor dos átomos de vanádio, analisando a magnitude da TF e o sinal EXAFS experimental e teórico correspondente a primeira esfera de coordenação da amostra AM05, Figura 34a e b, assim como para a amostra AM06, Figura 35a e b, observamos um bom ajuste do espectro experimental pelo modelo utilizado. Nos ajustes dos espectros das amostras AM05 e AM06 foi obtido um fator-R igual a 0,003 e 0,002, respectivamente, valores estes dentro da faixa aceitável para um ajuste considerado de boa qualidade. As pequenas diferenças entre o sinal experimental e teórico devem estar relacionadas principalmente aos efeitos de espalhamento múltiplo que não foram considerados durante a realização dos ajustes.

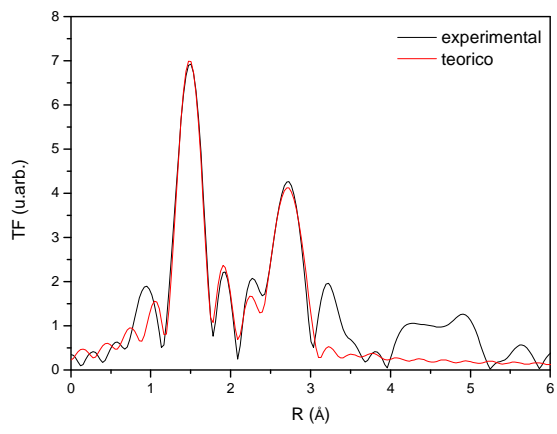

(a)

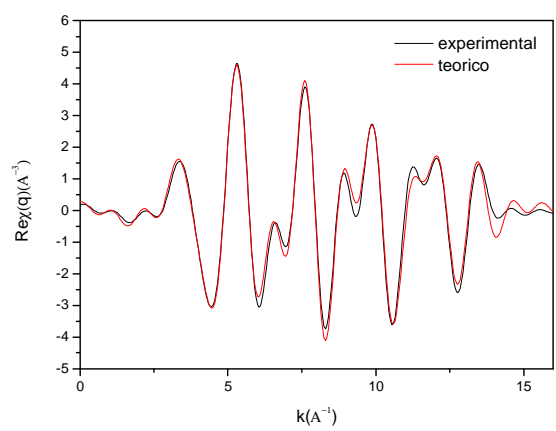

(b)

Figura 34 - Ajuste da amostra AM05: (a) magnitude da transformada de Fourier do espectro experimental e ajuste teórico; (b) espectro EXAFS experimental e ajuste teórico. 


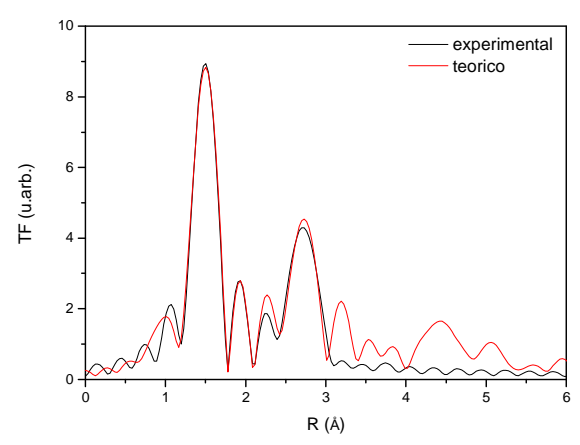

(a)

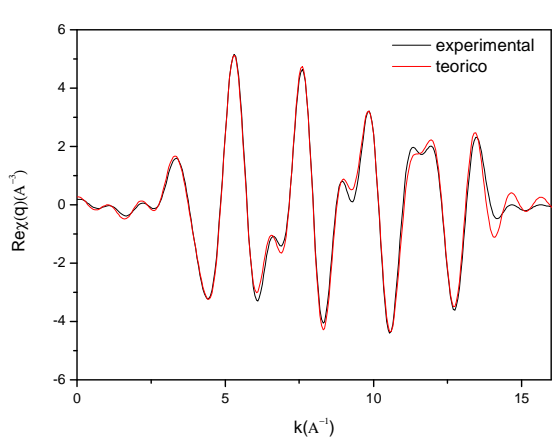

(b)

Figura 35 - Ajuste da amostra AM06: (a) magnitude da transformada de Fourier do espectro experimental e ajuste teórico; (b) espectro EXAFS experimental e ajuste teórico.

Tabela 6 - Resulta dos estruturais obtidos do ajustes do espectro de EXAFS para as amostras AM5 e AM06 para a primeira esfera de coordenação.

\begin{tabular}{c|ccc}
\hline \multicolumn{4}{c}{ 1 esfera $(\mathbf{V}-\mathbf{O})$} \\
\hline Amostra & $\mathbf{C N}$ & $\Delta \mathbf{R}(\AA)$ & $\boldsymbol{\sigma}^{2}(\AA)$ \\
AM05 & $4,98 \pm 1,25$ & $0,029 \pm 0,015$ & $0,003 \pm 0,001$ \\
AM06 & $4,30 \pm 1,02$ & $0,032 \pm 0,016$ & $0,001 \pm 0,001$ \\
\hline
\end{tabular}

Através da análise dos resultados da Tabela 6 é possível observar que ocorre um aumento na distância dos átomos de $\mathrm{O}$ com relação ao átomo de $\mathrm{V}$, em função da temperatura de síntese, quando comparado a amostra de referência. Essa maior distância foi constatada através do aumento de $\Delta \mathrm{R}$ quando comparado ao valor da amostra referência. Em bom acordo com os resultados de XANES, observou-se também um menor grau de distorção dessa primeira esfera de coordenação para a amostra AM06, quando comparada a amostra AM05, uma vez que o fator de Debye encontrado para essas amostras foram 0,003 e 0,001, respectivamente.Como esperado, a amostra AM05 também apresentou um menor grau de distorção comparado a amostra de referência. Em relação ao número de coordenação $(\mathrm{CN})$, é possível observar que o número encontrado está próximo ao da amostra de referência, o que é esperado uma vez que não foi possível observar grandes diferenças nas medidas de DRX e micro-Raman destas amostras. Além disso, mudanças significativas no número de coordenação para materiais nanoestruturados quando comparados com materiais em sua 
forma microestruturada somente são observados em materiais nanoestruturados com dimensões menores que $10 \mathrm{~nm}$. (100)

Analisando os resultados da Tabela 7, referentes aos resultados obtidos para a segunda esfera de coordenação, podemos observar que não há mudanças significativas entre as amostras estudadas e mesmo quando comparadas ao composto utilizado como referência.

Tabela 7 - Resultados estruturais obtidos do ajustes do espectro de EXAFS para as amostras AM5 e AM06 para a segunda esfera de coordenação.

\begin{tabular}{c|ccc}
\hline \multicolumn{4}{c}{ 2 esfera $(\mathbf{V}-\mathbf{V})$} \\
\hline Amostra & CN & $\Delta \mathbf{R}(\AA)$ & $\boldsymbol{\sigma}^{2}(\AA)$ \\
AM05 & $3,8 \pm 1,4$ & $0,029 \pm 0,015$ & $0,006 \pm 0,002$ \\
AM06 & $4,1 \pm 1,3$ & $0,027 \pm 0,007$ & $0,006 \pm 0,002$ \\
\hline
\end{tabular}

Desta forma, os resultados obtidos através da análise na região de EXAFS confirmam os resultados qualitativos obtidos através da análise na região de XANES para as amostras AM05 e AM06. Estas amostras apresentam um menor grau de distorção na primeira esfera de coordenação, distorção que esta relacionada à maior temperatura de tratamento. Está distorção está diretamente relacionada as posições dos átomos de $\mathrm{O}$ no plano basal do átomo absorvedor, ou seja, o átomo de V. (31)

\subsection{Estudo do mecanismo de crescimento do composto $\mathrm{V}_{2} \mathrm{O}_{5}$ nanoestruturado}

São apresentados a seguir os resultados obtidos em relação a cinética de crescimento da amostra $\mathrm{V}_{2} \mathrm{O}_{5} n \mathrm{H}_{2} \mathrm{O}$ na forma de nanofitas.

A Figura 36 apresenta o padrão de difração de raios $X$ da amostra considerada como a solução precursora (solução que contém nanofitas) e das amostras que foram obtidas a partir da diluição da amostra precursora e submetidas novamente ao tratamento hidrotermal. Serão 
apresentados somente os padrões de DRX das amostras denominadas de solução precursora, e que foram novamente submetidas ao tratamento hidrotermal com tempo de tratamento igual a zero, ou seja, a solução considerada primária e da solução tratada durante 7200 minutos.

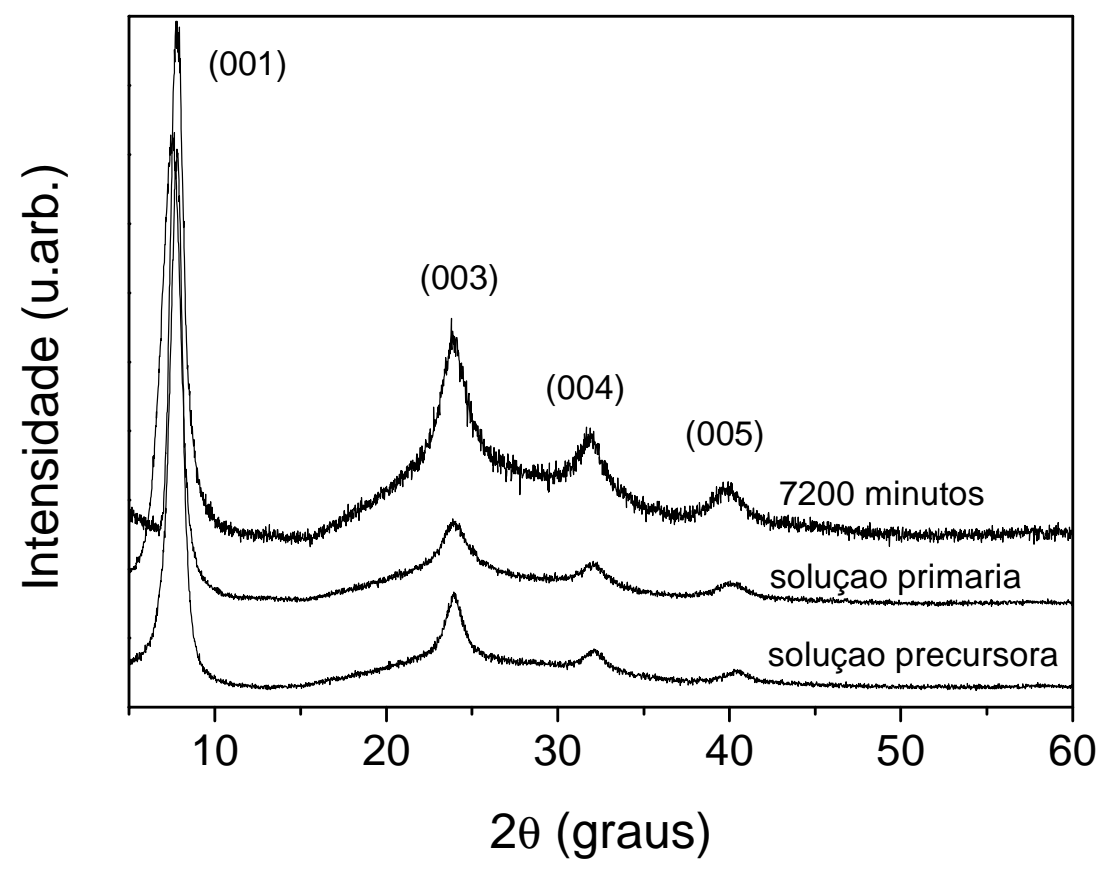

Figura 36 - Medidas de DRX da amostra utilizada como solução precursora e das amostras submetidas ao tratamento hidrotermal durante 0 e 7200 minutos.

Analisando a Figura 36 é possível observar que, confirmando os resultados obtidos anteriormente, todos os difratogramas apresentam uma série de picos referentes aos planos de difração $00 \mathrm{l}$ que foram indexados a fase $\mathrm{V}_{2} \mathrm{O}_{5} n \mathrm{H}_{2} \mathrm{O}$ monoclínica. Este resultado mostra que, quando a amostra foi submetida a um tratamento hidrotermal mantendo a temperatura fixa e variando o tempo de tratamento, não foi observada nenhuma mudança significativa na estrutura cristalina das amostras.

A técnica de FE-STEM, operando no modo de campo claro, foi utilizada na caracterização da morfologia e dimensão destas amostras. Através das Figura 37a e b que apresentam respectivamente as imagens de FE-STEM das nanofitas obtidas a partir da solução precursora e da amostra que foi submetida a um tratamento hidrotermal durante 7200 minutos, é possível observar que o aumento do tempo de tratamento hidrotermal não leva a uma mudança na morfologia das nanoestruturas obtidas. 


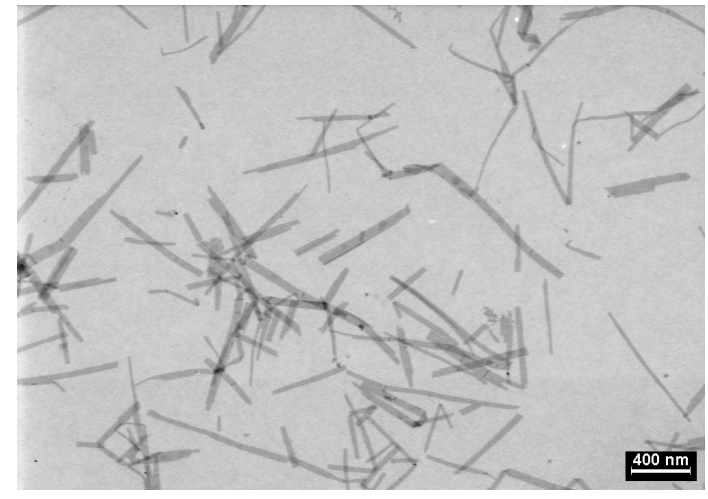

(a)

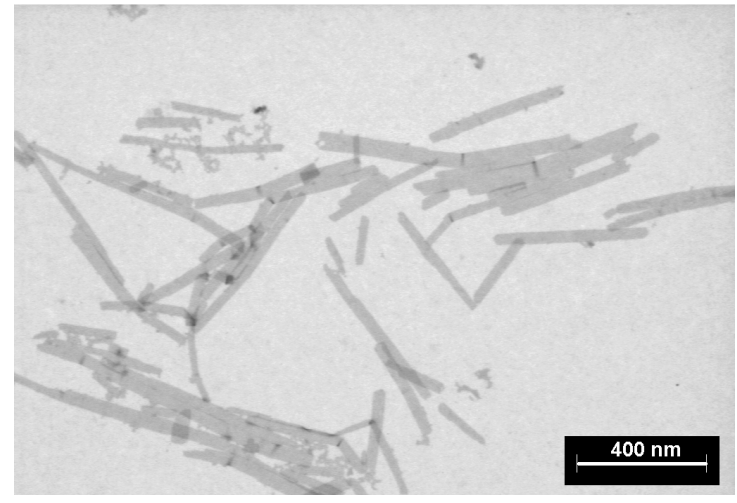

(b)

Figura 37 - Imagens de FE-STEM das nanofitas obtidas a partir da solução precursora (a) e a partir da amostra diluída e submetida a um tratamento hidrotermal durante 7200 minutos.

Entretanto, através da imagem apresentada na Figura 37b é possível observar na amostra tratada durante 7200 minutos a presença de algumas nanofitas apresentando um processo de coalescência lateral. Este mesmo comportamento foi observado em outras amostras que foram tratadas durante tempos inferiores a 7200 minutos.

$\mathrm{Na}$ seção anterior, as imagens de HR-TEM mostraram que essas fitas crescem inicialmente ao longo da direção [010], ou seja, na direção do comprimento das nanofitas. Como foi comentado anteriormente, o mecanismo de crescimento preferencial nesta direção tem sido atribuído ao mecanismo de crescimento descrito por Livage e colaboradores (25-27). A presença de nanofitas coladas lateralmente como no caso apresentado na Figura 37b, mostra que em certas condições, outro processo de crescimento ao longo da direção [100] pode estar ocorrendo.

De acordo com a literatura, além do mecanismo denominado como "Maturação de Ostwald”, ou "Ostwald Ripening” (OR) o crescimento descrito pelo mecanismo denominado de Coalescência Orientada, ou "Oriented attachament" (OA) tem se mostrado muito efetivo em condições hidrotermais, sendo observado em diferentes tipos de materiais nanoestruturados. $(3,7,11-13,52,60,62-64,66,68,70-75,79,81,101)$

De modo a realizar um estudo mais detalhado deste processo de crescimento lateral nestas nanofitas, foram realizadas medidas da variação da largura em função do tempo de tratamento hidrotermal.

A Figura 38 apresenta a distribuição da largura das nanofitas $(d)$ em função do tempo de tratamento da amostra. A largura foi estimada através da análise de aproximadamente 350 nanofitas observadas através de imagens de FE-STEM. Uma função do tipo Gaussiana foi 
utilizada com a finalidade de ajustar a distribuição dos resultados de forma a estimar o valor médio na medida da largura das nanofitas.

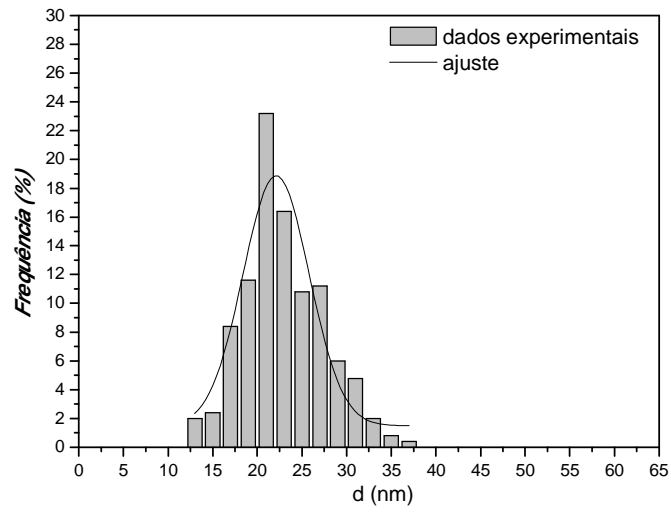

(a)

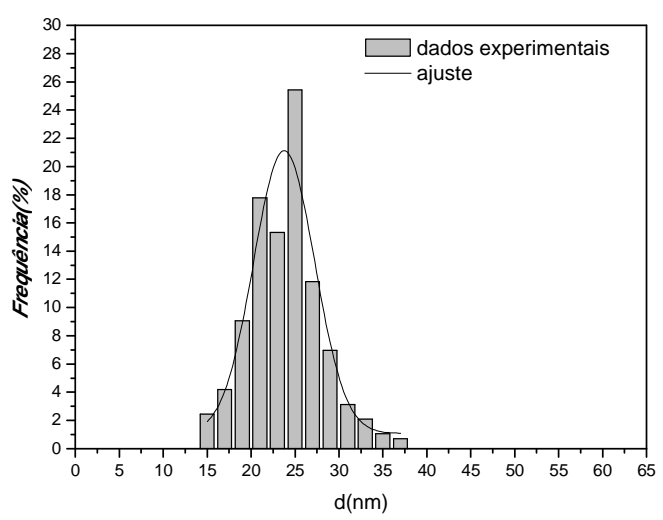

(c)

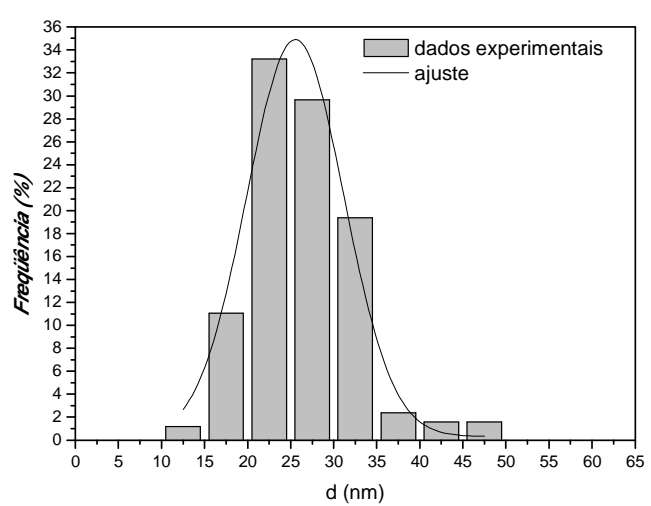

(e)

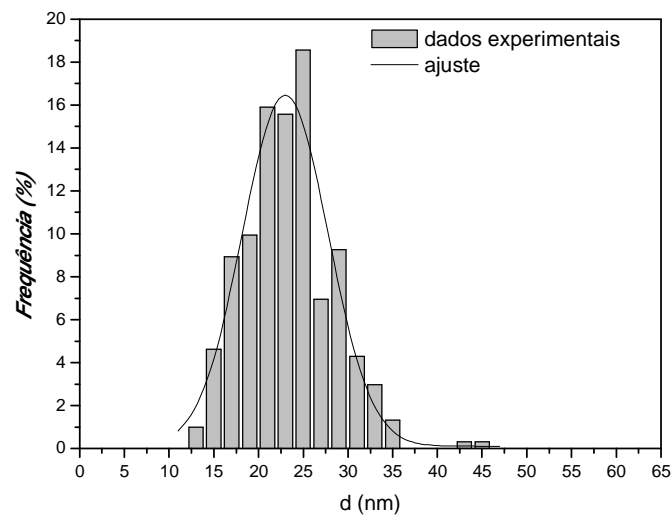

(b)

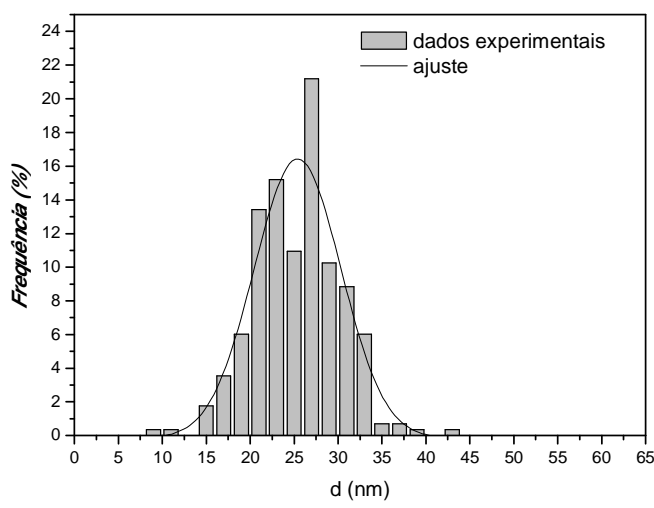

(d)

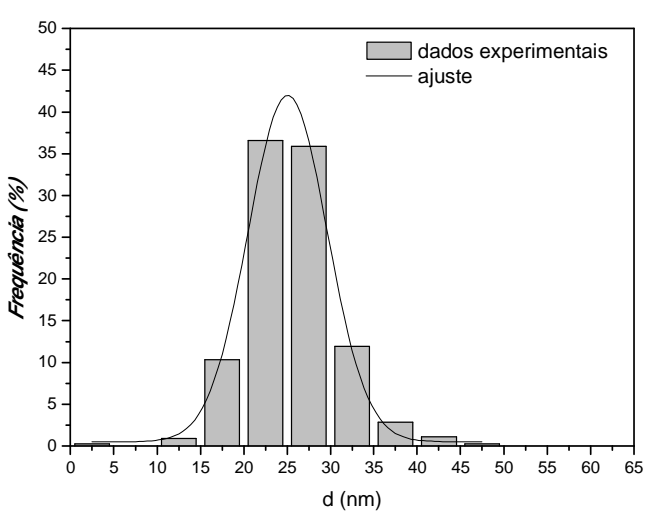

(f)

Continua... 


\section{Continuação...}

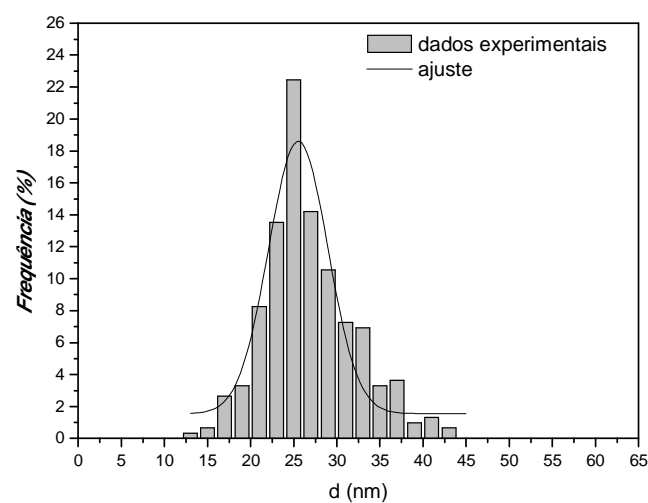

$(\mathrm{g})$

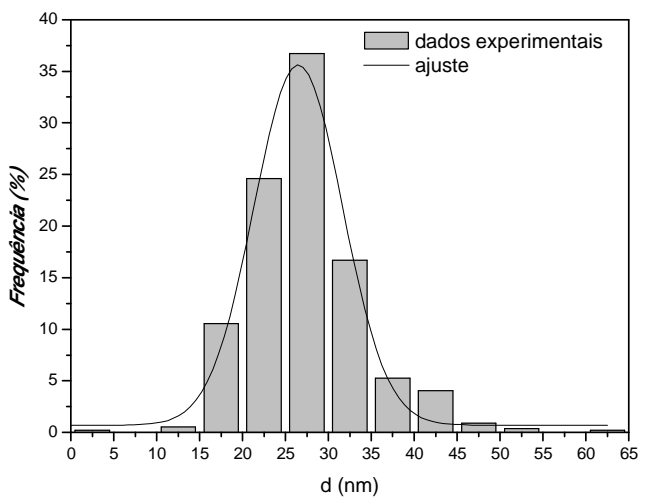

(i)

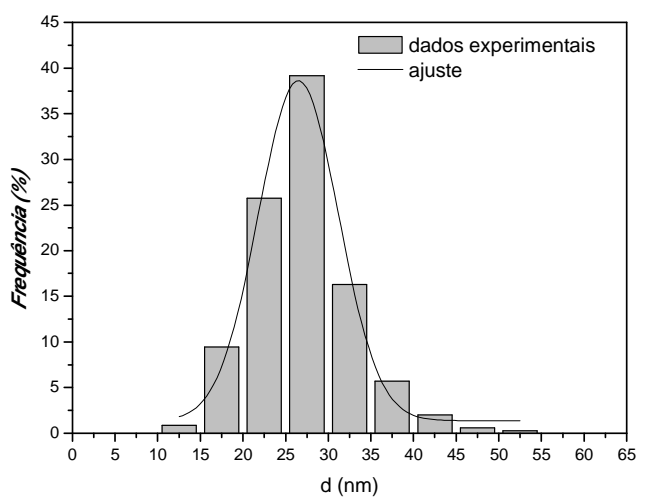

(h)

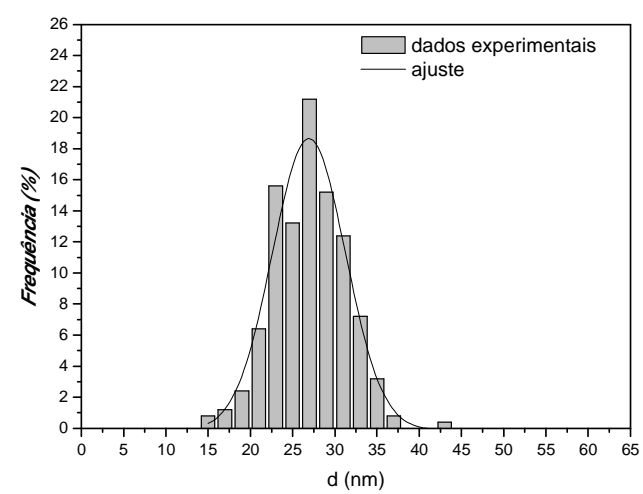

(j)

Figura 38 - Distribuição da largura das nanofitas $\mathrm{V}_{2} \mathrm{O}_{5} \mathrm{nH}_{2} \mathrm{O}$ submetidas a um tratamento hidrotermal a $80^{\circ} \mathrm{C}$ durante: (a) 0; (b) 240; (c) 480; (d) 720; (e) 1440; (f) 2160; (g) 2880; (h) 4320 e (i) 5760 e (j) 7200 minutos.

A Tabela 8 apresenta a largura média das nanofitas em função do tempo de tratamento hidrotermal. 
Tabela 8 - Largura média das nanofitas $(d)$ em função do tempo de tratamento hidrotermal a $80^{\circ} \mathrm{C}$.

\begin{tabular}{cc}
\hline $\begin{array}{c}\text { Tempo } \\
\text { de } \\
\text { tratamento (minutos) }\end{array}$ & d (nm) \\
\hline $\mathbf{0}$ & 22,1 \\
$\mathbf{2 4 0}$ & 22,3 \\
$\mathbf{4 8 0}$ & 23,8 \\
$\mathbf{7 2 0}$ & 24,7 \\
$\mathbf{1 4 4 0}$ & 25,5 \\
$\mathbf{2 1 6 0}$ & 25,1 \\
$\mathbf{2 8 8 0}$ & 25,5 \\
$\mathbf{4 3 2 0}$ & 26,5 \\
$\mathbf{5 7 6 0}$ & 26,6 \\
$\mathbf{7 2 0 0}$ & 26,9 \\
\hline
\end{tabular}

A Figura 39 mostra o comportamento da evolução da largura média em função do tempo de tratamento hidrotermal das amostras tratadas a $80^{\circ} \mathrm{C}$. Analisando os dados apresentados na Figura 39, é possível observar um pequeno aumento na largura das nanofitas à medida que o tempo de tratamento aumenta e uma tendência de estabilização a partir de 4000 minutos.

$\mathrm{O}$ comportamento observado no aumento da largura das nanofitas de $\mathrm{V}_{2} \mathrm{O}_{5} n \mathrm{H}_{2} \mathrm{O}$ é muito similar ao observado em outros materiais com crescimento através do mecanismo OA em condições de tratamento hidrotermal. $(11-13,64,66,67,73-75,101)$

A fim de verificar a cinética de crescimento na lateral das nanofitas através do mecanismo de crescimento por OA, foi utilizado o seu modelo adaptado, denominado de “polymerization OA model". Como mencionado anteriormente, este modelo proposto por Ribeiro e colaboradores foi obtido através de uma adaptação do mecanismo de crescimento via OA. (73) Esse modelo apresenta-se como mais apropriado ao caso estudado, pois diferente da equação clássica que considera o processo de coalescência de partículas esféricas com um termo $r_{i}^{3}$ proveniente do volume desta partícula (75), o modelo adaptado leva em consideração o crescimento através da coalescência de superfícies ativas, fazendo com que este modelo possa ser aplicado em qualquer direção de crescimento do cristal, ou seja, análises independentes podem ser feitas em cada direção na morfologia final da partícula. (73) 


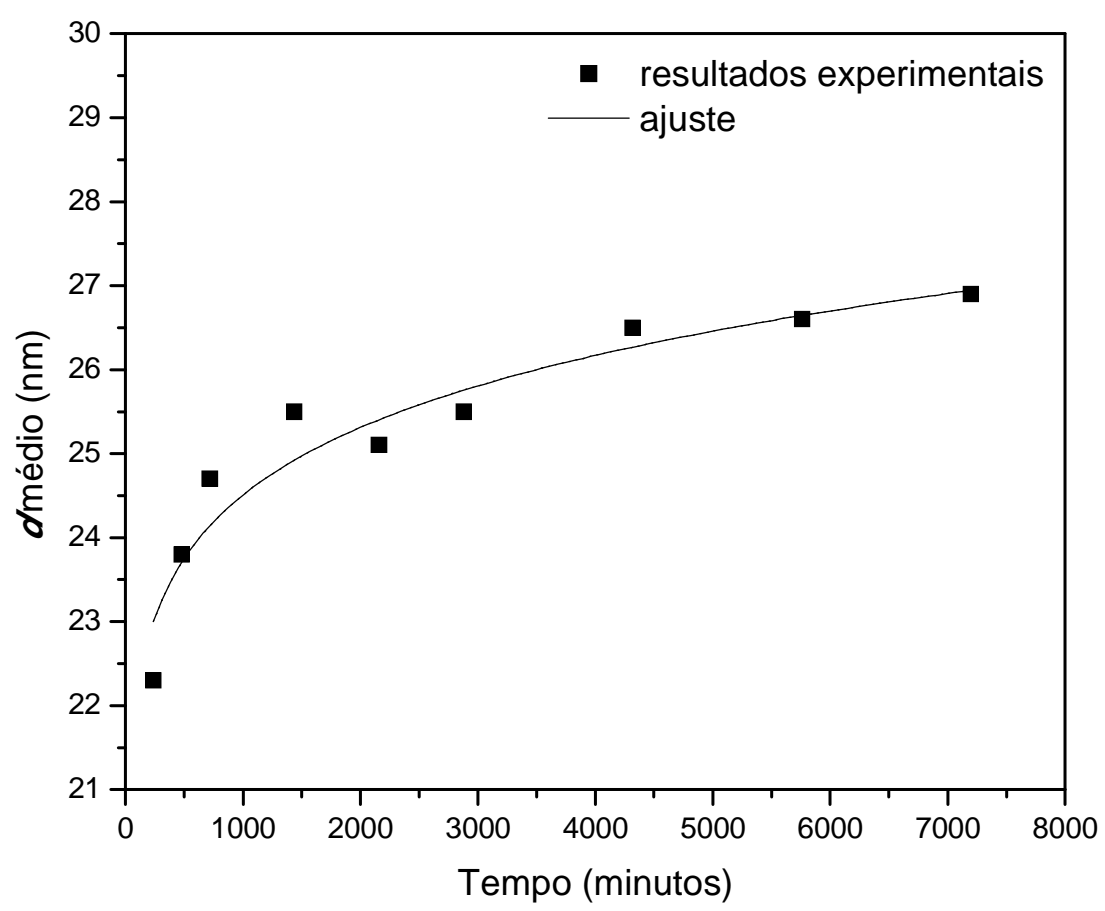

Figura 39 - Evolução temporal do tamanho médio da largura (d) em função do tempo de tratamento hidrotermal a $80^{\circ} \mathrm{C}$.

Para testar a validade deste modelo nos dados obtidos, os dados da Figura 39 foram ajustados através da Equação 2. Como pode ser observado, o ajuste dos dados experimentais (linha sólida na Figura 39) através da equação do modelo adaptado do mecanismo de crescimento por OA, descreve de forma adequada a cinética de crescimento observada para esta amostra. $\mathrm{O}$ parâmetro de ajuste, $\mathrm{R}^{2}$, obtido foi igual a 0,92 enquanto o valor de $\alpha$ foi igual a $0,04 \pm 0,01$.

Como descrito na seção 2.1.2, um estudo similar foi realizado com a amostra tratada a $120^{\circ} \mathrm{C}$ em função dos diferentes tempos de tratamento hidrotermal, A Figura 40 apresenta a distribuição da largura das nanofitas em função do tempo de tratamento das amostras quando tratadas a $120^{\circ} \mathrm{C}$. 


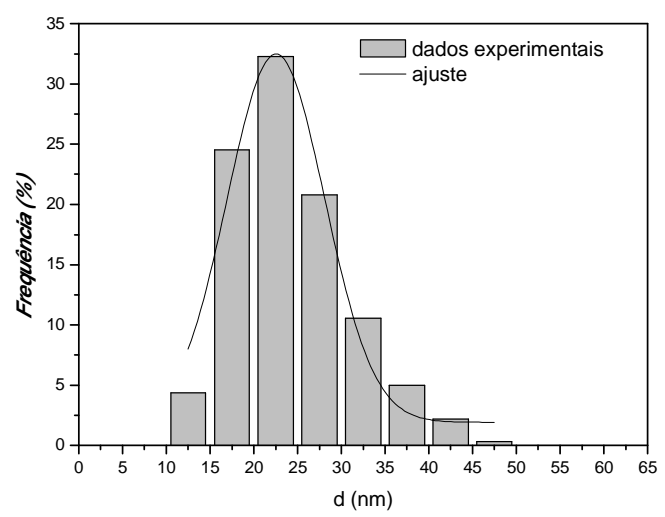

(a)

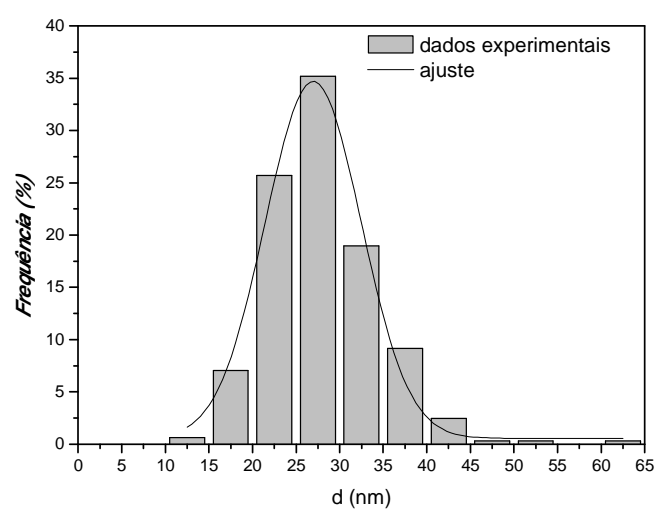

(c)

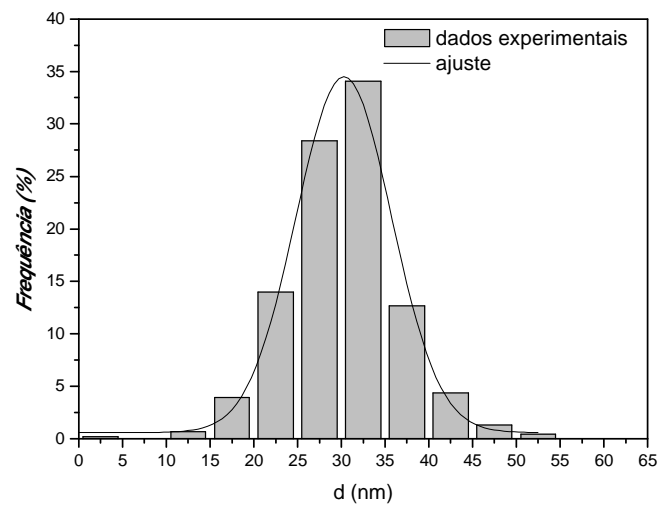

(e)

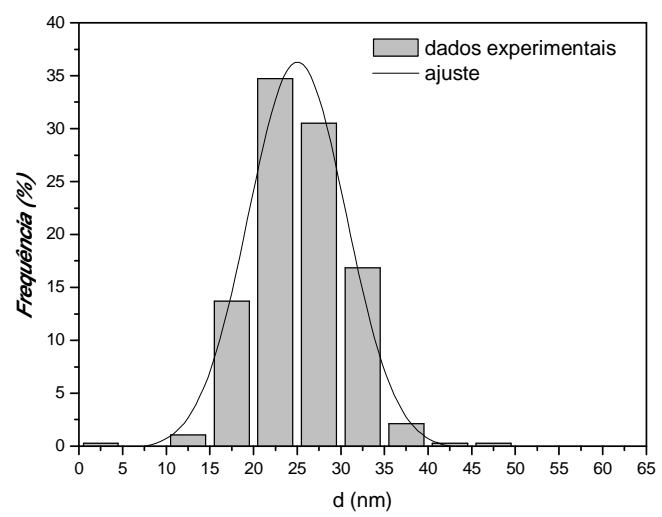

(b)

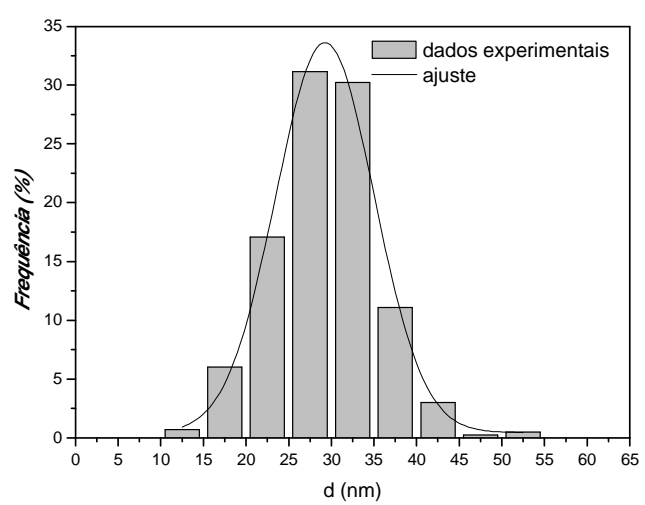

(d)

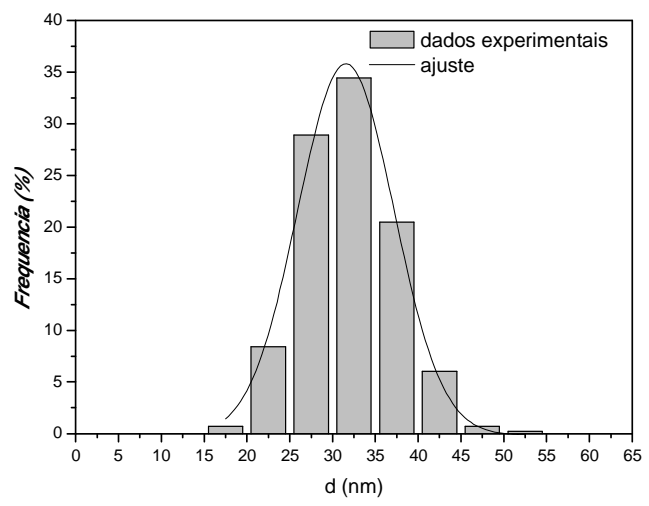

(f)

Continua... 


\section{Continuação...}

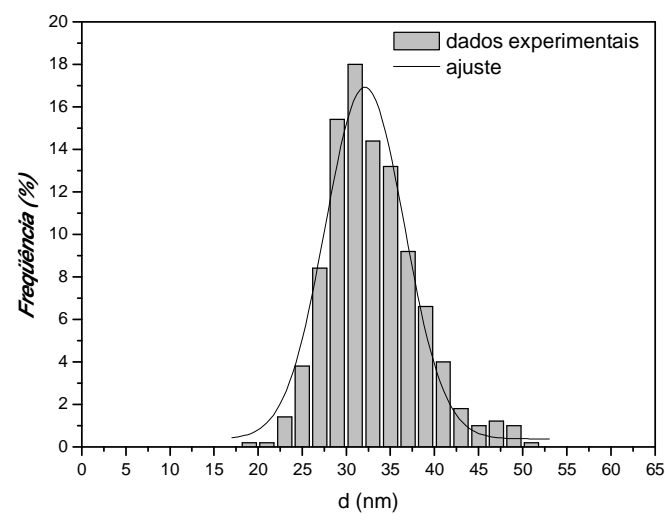

(g)

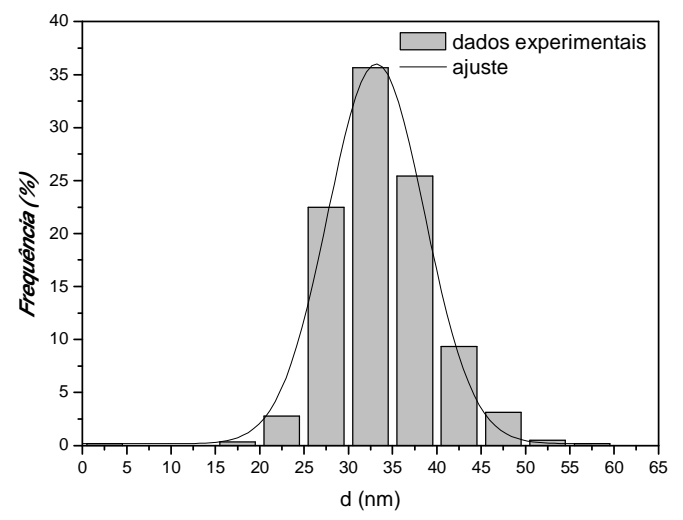

(h)

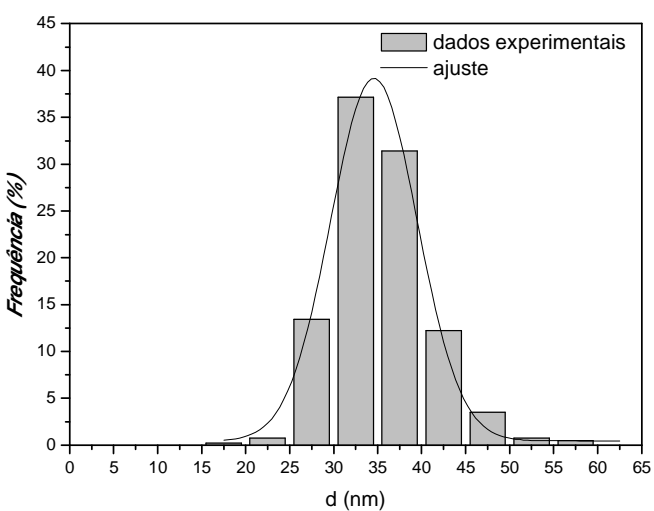

(i)

Figura 40 - Distribuição da largura das nanofitas $\mathrm{V}_{2} \mathrm{O}_{5} \mathrm{nH}_{2} \mathrm{O}$ submetidas a um tratamento hidrotermal a $120^{\circ} \mathrm{C}$ durante: (a) 0; (b) 240; (c) 360; (d) 480; (e) 720; (f) 1440; (g) 2880; (h) 4320 e (i) 7200 minutos.

A Tabela 9 apresenta a largura média das nanofitas $(d)$ em função do tempo de tratamento hidrotermal através do ajuste da distribuição de tamanhos utilizando uma função Gaussiana quando tratado a $120^{\circ} \mathrm{C}$. 
Tabela 9 - Largura média das nanofitas $(d)$ em função do tempo de tratamento hidrotermal a $120^{0} \mathrm{C}$.

\begin{tabular}{cc}
\hline $\begin{array}{c}\text { Tempo } \\
\text { de } \\
\text { tratamento (minutos) }\end{array}$ & d (nm) \\
\hline $\mathbf{0}$ & 22,5 \\
$\mathbf{2 4 0}$ & 25,0 \\
$\mathbf{3 6 0}$ & 27,0 \\
$\mathbf{4 8 0}$ & 29,2 \\
$\mathbf{7 2 0}$ & 30,3 \\
$\mathbf{1 4 4 0}$ & 31,5 \\
$\mathbf{2 8 8 0}$ & 32,1 \\
$\mathbf{4 3 2 0}$ & 33,2 \\
$\mathbf{7 2 0 0}$ & 34,6 \\
\hline
\end{tabular}

A Figura 41 mostra a evolução da largura média $(d)$ em função do tempo de tratamento hidrotermal das amostras tratadas a $120^{\circ} \mathrm{C}$. Comparado com os dados obtidos com a amostra tratada a $80^{\circ} \mathrm{C}$, os dados apresentados na Tabela 9 mostram um aumento mais significativo na largura das nanofitas na amostra tratada $120^{\circ} \mathrm{C}$.

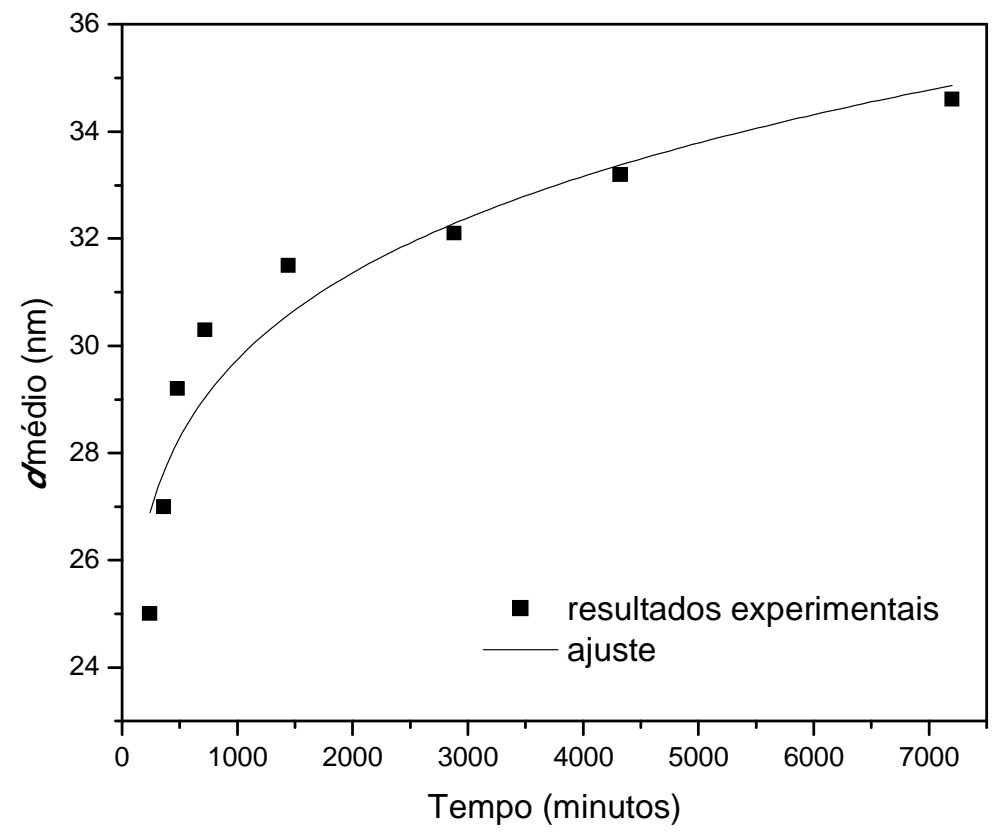

Figura 41 - Evolução temporal do tamanho médio da largura $(d)$ em função do tempo de tratamento hidrotermal a $120^{\circ} \mathrm{C}$. 
Podemos observar que a evolução no tamanho da largura das nanofitas quando tratadas a $120^{\circ} \mathrm{C}$ por diferentes tempos de tratamento, Figura 41, apresenta um comportamento similar ao observado na Figura 40, ou seja, um grande aumento nos períodos iniciais de tratamento e uma variação é menor a partir de 4000 minutos. Como observado no caso da amostra tratada a $80^{\circ} \mathrm{C}$, o ajuste dos dados experimentais através do modelo adaptado de crescimento por OA (linha solida na Figura 40) também descreve de forma adequada a cinética de crescimento observada. $\mathrm{O}$ parâmetro de ajuste, $\mathrm{R}^{2}$, obtido foi igual a 0,90 enquanto o valor de $\alpha$ foi igual a $0,06 \pm 0,01$.

Um baixo valor de $\alpha$, como observado para as duas amostras, é esperado uma vez que, como observado nas imagens de FE-STEM, o comprimento das nanofitas em contato lateral apresenta uma variação muito grande afetando de maneira significativa o processo de coalescência. Ribeiro e colaboradores também obtiveram um baixo valor de $\alpha$ para o caso de um processo com alto grau de dispersão, ou seja, grande variação no comprimento. (73)

Um importante ponto a destacar neste modelo está relacionado observação das partículas primárias, consideradas como partículas que não sofreram nenhum processo de coalescência. Para o caso em estudo, as partículas primárias foram consideradas como sendo as nanofitas obtidas com o tempo de tratamento sendo igual a " 0 ” minutos. No entanto, essa afirmação pode levar a possíveis erros, pois é difícil afirmar que nenhum processo de coalescência tenha ocorrido nestas condições. Além disso, o modelo aplicado considera a hipótese de que uma nanopartícula sofra coalescência apenas duas vezes e através das imagens de FE-STEM, é possível observar que em alguns casos mais duas faces podem sofrer o processo de coalescência. Apesar destas considerações, podemos observar que o crescimento lateral dessas nanofitas pode ser relativamente bem descrito pelo modelo adaptado de crescimento por OA.

O comportamento em função da temperatura de tratamento observado para estas duas amostras está em bom acordo com o trabalho realizado por Lee e colaboradores que mostrou que o aumento na temperatura de tratamento hidrotermal faz com que ocorra um aumento no grau de coalescência das nanoestruturas. (74) Segundo esses autores, o aumento no grau de coalescência pode estar relacionado ao aumento da mobilidade das partículas e conseqüentemente ao aumento da freqüência de colisão entre as mesmas. (74)

Diferentes trabalhos encontrados na literatura mostraram que o processo de coalescência em materiais nanoestruturados leva a formação de defeitos estruturais como deslocamentos e/ou falhas no empilhamento atômico na interface das nanopartículas que sofreram a coalescência. $(66,68,70,71,74)$ Desta forma, a observação destes tipos de 
defeitos nas amostras seria outra forma de confirmar que o processo de coalescência e que o crescimento lateral, que da origem a uma "nova" nanopartícula de maior dimensão lateral, pode realmente ser descrito pelo mecanismo de crescimento de OA.

Com o objetivo de verificar a existência destes defeitos em nossas amostras, a região de interface entre duas nanofitas de $\mathrm{V}_{2} \mathrm{O}_{5} n \mathrm{H}_{2} \mathrm{O}$ foi analisada utilizando a técnica de microscopia eletrônica em alta resolução (HR-TEM). No entanto, ao fazer as medidas de HRTEM nas amostras na forma de nanofitas, observamos que as mesmas eram muito instáveis a presença do feixe de elétrons provavelmente devido a presença de uma grande quantidade de moléculas de água em sua estrutura. Desta forma, para observar a existência destes defeitos na interface entre duas nanopartículas, foram utilizadas amostras nanoestruturadas em um estado mais desidratado que são mais estáveis ao feixe de elétrons.

Assim, para realizar este tipo de estudo, foi utilizada a amostra tratada a $200{ }^{\circ} \mathrm{C}$ por 24 horas (amostra AM06) que leva a formação da fase $\mathrm{V}_{2} \mathrm{O}_{5} 0,5 \mathrm{H}_{2} \mathrm{O}$ na forma de nanobastões e como foi apresentado na Figura 22d, esta amostra também apresenta o processo de crescimento lateral através do processo de coalescência. A Figura 42a mostra uma imagem em alta resolução da região de coalescência de dois nanobastões presentes na amostra AM06. A região identificada como A na Figura 42a corresponde a um dos nanobastões e a região identificada por B corresponde a interface entre dois nanobastões que sofreram um processo de coalescência lateral. Através da análise da imagem de HR-TEM expandido da região A, Figura $42 \mathrm{~b}$, podemos observar um parâmetro de rede de $b$ igual a $0,36 \mathrm{~nm}$ ao longo de seu comprimento e $a$ igual a $0,64 \mathrm{~nm}$ ao longo de sua largura. Como observado na seção anterior, estas distâncias correspondem respectivamente aos planos cristalográficos (010) e (200) da nanoestrutura $\mathrm{V}_{2} \mathrm{O}_{5} n \mathrm{H}_{2} \mathrm{O}$. Analisando a região B de forma mais detalhada, Figura 42c, é possível observar a presença defeitos do tipo deslocamento na região de interface dos bastões, confirmando o processo de coalescência das nanoestruturas e por conseqüência, que o mecanismo de crescimento por OA é efetivo ao longo do plano [100], isto é, na direção da largura da nanoestrutura.

Assim, é possível observar que o mecanismo de OA está presente de forma efetiva no processo de crescimento lateral das nanoestruturas 1-D de $\mathrm{V}_{2} \mathrm{O}_{5} n \mathrm{H}_{2} \mathrm{O}$ obtidas nas condições hidrotermais utilizadas neste trabalho. Entretanto, a possível presença do mecanismo de crescimento por OR no crescimento lateral não pode ser totalmente desconsiderada. 


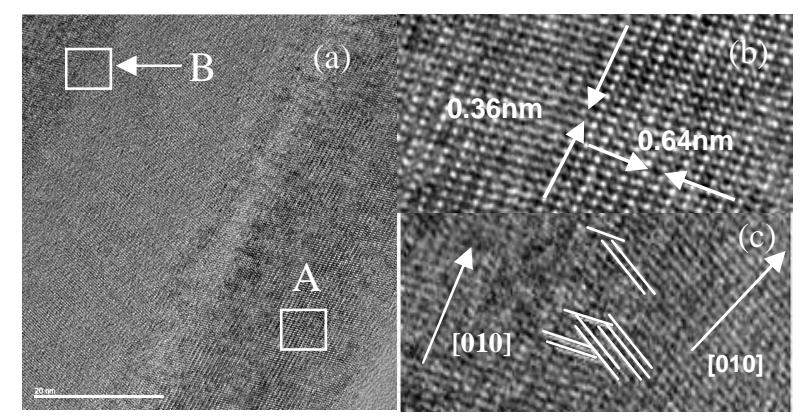

Figura 42 - (a) Imagens HR-TEM de dois nanobastões colados lateralmente e uma imagem de HR-TEM expandida da região A (b) e da região $\mathrm{B}$ (c).

Em resumo, através dos resultados até aqui apresentados, é possível afirmar que em um primeiro estágio ocorre o crescimento preferencial na direção [010] ao longo do comprimento das nanoestruturas seguido por um segundo estágio, um crescimento ao longo da direção [100] (largura dessa nanoestrutura) que foi associado ao mecanismo denominado como OA.

\subsection{Estudo da evolução morfológica das nanoestruturas de $\mathrm{V}_{2} \mathrm{O}_{5} n \mathrm{H}_{2} \mathrm{O}$}

Com o objetivo de melhor compreender a evolução morfológica observada em função dos parâmetros de síntese, será apresentado a seguir um estudo mais detalhado dos resultados obtidos.

A Tabela 10 apresenta um resumo das condições de síntese e as principais características apresentadas pelas amostras obtidas neste trabalho. 
Tabela 10 - Condições experimentais de síntese e características das amostras obtidas neste trabalho.

\begin{tabular}{ccccccc}
\hline Amostra* & $\begin{array}{c}\text { Temperatura } \\
\text { ('C) }\end{array}$ & $\begin{array}{c}\text { Tempo } \\
\text { hs) }\end{array}$ & $\begin{array}{c}\text { Pressão } \\
\left(\mathbf{K g f} / \mathbf{c m}^{\mathbf{2}}\right)\end{array}$ & $\begin{array}{c}\text { Estrutura } \\
\text { cristalina }\end{array}$ & $\begin{array}{c}\text { Quantidade } \\
\text { de água } \\
\text { intercalada } \\
\text { (n) }\end{array}$ & Morfologia \\
\hline AM01 & 60 & 6 & 3 & Monoclínica & 1,8 & nanofitas \\
AM02 & 120 & 24 & 7 & Monoclínica & 2,1 & nanofitas \\
AM03 & 160 & 24 & 11 & Monoclínica & 2,0 & nanofitas \\
AM04 & 180 & 6 & 13 & Monoclínica (M) & - & nanofitas (M) \\
AM05 & 180 & 24 & 13 & Ortorrônofica nanos (m) & nanofios \\
AM06 & 200 & 24 & 17 & Ortorrômbica & 0,5 & nanobastões \\
\hline
\end{tabular}

M= majoritário, $m=$ minoritário *.

A partir dos resultados apresentados anteriormente, observou-se que a mudança na estrutura a longa distância teve início quando a quantidade de água intercalada passou a diminuir ocorrendo simultaneamente uma diminuição da distância interplanar $(d)$. Ao passar de $n \cong 2$ para $n \cong 1,0$, a fase predominante passou a ser ortorrômbica observando assim que existe certa correlação entre a quantidade de água intercalada e a fase cristalina.

A mudança de morfologia das amostras teve início quando teve inicio a mudança da estrutura cristalina indicando que a mudança de morfologia estaria de certa forma relacionada à mudança de estrutura a longa distância da amostra. A principal diferença entre as duas fases cristalinas, monoclínica e ortorrômbica, está na quantidade de moléculas de água intercalada em sua estrutura. (35)

O início da mudança de morfologia ocorreu a partir do tratamento a $180^{\circ} \mathrm{C}$ durante 6 horas com uma mudança na morfologia passando de nanofitas para nanofios. Após 24 horas, observou-se somente a presença de nanofios. Além disso, os resultados apresentados anteriormente mostraram também que o aumento da temperatura de tratamento hidrotermal leva a um aumento no grau de coalescência das nanoestruturas.

Com o objetivo de melhor avaliar a evolução da largura das nanoestruturas em função do aumento da temperatura de tratamento, foi realizada a análise da largura das amostras AM02, AM03, AM05 e AM06 obtidas após 24 horas de tratamento hidrotermal.

A Figura 43 apresenta a distribuição da largura destas amostras. 


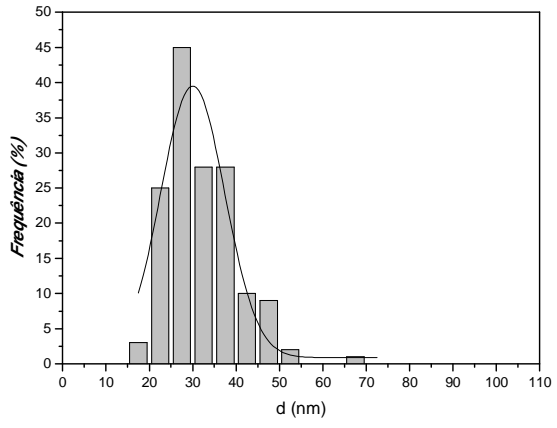

(a)

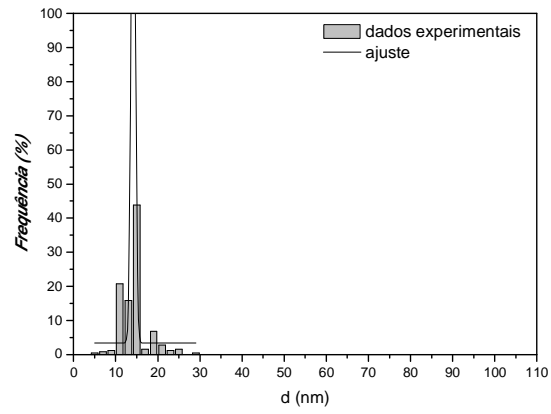

(c)

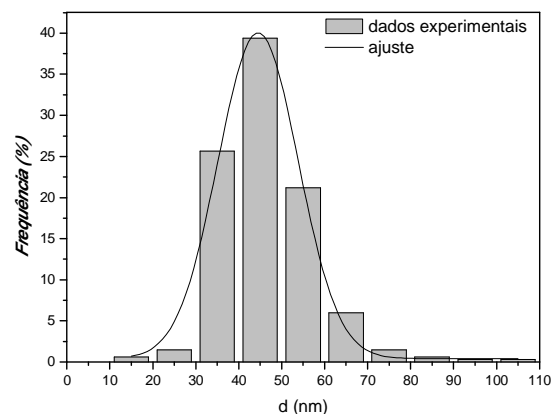

(b)

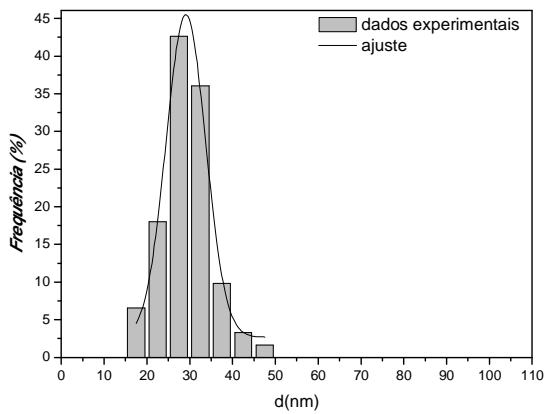

(d)

Figura 43 - Distribuição da largura das amostras submetidas a um tratamento hidrotermal em diferentes temperaturas durante 24 horas: (a) AM02; (b) AM03; (c) AM05; (d) AM06.

A Tabela 11 apresenta a largura média das nanoestruturas obtida através do ajuste da distribuição da largura dos dados apresentados na Figura 43 utilizando uma função Gaussiana.

Tabela 11 - Largura média $(d)$ das nanoestruturas para as amostras obtidas em diferentes temperaturas durante 24 horas:

\begin{tabular}{cc}
\hline Amostras & d (nm) \\
\hline AM02 & 30 \\
AM03 & 44 \\
AM05 & 14 \\
AM06 & 29 \\
\hline
\end{tabular}


Analisando os dados apresentados na Tabela 11 é possível observar inicialmente que, nas amostras possuindo a mesma fase cristalina e mesma morfologia, ou seja, as amostras AM02 e AM03, houve um aumento na largura média das nanofitas em função da temperatura de tratamento. Como discutido anteriormente, este aumento da largura foi atribuído a um aumento do processo de coalescência lateral das amostras através do mecanismo de OA. Um aumento da temperatura para $180^{\circ} \mathrm{C}$ (amostra AM05), quando somente nanoestruturas na forma de nanofios foram observadas, levou a uma diminuição da largura média das nanoestruturas e finalmente, aumento da temperatura de síntese para $200^{\circ} \mathrm{C}$ (AM06) levou a uma transformação dos nanofios para nanobastões e a um aumento na largura média das nanoestruturas.

Uma possível explicação para a mudança de morfologia de nanofitas para nanofios seria que estivesse ocorrendo um processo de quebra das nanofitas como proposto por Wei e colaboradores em seu trabalho. (58) De acordo com esses autores, de forma a diminuir a grande tensão devido ao processo de desidratação, essas nanofolhas quebrariam, dando origem então aos nanofios. (58)

Processo semelhante de ruptura foi observado por Li e colaboradores. (15) Ainda para este processo de transformação, Li e colaboradores propuseram que durante o processo de desidratação das nanofitas pode ocorrer um processo de dobramento dessas nanofitas. (15)

No entanto, a diferença de contraste entre as nanofitas e os nanofios observada nas imagens de microscopia eletrônica apresentadas anteriormente não indica que os nanofios sejam apenas nanofitas de menor tamanho lateral. Essa diferença de contraste observada indica que as amostras obtidas na forma ortorrômbica são nanoestruturas mais espessas. Quanto ao aumento na largura quando da passagem dos nanofios (AM05) para os nanobastões (AM06), este poderia ser explicado pelo mecanismo de crescimento por OA.

Outro ponto importante a se ressaltar através da análise das imagens de microscopia eletrônica, é de que existe uma diferença significativa entre os comprimentos das nanoestruturas das amostras AM05 e AM06. Essa grande diferença, muito provavelmente, deve estar ligada ao aumento de temperatura devido ao aumento da agitação do sistema e também da pressão exercida sobre ele causando uma grande tensão que estaria levando a ruptura desses nanofios.

Com o objetivo de obter maiores detalhes em relação à transformação das nanofitas em nanofios e dos nanofios em nanobastões, foram obtidas imagens da seção transversal destas amostras. 
Através da Figura 44a e b, que apresentam as imagens FE-MEV da seção transversal da amostra na forma de nanofios (AM05), é possível observar claramente que os nanofios apresentam uma seção transversal tendendo para uma forma retangular e não circular, ou seja, não parece estar ocorrendo um processo de dobramento das nanofitas.

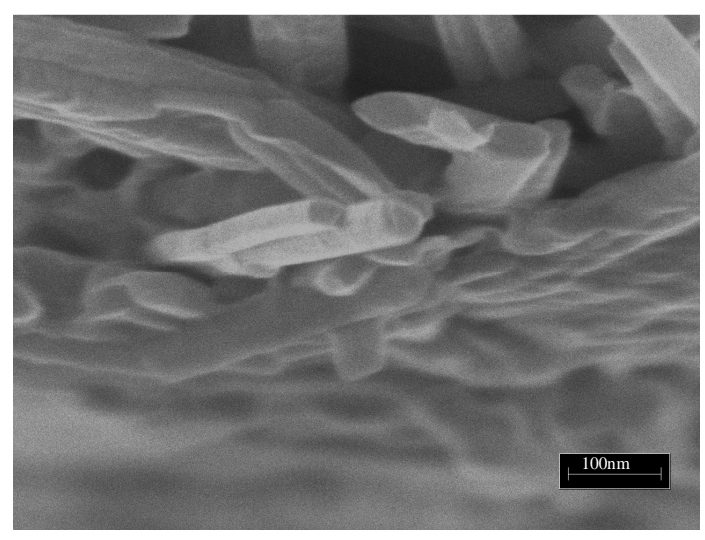

(a)

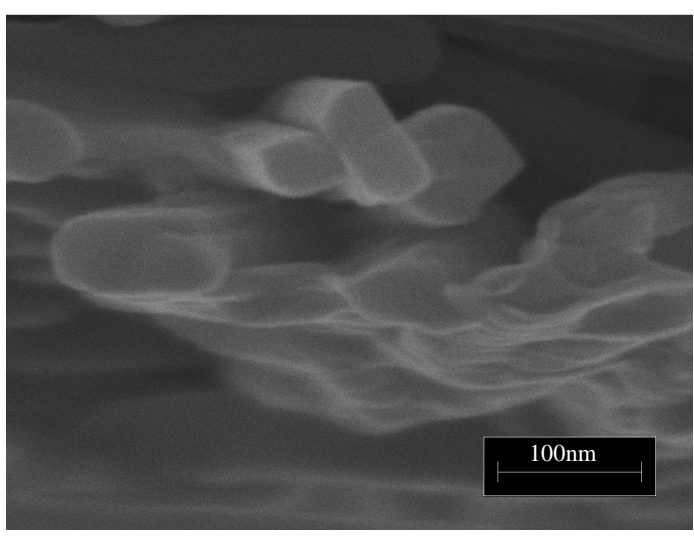

(b)

Figura 44 - (a) e (b) Imagens de FE-MEV da seção transversal da amostra AM05.

Em relação à amostra na forma de nanobastões (AM06), de forma similar a observada para a amostra AM05, é possível observar através da Figura 45a e b que os nanobastões também apresentam uma seção transversal retangular.

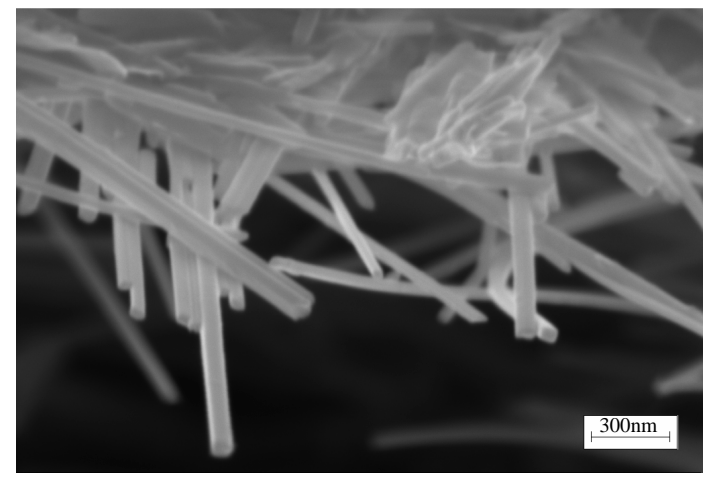

(a)

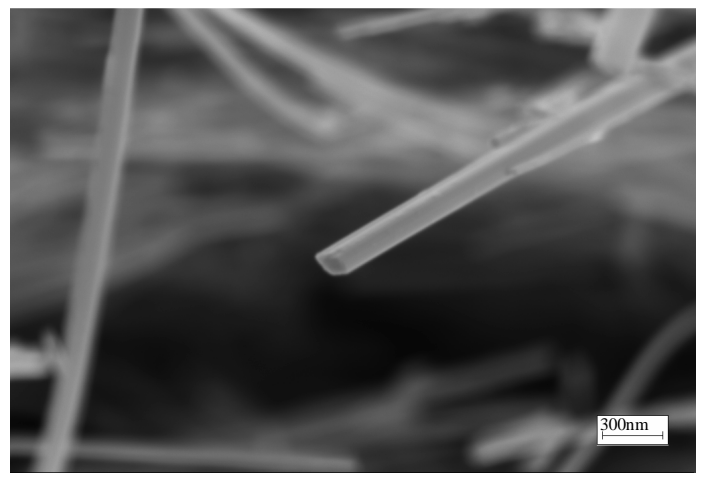

(b)

Figura 45 - (a) e (b) Imagens de FE-MEV da seção transversal da amostra AM06. 
A Figura 46a apresenta imagens de MET da seção transversal dos nanobastões (AM06). Assim como foi observado através das imagens de FE-MEV, as imagens de MET também mostram que esses nanobastões possuem uma seção transversal retangular. Através destas imagens é possível observar que alguns dos nanobastões apresentam uma trinca dividindo-o transversalmente. Este efeito pode estar relacionado ao procedimento que a amostra foi submetida de modo a obter as condições apropriadas para a observação da seção transversal por MET, procedimento este, descrito na seção 2.3.3.

Com o objetivo de confirmar a composição do material observado na Figura 46a, foi obtido espectro EDS dessa mesma região. O espectro de EDS, Figura 46b, confirma a composição da nanoestrutura analisada, apresentando as principais linhas de emissão de raios $\mathrm{X}$ situados em torno 0,5, 4,9 e 5,4keV. Essa linhas de emissão são referentes ao elemento V. (103) Podemos observar também a presença de um pico localizado em torno de $1,8 \mathrm{KeV}$ referente ao elemento Si.(103) A presença de Si é esperada uma vez que foi utilizado um substrato a base de Si cristalino. O pico localizado em torno de $0,5 \mathrm{keV}$ também pode ser atribuído a transição do elemento $\mathrm{O}$, enquanto que o primeiro pico, localizado em torno de $0,25 \mathrm{keV}$ e $8 \mathrm{keV}$, atribuído presença de carbono $\mathrm{C}$ e $\mathrm{Cu}$ (103), respectivamente, são proveniente dos materiais utilizado na preparação da amostra.

A Figura 46c apresenta imagem de HR-TEM da seção transversal da amostra AM06 confirmando a forma retangular. Diante disso, fica claro que as evoluções morfológicas das nanoestruturas obtidas não podem ser explicadas através de um modelo de dobramento. A forma retangular da seção transversal indica um crescimento na direção [001].

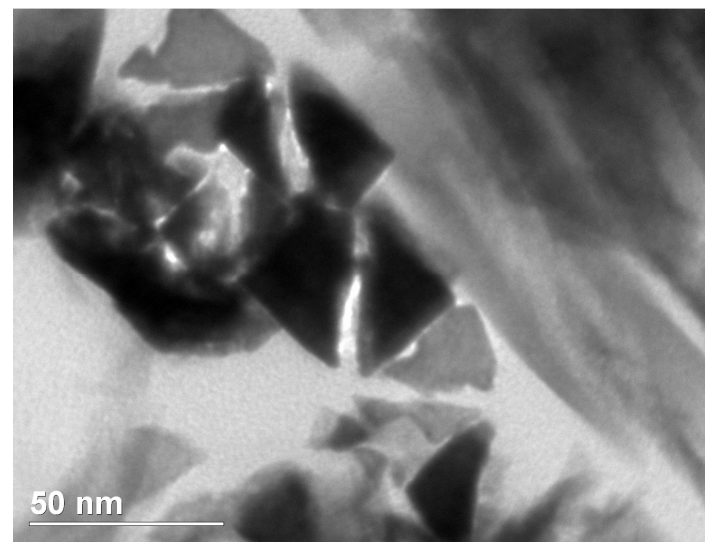

(a)

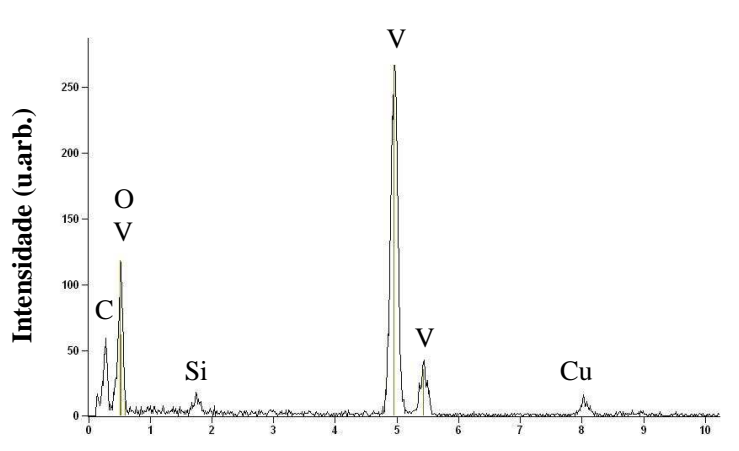

(b)

Continua... 
Continuação...

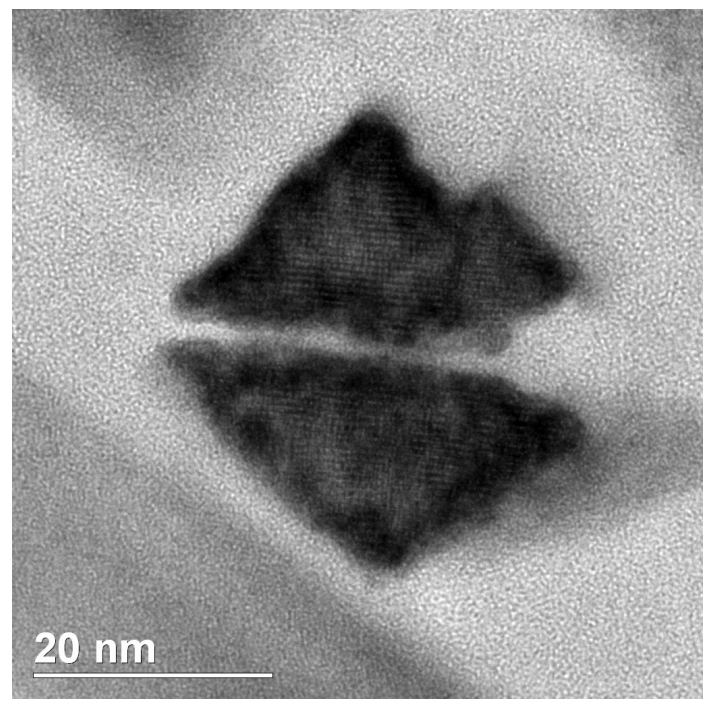

(c)

Figura 46 - (a) Imagens de MET da seção transversal da amostra AM06; (b) análise composicional por EDS da região observada em (a); (c) Imagens de HR-TEM da seção transversal da amostra AM06.

Como foi comentado anteriormente, o início do processo de mudança de morfologia de nanofitas para nanofios teve inicio quando ocorreu o inicio de transformação estrutural da fase cristalina ortorrômbica para a fase monoclínica. É bem conhecido que a energia de uma determinada superfície pode ser diferente em função da estrutura cristalina podendo assim fazer com que a velocidade de crescimento em uma determinada direção seja maior ou menor em relação a outras. $(64,65,70)$

De acordo com trabalho teórico realizado por Sayle e colaboradores, o plano (001) possui a menor energia superficial quando comparado aos outros planos na estrutura. (102) Embora o a energia superficial referente ao plano (001) possua valores menores comparado aos outros planos cristalográficos, o crescimento na direção cristalográfica (001) levaria a uma diminuição da energia superficial. (64) podendo ocorrer por um processo de recristalização ou por um processo de empilhamento planar de nanofitas na direção cristalográfica [001]. $(43,78)$

Baseado nos resultados até aqui apresentados, é possível concluir que somente o modelo de ruptura das fitas, observado por Li e colaboradores (15) e por Wei e colaboradores (58) não é suficiente para descrever a evolução de morfologia observada nas amostras estudadas neste trabalho. 


\subsubsection{Estudo da morfologia das nanoestruturas em solução através da técnica de SAXS}

Com objetivo de caracterizar a morfologia das nanoestruturas em solução e comparar com morfologia das nanoestruturas observadas após o processo de secagem, medidas de espalhamento de raios X a baixo ângulo (SAXS) das soluções obtidas após o tratamento hidrotermal foram realizadas em amostras obtidas em diferentes temperaturas de síntese.

Através da Figura 47 que apresenta as curvas de SAXS das amostras AM02, AM03, AM05 e AM06 é possível observar claramente um espalhamento diferente para as três amostras caracterizadas por microscopia eletrônica como apresentando diferentes morfologias. As curvas de espalhamento das amostras AM02 e AM03 são similares a alguns trabalhos encontrados na literatura no estudo de nanofitas de $\mathrm{V}_{2} \mathrm{O}_{5} n \mathrm{H}_{2} \mathrm{O}$. (21, 37) É possível observar que, em bom acordo com os dados de microscopia eletrônica, a amostra AM03 possui uma maior intensidade na curva de espalhamento que a amostra AM02 indicando possuir maiores dimensões.

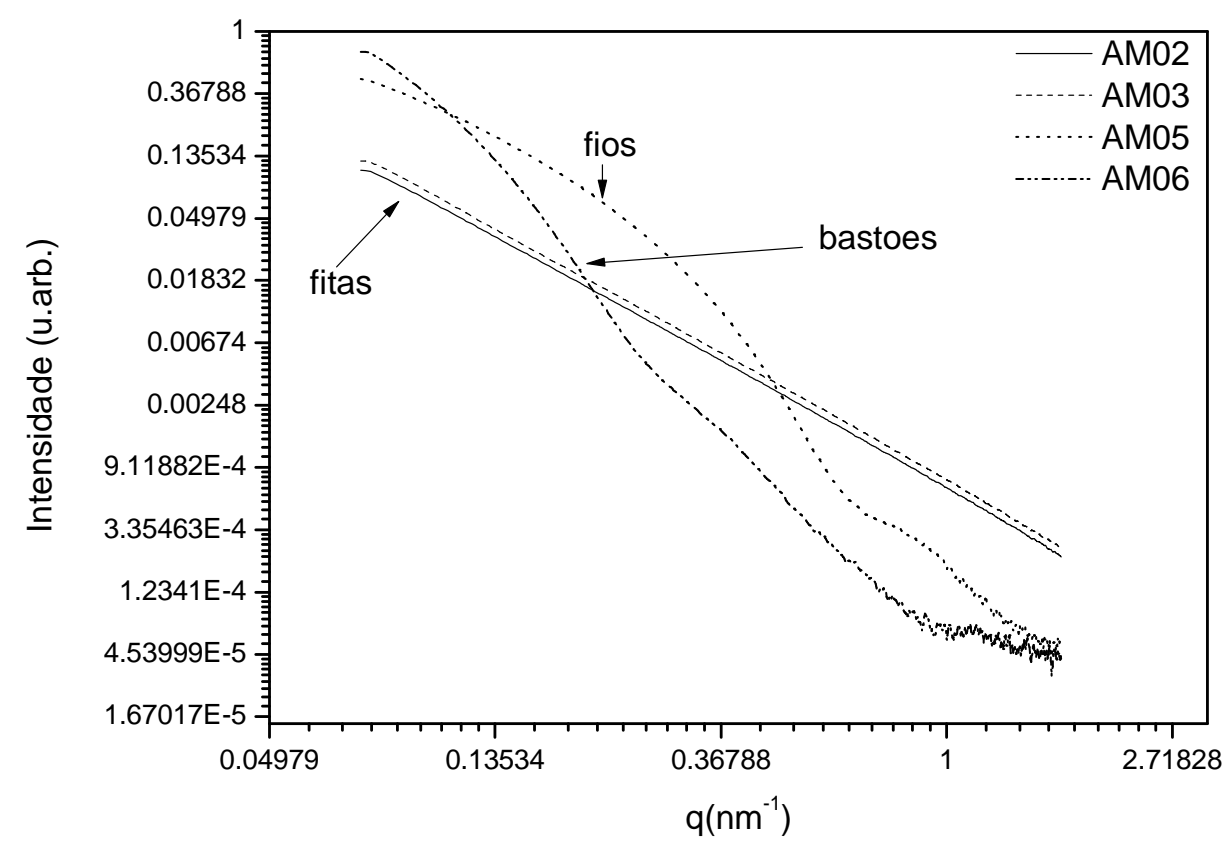

Figura 47 - Curvas de espalhamento de SAXS para as amostras AM02, AM03, AM05 e AM06. 
Para as amostras AM05 e AM06, embora seja possível observar através de imagens de microscopia eletrônica que elas possuem uma seção transversal retangular, diante da grande polidispersidade apresentada por essas nanoestruturas, o modelo que apresentou melhor ajuste dos dados experimentais foi o modelo de um cilindro, como ilustra a Figura 48.

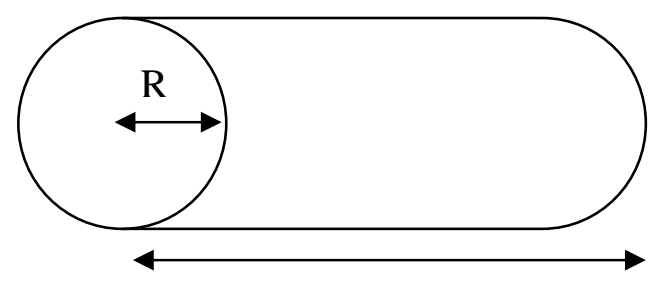

$\mathrm{L}$

Figura 48 - Modelo utilizado para o ajuste teórico dos dados para a AM05.

A Figura 49 apresenta a curva de SAXS da amostra AM05 com o ajuste teórico através do modelo proposto. $\mathrm{O} \chi^{2}$ encontrado para o ajuste dos dados experimentais pelo modelo proposto foi de $0,65 \cdot 10^{2}$. Em baixos ângulos é possível observar uma diferença entre o modelo proposto e os dados experimentais que pode estar relacionada a uma orientação preferencial das partículas no sistema. Os valores obtidos para os parâmetros R e L para este ajuste foram respectivamente $(5,5 \pm 0,5) \mathrm{nm}$ e $(210 \pm 10) \mathrm{nm}$. Embora ocorra uma diferença no ajuste para baixo ângulos é possível observar que o valor referente ao diâmetro dos nanofios está muito próximo ao valor obtido através da imagem de FE-STEM, no entanto, o valor de comprimento obtido é muito menor do que o observado na mesma imagem. 


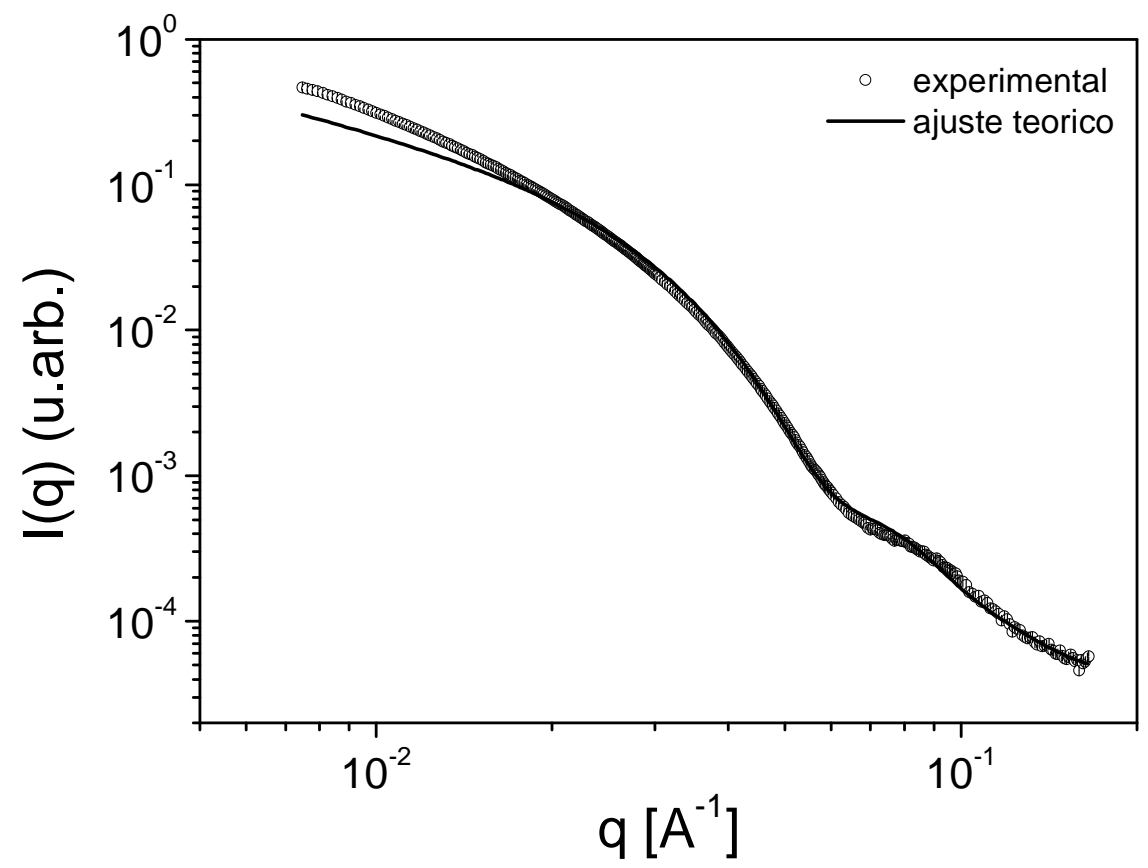

Figura 49 - Curva experimental do espalhamento de SAXS e ajuste teórico para a amostra AM05.

No caso da amostra AM06 (Figura 50), onde foi observado através das medidas de FE-STEM nanoestruturas na forma de bastões, é possível notar que o modelo utilizado para simular o espectro de SAXS da amostra AM05 também ajusta de forma satisfatória os resultados experimentais da amostra AM06 obtendo valores de $R=(12,3 \pm 0,5) \mathrm{nm}$ e $\mathrm{L}=(187 \pm 1) \mathrm{nm}$. O $\chi^{2}$ para o ajuste desta amostra foi de $0,39.10^{2}$. O valor obtido para o diâmetro e para o comprimento dos nanobastões também está em bom acordo ao observado através das imagens de FE-STEM. 


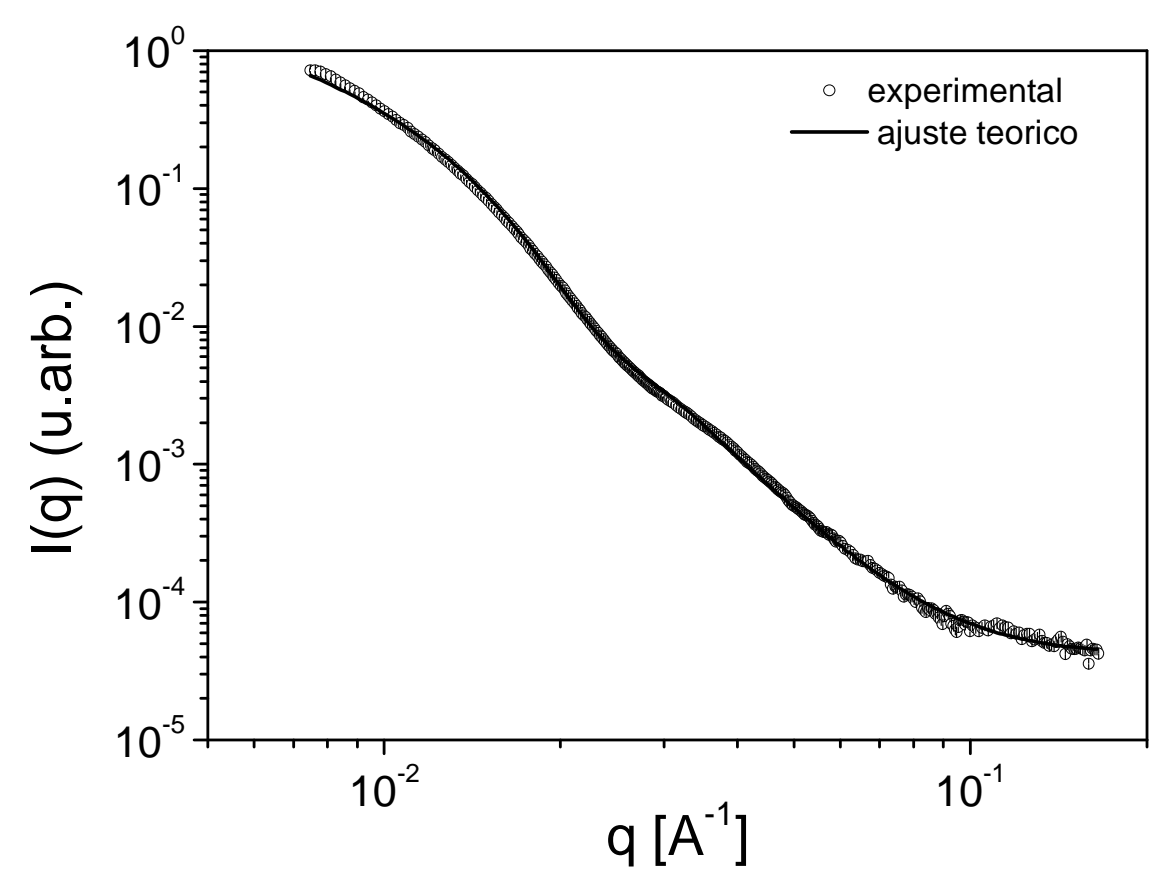

Figura 50 - Curva experimental do espalhamento de SAXS e ajuste teórico para a amostra AM06.

Desta forma, através do ajuste inicial dos dados experimentais, utilizando um fator de forma relativamente simples, como no caso de cilindros, foi possível observar através das medidas de SAXS que as nanoestruturas após o processo de secagem não sofrem nenhuma mudança significativa com relação as dimensões observadas por microscopia eletrônica, havendo uma diferença apenas com relação ao comprimento, que se mostrou difícil de ser estimado pela técnica de microscopia eletrônica. Para a amostra AM05, foi possível observar que um melhor ajuste necessita ser realizado, no entanto, fica claro que essa amostra possui uma morfologia semelhante à amostra AM06 com diferenças apenas em suas dimensões.

\subsubsection{Modelo proposto para a mudança de morfologia}

Baseado nos resultados obtidos durante a realização deste trabalho e através de alguns trabalhos presentes na literatura, a Figura 51 apresenta um esquema de uma proposta do mecanismo de evolução da morfologia das nanoestruturas obtidas nas condições de síntese descritas anteriormente. 


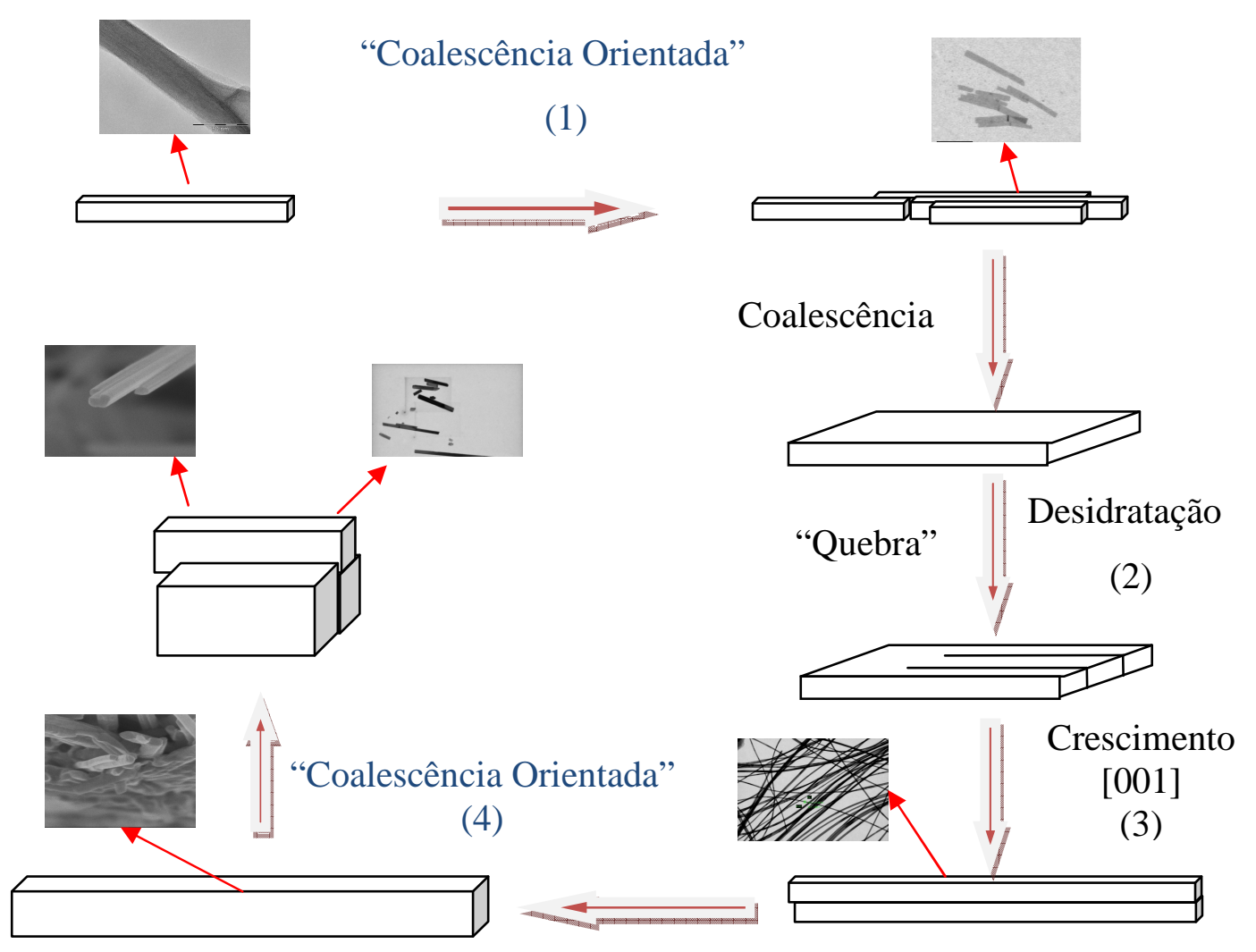

Figura 51 - Esquema do mecanismo de evolução da morfologia em condições hidrotermais a partir das nanofitas de $\mathrm{V}_{2} \mathrm{O}_{5} \mathrm{nH}_{2} \mathrm{O}$ até a formação de nanobastões.

Após a formação das nanofitas em condições hidrotermais, como descrito pelo modelo de Livage e colaboradores (26), ocorre o crescimento lateral dessas nanofitas através do processo de coalescência descrito pelo mecanismo de OA (1). Com o aumento da temperatura de tratamento começa a ocorrer um processo de desidratação (2), de maneira similar ao observado por Zhou e colaboradores. (56) Devido ao processo de desidratação, surge uma grande tensão na estrutura causando a quebra dessas nanofitas, de forma similar ao observado por Li e colaboradores. (15) Após esta ruptura, com o aumento da temperatura $\left(180^{\circ} \mathrm{C}\right)$ ocorre um crescimento na direção [001], dando origens a nanofios com seção transversal retangular (3). A forma que ocorre o crescimento na direção [001] não esta muito clara podendo ser através de empilhamento planar das nanofitas, como observado por Lou e colaboradores (78), ou como observado por Glushenkov e colaboradores, através de um processo de recristalização. (43) A uma temperatura maior $\left(200^{\circ} \mathrm{C}\right)$, com a diminuição da viscosidade, além do continuo processo de desidratação causando um aumento da tensão estrutural existente, ocorre a formação de nanobastões. O menor comprimento e flexibilidade podem 
estar relacionados ao seu menor estado de hidratação. Esses nanobastões apresentaram também uma maior dimensão lateral quando comparado aos nanofios que, como no caso das nanofitas, estaria ocorrendo por um processo de coalescência descrito pelo mecanismo de crescimento por OA (4).

\subsection{Estudo da síntese em presença de $\mathrm{NaOH}$}

Nesta seção serão apresentados os resultados obtidos da síntese e caracterização de compostos vanadatos utilizando a mesma rota adotada anteriormente.

Após a adição de $\mathrm{NaOH}$ a solução e utilizando o tratamento hidrotermal a uma temperatura de $120^{\circ} \mathrm{C}$ durante um período de 24 horas, foi possível observar a formação de uma quantidade de material muito pequena de material, ou seja, esta condição não apresentouse como eficiente para a obtenção de nanoestruturas de $\mathrm{Na}_{2} \mathrm{~V}_{6} \mathrm{O}_{16} 3,0 \mathrm{H}_{2} \mathrm{O}$. Diante disso, serão apresentados apenas os resultados referentes as amostras obtidas através do tratamento hidrotermal a partir de $140^{\circ} \mathrm{C}$ durante 24 horas. Quanto ao efeito de temperatura na síntese das nanoestruturas, foi adotado a rota para obtenção da amostra NaV02 por tratar-se de uma rota de apenas uma etapa. As amostras obtidas no intervalo de 140 e $200^{\circ} \mathrm{C}$ não apresentaram mudanças estruturais significativas, assim, serão apresentados somente os resultados obtidos com a amostra tratada a $200^{\circ} \mathrm{C}$ durante um período de 24 horas de tratamento hidrotermal, denominada NaV03.

A Figura 52 apresenta o padrão de DRX das amostras NaV01, NaV02 e NaV03, além das nanofitas de composição $\mathrm{V}_{2} \mathrm{O}_{5} n \mathrm{H}_{2} \mathrm{O}$, utilizada na preparação da amostra NaV01. 


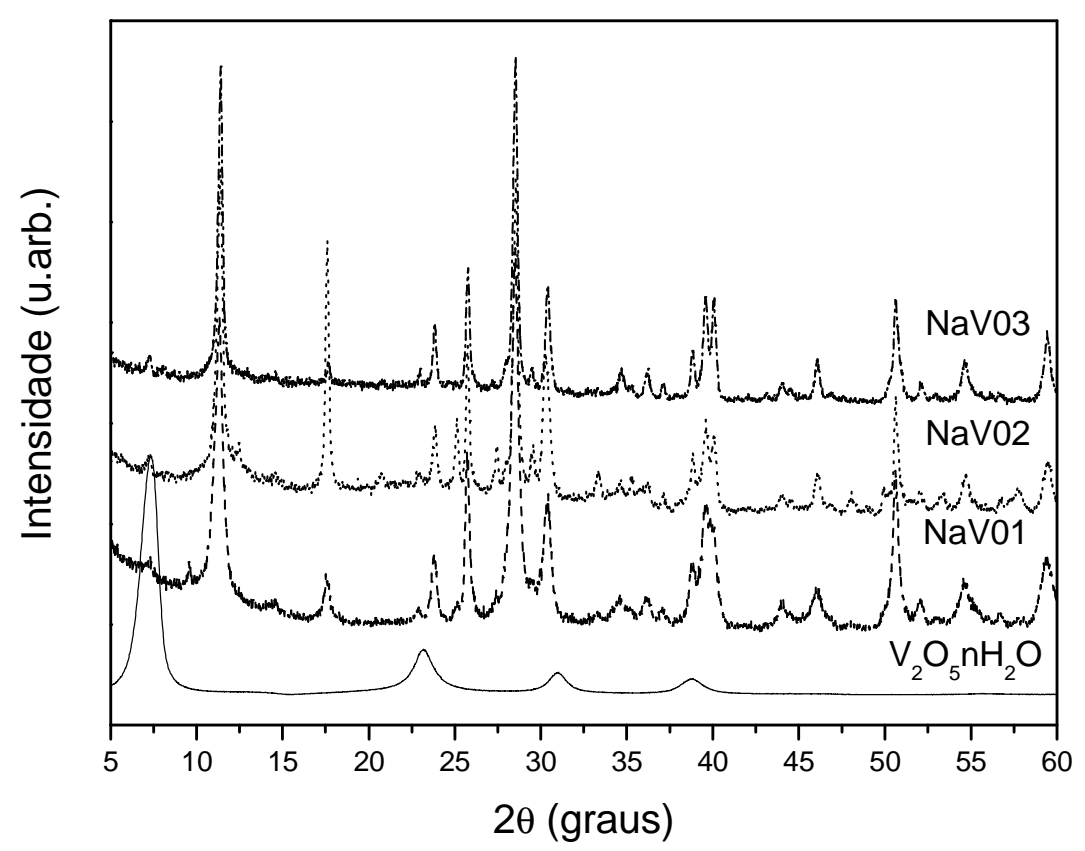

Figura 52 - Padrão de difração de raios X das nanofitas de $\mathrm{V}_{2} \mathrm{O}_{5} n \mathrm{H}_{2} \mathrm{O}$ e das amostras NaV01, NaV02 e NaV03 obtidas através do tratamento hidrotermal .

Como observado anteriormente, o padrão de DRX da amostra utilizada como precursora na síntese da amostra NaV01 apresenta um série de picos de difração $00 l$, indicando a formação da fase $\mathrm{V}_{2} \mathrm{O}_{5} n \mathrm{H}_{2} \mathrm{O}$ monoclínica com uma orientação preferencial na direção $c$. Através da análise dos padrões de difração das amostras NaV01, NaV02 e NaV03, é possível observar que a síntese hidrotermal na presença de $\mathrm{NaOH}$ leva a formação da fase $\mathrm{Na}_{2} \mathrm{~V}_{6} \mathrm{O}_{16} 3.0 \mathrm{H}_{2} \mathrm{O}$ monoclínica com os parâmetros de rede $a=12.17 \AA$, $b=3.602 \AA$ e $c=7.78=\AA$ (JCPDS número 16-0601). Além disso, foi possível observar que, independente da rota e das condições de síntese adotada, não é possível notar diferença na fase obtida.

A quantidade de água presente na estrutura e a estabilidade térmica foram investigadas através das medidas de TG. A Figura 53 apresenta as curvas de TG paras as amostras NaV01, NaV02 e NaV03. 


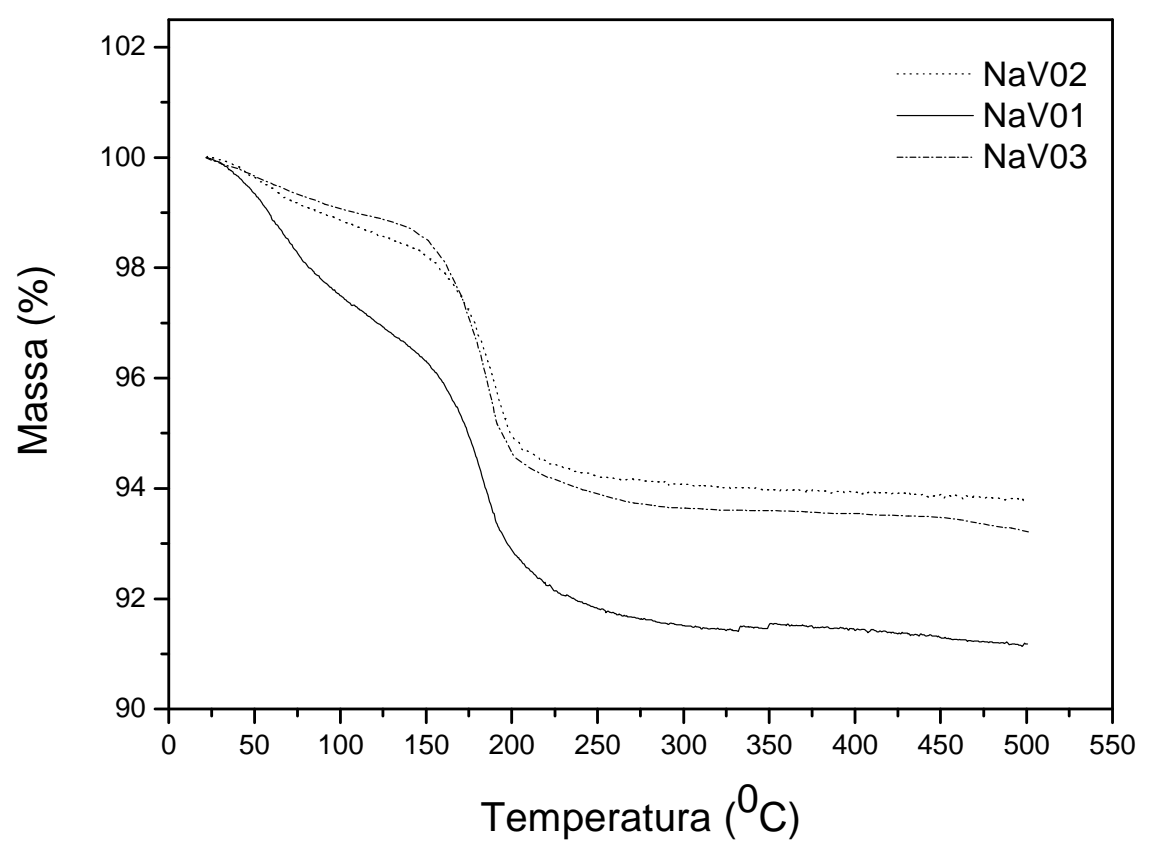

Figura 53 - Curva de TG das amostras NaV01, NaV02 e NaV03.

Através das medidas de TG apresentadas na Figura 53 é possível observar um perfil de desidratação semelhante nas três amostras indicando que possuem uma estrutura semelhante. Em bom acordo com os dados da literatura, as curvas de TG apresentam uma perda significativa de massa da temperatura ambiente até aproximadamente $500^{\circ} \mathrm{C}$, a partir da qual ocorre a estabilização (90). A análise das curvas de TG indicam que a temperatura ambiente as amostras contem respectivamente 3,3 e 2,2 e 2,4 moléculas de água em relação a $\mathrm{Na}_{2} \mathrm{~V}_{6} \mathrm{O}_{16}$ para as amostras NaV01, NaV02 e NaV03, mostrando que a rota de síntese não tem influencia sobre este parâmetro. A principal diferença quanto ao estado de hidratação das amostras NaV01 e NaV02 está localizada principalmente abaixo de $150^{\circ} \mathrm{C}$ devido provavelmente a presença de moléculas de água adsorvidas na estrutura.

Figura 54a, b e c apresentam, respectivamente, as imagens das amostras NaV01, NaV02 e NaV03 obtidas através de imagens de FE-STEM operando no modo de campo claro. Através destas imagens é possível observar que a morfologia das amostras NaV01, NaV02 e NaV03 são muito similares possuindo a forma de nanofios de diferentes dimensões. 


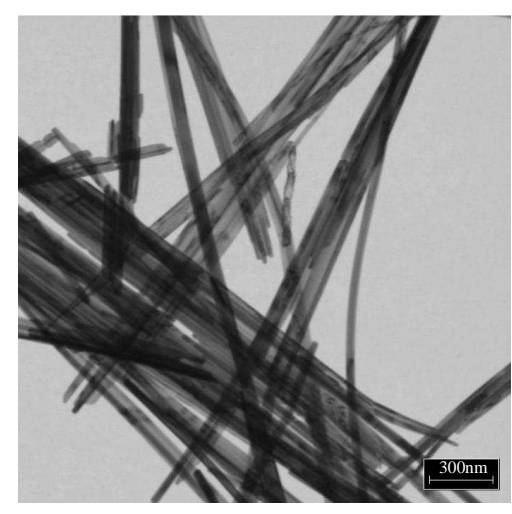

(a)

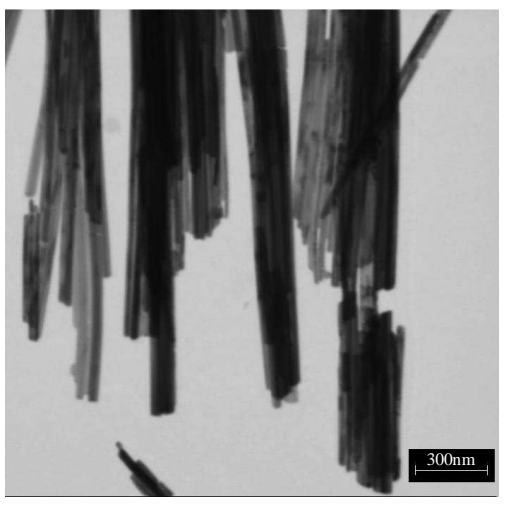

(b)

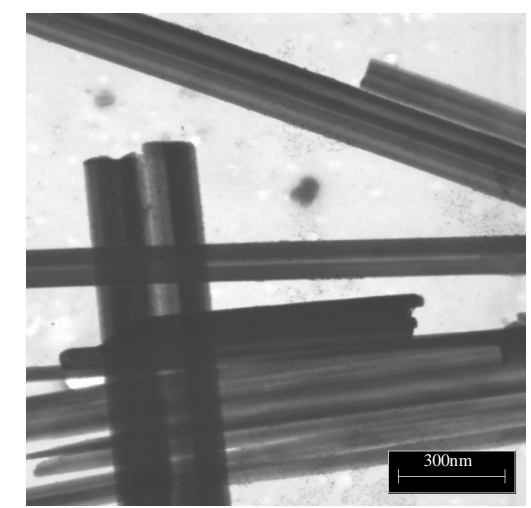

(c)

Figura 54 - Imagens de campo claro de FE-STEM das amostras (a) NaV01, (b)NaV02 e (c) NaV03.

A Figura 55 apresenta uma imagem de FE-STEM de campo escuro da mesma região obtida para a amostra NaV02 ( Figura 54b ) onde é possível observar de forma mais clara a presença de um aglomerados de nanofios.

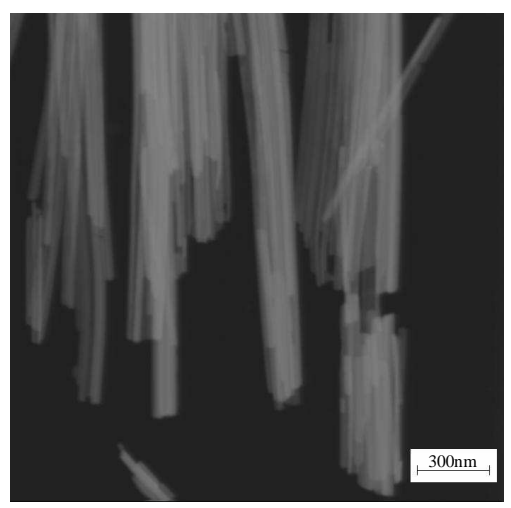

Figura 55 - Imagem de campo escuro de FE-STEM da amostra NaV02. 
Através do estudo da distribuição da largura destas nanofitas, Figura 56a (NaV01), Figura 56b (NaV02) e Figura 56c (NaV03), foi determinada uma largura média de 24,6 nm, $24,0 \mathrm{~nm}$ e 38,0 nm, respectivamente. Este mesmo tipo de nanoestrutura foi obtido a temperaturas superiores por outros autores $(90,93)$.

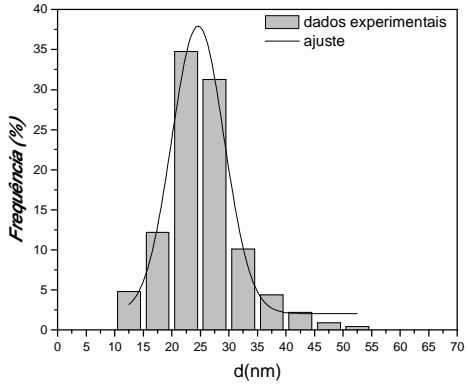

(a)

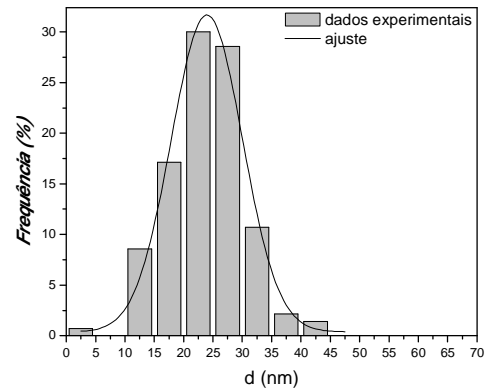

(b)

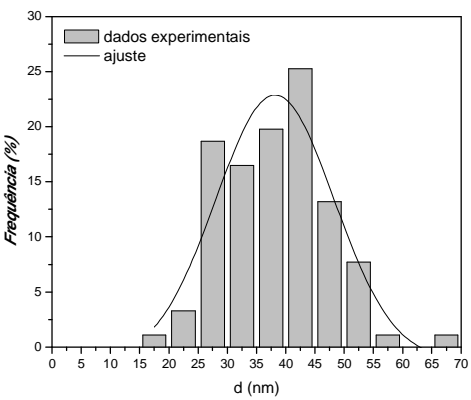

(c)

Figura 56 - Distribuição da largura das amostras obtidas através do tratamento hidrotermal: (a) NaV01; (b) $\mathrm{NaV02;} \mathrm{(c)} \mathrm{NaV03.}$

Para a amostra NaV02 foi realizada uma análise composicional da região A indicada na Figura 57a utilizando a técnica de espectroscopia de energia dispersiva de raios X (EDS). O espectro de EDS, Figura 57b, confirma a composição da nanoestrutura analisada com linhas localizadas em 0,5 e $4,9 \mathrm{keV}$ referentes ao elemento $\mathrm{V}$, enquanto que a linha localizada próximo a $1,0 \mathrm{KeV}$ é referente ao elemento $\mathrm{Na}$. (103) A linha localizada em torno de $0,5 \mathrm{keV}$ também pode ser atribuída a transição do elemento $O$, enquanto que a primeira linha localizada em torno de $0,25 \mathrm{keV}$ é atribuída a presença de carbono (C) (103)proveniente do 
filme da grade utilizada para a deposição da amostra. A analise por EDS das amostras NaV01 e NaV03, apresentou resultados similares ao observado para a amostra NaV02.
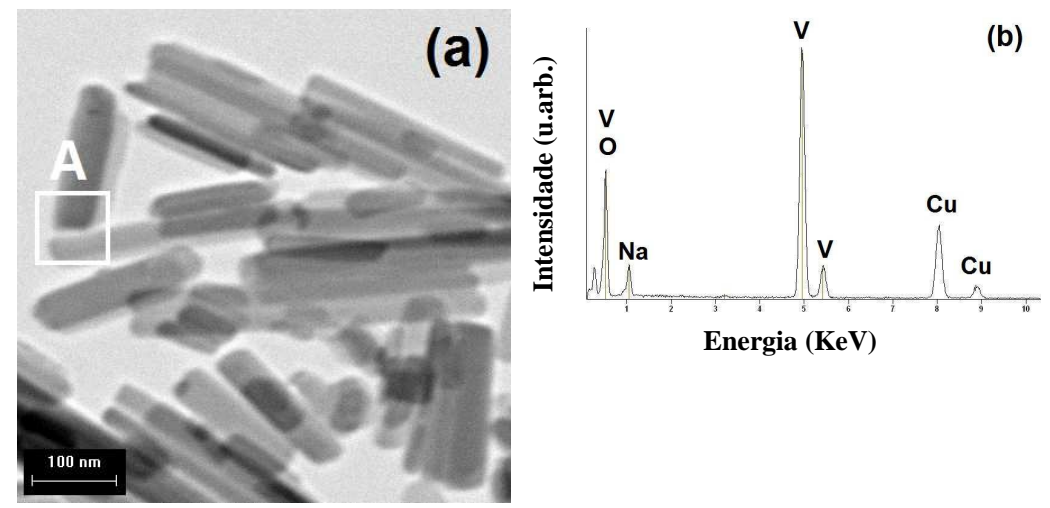

Figura 57 - (a) Imagens MET da amostra NaVO2; (b) Espectro EDS da região A.

Imagens de HR-TEM da amostra NaV01, Figura 58a e b, revelam a natureza policristalina das nanoestruturas obtidas. É possível também observar que algumas regiões apresentam diferentes contrastes o que pode estar relacionado a alta porosidade presente no material. Comportamento semelhante foi observado nas amostras NaV02 e NaV03.
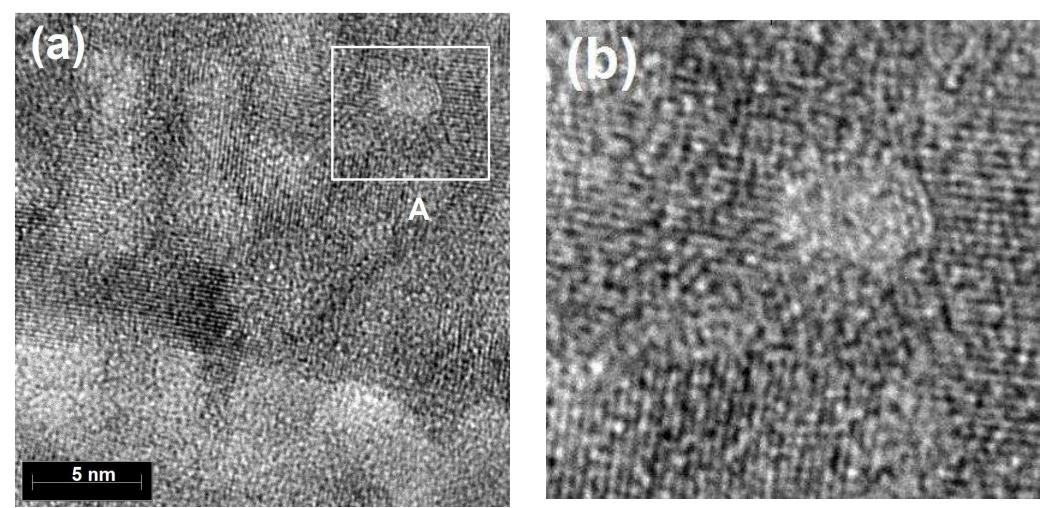

Figura 58 - (a) Imagens de HR-TEM da amostra NaV01; (b) imagem ampliada da região A, indicada na Figura $57 a$.

Segundo trabalhos encontrados na literatura, ainda não está claro o mecanismo de crescimento destas nanoestruturas unidimensionais. Entretanto, o trabalho aqui realizado mostra que não existe a necessidade da adição de “templates” para que estas nanoestruturas sejam obtidas. $(85,90,93)$ Baseado nos resultados apresentados, fica claro que mecanismo de crescimento desses nanofios não depende da rota adotada e que a reação de formação dos 
nanofios ocorre de forma semelhante. A reação entre o $\mathrm{NaOH}$ e as nanofitas de $\mathrm{V}_{2} \mathrm{O}_{5} n \mathrm{H}_{2} \mathrm{O}$ leva ao aumento do $\mathrm{pH}$ gerando uma instabilidade das nanofitas de $\mathrm{V}_{2} \mathrm{O}_{5} n \mathrm{H}_{2} \mathrm{O}$ dando assim origem a espécies polivanadatos. Assim, as espécies de polivanadatos irão reagir com os íons de $\mathrm{Na}^{2+}$ levando ao crescimento dos nanofios de $\mathrm{Na}_{2} \mathrm{~V}_{6} \mathrm{O}_{16} n \mathrm{H}_{2} \mathrm{O}$, independente da rota de síntese empregada. Pang e colaboradores também atribuíram a formação de nanofitas de $\mathrm{Ba}_{1+\mathrm{x}} \mathrm{V}_{6} \mathrm{O}_{16} n \mathrm{H}_{2} \mathrm{O}$ a reação entre as espécies de polivanadatos formado pelo aumento do $\mathrm{pH}$ e os íons de $\mathrm{Ba}^{2+}$ presentes na solução. (88)

Entretanto, vale ressaltar que a obtenção dos nanofios de $\mathrm{Na}_{2} \mathrm{~V}_{6} \mathrm{O}_{16} n \mathrm{H}_{2} \mathrm{O}$ através de apenas uma etapa, amostra $\mathrm{NaV02}$, apresenta-se como uma rota mais interessante do ponto de vista de aplicação. Diferente do que foi observado na literatura, na rota onde foi utilizada apenas uma etapa para a preparação de nanofios através do uso de $\mathrm{V}_{2} \mathrm{O}_{5}-\mathrm{H}_{2} \mathrm{O}_{2}$, foi possível obter nanoestruturas de forma simples, controlada e homogênea. (92)

A Figura 59 apresenta o espectro XANES normalizado das amostras NaV01, NaV02, $\mathrm{V}_{2} \mathrm{O}_{5} n \mathrm{H}_{2} \mathrm{O}$ e da fase $\mathrm{V}_{2} \mathrm{O}_{5}$ ortorrômbica. A principal diferença observada no espectro XANES está relacionada à alta intensidade do pico da pré-borda em relação a fase $\mathrm{V}_{2} \mathrm{O}_{5} n \mathrm{H}_{2} \mathrm{O}$ e na diferença das oscilações na região da pós-borda de absorção. Não foi possível realizar medidas de XANES na amostra NaV03.

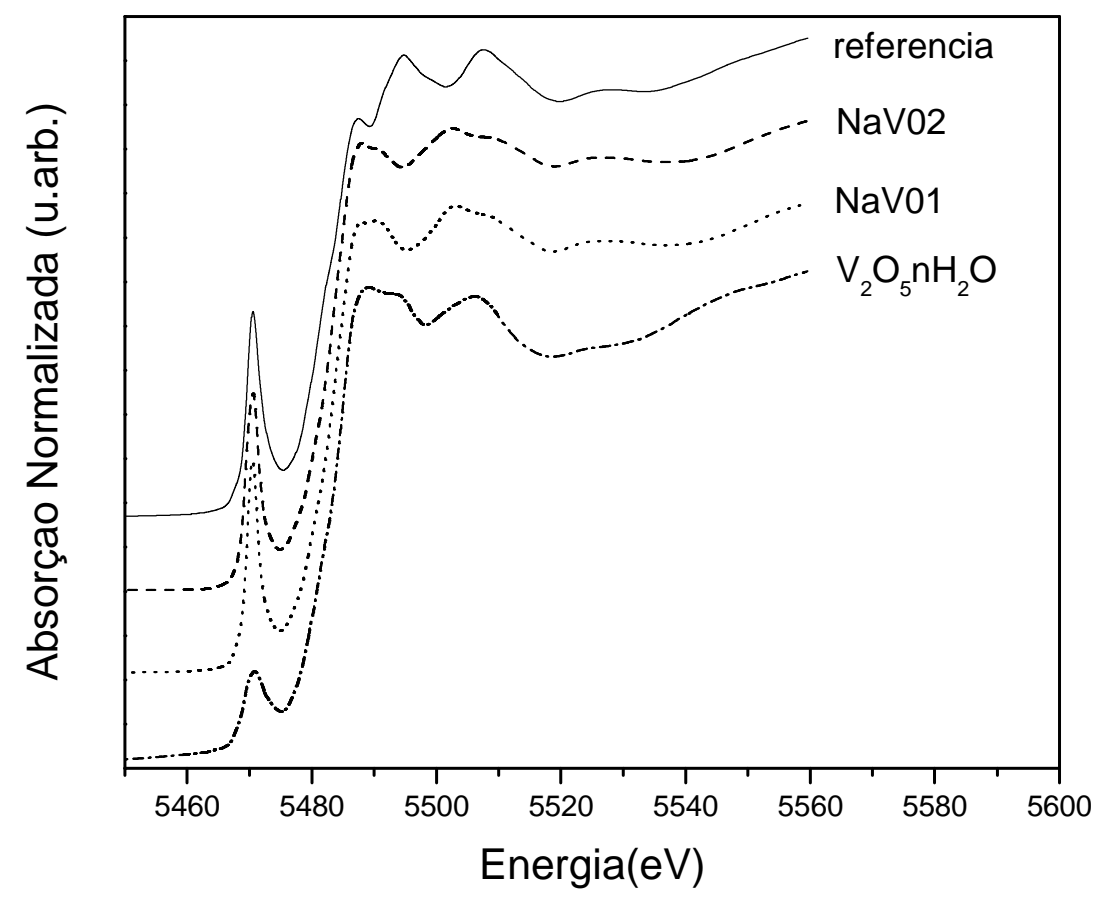

Figura 59 - Espectro XANES na borda $\mathrm{K}$ do Vanádio das amostras $\mathrm{NaV01}$, NaV02, do composto $\mathrm{V}_{2} \mathrm{O}_{5} \mathrm{nH}_{2} \mathrm{O}$ e da fase $\mathrm{V}_{2} \mathrm{O}_{5}$ ortorrômbica. 
Com o objetivo de melhor avaliar possíveis mudanças na região de pré-borda do espectro XANES, a Figura 60a apresenta uma expansão da região de pré-borda da amostra estudada em comparação com o composto de referência. Como mencionado anteriormente, a intensidade do pico da pré-borda está diretamente relacionada a ordem local do átomo de $\mathrm{V}$.

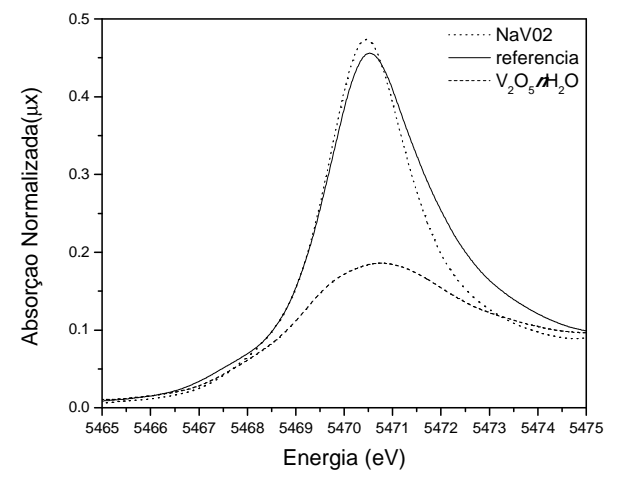

(a)

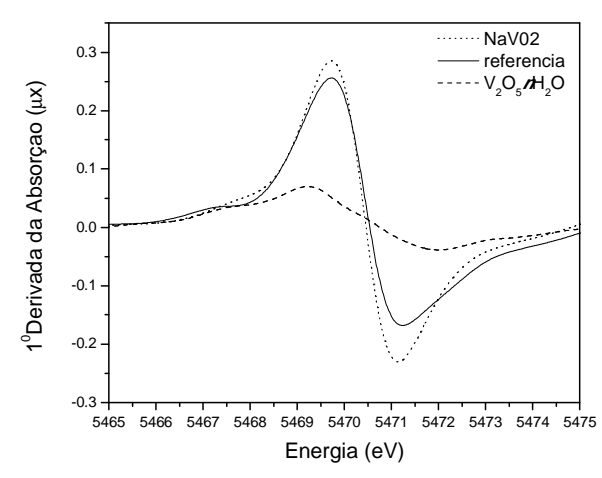

(b)

Figura 60 - (a) região da pré-borda do espectro XANES das amostras NAV02 e $\mathrm{V}_{2} \mathrm{O}_{5} \mathrm{nH}_{2} \mathrm{O}$ e do composto $\mathrm{V}_{2} \mathrm{O}_{5}$ ortorrômbico; (b) primeira derivada dos espectros apresentados na Figura 59a.

A baixa intensidade do pico da pré-borda observado para o composto $\mathrm{V}_{2} \mathrm{O}_{5} n \mathrm{H}_{2} \mathrm{O}$ está relacionado ao grau de simetria local na unidade $\mathrm{VO}_{5}$. (31) Embora a fase $\mathrm{V}_{2} \mathrm{O}_{5}$ ortorrômbica seja composta por octaedros de $\mathrm{VO}_{5}$ enquanto que o composto $\mathrm{Na}_{2} \mathrm{~V}_{6} \mathrm{O}_{16} n \mathrm{H}_{2} \mathrm{O}$ monoclínico (amostras NaV01 e NaV02) é composto por octaedros de $\mathrm{VO}_{6}$ [19], é possível observar através da análise da região de pré-borda que os nanofios composição $\mathrm{Na}_{2} \mathrm{~V}_{6} \mathrm{O}_{16} n \mathrm{H}_{2} \mathrm{O}$ de fase monoclínica possuem estrutura local em torno do átomo de $\mathrm{V}$ similar ao composto $\mathrm{V}_{2} \mathrm{O}_{5}$ de fase ortorrômbica.

Além disso, através das Figura 60a e b, é possível observar que a energia do pico da pré-borda e de sua primeira derivada não apresenta deslocamentos significativos quando comparado a fase $\mathrm{V}_{2} \mathrm{O}_{5}$ ortorrômbica, indicando que o estado de oxidação dos átomos de $\mathrm{V}$ nos nanofios de $\mathrm{Na}_{2} \mathrm{~V}_{6} \mathrm{O}_{16} n \mathrm{H}_{2} \mathrm{O}$ são similares ao composto de referência, i.e., $\mathrm{V}^{5+}$. Este resultado difere ao observado por Zhou e colaboradores, onde foi proposta a presença de átomos de vanádio $\mathrm{V}^{5+} \mathrm{e} \mathrm{V}^{4+}$ nas nanoestruturas de $\mathrm{Na}_{2} \mathrm{~V}_{6} \mathrm{O}_{16} n \mathrm{H}_{2} \mathrm{O}$. (90)

Em resumo, os resultados apresentados mostram a possibilidade de se obter a fase $\mathrm{Na}_{2} \mathrm{~V}_{6} \mathrm{O}_{16} n \mathrm{H}_{2} \mathrm{O}$ na forma de nanofios utilizando uma temperatura de tratamento relativamente 
baixa quando comparado a outros trabalhos na literatura. Assim como no caso da síntese da amostra $\mathrm{V}_{2} \mathrm{O}_{5} n \mathrm{H}_{2} \mathrm{O}$, a rota de síntese empregada pode ser considerada simples e limpa e pode ser considerada promissora na obtenção de nanoestruturas de oxido vanádio contendo diferentes cátions em sua estrutura. 


\section{CONCLUSÕES}

A síntese da fase $\mathrm{V}_{2} \mathrm{O}_{5} n \mathrm{H}_{2} \mathrm{O}$ contendo diferentes quantidades de água ( $n$ ) e diferentes morfologias foi realizada através do método hidrotermal baseado na decomposição do peróxido de vanádio. Os resultados mostraram que é possível amostras apresentando diferentes fases cristalinas controlando apenas o tempo e a temperatura de tratamento hidrotermal. O controle preciso desses parâmetros, proporcionado pelo sistema experimental utilizado, mostrou ser fundamental na obtenção de uma determinada fase cristalina, quantidade de água intercalada e morfologia.

$\mathrm{O}$ processo de desidratação da fase $\mathrm{V}_{2} \mathrm{O}_{5} n \mathrm{H}_{2} \mathrm{O}$ monoclínica apresentou-se dependente da temperatura e do tempo de tratamento. Observou-se que este processo dá origem a fase cristalina $\mathrm{V}_{2} \mathrm{O}_{5} n \mathrm{H}_{2} \mathrm{O}$ ortorrômbica, bem como a nanoestruturas com diferentes morfologias, na forma de fios ou bastões. Nas amostras da fase $\mathrm{V}_{2} \mathrm{O}_{5} n \mathrm{H}_{2} \mathrm{O}$ monoclínica, foi detectada a coexistência de íons $\mathrm{V}^{4+} \mathrm{e}^{5+}$ com a quantidade de íons de $\mathrm{V}^{4+}$ dependendo do estado de hidratação da estrutura. Para as amostras da fase $\mathrm{V}_{2} \mathrm{O}_{5} n \mathrm{H}_{2} \mathrm{O}$ ortorrômbica, somente a presença de íons $\mathrm{V}^{5+}$ foi observada.

A análise do espectro de XAS na região de XANES e EXAFS mostrou que a estrutura atômica local ao redor dos átomos de $\mathrm{V}$, nas amostras da fase $\mathrm{V}_{2} \mathrm{O}_{5} n \mathrm{H}_{2} \mathrm{O}$ ortorrômbica, apresentou um maior grau de simetria quando comparado a fase $\mathrm{V}_{2} \mathrm{O}_{5}$ ortorrômbica na sua forma microestruturada. Além disso, este maior grau de simetria mostrou-se dependente da temperatura de síntese.

Através do estudo da cinética de crescimento lateral em função do tempo de tratamento das nanoestruturas de $\mathrm{V}_{2} \mathrm{O}_{5} n \mathrm{H}_{2} \mathrm{O}$ foi possível verificar que a evolução da largura das nanofitas pode ser bem descrita pelo modelo adaptado do mecanismo de crescimento denominado de Coalescência Orientada (OA). 
Imagens de microscopia eletrônica de transmissão de alta resolução (HR-TEM) mostraram que o as nanoestruturas $\mathrm{V}_{2} \mathrm{O}_{5} n \mathrm{H}_{2} \mathrm{O}$ apresentam uma natureza monocristalina, com um crescimento inicial na direção [010] seguido do crescimento na direção [100]. Através de imagens de HR-TEM foi possível também verificar a existência de defeitos na região de interface entre duas nanoestruturas após o processo de coalescência, confirmando que o mecanismo de crescimento lateral observado nestas amostras pode ser descrito pelo mecanismo de OA

Em relação à evolução morfológica observada nas nanoestruturas obtidas em função da temperatura de tratamento hidrotermal, os resultados indicaram que existe certa correlação entre a mudança de morfologia, a mudança de estrutura a longa distância e a quantidade de água intercalada na amostra. Diante dos resultados obtidos, foi proposto um modelo que descreve de forma adequada a evolução morfológica das nanoestruturas de nanofitas para nanofios e/ou nanobastões.

Também foi possível observar que a síntese via tratamento hidrotermal do peróxido de vanádio na presença de hidróxido de sódio $(\mathrm{NaOH})$ apresentou resultados promissores no que diz respeito a obtenção, de uma forma simples e relativamente rápida, de compostos de vanádio com cátions intercalados em sua estrutura. 


\section{SUGESTÕES PARA TRABALHOS FUTUROS}

Os resultados apresentados neste trabalho sugerem que o uso de cálculos Ab initio das energias superficiais da amostra $\mathrm{V}_{2} \mathrm{O}_{5}$ hidratada pode ser útil na tentativa de melhor compreender a evolução morfológica observada nas nanoestruturas obtidas.

Diante do potencial de aplicação dos materiais nanoestruturados estarem diretamente relacionados à sua estrutura e morfologia, a busca da aplicação, como em fotocatálise ou como em sensores, das diferentes nanoestruturas obtidas neste trabalho apresenta-se muito promissora.

Os resultados quanto a obtenção de compostos vanadatos contendo cátions em sua estrutura, também se apresentaram como promissores devido aos diversos artigos publicados recentemente sobre a síntese de compostos, principalmente no que diz respeito a sua aplicação tecnológica. 


\section{REFERÊNCIAS}

1 WANG, Y.; CAO, G. Synthesis and enhanced intercalation properties of nanostructured vanadium oxides. Chemistry of Materials, v.18, n. 12, p. 2787-2804, 2006.

2 WANG, X.; LI, Y. Solution-based synthetic strategies for 1-D nanostructures. Inorganic Chemistry, v.45, n. 19, p. 7522-7534, 2006.

3 BURDA, C. et al. Chemistry and properties of nanocrystals of different shapes. Chemistry Reviews, v.105, n. 4, p. 1025-1102, 2005.

4 XIA, Y.N. et al. Unconventional methods for fabricating and patterning nanostructures. Chemical Reviews, v.99, n. 7, p. 1823-1848, 1999.

5 ALIVISATOS, A.P. Perspectives on the physical chemistry of semiconductor nanocrystals. Journal of Physical Chemistry, v.100, n. 31, p. 13226-13239, 1996.

6 CADEMARTIRI, L.; OZIN, G.A. Ultrathin nanowires-a materials chemistry perspective. Advanced Materials, v.21, n. 10, p. 1013-1020, 2009.

7 PENG, X.G. et al. Shape control of CdSe nanocrystals. Nature, v.404, n. 6773, p. 59-61, 2000.

8 PENG, X.G. Mechanisms for the shape-control and shape-evolution of colloidal semiconductor nanocrystals. Advanced Materials, v.15, n. 5, p. 459-463, 2003. 
9 JUN, Y.W. et al. Surfactant-assisted elimination of a high energy facet as a means of controlling the shapes of $\mathrm{TiO}_{2}$ nanocrystals. Journal of the American Chemical Society, v.125, n. 51, p. 15981-15985, 2003.

10 LEITE, E.R. et al. Synthesis of niobia nanocrystals with controlled morphology. Journal of Physical Chemistry B, v.110, n. 37, p. 18088-18090, 2006.

11 RIBEIRO, C. et al. Anisotropic growth of oxide nanocrystals: insights into the rutile $\mathrm{TiO}_{2}$ phase. Journal of Physical Chemistry C, v.111, n. 16, p. 5871-5875, 2007.

12 RIBEIRO, C. et al. Role of the oriented attachment mechanism in the phase transformation of oxide nanocrystals. Chemistry-a European Journal, v.13, n. 20, p. 5798-5803, 2007.

13 RIBEIRO, C. et al. Phase transformation in titania nanocrystals by the oriented attachment mechanism: the role of the ph value. Chemistry-a European Journal, v.15, n. 9, p. 22172222, 2009.

14 FEI, H.L. et al. Synthesis of hollow $\mathrm{V}_{2} \mathrm{O}_{5}$ microspheres and application to photocatalysis. Solid State Sciences, v.10, n. 10, p. 1276-1284, 2008.

15 LI, B.X. et al. Vanadium pentoxide nanobelts and nanorolls: from controllable synthesis to investigation of their electrochemical properties and photocatalytic activities. Nanotechnology, v.17, n. 10, p. 2560-2566, 2006.

16 LIU, J.F. et al. Preparation and gas sensing properties of vanadium oxide nanobelts coated with semiconductor oxides. Sensors and Actuators B-Chemical, v.115, n. 1, p. 481-487, 2006.

17 LIU, J.F. et al. Vanadium pentoxide nanobelts: highly selective and stable ethanol sensor materials. Advanced Materials, v.17, n. 6, p. 764-770, 2005.

18 SERIER, H. et al. Designing the width and texture of vanadium oxide macroscopic fibers: towards tuning mechanical properties and alcohol-sensing performance. Advanced Functional Materials, v.16, n. 13, p. 1745-1753, 2006.

19 LEROY, C.M. et al. Designing nanotextured vanadium oxide-based macroscopic fibers: application as alcoholic sensors. Chemistry of Materials, v.19, n., p. 3988-3999, 2007. 
20 PONZIO, E.A.; BENEDETTI, T.M.; TORRESI, R.M. Electrochemical and morphological stabilization of $\mathrm{V}_{2} \mathrm{O}_{5}$ nanofibers by the addition of polyaniline. Electrochimica Acta, v.52, n. 13, p. 4419-4427, 2007.

21 WANG, Y. et al. Synthesis and electrochemical properties of vanadium pentoxide nanotube arrays. Journal of Physical Chemistry B, v.109, n. 8, p. 3085-3088, 2005.

22 HUGUENIN, F.; TICIANELLI, E.A.; TORRESI, R.M. XANES study of polyaniline- $\mathrm{V}_{2} \mathrm{O}_{5}$ and sulfonated polyaniline- $\mathrm{V}_{2} \mathrm{O}_{5}$ nanocomposites. Electrochimica Acta, v.47, n. 19, p. 31793186, 2002.

23 HOLLAND, G.P. et al. Comparison of $\mathrm{V}_{2} \mathrm{O}_{5}$ xerogels prepared by the vanadate and alkoxide routes using X-ray absorption and other methods. Journal of the Electrochemical Society, v.150, n. 6, p. A721-A725, 2003.

24 XIONG, C.R. et al. Fabrication of silver vanadium oxide and $\mathrm{V}_{2} \mathrm{O}_{5}$ nanowires for electrochromics. Acs Nano, v.2, n. 2, p. 293-301, 2008.

25 LIVAGE, J. Vanadium pentoxide gels Chemistry of Materials, v.3, n. 4, p. 578-593, 1991.

26 LIVAGE, J. Synthesis of polyoxovanadates via "chimie douce". Coordination Chemistry Reviews, v.178, n., p. 999-1018, 1998.

27 LIVAGE, J. Interface properties of vanadium pentoxide gels. Materials Research Bulletin, v.26, n. 11, p. 1173-1180, 1991.

$28 \mathrm{WANG}$, Y. et al. Effects of thermal annealing on the Li+ intercalation properties of $\mathrm{V}_{2} \mathrm{O}_{5}$ center dot $\mathrm{nH}_{(2)} \mathrm{O}$ xerogel films. Journal of Physical Chemistry B, v.109, n. 22, p. 1136111366, 2005.

29 ALONSO, B.; LIVAGE, J. Synthesis of vanadium oxide gels from peroxovanadic acid solutions: a V-51 NMR study. Journal of Solid State Chemistry, v.148, n. 1, p. 16-19, 1999.

30 MANSOUR, A.N. et al. In situ X-ray absorption study of cycled ambigel $\mathrm{V}_{2} \mathrm{O}_{5}$ center dot $\mathrm{n}$ $\mathrm{H}_{2} \mathrm{O}$ (n approximate to 0.5 ) composite cathodes. Journal of the Electrochemical Society, v.152, n. 7, p. A1312-A1319, 2005. 
31 MANSOUR, A.N. et al. Thermogravimetry and X-ray absorption spectroscopy study of heated $\mathrm{V}_{2} \mathrm{O}_{5}$ center dot $\mathrm{nH}_{(2)} \mathrm{O}$ aerogels and ambigels. Journal of the Electrochemical Society, v.149, n. 12, p. A1589-A159, 2002.

32 ALDEBERT, P. et al. Layered structure of vanadium pentoxide gels. Materials Research Bulletin, v.16, n. 6, p. 669-676, 1981.

33 LEGENDRE, J.J.; LIVAGE, J. Vanadium pentoxide gels .2. structural study by electron diffraction. Journal of Colloid and Interface Science, v.94, n. 1, p. 75-83, 1983.

34 LEGENDRE, J.J. et al. Vanadium pentoxide gels .2. structural study by x-ray diffraction. Journal of Colloid and Interface Science, v.94, n. 1, p. 84-89, 1983.

35 ABELLO, L. et al. Structural study of gels of $\mathrm{V}_{2} \mathrm{O}_{5}$ - vibrational spectra of xerogels. Journal of Solid State Chemistry, v.56, n. 3, p. 379-389, 1985.

36 YAO, T.; OKA, Y.; YAMAMOTO, N. Layered structures of hydrated vanadium-oxides. 1. alkali-metal intercalates $\mathrm{A}_{0.3} \mathrm{~V}_{2} \mathrm{O}_{5} \cdot \mathrm{NH}_{2} \mathrm{O}(\mathrm{A}=\mathrm{NA}, \mathrm{K}, \mathrm{RB}, \mathrm{CS}$ AND NH4). Journal of Materials Chemistry, v.2, n. 3, p. 331-336, 1992.

37 PETKOV, V. et al. Structure of $\mathrm{V}_{2} \mathrm{O}_{5}$ center dot $\mathrm{nH}_{(2)} \mathrm{O}$ xerogel solved by the atomic pair distribution function technique. Journal of the American Chemical Society, v.124, n. 34, p. 10157-10162, 2002.

38 STIZZA, S. et al. Structure of oriented $\mathrm{V}_{2} \mathrm{O}_{5}$ gel studied by polarized X-Ray-absorption spectrocopy at the vanadium K edge. Physical Review B, v.40, n. 18, p. 12229-12236, 1989.

39 GIORGETTI, $\mathrm{M}$. et al. Evidence of bilayer structure in $\mathrm{V}_{2} \mathrm{O}_{5}$ xerogel. Inorganic Chemistry, v.39, n. 7, p. 1514-1517, 2000.

40 NABAVI, M. et al. XANES and V-51 NMR-study of vanadium oxygen compounds. Journal of Physics and Chemistry of Solids, v.51, n. 12, p. 1375-1382, 1990.

41 VELAZQUEZ, J.R.; BANERJEE, S. Catalytic growth of single-crystalline $\mathrm{V}_{2} \mathrm{O}_{5}$ nanowire arrays. Small, v.5, n. 9, p. 1025-1029, 2009.

42 CHOU, J.Y. et al. Vanadium oxide nanowire phase and orientation analyzed by Raman spectroscopy. Journal of Applied Physics, v.105, n. 3, p.0343101-0343106, 2009. 
43 GLUSHENKOV, A.M. et al. A novel approach for real mass transformation from $\mathrm{V}_{2} \mathrm{O}_{5}$ particles to nanorods. Crystal Growth \& Design, v.8, n. 10, p. 3661-3665, 2008.

44 PINNA, N. et al. Divanadium pentoxide nanorods. Advanced Materials, v.15, n. 4, p. 329-331, 2003.

45 LEE, K.; WANG, Y.; CAO, G.H. Dependence of electrochemical properties of vanadium oxide films on their nano- and microstructures. Journal of Physical Chemistry B, v.109, n. 35, p. 16700-16704, 2005.

46 CHANDRAPPA, G.T. et al. Hydrothermal synthesis of vanadium oxide nanotubes from $\mathrm{V}_{2} \mathrm{O}_{5}$ gels. Catalysis Today, v.78, n. 1-4, p. 85-89, 2003.

47 CHANDRAPPA, G.T. et al. Vanadium oxide: from gels to nanotubes. Journal of Sol-Gel Science and Technology, v.26, n. 1-3, p. 593-596, 2003.

48 KRUMEICH, F. et al. Morphology and topochemical reactions of novel vanadium oxide nanotubes. Journal of the American Chemical Society, v.121, n. 36, p. 8324-8331, 1999.

49 NIEDERBERGER, M. et al. Low-cost synthesis of vanadium oxide nanotubes via two novel non-alkoxide routes. Chemistry of Materials, v.12, n. 7, p. 1995-2000, 2000.

$50 \mathrm{KWEON}, \mathrm{H}$. et al. Effect of water intercalation on VOx layers in dodecylamineintercalated vanadium oxide nanotubes. Physical Review B, v.76, n. 4, p. 1098-0121, 2007.

51 BYRAPPA, K.; YOSHIMURA, M. Handbook of hydrothermal technology. Norwich: Noyes Publications, 2001.

52 YOSHIMURA, M.; BYRAPPA, K. Hydrothermal processing of materials: past, present and future. Journal of Materials Science, v.43, n. 7, p. 2085-2103, 2008.

53 LI, G.C.; JIANG, L.; PENG, H.R. A simple route to $\mathrm{V}_{2} \mathrm{O}_{5}$ center dot $\mathrm{xH}_{(2)} \mathrm{O}$ bundle-like nanostructures. Materials Letters, v.61, n. 19-20, p. 4070-4072, 2007.

$54 \mathrm{HU}$, C.C.; CHANG, K.H. Hydrothermal synthesis of $\mathrm{V}_{2} \mathrm{O}_{5}$ center dot $1.9 \mathrm{H}_{(2)} \mathrm{O}$ single crystals with novel electrochemical characteristics. Electrochemical and Solid State Letters, v.7, n. 11, p. A400-A403, 2004. 
55 PAN, D.Y. et al. Hydrothermal preparation of long nanowires of vanadium oxide. Journal of Materials Research, v.17, n. 8, p. 1981-1984, 2002.

56 ZHOU, F. et al. Vanadium pentoxide nanowires: hydrothermal synthesis, formation mechanism, and phase control parameters. Crystal Growth \& Design, v.8, n. 2, p. 723-727, 2008.

57 GAO, S.K. et al. Single-crystal vanadium pentoxide nanowires. Journal of Nanoscience and Nanotechnology, v.8, n. 7, p. 3500-3503, 2008.

58 WEI, M.D. et al. A new metastable phase of crystallized $\mathrm{V}_{2} \mathrm{O}_{4}$ center dot $0.25 \mathrm{H}_{(2)} \mathrm{O}$ nanowires: synthesis and electrochemical measurements. Advanced Materials, v.17, n. 24, p. 2964-2967, 2005.

59 CHEN, W. et al. Synthesis of vanadium oxide nanotubes from $\mathrm{V}_{2} \mathrm{O}_{5}$ sols. Materials Letters, v.58, n. 17-18, p. 2275-2278, 2004.

60 LIFSHITZ, I.M.; SLYOZOV, V.V. The kinetics of precipitation from supersaturated solid solutions. Journal of Physics and Chemistry of Solids, v.19, n. 1-2, p. 35-50, 1961.

61 HUANG, F.; ZHANG, H.Z.; BANFIELD, J.F. The role of oriented attachment crystal growth in hydrothermal coarsening of nanocrystalline ZnS. Journal of Physical Chemistry B, v.107, n. 38, p. 10470-10475, 2003.

62 HUANG, F.; ZHANG, H.Z.; BANFIELD, J.F. Two-stage crystal-growth kinetics observed during hydrothermal coarsening of nanocrystalline ZnS. Nano Letters, v.3, n. 3, p. 373-378, 2003.

63 GRATZ, H. Ostwald ripening: new relations between particle growth and particle size distribution. Scripta Materialia, v.37, n. 1, p. 9-16, 1997.

64 BANFIELD, J.F. et al. Aggregation-based crystal growth and microstructure development in natural iron oxyhydroxide biomineralization products. Science, v.289, n. 5480, p. 751-754, 2000 .

65 PENN, R.L.; BANFIELD, J.F. Morphology development and crystal growth in nanocrystalline aggregates under hydrothermal conditions: insights from titania. Geochimica Et Cosmochimica Acta, v.63, n. 10, p. 1549-1557, 1999. 
66 LEE, E.J.H. et al. Oriented attachment: an effective mechanism in the formation of anisotropic nanocrystals. Journal of Physical Chemistry B, v.109, n.109, p. 20842-20846, 2005 .

67 WANG, Y.H. et al. NaOH concentration effect on the oriented attachment growth kinetics of ZnS. Journal of Physical Chemistry B, v.111, n. 19, p. 5290-5294, 2007.

68 NESPOLO, M.; FERRARIS, G. The oriented attachment mechanism in the formation of twins - a survey. European Journal of Mineralogy, v.16, n. 3, p. 401-406, 2004.

69 NESPOLO, M.; FERRARIS, G. Applied geminography - symmetry analysis of twinned crystals and definition of twinning by reticular polyholohedry. Acta Crystallographica Section A, v.60, n.1, p. 89-95, 2004.

70 PENN, R.L.; BANFIELD, J.F. Oriented attachment and growth, twinning, polytypism, and formation of metastable phases: insights from nanocrystalline $\mathrm{TiO}_{2}$. American Mineralogist, v.83, n. 9-10, p. 1077-1082, 1998.

71 PENN, R.L.; BANFIELD, J.F. Imperfect oriented attachment: dislocation generation in defect-free nanocrystals. Science, v.281, n. 5379, p. 969-971, 1998.

72 GILBERT, B. et al. Special phase transformation and crystal growth pathways observed in nanoparticles. Geochemical Transactions, v.4, n.4, p. 20-27, 2003.

73 RIBEIRO, C. et al. Oriented attachment mechanism in anisotropic nanocrystals: a "polymerization" approach. Chemphyschem, v.7, n. 3, p. 664-670, 2006.

74 LEE, E.J.H. et al. Growth kinetics of tin oxide nanocrystals in colloidal suspensions under hydrothermal conditions. Chemical Physics, v.328, n. 1-3, p. 229-235, 2006.

75 RIBEIRO, C. et al. A kinetic model to describe nanocrystal growth by the oriented attachment mechanism. Chemphyschem, v.6, n. 4, p. 690-696, 2005.

76 YANG, H.G.; ZENG, H.C. Self-construction of hollow $\mathrm{SnO}_{2}$ octahedra based on twodimensional aggregation of nanocrystallites. Angewandte Chemie-International Edition, v.43, n. 44, p. 5930-5933, 2004. 
77 PACHOLSKI, C.; KORNOWSKI, A.; WELLER, H. Self-assembly of ZnO: from nanodots, to nanorods. Angewandte Chemie-International Edition, v.41, n. 7, p. 11881191, 2002.

78 LOU, X.W.; ZENG, H.C. Complex alpha- $\mathrm{MoO}_{3}$ nanostructures with external bonding capacity for self-assembly. Journal of the American Chemical Society, v.125, n.9, p. 26972704, 2003.

79 LIU, B.; ZENG, H.C. Hydrothermal synthesis of $\mathrm{ZnO}$ nanorods in the diameter regime of $50 \mathrm{~nm}$. Journal of the American Chemical Society, v.125, n. 15, p. 4430-4431, 2003.

80 LIU, B.; ZENG, H.C. Mesoscale organization of $\mathrm{CuO}$ nanoribbons: formation of "dandelions". Journal of the American Chemical Society, v.126, n. 26, p. 8124-8125, 2004.

81 PORTEHAULT, D. et al. Twinning driven growth of manganese oxide hollow cones through self-assembly of nanorods in water. Crystal Growth \& Design, v.9, n. 6, p. 2562$2565,2009$.

82 IWANAGA, S. et al. Thermopower and electrical conductivity of sodium-doped $\mathrm{V}_{2} \mathrm{O}_{5}$ thin films. Journal of Applied Physics, v.101, n. 12.,p. 1237091-1237098, 2007.

83 REDDY, C.V.S.; YEO, I.H.; MHO, S.I. Synthesis of sodium vanadate nanosized materials for electrochemical applications. Journal of Physics and Chemistry of Solids, v.69, n. 5-6, p. 1261-1264, 2008.

84 LIM, S.H. et al. Synthesis, characterizations, and field emission studies of crystalline $\mathrm{Na}_{2} \mathrm{~V}_{6} \mathrm{O}_{16}$ nanobelt paper. Journal of Applied Physics, v.100, n. 1, p.0161051-0161053, 2006.

85 LIU, H.M. et al. Facile synthesis of $\mathrm{NaV}_{6} \mathrm{O}_{15}$ nanorods and its electrochemical behavior as cathode material in rechargeable lithium batteries. Journal of Materials Chemistry, v.19, n. 42, p. 7885-7891, 2009.

86 JOUANNEAU, S.; VERBAERE, A.; GUYOMARD, D. On a new calcium vanadate: synthesis, structure and Li insertion behavior. Journal of Solid State Chemistry, v.172, n. 1, p. 116-122, 2003.

87 JOUANNEAU, S. et al. New alkaline earth substituted lithium trivanadates: synthesis, characterization and lithium insertion behavior. Journal of Materials Chemistry, v.13, n. 7, p. 1827-1834, 2003. 
88 PANG, S.P. et al. Synthesis of $\mathrm{Ba}_{1+\mathrm{x}} \mathrm{V}_{6} \mathrm{O}_{16}$ center dot $\mathrm{nH}_{(2)} \mathrm{O}$ single-crystalline nanobelts and seamless ring-like structures. Journal of Crystal Growth, v.293, n. 2, p. 423-427, 2006.

89 FEI, H.L. et al. Novel bi-cation intercalated vanadium bronze nano-structures for stable and high capacity cathode materials. Electrochemistry Communications, v.10, n. 10, p. 1541-1544, 2008.

90 ZHOU, G.T.; WANG, X.C.; YU, J.C. Selected-control synthesis of $\mathrm{NaV}_{6} \mathrm{O}_{15}$ and $\mathrm{Na}_{2} \mathrm{~V}_{6} \mathrm{O}_{16}$ center dot $3 \mathrm{H}_{(2)} \mathrm{O}$ single-crystalline nanowires. Crystal Growth \& Design, v.5, n. 3, p. 969-974, 2005.

91 DURUPTHY, O. et al. Influence of $\mathrm{pH}$ and ionic strength on vanadium(V) oxides formation. From $\mathrm{V}_{2} \mathrm{O}_{5}$ center dot $\mathrm{nH}_{(2)} \mathrm{O}$ gels to crystalline $\mathrm{NaV}_{3} \mathrm{O}_{8}$ center dot $1.5 \mathrm{H}_{(2)} \mathrm{O}$. Journal of Materials Chemistry, v.15, n. 10, p. 1090-1098, 2005.

92 LEI, S.J. et al. Preparation of aligned $\mathrm{MnV}_{2} \mathrm{O}_{6}$ nanorods and their anodic performance for lithium secondary battery use. Nanotechnology, v.18, n. 17, p.1756051-1756058, 2007.

$93 \mathrm{YU}$, J.G. et al. A simple and general method for the synthesis of multicomponent $\mathrm{Na}_{2} \mathrm{~V}_{6} \mathrm{O}_{16}$ center dot $3 \mathrm{H}(2) \mathrm{O}$ single-crystal nanobelts. Journal of the American Chemical Society, v.126, n. 11, p. 3422-3423, 2004.

94 SOUZA, A.G. et al. Raman spectra in vanadate nanotubes revisited. Nano Letters, v.4, n. 11, p. 2099-2104, 2004.

95 NEVES, P.P., Caracterização estrutural de cerâmicas ferroelétricas $\mathbf{P b}_{1-\mathbf{x}} \mathbf{L a}_{\mathbf{x}} \mathbf{T i O}_{\mathbf{3}} \mathbf{e}$ $\mathbf{P b}_{1-\mathrm{x}} \mathbf{B a}_{\mathbf{x}} \mathbf{Z r}_{0,65} \mathbf{T i}_{0,35} \mathbf{O}_{3}$ por espectroscopia de absorção e difração de raios X. 2006. 148 p. Tese (Doutorado em Física Aplicada) - Instituto de Física de São Carlos, Universidade de São Paulo, São Carlos, 2006.

96 RAVEL, B.; NEWVILLE, M. ATHENA and ARTEMIS: interactive graphical data analysis using IFEFFIT. Physica Scripta, v.T115, n.7, p. 1007-1010. 2005.

97 RAVEL, B.; NEWVILLE, M. ATHENA, ARTEMIS, HEPHAESTUS: data analysis for X-ray absorption spectroscopy using IFEFFIT. Journal of Synchrotron Radiation, v.12, n.4., p. 537-541, 2005.

98 NEWVILLE, M. IFEFFIT: interactive XAFS analysis and FEFF fitting. Journal of Synchrotron Radiation, v.8, n.2., p. 322-324. 2001. 
99 NEWVILLE, M. EXAFS analysis using FEFF and FEFFIT. Journal of Synchrotron Radiation, v.8, n.2, p. 96-100, 2001.

100 KUBO, T.; NAKAHIRA, A. Local structure of $\mathrm{TiO}_{2}$-derived nanotubes prepared by the hydrothermal process. Journal of Physical Chemistry C, v.112, n. 5, p. 1658-1662, 2008.

101 RIBEIRO, C. et al. Study of synthesis variables in the nanocrystal growth behavior of tin oxide processed by controlled hydrolysis. Journal of Physical Chemistry B, v.108, n. 40, p. 15612-15617, 2004.

102 SAYLE, D.C. et al. Computer modelling of $\mathrm{V}_{2} \mathrm{O}_{5}$ : surface structures, crystal morphology and ethene sorption. Journal of Materials Chemistry, v.6, n. 4, p. 653-660, 1996.

103 THOMPSON, A.C. et al. X-Ray data Booklet.. Berkeley: University of California, 2001. 


\section{APÊNDICE 1}

\section{A.1 ESPECTROSCOPIA DE ABSORÇÃO DE RAIOS X (XAS)}

Nesta seção será apresentado maiores detalhes a respeito da técnica e as fundamentações da espectroscopia de absorção de raios X (XAS).

\section{A.1.1 Absorção de fótons pela matéria}

A absorção de fótons pela matéria se dá pela interação entre o fóton incidente e os elétrons dos átomos que constituem um material. Este processo pode ocorrer das seguintes maneiras (2):

- Espalhamento Thompon (elástico);

- Espalhamento Compton (inelástico);

- Efeito fotoelétrico;

- Produção de pares.

Nos processos de espalhamento, o produto da interação, é um fóton com direção de propagação diferente à do fóton incidente. O fóton espalhado pode ter energia menor (espalhamento inelástico, chamado de espalhamento Compton) ou igual (espalhamento elástico, chamado de espalhamento Thompon) à do fóton incidente. 
Nos dois últimos processos acima listados, o fóton cede toda sua energia a um ou mais elétrons do material, sendo, portanto totalmente absorvido. Todos esses processos retiram fótons do feixe incidente, atenuando sua intensidade. A probabilidade de ocorrência de cada um desses processos é dada por sua seção de choque. A Figura A.1 apresenta um gráfico da seção de choque total e parcial devido a cada um desses processos de interação em função da energia do fóton para um átomo de cobre.

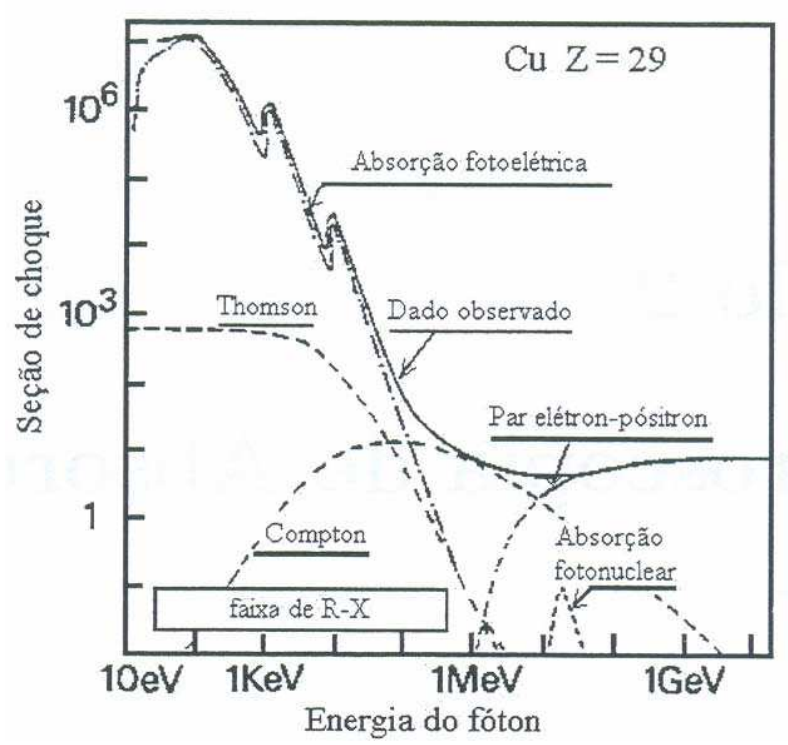

Figura A.1 - Seção de choque de absorção para um átomo de cobre. (95)

Geralmente, a faixa de energia de interesse nas medidas de XAS é determinada pelo intervalo que compreende as bordas $K, L$ e $M$ dos elementos químicos, que varia de algumas centenas de elétron-volt (eV) até $105 \mathrm{eV}$. Na Figura A.1 pode-se observar que para energias de até $105 \mathrm{eV}$ o efeito fotoelétrico tem uma seção de choque de cerca de uma ordem de grandeza maior do que a dos processos de espalhamento e o processo de produção de pares só tem probabilidade não nula acima de $106 \mathrm{eV}$.

O coeficiente de absorção linear, $\mu$, é definido pela relação (1):

$$
I=I_{0} e^{-\mu t}
$$

onde $\boldsymbol{I}$ é a intensidade da radiação transmitida, $\boldsymbol{I}_{\boldsymbol{o}}$ é a intensidade incidente e $\boldsymbol{t}$ a espessura do material. 
No caso do efeito fotoelétrico, o fóton incidente é completamente absorvido transferindo toda sua energia para um elétron do material. Esse elétron será excitado para um nível desocupado com uma energia cinética $\left(\boldsymbol{E}_{\boldsymbol{c}}\right)$ dada por $(1,2)$ :

$$
E_{\sigma}=\frac{p^{2}}{2 m}=h v-E_{0}
$$

Na equação acima, $\boldsymbol{p}$ é o momento linear do elétron, $\boldsymbol{E}_{\boldsymbol{o}}$ é a sua energia de ligação e $\boldsymbol{h} v$ é a energia do fóton incidente, $v$ a freqüência da radiação incidente e $\boldsymbol{h}$ a constante de Planck.

Pode-se escrever a energia cinética do elétron dada na expressão (2), em função do número de onda $\boldsymbol{k}$, o qual se relaciona com o momento linear $\boldsymbol{p}$ e o comprimento de onda do elétron $\left(\lambda_{\boldsymbol{e}}\right)$ por meio da equação $(1,2)$ :

$$
k=\frac{p}{\hbar}=\frac{2 \pi}{\lambda_{g}}
$$

\section{A.1.2 Espectroscopia de absorção de raios X (XAS)}

Na espectroscopia de absorção de raios $X$, um fóton de energia definida atinge a amostra e é absorvido por efeito fotoelétrico. Quando a energia desse fóton é suficiente para excitar um elétron de um nível profundo do material a um nível desocupado, a taxa de absorção aumenta rapidamente e o espectro mostra um salto como mostra a Figura 17. A esse salto dá-se o nome de borda de absorção. Quando o elétron é excitado do nível $1 s$, chamamos essa borda de absorção $\boldsymbol{K}$ e de borda $\boldsymbol{L}$ quando o elétron e retirado do nível n=2, a borda $\boldsymbol{M}$ corresponde ao nível $\mathrm{n}=3$ e assim sucessivamente. $\mathrm{Na}$ verdade, existem 3 bordas $\boldsymbol{L}$ pois o nível $\mathrm{n}=2$ é dividido nos níveis $2 \mathrm{~s}$ (borda $\left.\mathrm{L}_{\mathrm{I}}\right), 2 \mathrm{p}_{1 / 2}\left(\mathrm{~L}_{\mathrm{II}}\right)$ e $2 \mathrm{p}_{3 / 2}\left(\mathrm{~L}_{\mathrm{III}}\right)$. Analogamente, existem 5 bordas $\boldsymbol{M}$. (95)

Para fótons com energias maiores que a energia de ligação do elétron, o elétron excitado tem uma energia cinética não nula podendo se deslocar pelo material interagindo com os átomos em torno do átomo absorvedor. Desse processo de interação, surgem as oscilações no coeficiente de absorção para energias do fóton logo acima da borda, como observado na Figura 17, as oscilações chamadas de EXAFS (Extended X-Ray Absorption Fine 
Structure). A análise destas oscilações fornece informações estruturais sobre o arranjo atômico em torno do átomo absorvedor. (1)

Como mencionado anteriormente, o espectro de absorção está dividido em três regiões: a região de pré-borda, a região XANES (X-Ray Absorption Near Edge Structure) e a região EXAFS, Figura 17.

A técnica de espectroscopia de absorção de raios $\mathrm{X}$ tem sido utilizada nos últimos 20 anos como uma ferramenta poderosa para descrever a estrutura atômica local e de médio alcance dos átomos em amostras no estado sólido, liquido e mesmo gasoso. Em contraste com o método de difração de raios X (DRX), esta técnica pode ser aplicada no estudo estrutural de materiais que não apresentem ordem a longo alcance. Através da escolha adequada da borda de absorção, essa técnica fornece informações sobre as propriedades eletrônicas e estruturais em torno do elemento absorvedor. Nos últimos anos, está técnica vem sendo aplicada no estudo de uma grande variedade de sistemas desde sólidos amorfos a sistemas dispersos, assim como filmes finos e materiais cristalinos.

\section{A.1.2.1 A região de EXAFS}

Nesta seção será apresentada uma discussão detalhada a respeito do espectro de XAS na região de EXAFS.

\section{A.1.2.1.1 Origem do sinal EXAFS}

O coeficiente de absorção $\mu$ para o fotoelétron é dado pela regra de ouro de Fermi $(1,2)$ :

$$
\mu \propto|\langle i|V| f\rangle|^{2} \delta\left(h v-E_{f}+E_{i}\right)
$$


onde $|\mathbf{i}\rangle$ e $|\mathbf{f}\rangle$ são os estados inicial e final do fotoelétron arrancado, respectivamente, $\boldsymbol{E}_{\boldsymbol{i}}$ e $\boldsymbol{E}_{\boldsymbol{f}}$ são as energias desses estados, $\boldsymbol{V}$ é o potencial de interação da radiação eletromagnética incidente com os elétrons ligados do material e $\boldsymbol{h} v$ a energia do fóton incidente. A função delta garante a conservação de energia. $O$ potencial de intervalo $\boldsymbol{V}$ pode ser escrito em uma expansão de múltipolos. Considerando apenas o primeiro termo não nulo dessa expressão, obtemos a regra de ouro de Fermi na aproximação dipolar. Dentro dessa aproximação, existe uma relação de simetria entre o estado inicial e o estado final do fotoelétron que dá origem as chamadas regras de seleção na aproximação dipolar, $\Delta l= \pm 1$ e $\Delta s=0$. Assim, ao medirmos um espectro de absorção nas bordas $\boldsymbol{K}$ (nível 1s) e $\boldsymbol{L}_{\boldsymbol{I}}$ (nível 2s), estaremos sondando estados finais de simetria p; nas bordas $\boldsymbol{L}_{\boldsymbol{I I}}$ e $\boldsymbol{L}_{\boldsymbol{I I I}}$ (níveis $2 \mathrm{p}_{1 / 2}$ e $2 \mathrm{p}_{3 / 2}$ ) sondamos estados $\boldsymbol{s}$ e $\boldsymbol{d}$ e assim por diante. (95)

Segundo a equação (4), o coeficiente de absorção depende do estado inicial e final do fotoelétron. $\mathrm{O}$ estado inicial é um estado do nível $\mathrm{n}=1$ ou 2 dependendo se estamos tratando de uma borda $\boldsymbol{K}$ ou $\boldsymbol{L}$. Esses níveis, exceto para átomos muito leve como hidrogênio e hélio, são pouco afetados pela vizinhança do átomo absorvedor pelo fato de estarem blindados das ligações químicas pelos elétrons de níveis de energia mais externos. O estado final do fotoelétron após o processo de absorção, corresponde ao elétron em um nível excitado com uma energia cinética dada pela equação 2.

O comprimento de onda desse elétron é dado pela relação de De Broglie (2):

$$
\lambda_{c}=\frac{h}{p}
$$

Das relações (2) e (5) vemos que o comprimento de onda do fotoelétron emitido depende da energia do fóton incidente. Quando o átomo absorvedor está inserido em uma matriz sólida, a função de onda do fotoelétron será espalhada pelos átomos em torno do absorvedor como mostra esquematicamente a Figura A.2. (95)

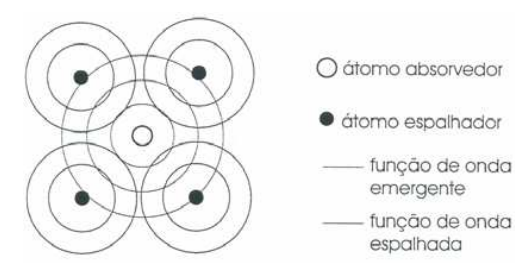

Figura A.2 - Esquema da função de onda do fotoelétron sendo espalhada pelos átomos vizinhos ao átomo absorvedor. (95) 
A parte da função de onda que é retroespalhada irá sofrer interferência com a própria onda emergente e o estado final do fotoelétron é dado pela resultante desse processo de interferência. Dependendo se a interferência é construtiva ou destrutiva, a amplitude total do estado final eletrônico será ampliada ou atenuada, modificando assim a probabilidade de absorção do fóton segundo a equação (4). Variando-se a energia do fóton incidente e, conseqüentemente, $\lambda_{\mathrm{e}}$, a fase relativa entre a onda emergente e a fração retroespalhada é modificada. Por isso, o coeficiente de absorção em função da energia do fóton, alterna entre picos e vales (como visto na Figura 17) correspondentes às interferências construtivas e destrutivas. (1)

\section{A.1.2.1.2 A Equação de EXAFS}

A função que descreve o sinal de EXAFS, $\chi(\boldsymbol{k})$, é definida como a parte oscilatória do coeficiente de absorção $\left(\mu-\mu_{o}\right)$ normalizada pelo salto da absorção atômico $\left(\Delta \mu_{o}\right)$. (1)

$$
\chi(k)=\frac{\mu-\mu_{0}}{\Delta \mu_{0}}
$$

A absorção atômica $\left(\mu_{o}\right)$ consiste na absorção devida unicamente ao átomo absorvedor, desconsiderando a perturbação dos átomos vizinhos. Considerando que estamos tratando de uma borda $\boldsymbol{K}, \chi(\boldsymbol{k})$ é descrito pela equação: (1)

$$
x(k)=\sum_{j} S_{0}^{2} \frac{N_{j}}{k R_{j}^{2}}\left|F_{j}(k, \pi)\right| \operatorname{sen}\left[2 k R_{j}+\emptyset_{j}(k)\right] e^{-2 \sigma_{j}^{2} k^{2}} e^{-2 R_{j} / L(k)}
$$

A equação (7) descreve a modificação no coeficiente de absorção devido ao espalhamento da função de onda do fotoelétron por $\boldsymbol{N}_{j}$ vizinhos distantes $\boldsymbol{R}_{\boldsymbol{j}}$ do absorvedor. A soma em $\boldsymbol{j}$ é feita sobre todas as esferas de vizinhos. O número de onda $\boldsymbol{k}$ do elétron é dado por (1):

$$
k=\frac{p}{\hbar}=\sqrt{2 m\left(h v-E_{0} / \hbar\right.}
$$

onde $\boldsymbol{E}_{\boldsymbol{o}}$ é a energia de ligação do fotoelétron. 
O resultado do processo de interferência entre a função de onda emergente e a função de onda retroespalhada é descrito pela função seno na equação (7). $\mathrm{O}$ argumento da função seno tem dois termos: o primeiro $\left(\mathbf{2} \boldsymbol{k} \boldsymbol{R}_{\boldsymbol{j}}\right)$ está relacionado a defasagem da função de onda do fotoelétron após percorrer um caminho $2 \boldsymbol{R}_{\boldsymbol{j}}$ que corresponde a sair do átomo absorvedor ser espalhado e voltar. O segundo é a defasagem $\varphi_{j}(\boldsymbol{k})$ sofrida pela função de onda do fotoelétron ao interagir com os potenciais dos átomos absorvedor e espalhador. Por isso, $\varphi_{j}(\boldsymbol{k})$ pode ser escrito como (1):

$$
\emptyset_{j}(k)=\Psi_{j}(k)+2 \delta(k)
$$

onde $\psi_{j}(\boldsymbol{k})$ é a diferença de fase devido ao espalhamento da função de onda eletrônica pelo potencial atômico central. $\mathrm{O}$ fator 2 conta está relacionado ao processo de ida e de volta. A Figura A.3 apresenta exemplos de funções de fase calculadas para diferentes elementos químicos. Podemos ver que para elementos leves, a função de fase tem um comportamento quase linear com $k$.

O termo $\boldsymbol{F}_{j}(\boldsymbol{k}, \pi)$ na equação (7) corresponde a amplitude de retroespalhamento e é dado pela probabilidade da função de onda do fotoelétron ser espalhada em um ângulo de $180^{\circ}$ pelos átomos vizinhos. Como mostra a Figura A.3, para átomos leves, $\boldsymbol{F}(\boldsymbol{k}, \pi)$ é grande para pequenos valores de $\boldsymbol{k}$, decrescendo rapidamente com o aumento de $\boldsymbol{k}$. Para maiores valores do número atômico e para valores intermediários de $\boldsymbol{k}$, observamos a presença de máximos na função $\boldsymbol{F}(\boldsymbol{k}, \pi)$. Esse comportamento característico da amplitude de retroespalhamento com $\boldsymbol{Z}$ permite a distinção entre diferentes elementos espalhadores, desde que os possíveis espalhadores não tenham números atômicos muito próximos. (3)

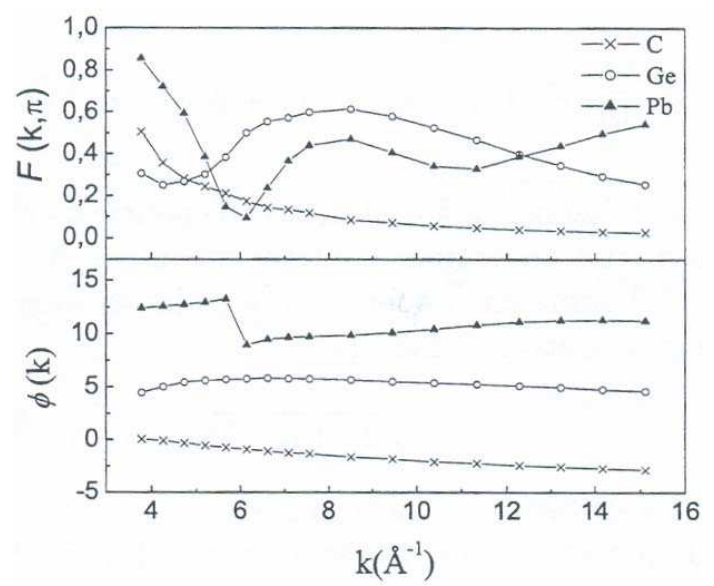

Figura A.3 - Funções de fase e amplitude calculadas teoricamente. Os dados para essa figura retirados da referência. (3) 
Devido ao efeito de desordem tanto térmica como estrutural, os átomos espalhadores de uma mesma esfera de vizinhos não estão todos exatamente a mesma distância do absorvedor. Aproximando a distribuição de distâncias interatômicas por uma forma gaussiana (chamada de aproximação harmônica), o efeito da desordem é descrito na equação de EXAFS pelo termo $\exp \left(-2 \sigma^{2} \kappa^{2}\right)$, onde $\sigma^{2}$ é o desvio quadrático médio da distribuição de distâncias, definido como $\sigma^{2}=\left\langle|\boldsymbol{r}-R|^{2}\right\rangle$. O termo $\exp \left[-2 \sigma^{2} \boldsymbol{k}^{2}\right]$ também é chamado de fator de DebyerWaller. No entanto, cabe ressaltar que o fator de Debyer-Waller obtido na análise das oscilações EXAFS apresenta algumas diferenças em relação ao obtido por difração de raios X. O EXAFS não é sensível a variações angulares que mantêm a distância interatômica fixa. Além disso, como $\sigma^{2}$ mede a largura da distribuição de distâncias em torno de $\boldsymbol{R}_{\boldsymbol{j}}$, no caso de haver uma desordem estrutural estática na esfera de vizinhos $\boldsymbol{j}$, essa desordem também será incluída no valor de $\sigma^{2}$ medido por EXAFS. Finalmente, devido a maneira como o fator de Debyer-Waller é extraído dos dados experimentais, seu valor é, em geral, relativo a um padrão utilizado. (1)

Os espalhamentos inelásticos sofridos pelo fotoelétron dentro da matriz sólida fazem o mesmo perder coerência e, portanto, deixar de contribuir para o fenômeno de interferência, tendo como resultado uma atenuação do sinal EXAFS. Essa atenuação é descrita atribuindo-se ao fotoelétron um tempo de vida finito ou, de forma equivalente, um livre caminho médio. $\mathrm{O}$ livre caminho médio, $\boldsymbol{L}(\boldsymbol{k})$, é um parâmetro que representa de maneira estatística a distância média percorrida pelo fotoelétron antes de ser espalhado inelasticamente. Na expressão (8), o efeito do espalhamento inelástico é levado em conta através do termo $\exp \left[-2 R_{j} / \boldsymbol{L}(\boldsymbol{k})\right]$ onde $\boldsymbol{L}$ (k) é o livre caminho médio do fotoelétron e, para a região de EXAFS, assume valores da ordem de 10 a $20 \AA$ A. O decaimento exponencial da amplitude do sinal EXAFS com a distância faz com que essa técnica seja sensível apenas a estrutura local em torno do átomo absorvedor. (1)

O fator $S_{0}^{2}$, na equação (7), é chamado de fator de redução de amplitude e assume valores típicos entre 0,7 e 1,1. A inclusão de $S_{0}^{2}$ é uma maneira aproximada de considerar efeitos de muitos corpos. (1) Na maioria dos casos, a equação (7) é utilizada considerando o fenômeno de espalhamentos simples, isto é, o fotoelétron é retroespalhado uma única vez por uma determinada esfera de vizinhos e volta ao absorvedor. No entanto, a probabilidade de que espalhamentos múltiplos ocorram não é nula e depende sensivelmente da energia do fotoelétron. Uma teoria foi desenvolvida onde formalmente a equação (7) é mantida, porém $\boldsymbol{R}_{\boldsymbol{j}}$ passa a representar o meio caminho percorrido pelo foto elétron considerando os diferentes 
espalhamentos múltiplos possíveis (incluindo os espalhamentos simples). Os termos de amplitude e fase são substituídos por funções efetivas. Essa é a base dos cálculos feitos com o programa FEFF (4), utilizado nessa tese nos cálculos de funções de fase e amplitude teóricas.

\section{A.1.2.1.3 Análise padrão das oscilações EXAFS}

O resultado de uma medida de EXAFS consiste em um espectro de absorção em função da energia do fóton incidente na amostra, como mostra Figura A.4a. A análise de dados padrão consiste em extrair o sinal EXAFS desse espectro e obter os valores para número de vizinhos $(\boldsymbol{N})$, distância interatômica $(\boldsymbol{R})$ e fator de desordem $\left(\sigma^{2}\right)$ para a esfera de vizinhos de interesse.

O primeiro passo na análise de dados é a subtração da linha de base de absorção ( $\mu_{\mathbf{b}}$ na Figura A.4a) que tem sua origem na atenuação devido a fotoexcitação de elétrons menos ligados e a outros fenômenos como espalhamento elástico e Compton. Esta atenuação antes da borda possui um comportamento monotônico com a energia. Para a subtração de $\mu_{\mathbf{b}}$ é feito um ajuste na região antes da borda estendo-o para todo o intervalo medido. Normalmente é usada como curva de ajuste para $\mu_{\mathbf{b}}$ uma função bem comportada, como um polinômio de grau 1.

Após a subtração de $\mu_{b}$ é necessário separar o sinal EXAFS $(\chi(\mathrm{k}))$ da absorção total. Para isso, subtrai-se do sinal total a parte que chamamos de absorção atômica $\left(\mu_{o}\right)$. $O \mu_{o}$ consiste na absorção do material devido unicamente ao elemento absorvedor desconsiderando a interação com os átomos vizinhos. Na prática, as variações senoidais em $\chi(\mathrm{k})$ são de freqüência suficientemente alta em relação às variações em $\mu_{o}$, de tal forma que, ajustando-se a região de EXAFS por um polinômio de baixo grau o ajuste irá aproximar a $\mu_{o}$. Assim, a absorção atômica é ajustada por um polinômio de grau entre 3 e 5, e subtraída. Esse passo da análise dos dados deve ser feito com muito cuidado, pois o uso de uma função de ajuste inadequada pode distorcer o sinal EXAFS. O uso de funções que oscilem em alta frequiência para ajustar $\mu_{o}$ pode levar ao ajuste das próprias oscilações do sinal EXAFS tendo como consequiência a perda de informação.

O sinal EXAFS é sempre mostrado em função do número de onda $\boldsymbol{k}$, como mostra a Figura A.4b. A relação entre $\boldsymbol{k}$ e a energia do fóton incidente é dada pela equação (8), onde $\boldsymbol{E}_{\boldsymbol{o}}$ 
é a energia de ligação do elétron excitado. Normalmente, estipula-se $\boldsymbol{E}_{\boldsymbol{o}}$ como sendo um ponto característico da subida da borda, adotando-se o mesmo critério para todos os espectros. O sinal EXAFS obtido consiste na soma de contribuições de várias esferas de vizinhos, representada pela somatória na equação EXAFS (equação (7)). Ou seja, $\chi(\boldsymbol{k})$ é dado pela soma de senóides de diferentes freqüências. Para separar as contribuições de cada distância (ou freqüência), é feita uma transformada de Fourier do espectro da Figura A.4b. Como o sinal EXAFS decai exponencialmente em $k$ através do termo de Debye- Waller, usualmente, antes de passar pela transformação de Fourier, o sinal $\chi(\boldsymbol{k})$ é multiplicado por um fator de peso em $\boldsymbol{k}\left(\boldsymbol{k}_{1}, \boldsymbol{k}_{2} \boldsymbol{e} \boldsymbol{k}_{3}\right)$. Isso é feito para que as oscilações ao longo de todo intervalo tenham aproximadamente a mesma amplitude e assim contribuam de maneira equivalente.
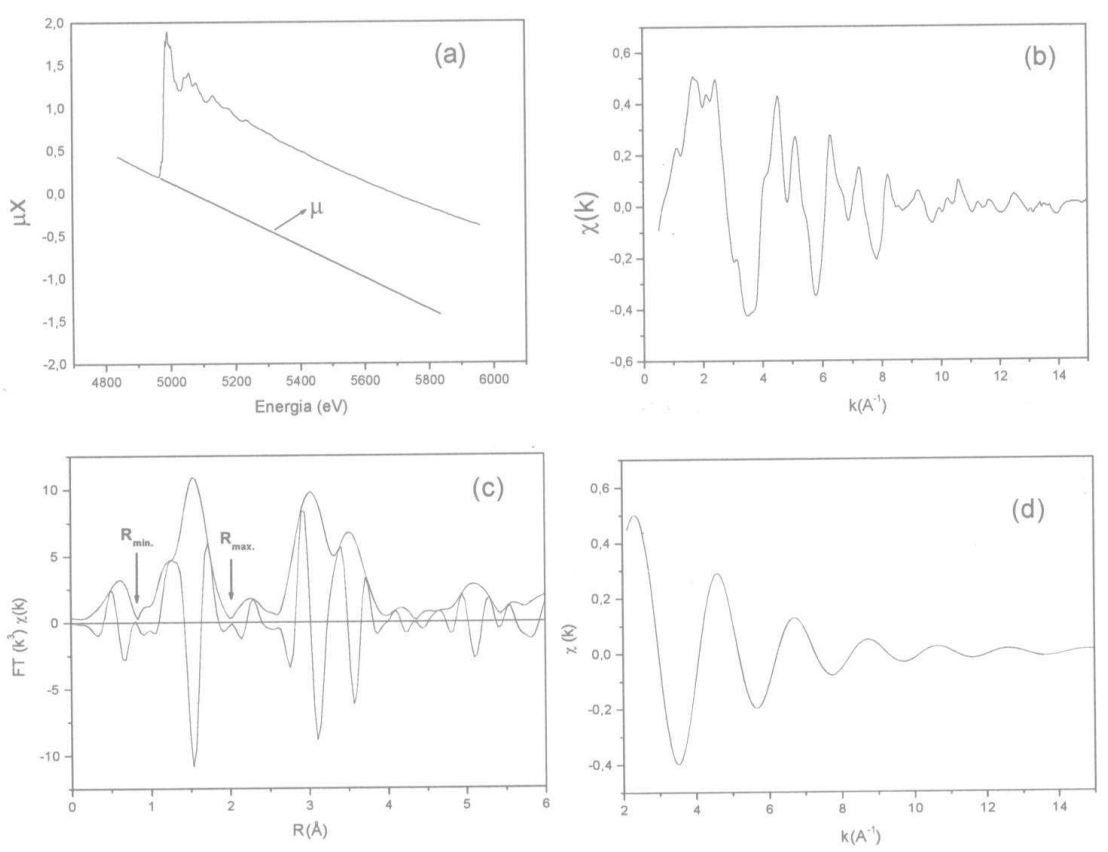

Figura A.4 - Diferentes etapas na análise de dados de EXAFS (a) subtração da linha de base $\mu$ e da absorção atômica $\mu_{0}$. (b) sinal EXAFS extraído em $k$ em função do número de onda $k$. (c) Transformada de Fourier do sinal EXAFS indicando o intervalo usado para a transformada inversa, mostrada em (d). (95)

A transformada de Fourier é feita de $-\infty$ a $+\infty$. No entanto, a medida possui um intervalo limitado. Assim, ao efetuarmos a transformação de Fourier o decaimento abrupto das oscilações nos extremos do intervalo medido gera um ruído de alta freqüência no sinal transformado. Os efeitos de borda, como são chamados, podem ser minimizados impondo-se uma função janela que tenda suavemente a zero nos extremos. Além disso, toma-se o cuidado 
de definir os extremos dos intervalos em pontos onde $\chi(\boldsymbol{k})$ cruza o zero. É claro que mesmo uma janela suave modifica o resultado da transformada de Fourier de alguma maneira. Por isso, é imprescindível que dados que serão comparados posteriormente sejam analisados da mesma maneira, com os mesmos pesos em $\boldsymbol{k}$ e mesmas janelas. Além disso, o intervalo $\Delta \boldsymbol{k}$ escolhido para a transformação deve ser o mesmo para todos os espectros, pois o intervalo em $\boldsymbol{k}$ modifica a resolução em $\boldsymbol{R}$.

A transformada de Fourier (TF) do espectro está indicada Figura A.4c. Essa curva é chamada de pseudo-RDF (RDF é a sigla em inglês para Função de Distribuição Radial). Ela define a probabilidade de se encontrar um átomo qualquer distante $\boldsymbol{R}$ do elemento absorvedor, localizado em $\boldsymbol{R}=\mathbf{0}$. O termo pseudo vem do fato da escala $\mathrm{R}$ mostrada na Figura A.4c não corresponder às distâncias interatômicas reais. Isso porque a função de fase $\varphi(\boldsymbol{k})$, presente juntamente com $\boldsymbol{R}$ no argumento da função seno da equação de EXAFS (equação (7)) não foi levada em consideração até o momento. O efeito da função de fase no espaço real é produzir um deslocamento $\Delta \boldsymbol{R}$. Essa correção pela função da fase é feita, geralmente, no passo seguinte da análise, que consiste no ajuste dos dados. A menos deste deslocamento, é possível ter uma idéia de como a vizinhança química do elemento absorvedor se compõe ou evolui através da comparação com TFs de outros espectros.

A obtenção dos valores de $\boldsymbol{R}, \boldsymbol{N}$ e $\sigma^{2}$ é feita por um processo de filtro do sinal EXAFS proveniente da esfera de vizinhos de interesse e ajustar o sinal obtido usando a equação EXAFS. Em outras palavras, é feita a transformada de Fourier inversa do intervalo que compreende o pico da TF referente a esfera de vizinhos escolhida. Na Figura A.4c é assinalado um exemplo de intervalo para selecionar a esfera de coordenação. O resultado da transformada inversa é o sinal EXAFS proeminente apenas da esfera de vizinhos escolhida, Figura A.4d. Isto é, foi eliminada a somatória da equação de EXAFS.

Analisando a equação (7), vemos que além de $\boldsymbol{R}, N$ e $\sigma^{2}$, as funções amplitude de retro-espalhamento, $\boldsymbol{F}(\boldsymbol{k})$, e fase, $\varphi(\boldsymbol{k})$, também são desconhecidas. Portanto, antes do ajuste é preciso obter essas funções. Existem duas maneiras de se obtê-las: através da medida de padrões ou por simulações teóricas. Uma amostra padrão consiste de uma amostra com estrutura conhecida onde os elementos: absorvedor e espalhado são os mesmos da amostra estudada. Assim, conhecendo-se $\boldsymbol{R}$ e $\boldsymbol{N}$ para o padrão é possível extrair as funções de fase e amplitude através das relações:

$$
A(k)_{e x p}=\left[R^{2}(k)+I^{2}(k)\right]^{\frac{1}{2}}
$$




$$
\phi(k)_{\operatorname{sxp}}=\operatorname{arctg}\left(\frac{I(k)}{R(k)}\right)
$$

onde $\boldsymbol{R}(\boldsymbol{k})$ e $\boldsymbol{I}(\boldsymbol{k})$ são as partes real e imaginária da transformada inversa. A função $\boldsymbol{A}(\boldsymbol{k})$ acima inclui $\boldsymbol{F}(\boldsymbol{k})$ e todos os demais termos de amplitude (livre caminho médio e Debye-Waller) na equação (7). Consideramos que as funções $\boldsymbol{A}(\boldsymbol{k}) \boldsymbol{e} \varphi(\boldsymbol{k})$ encontradas para o padrão podem ser usadas para a amostra. A transferência das funções de fase e amplitude, isto é, o quanto as funções extraídas do sinal do padrão são similares as da amostra em estudo, será tanto melhor quanto mais próximas forem as estruturas dos dois sistemas. Como $\boldsymbol{A}(\boldsymbol{k})_{\exp }$ contém o termo de Debye-Waller do padrão, o valor de $\sigma^{2}$ encontrado para a amostra é na verdade um $\Delta \sigma^{2}$ relativo à amostra padrão. (1)

É fácil imaginar, que em muitos casos não é possível obter amostras padrões. Nesse caso, são utilizados cálculos teóricos para a obtenção dos termos $\boldsymbol{F}(\boldsymbol{k}), \boldsymbol{L}$ e $\varphi(\boldsymbol{k})$. O programa padrão utilizado atualmente para esses cálculos é o programa FEFF (4) que tem se tornado uma ferramenta importante em simulações e análise de dados de EXAFS e XANES. Obtidas as funções de fase e amplitude, finalmente é feito o ajuste do sinal EXAFS filtrado para a obtenção dos valores de $\boldsymbol{N}, \boldsymbol{R}$ e $\sigma$. A correção ao valor de $\boldsymbol{E}_{\boldsymbol{o}}$ estipulado no início da análise também é um parâmetro de ajuste.

\section{A.1.2.1.4 Efeito do intervalo em $k$ do sinal EXAFS}

A relação que determina a resolução $\Delta \boldsymbol{R}$ com que se consegue distinguir duas distâncias interatômicas diferentes é dada por: $\Delta k \Delta R=\pi / 2$, onde $\Delta k$ é o intervalo no espaço $\boldsymbol{k}$ do sinal EXAFS medido. Portanto, quanto menor a diferença entre as distâncias que se deseja distinguir, maior deverá ser a extensão em $\boldsymbol{k}$ do sinal EXAFS medido. Considerando que o sinal EXAFS decai em $\boldsymbol{k}$ pelo termo de desordem e pela dependência da função de amplitude com $\boldsymbol{k}$, pode-se ver diretamente que retirar informações em longas extensões em $\boldsymbol{k}$ não é uma tarefa fácil. Para um sinal EXAFS medido até $k=19,5 \AA^{-1}$, teremos um $\Delta \boldsymbol{R}$ da ordem de 0,09 A. $(1,7)$ 


\section{A.1.3 Região de XANES}

\section{A.1.3.1 Análise dos espectros de XANES}

Como foi citado anteriormente, o espectro da borda de absorção (XANES) pode ser dividido em duas regiões. A análise da região da pré-borda pode fornecer informações qualitativas importantes sobre o estado de oxidação e sobre a simetria do sítio do átomo absorvedor, enquanto que a análise da região logo após a borda pode fornecer informações estruturais a curta e a média distância. Isso se deve ao fato de que os fenômenos de espalhamento múltiplo, observados nesta faixa de energia, envolvem a participação dos átomos situados além da primeira esfera de coordenação. A análise da região da pré-borda tem sido utilizada por muitos pesquisadores na obtenção de informações estruturais e eletrônicas, principalmente no estudo de metais de transição. A região de pré-borda de absorção K da maioria dos elementos de transição é caracterizada por apresentar estruturas de absorção as quais estão relacionadas a transições para níveis internos do átomo. As estruturas observadas na região da pré-borda nos elementos de transição dependem da geometria e das distâncias de ligação com os átomos vizinhos, bem como do estado de oxidação do átomo absorvedor. Tem sido observado que quanto maior o grau de desordem ao redor do átomo absorvedor, maior será a intensidade das estruturas na região da pré-borda. Para um mesmo átomo com o mesmo número de oxidação, a intensidade e a posição da estrutura da pré-borda pode variar com o número de coordenação do átomo absorvedor $(5,6)$. Quando o estado de oxidação de um elemento aumenta, observa-se um deslocamento da borda de absorção para altas energias. Para uma diferença de uma unidade no estado de oxidação de um elemento em uma dada coordenação, um aumento de $5 \mathrm{eV}$ pode ser observado na posição da borda de absorção. Alguns dos fatores que contribuem para este deslocamento são as distâncias interatômicas, as quais diminuem com o aumento do estado de oxidação para átomos em uma mesma geometria, ou o estado eletrônico do átomo absorvedor. Os espectros XANES tem sido alvo de inúmeros estudos. (7) A análise os espectros XANES tornou-se mais acessível após 1991 com os avanços introduzidos no formalismo de espalhamento múltiplo. $(1,7)$ Atualmente, muitos exemplos podem ser encontrados na literatura sobre a obtenção de informações estruturais a curta e a média distância a partir da simulação da região XANES do 
espectro de absorção. Cabe salientar, entretanto, que a obtenção do espectro XANES teórico está limitado a materiais onde a estrutura cristalográfica, ou seja, seu grupo pontual seja conhecido. 


\section{REFERÊNCIAS}

1 KONINGSBERGER, D.C. et al. XAFS spectroscopy; fundamental principles and data analysis. Topics in Catalysis, v.10, n. 3-4, p. 143-155, 2000.

2 MERZBACHER, E.. Quantum mechanics. New York: John Wiley \& Sons, 1988.

3 TEO, B.K.LEE, P.A. Ab-initio calculations of amplitude and phase functions for extended $\mathrm{X}$-ray absorption fine-structure spectroscopy. Journal of the American Chemical Society, v.101, n. 11, p. 2815-2832, 1979.

4 REHR, J.J. et al. Atomic-XAFS and XANES. Physica B-Condensed Matter, v.208, n. 1-4, p. 23-26, 1995.

5 FARGES, F. Coordination of Ti in crystalline and glassy fresnoites: a high-resolution XANES spectroscopy study at the Ti K-edge. Journal of Non-Crystalline Solids, v.204, n. 1, p. 53-64, 1996.

6 FARGES, F. et al. Coordination chemistry of Ti(IV) in silicate glasses and melts .1. XAFS study of titanium coordination in oxide model compounds. Geochimica Et Cosmochimica Acta, v.60, n. 16, p. 3023-3038, 1996.

7 ANKUDINOV, A.L.; REHR, J.J. Development of XAFS theory. Journal of Synchrotron Radiation, v.10, n., p. 366-368, 2003. 


\section{APÊNDICE 2}

\section{A.2 - MEDIDAS DE ESPALHAMENTO DE RAIOS X A BAIXO ÂNGULO (SAXS)}

Como mencionado anteriormente, a técnica de espalhamento de raios $\mathrm{X}$ a baixo ângulo (SAXS) é muito utilizada no estudo de sistemas coloidais uma vez que pode fornecer informações em escala nanométrica sobre o tamanho, a forma e as possíveis interações entre as partículas espalhadoras contidas nestes sistemas.

Antes da análise dos dados é necessário o correto tratamento dos dados, que basicamente consiste da normalização do sinal obtido pela intensidade do feixe incidente e multiplicando pela absorção da amostra. O espalhamento da solução, ou o meio que contém a amostra, deve ser subtraído do espalhamento obtido para a solução contendo as amostras que se deseja estudar. Para realizar este tratamento de dados é possível utilizar o programa FIT2D. Os dados experimentais são apresentados como intensidade em função do vetor de espalhamento $q$, onde $q=(4 \pi / \lambda) \operatorname{sen} \theta$, sendo $\lambda$ o comprimento da radiação incidente e $2 \theta \mathrm{o}$ ângulo de espalhamento.

O modelo teórico utilizado na análise dos dados é mostrado na equação abaixo:

$$
I(q)=S c P(q)+B a c k
$$

onde $S c$ é um fator de escala, Back é uma componente constante que pode servir como pequena correção para subtração do espalhamento do solvente; $P(q)$ é o fator de forma 
utilizado no modelo, sendo este normalizado à unidade para $q=0$. Basicamente, dependendo da forma da partícula, diferentes expressões devem ser utilizadas para $P(q)$. (1)

Para o nosso caso foi utilizado expressões de cilindros longos (raio R, comprimento $\mathrm{L}$ e polidispersidade relativa sigma) com polidispersidade nos valores de raio.

Assumindo que as partículas possuem uma dimensão muito maior do que as outras, é possível utilizar a aproximação de desacoplamento (2) e o fator de forma pode ser reescrito como:

$$
P(q)=P_{R O D}(q)\left\langle F_{C S}(q)\right\rangle
$$

O termo $F_{C S}(q)$ é a amplitude de espalhamento para a secção transversal da partícula enquanto que o termo $P_{R O D}(q)$ está relacionado ao fator de forma de espalhamento para um bastão infinitamente fino, (3)

$$
\begin{gathered}
P_{R O D}(q, L)=2 \operatorname{Si}(q L) /(q L)-4 \sin ^{2}(q L / 2) /\left(q^{2} L^{2}\right) \\
\operatorname{Si}(x)=\int_{0}^{x} t^{-1} \sin t d t \quad(\mathrm{~A} 2-4)
\end{gathered}
$$

Para cilindros $F_{C S}(q)$ é dado por,

$$
F_{C S}(q)=\left(\frac{2 J_{1}(q R)}{q R}\right)^{2}
$$

sendo $J_{1}(x)$ uma função de Bessel de primeiro tipo e primeira ordem.

A polidispersidade foi incluída utilizando a distribuição Schultz-Zimm (4) 


$$
\begin{gathered}
\left\langle F_{C S}(q)\right\rangle=\frac{\int_{0}^{\infty} D(r) F_{C S}(q, r) d r}{\int_{0}^{\infty} D(r) d r} \\
D(x)=\left(\frac{z+1}{x_{0}}\right)^{z+1} \frac{x^{z}}{\Gamma(z+1)} \exp \left(-(z+1) \frac{x}{x_{0}}\right)
\end{gathered}
$$

Sendo $\Gamma(x)$ a função Gamma real, $x_{0}$ é o centro de massa da distribuição e $z$ é relacionado com a polidispersidade relativa $\sigma_{R} / R$ de raio pela relação $z=1 /\left(\sigma_{R} / R\right)^{2}-1$.

O ajuste dos dados experimentais é feito utilizando otimização por quadrados mínimos descrita em. $(1,4)$ A qualidade do ajuste é indicada pelo teste "chi-quadrado reduzido" $\chi_{r}^{2}$ :

$$
\chi_{r}^{2}=\frac{1}{N-M} \sum_{i=1}^{N}\left(\frac{I^{\exp }\left(q_{i}\right)-I^{\mathrm{mod}}\left(q_{i}\right)}{\sigma_{i}}\right)
$$

Onde $N$ é o número de pontos experimentais, $I^{\exp }\left(q_{i}\right)$ é o valor dos dados experimentais para um dado ponto qi com respectivas incertezas si. $I^{\bmod }\left(q_{i}\right)$ é o valor teórico dado pelo modelo utilizado, que depende dos parâmetros $a_{j}, \operatorname{com} j=1, \ldots, M$. Aqui, $N$ - $M$ é o número de graus de liberdade dos dados. No processo de ajuste dos dados, a minimização da equação acima fornece o conjunto de parâmetros aj que melhor ajusta os dados experimentais. Para a minimização dos dados foram utilizados os métodos de Levenberg-Marquardt e "grid search" (4). 
152 


\section{REFERÊNCIAS}

1 PEDERSEN, J.S., Analysis of small-angle scattering data from colloids and polymer solutions: modeling and least-squares fitting. Advances in Colloid and Interface Science, v.70, n.4, p. 171-210, 1997.

2 KOTLARCHYK, M.; CHEN, S.H. Analysis of small-angle neutron-scattering spectra from polydisperse interacting colloids. Journal of Chemical Physics, v.79, n. 5, p. 2461-2469, 1983.

3 NEUGEBAUER T. Calculation of the light diffusion of filament chain solutions. Annalen der Physik, v. 42, n. 7, p. 509-533, 1942.

4 PRESS, W.H; FLANNERY, B.P.; TEUKOLSKY, S.A; VETTERLING, W.T. Numerical recipes. Cambridge: Cambridge University Press, 1989. 